\title{
CORRELATOS ESTRUCTURALES DE LAS ALTERACIONES COGNITIVAS EN NIÑOS CON TEA
}

Tesis doctoral presentada por:

\section{Francisca Castellano García}

Para obtener el grado de doctora por la Universitat Jaume I de Castellón

\author{
Directores: \\ Dr. César Ávila Rivera \\ Dra. Noelia Ventura Campos \\ Dra. Sonia Martínez Sanchis
}

Programa de Doctorado en Psicopatología, Salud y Neuropsicología

Departamento de Psicología Básica, Clínica y Psicobiología

Universitat Jaume I

Castellón, Mayo 2017 
A Javier, Balma, Sarai, María, Rocío y a esa parte de mi familia que también llevo en el corazón. 
“Desde 1938 me ha llamado la atención una condición que difiere de forma tan marcada y única de algo que ya esté descrito, que cada caso merece - y, yo espero va a recibir una detallada consideración acerca de sus fascinantes peculiaridades"

Leo Kanner, 1943

"Hay otros dos fenómenos especialmente ricos en expresión anímica: la mirada, que solo en el hombre ofrece sus tan complejas posibilidades, y el lenguaje, exclusivo éste del ser humano. Es imposible describir con palabras científicamente exactas todo lo que "dice" la mirada de una persona"

Hans Asperger, 1952 


\section{AGRADECIMIENTOS}

Esta tesis es fruto de la valentía por parte de un grupo de niños y de niñas que quisieron aportar su granito de arena en este proyecto. Realmente los protagonistas principales son todos ellos y quisiera darles las gracias por su empeño y su esfuerzo. Sin ellos no habría sido posible haber realizado este trabajo, así que esta tesis va dedicada a todos los niños y niñas con autismo.

Mi más sincero agradecimiento va dirigido a mis directores de tesis por su interés, su apoyo y todos los conocimientos que han compartido conmigo. Agradecer, especialmente, al Dr. César Ávila haber aceptado este estudio en un momento delicado en la universidad y por la confianza depositada en mi desde el principio. Su contribución al campo del autismo ha sido de vital importancia, así como su interés y su implicación. Gracias, como no, a la Dr. Noelia Ventura por la delicadeza y la paciencia con la que me explicaba aspectos complicados relacionados con la neuroimagen y a "su princesita" porque ha estado presente en la última fase de esta tesis. Mi agradecimiento también a la Dra. Sonia Martínez por los ánimos que me ha dado en todo momento. Gracias a los tres por haberme permitido conocer el mundo tan complicado de la investigación, por hacerme sentir un miembro más del equipo y por ayudarme a saltar todos los obstáculos que han ido apareciendo en el camino, que no han sido pocos.

Especialmente, quiero agradecer al Dr. Josep Artigas, al que considero mi maestro, que haya compartido conmigo su sabiduría y su buen quehacer durante todos estos años y que me haya abierto "el corazón y la mente" hacia el fascinante mundo del autismo.

Quiero agradecer a las dos asociaciones, la Asociación Asperger de Castellón y la Asociación Asperger de Valencia, el interés mostrado y el empeño para que saliera adelante este proyecto. Principalmente, agradecer a todas las familias, asociadas y no asociadas, así como a todas aquellas otras familias que no tienen nada que ver con las asociaciones y que han querido que sus hijos formaran parte y colaboraran también en este proyecto, gracias de corazón a todos.

Gracias al personal de la Clínica Campanar de Valencia, por el cariño, el cuidado y la delicadeza mostrada con todos los niños durante casi el año y medio que estuvimos realizando las pruebas de neuroimagen. 
No puedo olvidarme de Conchita y de Carlos. Gracias por cuidarme tan bien cuando me escapaba y me recluía en vuestra maravillosa "Casatoya" para escribir esta tesis rodeada de silencio y de montañas.

Santi y Juan gracias por vuestra solidaridad, vuestras canciones y el apoyo de vuestros grupos musicales.

Finalmente, a mi querida familia y a mis tan entrañables amigos, que también forman parte de mi familia, mil gracias, no solo por caminar conmigo y sufrir los contratiempos cada día sino también por compartir mis zapatos en este largo camino. Javi, Balma, María y Sara gracias por madrugar durante no sé cuantos sábados, acompañarme a Valencia y ayudarme. Gracias Sarai por animarme desde la distancia. 


\section{ÍNDICE GENERAL}

I- JUSTIFICACIÓN .....................................................................................15

II- MARCO TEÓRICO ...........................................................................17

1- EL DESARROLLO CEREBRAL HUMANO ............................................ 17

1.1. Maduración cerebral típica en los primeros años de vida .......................................... 18

1.2. Estudios posteriores (Infancia-Adolescencia) ............................................................. 24

2- EL TRASTORNO DE ASPERGER: Un poco de historia............................... 29

3- ALTERACIONES EN LA TRAYECTORIA DEL DESARROLLO

CEREBRAL EN NIÑOS CON TEA .............................................................. 43

3.1. Desarrollo cerebral en los primeros años de vida.................................................... 43

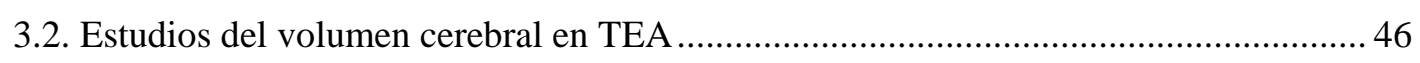

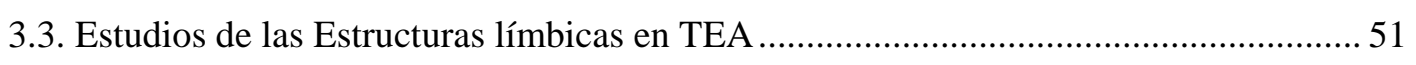

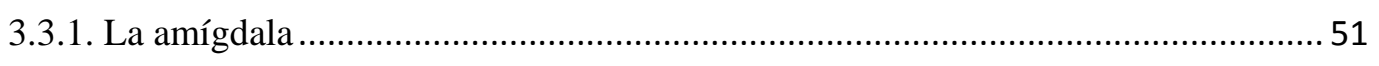

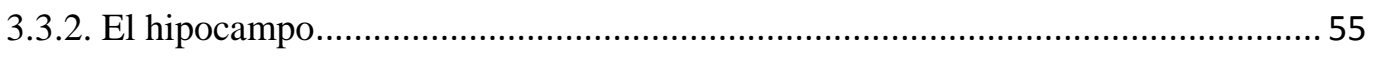

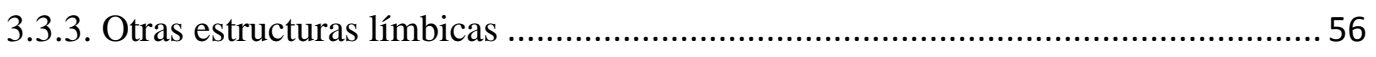

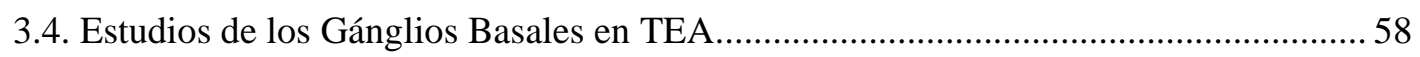

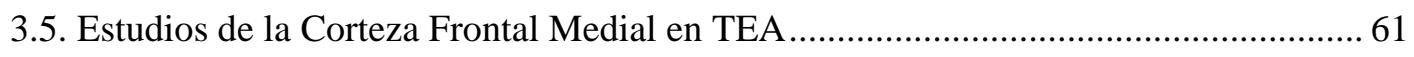

3.6. Estudios de la Corteza Frontal Lateral en TEA .............................................................. 62

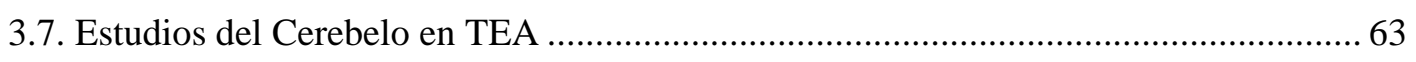

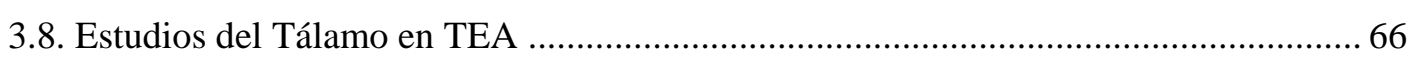

4- ALTERACIONES NEUROPSICOLÓGICAS EN NIÑOS CON TEA.......... 70

4.1. Desarrollo de la Teoría de la Mente en niños con desarrollo típico ............................... 71

4.2. Desarrollo de la Teoría de la Mente en niños con TEA .................................................. 74

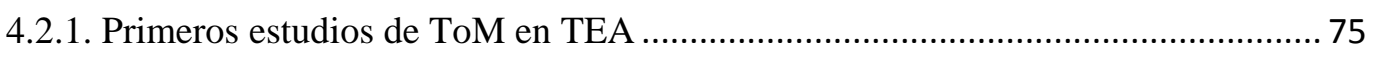

4.2.2. Estudios posteriores sobre ToM en TEA: tareas más complejas ............................ 79

4.2.2.1. Falsas creencias de segundo orden ................................................................. 79

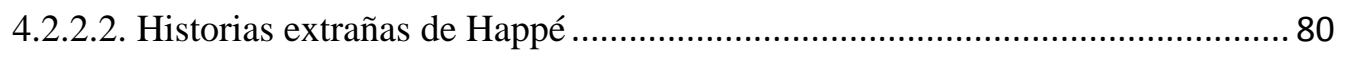

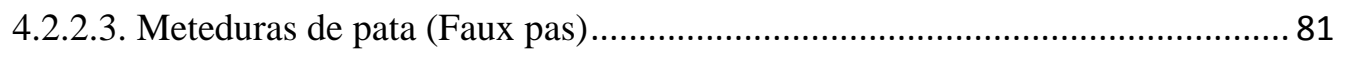

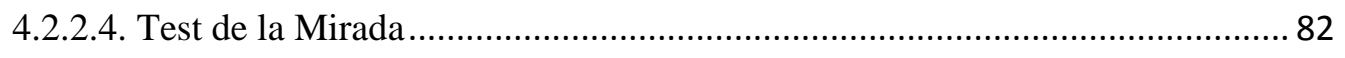

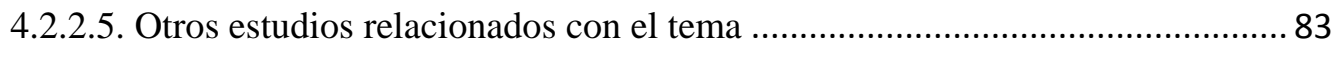

4.2.2.6. Inteligencia, Lenguaje y ТoM ……………............................................ 85

4.2.2.7. Funcionamiento ejecutivo y ToM …........................................................ 87

4.3. Teoría de la Empatía-Sistematización .......................................................................... 88 
5.1. Alteraciones sensoriales en niños con TEA

5.2. Estudios sobre procesamiento sensorial en TEA que han utilizado el Cuestionario

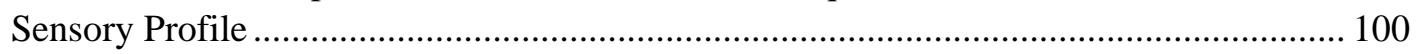

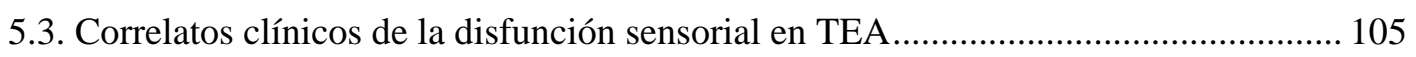

III- PLANTEAMIENTO EXPERIMENTAL Y OBJETIVOS .......... 108

IV- METODOLOGÍA _...................................................................................114

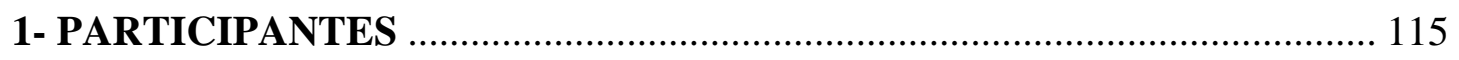

2- CRITERIOS DIAGNÓSTICOS DEL MANUAL DIAGNÓSTICO Y ESTADÍSTICO DE LOS TRASTORNOS MENTALES, QUINTA EDICIÓN

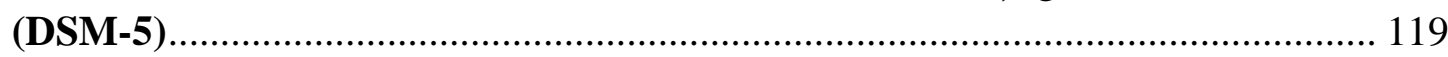

3- DESCRIPCIÓN DE LAS VARIABLES NEUROPSICOLÓGICAS ............ 121

3.1. Inteligencia: Wechsler Intelligence Scale for Children (Wechsler, 2005) ................. 121

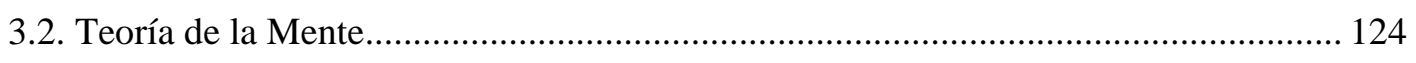

3.2.1. Test de la Mirada (Baron-Cohen et al., 2001) ................................................... 125

3.2.2. Historias Meteduras de pata (Baron-Cohen et al., 1999) ................................... 126

3.2.3. Falsas Creencias de $2^{\circ}$ Orden (Perner \& Wimmer, 1985; Sullivan et al., 1994). 127

3.2.4. Historias Extrañas (Happé, 1994) ……………………………............... 130

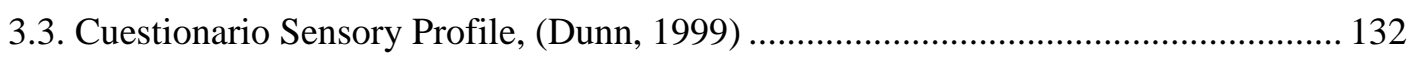

3.4. Cociente de Empatía y Sistematización para niños (Baron-Cohen et al., 2009) ......... 133

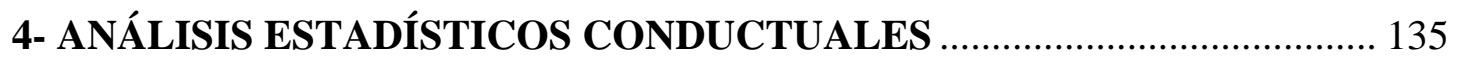

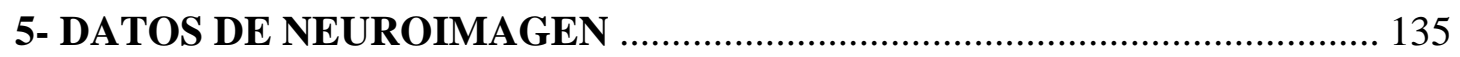

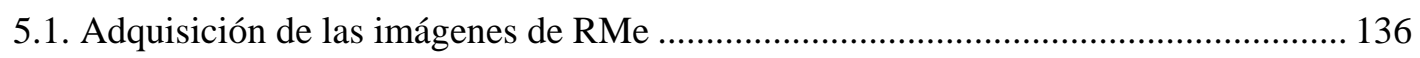

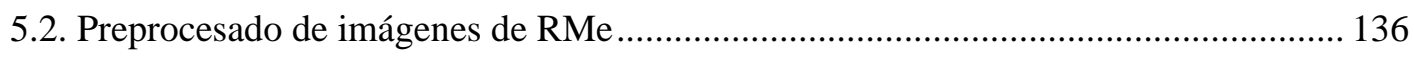

5.3. Análisis estadístico de imágenes de RMe ………..................................................... 137

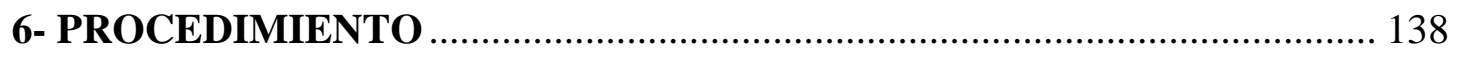

V- RESULTADOS...........................................................................143

1- COMPARACIÓN ENTRE GRUPOS ....................................................... 143

2- VARIABLES NEUROPSICOLÓGICAS: DIFERENCIAS

CONDUCTUALES Y REGRESIONES ....................................................... 143

2.1. Pruebas de inteligencia: Escala de Inteligencia Wechsler para Niños - IV (WISC-IV)

2.2. Pruebas de Teoría de la Mente (ToM).................................................................... 149

2.3. Cuestionario Sensory Profile, versión corta (CSP) ................................................... 152

2.4. Cuestionarios: Cociente Empatía (CE) y Cociente Sistematización (CS)................... 159

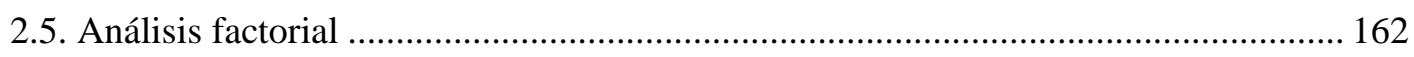


VI- DISCUSIÓN Y CONCLUSIONES...................................................... 167

VII- BIBLIOGRAFÍA...................................................................191 


\section{ABREVIATURAS:}

AAF Autismo Alto Funcionamiento

BA Área Brodman

CAT Computational Anatomy Toolbox

CE Cociente de Empatía

CINV Cociente Intelectual No Verbal

CI Cociente Intelectual Total

CIV Cociente Intelectual Verbal

CS Cociente de Sistematización

CSP Cuestionario Sensory Profile

FWE Family Wise Error

IG Inteligencia General

LCR Líquido cefalorraquídeo

MT Memoria de Trabajo

RM Resonancia Magnética

RMe Resonancia Magnética estructural

RMf Resonancia Magnética funcional

ROI Regiones de Interés

SA Síndrome Asperger

SB Sustancia Blanca

SG Sustancia Gris

SPM Mapa Estadístico Paramétrico (Statistical Parametric Mapping)

SPSS Statistical Package for the Social Sciences

SVC Small Volume Correction

TDAH Trastorno por Déficit de Atención con Hiperactividad

TEA Trastornos del Espectro del Autismo

TE-S Teoría de la Empatía-Sistematización

TIV Volumen Total Intracraneal (Total Intracraneal Volume) 
TND

ToM

TOM

TPM

VBM

VP
Trastornos del Neurodesarrollo

Teoría de la Mente

Template-O-Matic

Mapa Paramétrico Estadístico (Statistical Parametric Mapping)

Morfometría Basada Vóxel, (Voxel Based Morphometry)

Velocidad de Procesamiento 


\section{I- JUSTIFICACIÓN}

Los trastornos del neurodesarrollo son problemas que aparecen durante la infancia y están vinculados con la maduración del cerebro, por lo que se manifiestan desde edades muy tempranas y su expresión va variando a lo largo de las diferentes etapas del desarrollo. El Trastorno del Espectro del Autismo (TEA) se incluye dentro de este tipo de trastornos. En los últimos años, con el avance rápido de métodos modernos de neuroimagen se han realizado estudios longitudinales y transversales que han aportado importantes conocimientos sobre las bases neurobiológicas de dicho trastorno. La literatura publicada sobre este trastorno indica que, en los primeros años de vida postnatal, los niños con autismo presentan una trayectoria de desarrollo cerebral atípica, con un crecimiento acelerado en el volumen cerebral que se inicia después del primer año, especialmente en los lóbulos frontales y temporales, y continúa hasta 5-6 años para empezar a disminuir dicho crecimiento después de esta edad y a no existir diferencias significativas respecto a la población con desarrollo típico a partir de la adolescencia y en la edad adulta. De modo que, pese a que el TEA se considera un trastorno del neurodesarrollo, no muestra diferencias estructurales claras después de la adolescencia.

Los resultados obtenidos en los estudios de neuroimagen indican que el TEA es un trastorno de procesamiento emocional y conductual, que presenta una alta heterogeneidad en cuanto a manifestaciones neuropsicológicas hasta el punto de mostrar funciones más o menos alteradas dependiendo de individuos. Así, por ejemplo, en cuanto al tema del desarrollo del lenguaje y de la comunicación, podemos encontrar un amplio abanico de déficits en los niños con TEA, desde los que no han podido desarrollar un habla funcional y presentan dificultades significativas hasta los que tienen un lenguaje razonablemente bueno, con un nivel amplio de vocabulario y de fluidez verbal, pero con problemas en los aspectos pragmáticos del mismo (uso del lenguaje en la comunicación social). Si analizamos las habilidades en cuanto a cognición social, podemos observar desde individuos que evitan cualquier tipo de interacción social hasta otros que buscan relacionarse continuamente; o bien, niños que no mantienen ningún tipo de contacto visual y otros que sí pueden hacerlo, aunque sea de forma esporádica. 
Algunas personas con TEA pueden tener intereses restringidos y tener conocimientos amplios sobre un tema concreto, dedicar mucho tiempo a buscar y almacenar cantidad de información sobre el mismo, sin embargo, otras no. Pueden también mostrar problemas de procesamiento sensorial tales como hipersensibilidad o hiposensibilidad, por ejemplo, tener un umbral de dolor aparentemente alto o bajo, o pueden sentirse extremadamente alterados ante ruidos fuertes o ruidos concretos, o ante determinados olores,...pero son características que muestran estos individuos de forma muy diversa y dentro de un espectro muy amplio de matices.

El planteamiento global de este trabajo persigue una aproximación nueva que se basa en la idea de comprobar si la variedad conductual observada en individuos con autismo puede ser explicada a partir de las diferencias individuales en las estructuras de zonas específicas del cerebro relacionadas con esas funciones.

Mediante un estudio correlacional entre variables morfométricas y variables conductuales, el proyecto está dirigido al estudio de la relación existente entre las diferencias observadas en determinadas zonas cerebrales en niños con TEA y el rendimiento obtenido en una serie de pruebas neuropsicológicas. 


\section{II- MARCO TEÓRICO}

\section{1- EL DESARROLLO CEREBRAL HUMANO}

El desarrollo del cerebro empieza muy pronto en la vida prenatal, continúa en la edad adulta joven y va acompañado de cambios considerables en la sustancia gris (SG) y sustancia blanca (SB) (Jetha \& Segalowitz, 2012). La caracterización de los cambios anatómicos que ocurren y el dimorfismo sexual asociado que tienen lugar durante las dos primeras décadas de vida pueden ayudar a comprender los patrones de desarrollo típicos y atípicos y las diferencias de sexo en los trastornos del neurodesarrollo (Sussman, Leung, Chakravarty, Lerch \& Taylor, 2016). Estudios previos centrados en el volumen cerebral total han informado de que éste seguía una trayectoria en forma de $\mathrm{U}$ invertida: aumentaba muy rápido en la infancia, alcanzaba su punto máximo alrededor de los 10-12 años de edad para declinar posteriormente durante la adolescencia tardía (Lenroot et al., 2007). El volumen total cerebral de SG sigue una tendencia similar, de hecho, estudios volumétricos de imágenes por resonancia magnética (RM) han indicado aumentos en el volumen de SG a lo largo del neocórtex desde la infancia hasta la adolescencia que luego van disminuyendo hasta la edad adulta (Gogtay et al., 2004; Sowell, Thompson, Tessner \& Toga, 2001; Lenroot et al., 2007). Respecto al volumen de SB, ésta seguía una trayectoria de desarrollo diferente, es decir, un aumento constante y casi lineal a lo largo de la infancia y la adolescencia (Pfefferbaum et al., 1994; Giedd et al., 1999; Lenroot et al., 2007).

En primer lugar, realizaremos una descripción de la trayectoria del desarrollo del cerebro infantil en los primeros años de vida para entender cómo influye esta maduración de manera decisiva en el desarrollo adecuado de funciones superiores como, por ejemplo, la cognición o el lenguaje. Además, nos ayudará a entender qué aspectos del proceso de desarrollo cerebral está alterado en los trastornos del neurodesarrollo. Después aportaremos una serie de estudios realizados con niños y adolescentes que nos permitirán tener una idea clara acerca del patrón de desarrollo cerebral típico durante etapas posteriores. 


\subsection{Maduración cerebral típica en los primeros años de vida}

El cerebro humano crece significativamente durante los primeros años de vida. El volumen cerebral de los neonatos es de 380 a $420 \mathrm{~cm} 3$ (Hüppi et al., 1998), de 2 a 4 semanas de edad es de aproximadamente el $36 \%$ y al año es de un $72 \%$ del volumen del adulto (Knickmeyer et al., 2008). A los 3 años, el volumen cerebral total es de aproximadamente el $80 \%$ de su tamaño máximo y alcanza de 90 a $92 \%$ a los 9 años (rango de 7 a 11 años) (Caviness, Kennedy, Bates \& Makris, 1996a; Caviness, Meyer, Makris \& Kennedy, 1996b). De hecho, el volumen intracraneal aumenta en cerca de $300 \mathrm{ml}$ entre los 3 meses y 10 años (Pfefferbaum et al., 1994), con un pico máximo del volumen cerebral total a los 10,5 años en las mujeres y a los 14,5 años en los hombres (Lenroot et al., 2007).

Es un proceso que abarca toda la infancia y la adolescencia. Los patrones de desarrollo facilitan la aparición progresiva de funciones cognitivas de orden superior durante toda esta etapa (Marsh, Gerber \& Peterson, 2008). Las alteraciones en estos patrones de desarrollo parecen estar involucradas en la patogénesis de varios trastornos del neurodesarrollo, por ejemplo, los Trastornos del Espectro del Autismo (TEA). El desarrollo de la SG es un proceso dinámico y complejo que requiere una serie de procesos encadenados que se van produciendo durante la maduración cerebral. Una diferencia importante entre el sistema nervioso de los bebés y de los niños en comparación con el de los adultos es que presentan mayor capacidad de plasticidad en el cerebro en desarrollo. El cerebro del niño es más plástico y esto explica la capacidad que tienen para aprender habilidades nuevas con bastante rapidez o la recuperación de las lesiones cerebrales. Hay una serie de mecanismos cerebrales básicos que permiten que el sistema nervioso se forme a partir de la experiencia durante la infancia. Entre ellos cabe destacar la sobreproducción y la supresión de las neuronas y de las sinapsis, y la estabilización dependiente de la actividad de las sinapsis (Johnston et al., 2009). La plasticidad en el cerebro del niño se mejora porque la organización de las redes de sinapsis neuronales y las vías de la sustancia blanca están en continua formación hasta la adolescencia e incluso más tarde (Johnston, 2004). La plasticidad sináptica es el mecanismo más importante que permite al cerebro en desarrollo adaptarse a las demandas ambientales y almacenar la información a lo largo de la vida (Lau \& Zukin, 2007). Este término incluye cambios que aumentan o disminuyen la eficacia de las 
sinapsis, así como poda sináptica. En el cerebro humano, los cambios en el número de sinapsis son especialmente dinámicos en la corteza cerebral en la infancia y la niñez (Huttenlocher \& Dabholkar, 1997). Las sinapsis se producen a un ritmo rápido en el período postnatal y alcanzan una densidad que es el doble del nivel de adultos a los 2 años de edad para empezar a disminuir en la adolescencia temprana. Este proceso de proliferación y de poda sináptica va a depender tanto de programas intrínsecos como de influencias ambientales (Johnston et al., 2009). La poda sináptica se refiere a la eliminación programada de las conexiones sinápticas no utilizadas, de modo que las poblaciones neuronales preexistentes se pierden, ya que no logran integrarse en un dominio funcional, habilidad de desarrollo o proceso cognitivo (Lange et al., 2015). Las conexiones entre las neuronas se multiplican rápidamente en los primeros 2 años de vida a través de la sinaptogénesis. Después de los primeros 2 años de vida hay una etapa de poda sináptica que va a permitir que el cerebro se adapte a las necesidades ambientales particulares de un individuo (Rauschecker \& Marler, 1987). Una distribución sináptica más restringida y mejor especializada produce un funcionamiento cerebral más eficiente además de aumentar la velocidad de transmisión neuronal de los circuitos regionales (O’Hearn, Asato, Ordaz \& Luna, 2008). Los estudios de morfometría cerebral han indicado que diferentes partes del cerebro sufren este proceso en distintos momentos del desarrollo. Por ejemplo, el área 1 de la corteza visual madura en la primera infancia, las sinapsis en la corteza auditiva continúan desarrollándose hasta la última infancia y el giro frontal medio de la corteza prefrontal continúa madurando hasta llegar a la adolescencia (Huttenlocher, 1990; Huttenlocher \& Dabholkar, 1997). Así, el adelgazamiento cortical durante la adolescencia probablemente refleja la poda o eliminación de conexiones sinápticas innecesarias o no usadas que refina y consolida muchos procesos cognitivos durante este período (Marsh, Gerber \& Peterson, 2008). En áreas sensoriomotoras primarias hay mayor densidad de SG en edades más tempranas, sin embargo, en áreas de asociación de mayor complejidad, como la corteza prefrontal dorsolateral, parietal inferior y giro temporal superior, se produce más tarde (Giedd \& Rapoport, 2010).

El desarrollo de la SG es relativamente estable en la adolescencia. Sin embargo, el desarrollo de la SB continúa a lo largo de la edad adulta (Benes, 1989; Yakovlev \& Lecours, 1967). Se cree que los cambios relacionados con la edad en la mielinización subyacen a la maduración prolongada de la sustancia blanca (O’Hearn, Asato, Ordaz \& 
Luna, 2008). La mielinización es el proceso de adquisición de mielina, vainas blancas grasas formadas por oligodendrocitos que envuelven a los axones y aumentan la velocidad de las señales neuronales. Los estudios histológicos indican que la mielinización comienza durante el segundo trimestre del embarazo y continúa en la vida adulta. Además, la mielinización en el sistema nervioso periférico parece preceder al desarrollo en el sistema nervioso central (Yakovlev \& Lecours, 1967). Los estudios volumétricos de RM de los cambios relacionados con la edad en la SB indican un aumento constante del volumen de la misma desde la primera infancia hasta la edad adulta con tasas similares en los diferentes lóbulos cerebrales (Giedd et al., 1999; Lenroot \& Giedd, 2006; Lenroot et al., 2007). Se han encontrado algunas diferencias regionales en el lóbulo temporal (Paus, 1999) y en el hipocampo (Benes, Turtle, Khan, \& Farol, 1994), indicando un desarrollo prolongado de estas áreas que continúa hasta la sexta década de vida. Una característica importante que sólo recientemente se ha apreciado es que la mielina no simplemente maximiza la velocidad de transmisión sino que también modula el sincronismo y la sincronía de los patrones de disparo neuronales que crean redes funcionales en el cerebro (Fields \& Stevens-Graham, 2002).

El estudio del desarrollo cerebral en los primeros años de vida no solo se ha basado en aspectos relacionados con la plasticidad cerebral, la sinaptogénesis o la mielinización. También hay estudios que se han centrado en el desarrollo de estructuras corticales como, por ejemplo, las áreas frontotemporales (Tanaka, Matsui, Uematsu, Noguchi \& Mayawaki, 2012) y el lóbulo prefrontal (Matsui et al., 2016), o estructuras subcorticales como la amígdala y el hipocampo (Uematsu, 2012; Hou, Yang \& Yuan, 2013), entre otras.

Choe et al. (2013) llevaron a cabo un estudio sobre el crecimiento regional del cerebro a partir de un análisis morfométrico (volúmenes globales y locales) entre 3 y 13 meses. Partieron de una muestra de 27 niños (14 niños y 13 niñas), con desarrollo típico que nacieron a término. Usaron un diseño transversal (33 exploraciones cerebrales) de 3 a 4 meses de edad $(\mathrm{n}=5)$, de 6 a 7 meses de edad $(\mathrm{n}=19)$, y de 12 a 13 meses de edad $(\mathrm{n}=$ 9). Los resultados indicaron respecto al volumen total, que todas las regiones del cerebro, excepto el mesencéfalo, mostraron un crecimiento significativo de 3 a 13 meses, especialmente el putamen, los hemisferios cerebelares, el cerebelo y el cuarto ventrículo, que aumentaron casi el doble, lo que sugiere que la tasa de crecimiento volumétrico de estas regiones fue mayor que la del volumen total del cerebro durante 
este período. Los resultados del estudio también mostraron un crecimiento relativamente más lento de la amígdala y el hipocampo durante la infancia antes de alcanzar su volumen total esperado $(46,5 \%$ y $56,1 \%$ de $\operatorname{los} 7$ a 11 años, respectivamente). El volumen de los lóbulos temporales anteriores aumenta bruscamente hasta los 2 años de edad (Utsunomiya et al., 1999). En el hipocampo, se observó una asimetría hacia la derecha, que también ha sido documentada en otros estudios de niños recién nacidos prematuros y en los nacidos a término (Thompson et al., 2009), en niños mayores y adolescentes (Giedd et al., 1996; Pfluger et al., 1989) y en adultos (Jack et al., 1989; Li, Ga, Huo, Li, \& Gao, 2007; Ystad et al., 2009). En este estudio, Choe et al. (2013) también encontraron una consistente asimetría del hipocampo hacia la derecha, dato que sugiere que la dominación hippocampal derecha está presente en el nacimiento y persiste a través de la edad. El hipocampo derecho es crítico para la formación de la memoria episódica y espacial (Burgess, Maguire \& O’Keefe, 2002).

También encontraron trayectorias asimétricas de desarrollo en los ganglios basales, un grupo de núcleos implicados en la regulación y el aprendizaje motores (Packard \& Knowlton 2002). Similar a los informes previos en niños mayores (Giedd et al., 1996; Reiss et al., 1996), el núcleo caudado derecho era más grande cuando se combinaron todas las edades. El patrón lateral derecho de crecimiento del caudado ya está presente en la infancia y no puede cambiar significativamente a lo largo de la edad. Respecto al putamen, se observó una asimetría hacia la izquierda a los 3 a 4 meses, pero no entre los 6 y 7 meses. Sin embargo, a los 12 a 13 meses de edad, se encontró que el putamen derecho era consistentemente mayor que el putamen izquierdo. Finalmente, encontraron asimetría cerebral hacia la izquierda en el hemisferio cerebeloso izquierdo que era más grande que el derecho, resultado que puede representar un paso de maduración transitorio en un período caracterizado por el creciente desarrollo de la coordinación motora y del equilibrio (Choe et al., 2013).

Un estudio longitudinal prospectivo fue realizado por Knickmeyer et al. (2008), para determinar el desarrollo estructural del cerebro en los primeros 2 años después del nacimiento en niños nacidos a término. La muestra era de 98 niños (49 niños y 49 niñas) a los que se les realizaron pruebas de morfometría cerebral de alta resolución. Estos autores concluyeron que, en esta franja de edad, hay un aumento considerable en el tamaño total del cerebro, alcanzando el 80-90\% del volumen adulto a los 2 años 
(Pfefferbaum et al., 1994). La rápida generación de nuevas sinapsis en los dos primeros años de vida (Huttenlocher \& Dabholkar, 1997; Glantz et al., 2007) se corresponde con un aumento en el volumen total de SG que alcanza su máximo alrededor de los 2 años (Hüppi et al., 1998; Matsuzawa et al., 2001; Gilmore et al., 2007b). Por tanto, se produce un crecimiento rápido de todo el cerebro durante el primer año de vida pero este crecimiento es más lento durante el segundo año de vida. Los resultados también indicaron que el núcleo caudado y el hipocampo aumentaron en volumen desde 1 año a 2 años, pero sólo el núcleo caudado siguió aumentando cuando se normalizó el volumen total del cerebro, mientras que el crecimiento del hipocampo fue relativamente pequeño. De modo que, diferentes estructuras subcorticales tienen distintas trayectorias de desarrollo durante este período. Para finalizar, observaron un notable aumento del $240 \%$ en el tamaño del cerebelo en el primer año. Debido a que el cerebelo está implicado en la coordinación motora y el equilibrio (Bastian \& Thach, 2002), este crecimiento considerable explicaría los rápidos desarrollos motores de la infancia.(Ver Figura 1).

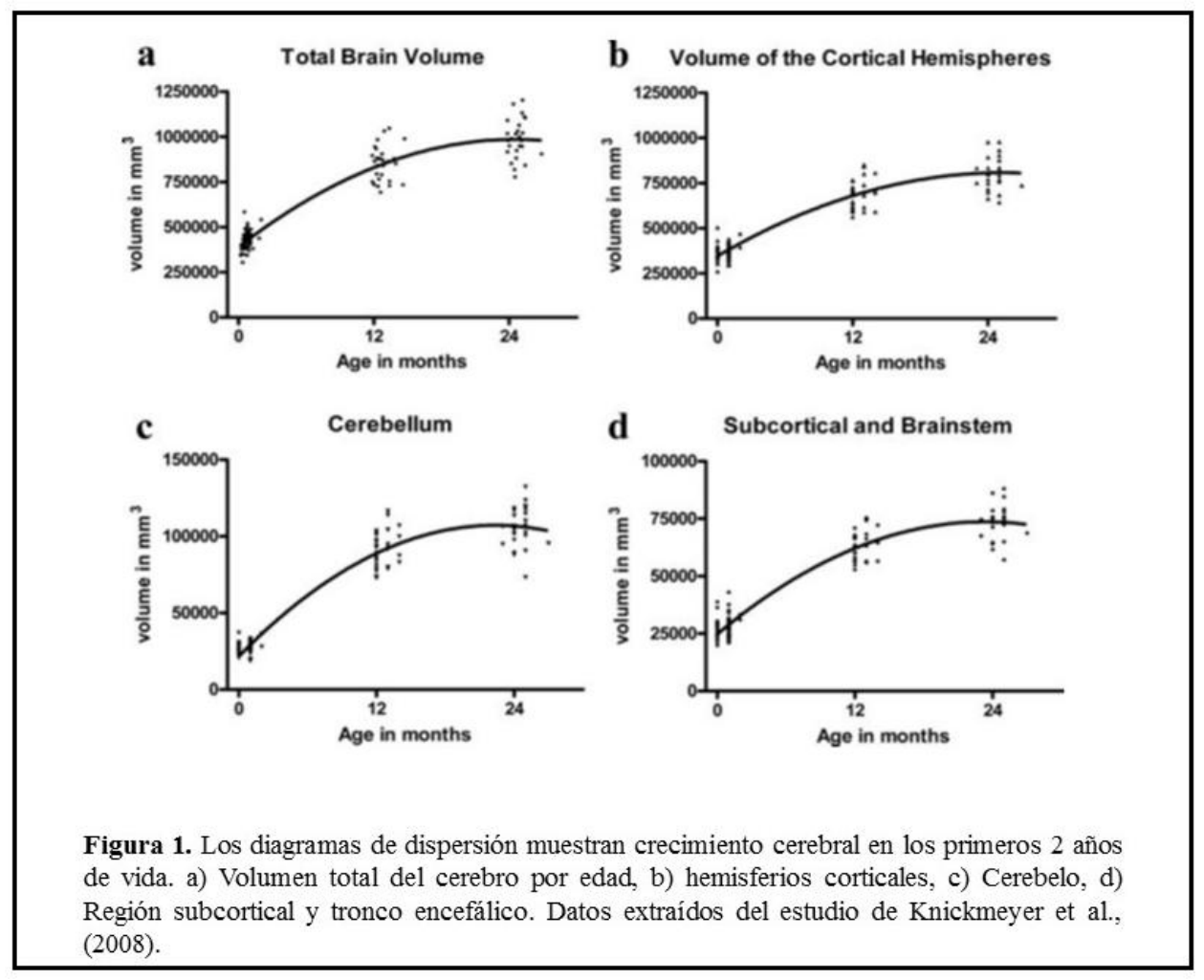

Los resultados del hipocampo obtenidos en el estudio de Knickmeyer et al. (2008) son compatibles con los obtenidos por Utsunomiya et al. (1999) con un grupo de 42 niños japoneses (19 niños y 23 niñas) con edades comprendidas entre 3 semanas y 14 años 
(edad media, 5 años). Utilizando técnicas de morfometría cerebral, estudiaron las características del desarrollo del lóbulo temporal y de la formación hipocampal durante la primera infancia. Encontraron que había una diferencia del 5\% en el volumen del hipocampo al comparar niños entre 1 y 2 años de edad con los de 3 a 4 años de edad. De modo que, el volumen del hipocampo aumentó bruscamente hasta la edad de 2 años pero, después de esta edad, siguió aumentando lentamente. Observaron diferencias estadísticamente significativas en la asimetría derecha-izquierda desde la infancia temprana, tanto en el desarrollo del hipocampo como de los lóbulos temporales anteriores. Encontraron que el hipocampo derecho era mayor que el izquierdo en 38 casos $(91 \%)$ y los lóbulos temporales anteriores derechos, también mayores que los izquierdos en 32 casos $(76 \%)$.

Kretschmann, Kammradt, Krauthausen, Sauer \& Wingert (1986) informaron que el volumen de la formación del hipocampo humano aumenta dramáticamente en la segunda mitad del embarazo, mientras que un aumento aún mayor ocurre entre el primer y el segundo año de vida postnatal, así, el mayor aumento se produce en este período.

Uematsu et al. (2012) llevaron a cabo otro estudio con un grupo de 111 japoneses con desarrollo típico (58 varones y 53 mujeres) y con un rango de edad de 1 mes a 25 años. El objetivo del estudio era examinar las trayectorias de desarrollo volumétrico típicas de la amígdala y el hipocampo desde la infancia hasta la edad adulta temprana. Se realizó un estudio morfométrico de corte transversal del crecimiento amigdalar y del hipocampo. Los resultados indicaron cambios de volumen no lineales relacionados con la edad, especialmente durante los primeros años de vida, tanto en la amígdala como en el hipocampo, independientemente del sexo. Los picos de edades máximos de los volúmenes de la amígdala y del hipocampo se produjeron en la preadolescencia (9-11 años). De este modo, el volumen máximo de la amígdala se alcanzó en esa franja de edad. Por otra parte, el estudio mostró un aumento no lineal, relacionado con la edad en el desarrollo después de 4 años tanto en los chicos como en las chicas. Este estudio transversal mostró cómo la amígdala y el hipocampo en sujetos con desarrollo típico se desarrollan desde la infancia hasta la adultez temprana y sugiere que la infancia y la preadolescencia son períodos críticos para el desarrollo cerebral.

Durante la niñez, el cerebro humano muestra algunos de sus mayores cambios tanto en sus características anatómicas como fisiológicas. El crecimiento estructural se 
acompaña de cambios morfológicos significativos con aumentos en el área cortical, disminución del grosor cortical y cambio del volumen cortical que varía ampliamente según la región, así como aumentos diferentes de estructuras subcorticales cerebrales, núcleos profundos y cerebelo. Estos años se pueden concebir como un período de desarrollo generalmente dominado por procesos progresivos dinámicos y robustos, con énfasis en el crecimiento, la expansión, "construcción" y "florecimiento", que luego serán podados y afinados con la maduración y la experiencia continuas (Brown \& Jernigan, 2012). El hipocampo, la amígdala, los ganglios basales y la corteza prefrontal se desarrollan de forma decisiva en los primeros años vida, contribuyendo con ello al aprendizaje socioemocional (amígdala/hipocampo) y al aprendizaje de patrones de respuesta claves y esenciales para la supervivencia (ganglios basales).

\subsection{Estudios posteriores (Infancia-Adolescencia)}

El desarrollo cerebral durante la infancia tardía y la adolescencia se caracteriza por una disminución de SG, un aumento de SB y del volumen ventricular (Ostby et al., 2009). En general se reconoce que el volumen de sustancia gris aumenta en la primera infancia y disminuye durante la adolescencia (Jernigan et al., 1991; Reiss et al, 1996; Giedd et al., 1999; Sowell et al., 1999; Lenroot et al., 2007; Wilke et al., 2007; Shaw et al., 2008). Esto se debe a la arborización sináptica temprana y a la poda posterior (Huttenlocher, 1990). Los resultados indican que la SG en las estructuras subcorticales muestran diferentes trayectorias de desarrollo (Giedd et al., 1996b; Sowell, Trauner, Gamst \& Jernigan, 2002; Toga, Thompson \& Sowell, 2006).

Un estudio llevado a cabo por Ostby et al. (2009), se centró en describir y comparar las trayectorias de desarrollo de varias estructuras subcorticales en una muestra de niños, adolescentes y jóvenes adultos $(n=171$, rango de edad: 8-30 años) partiendo de un enfoque de segmentación de todo el cerebro para describir la trayectoria de desarrollo de 16 volúmenes neuroanatómicos. Los resultados indicaron que la SG disminuye de forma no lineal en el córtex cerebral y linealmente en el núcleo caudado, putamen, globo pálido y núcleo accumbens, mientras que la amígdala y el hipocampo muestran ligeros aumentos no lineales en el volumen de SG. Por otro lado, el volumen de SB aumentó no linealmente en el cerebro y cerebelo, con una maduración temprana en la 
SB cerebelar. Además de similitudes en las trayectorias del desarrollo dentro de las regiones subcorticales, estos resultados también mostraron diferencias entre estructuras dentro de las mismas regiones: en los ganglios basales, el núcleo caudado mostró una relación más débil respecto a la edad que el putamen y el globo pálido, mientras que en el cerebelo se encontraron diferencias entre el desarrollo entre la SG y la SB.

El grupo de Sussman (2016) llevó a cabo un estudio con participantes con desarrollo típico (96 hombres y 96 mujeres; rango de edad 4-18 años). Este estudio es el primero en proporcionar un análisis completo de las trayectorias de desarrollo cortical (volumen cerebral total, volúmenes de SG y SB, superficie cortical, grosor cortical y volumen cortical), del desarrollo subcortical (volumen del hipocampo y de los gánglios basales y sus subestructuras) así como las estructuras cerebelares. El grupo de participantes lo dividieron por sexos, hombres y mujeres, y cada uno de ellos en cuatro subgrupos, con cuatro rangos de edad (4-7, 8-11, 12-15 y 16-18). El estudio pretendía realizar un análisis transversal completo de los cambios cerebrales relacionados con la edad que ocurren durante la infancia y la adolescencia. Se encontró el volumen total del cerebro aumentaba linealmente con la edad. Tanto los volúmenes de SG como de SB aumentaron linealmente con el aumento del volumen total del cerebro. Los volúmenes totales del cerebro, la SG y la SB fueron mayores en los hombres en comparación con las mujeres en un $7,3 \%, 10,4 \%$ y $7,5 \%$, respectivamente, durante la niñez y la adolescencia. (Ver Figura 2).

Estudios previos también han obtenido una diferencia volumétrica muy similar de 810\% (Giedd, Castellanos, Rajapakse, Vaituzis \& Rapoport, 1997; Lenroot et al., 2007; Paus, 2010). El volumen cortical total siguió un ajuste cuadrático que empezó a disminuir alrededor de los 12 años de edad. Encontraron que el grosor cortical disminuyó linealmente con la edad en todas las regiones corticales excepto en los polos temporales superior y medio bilaterales, que no cambia significativamente con la edad. Estos resultados del grosor cortical generalizado son consistentes con estudios previos (Sowell et al., 2004; Paus, Keshavan \& Giedd, 2008; Muftuler et al., 2011). También encontraron que la superficie cortical de las siguientes regiones variaba linealmente con la edad: giro frontal inferior izquierdo (opercular y triangular), área motora suplementaria izquierda, giro cingulado anterior izquierdo y giro paracingulado, giro temporal inferior izquierdo, giro parahipocampal izquierdo, precuneo izquierdo, polo temporal superior derecho, giro recto derecho y polo temporal medio bilateral. Todas 
estas regiones tenían una superficie cortical creciente con la edad excepto el precuneo izquierdo y el giro recto derecho. Además, la mayoría de las regiones corticales cambiaban el volumen cortical en función de la edad. Los resultados obtenidos respecto a las trayectorias de desarrollo subcortical, fueron los siguientes. El volumen del hipocampo izquierdo aumentó linealmente con la edad, sin embargo, no sucedió lo mismo con el volumen del hipocampo derecho. Los volúmenes del tálamo, núcleo caudado y del putamen disminuyeron con la edad. El análisis del volumen del cerebelo reveló un efecto de la edad que seguía una tendencia lineal (lóbulos III, IV, V, VIIIB, IX, Crus I) o una tendencia cuadrática (VI, VIIB, VIIIA) dependiendo de los lóbulos. Se encontró que el volumen del cerebelo total era significativamente menor en mujeres que en hombres, independientemente de la edad (Sussman, Leung, Chakravarty, Lerch \& Taylor, 2016).

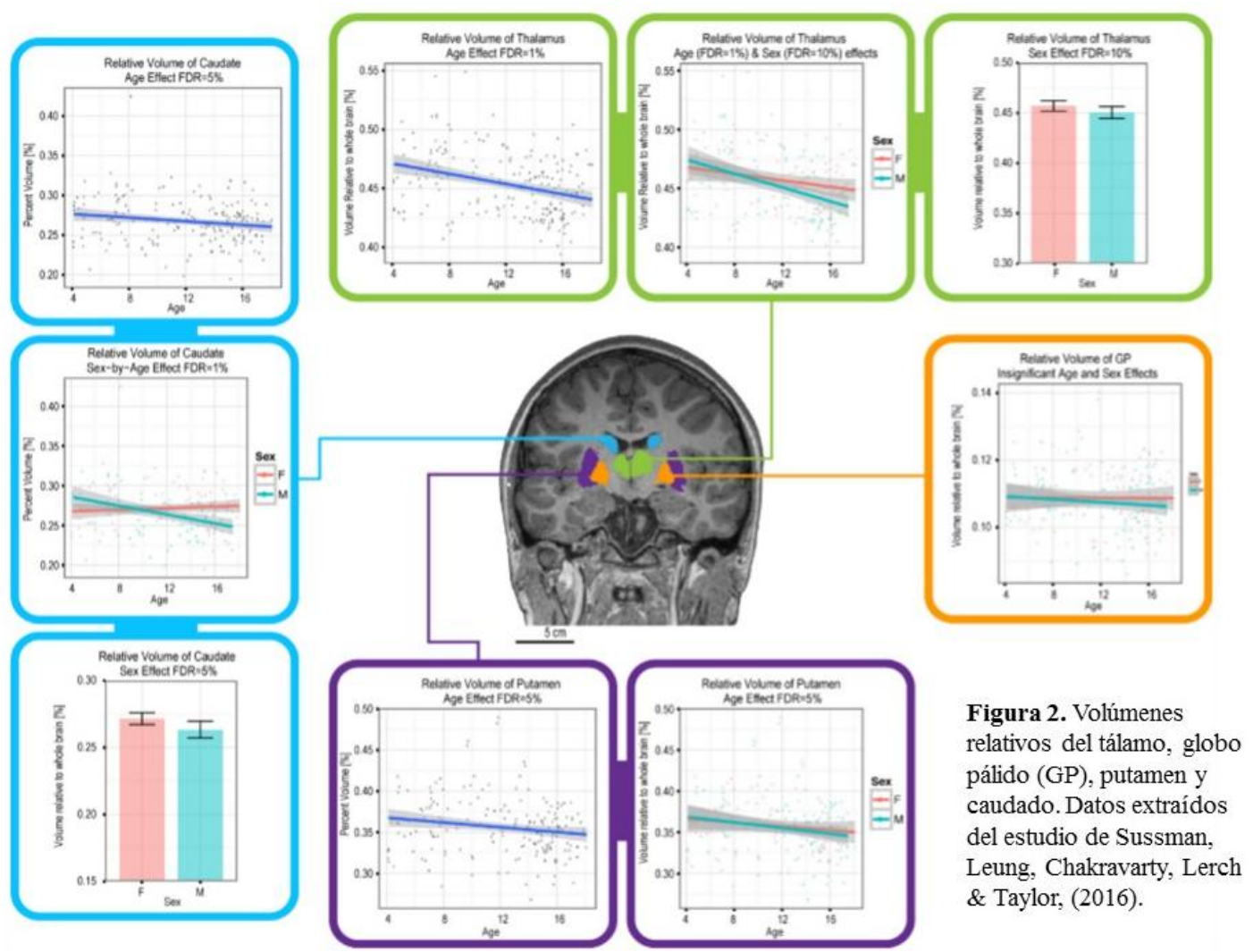

Algunos de los resultados publicados por el grupo de Sussman son similares a los que encontraron Dennison et al. (2013), quienes estudiaron los cambios de maduración en el estriado, globo pálido, hipocampo, amígdala y tálamo durante la adolescencia temprana 
y media utilizando un diseño longitudinal y consideraron que esta etapa se caracterizaba por cambios sorprendentes en la maduración subcortical del cerebro. En su estudio se adquirieron imágenes de resonancia magnética de 60 sujetos adolescentes (28 mujeres) con un rango de edad 12,5 y 16,5 años. Los resultados del estudio indicaron que el núcleo caudado, el tálamo y el putamen disminuyeron en cuanto al volumen, más en las mujeres que en los hombres, y las disminuciones en el putamen y el tálamo fueron mayores en el hemisferio izquierdo. El globo pálido aumentó de tamaño, pero más en el hemisferio izquierdo. Mientras que el núcleo accumbens izquierdo, aumentó de tamaño y el núcleo accumbens derecho disminuyó en tamaño durante el período de seguimiento. Los aumentos en el volumen del hipocampo fueron mayores en el hemisferio derecho. El aumento de volumen en el hipocampo, el globo pálido y núcleo accumbens izquierdo y la disminución de volumen en el putamen, el núcleo caudado, el tálamo y el núcleo accumbens derecho son en general coherentes con otras publicaciones (Durston et al., 2001; Sowell et al., 2002; Urošević et al., 2012). Los resultados del estudio apoyan la idea de que en este período de la vida se producen asimetrías en el desarrollo cerebral de estructuras subcorticales. Específicamente, el putamen era más grande en el hemisferio izquierdo que en el hemisferio derecho al inicio pero no en el seguimiento. De forma similar, el hipocampo derecho no era más grande que el izquierdo en la línea de base, pero aumentó más que el izquierdo durante este período de desarrollo para ser significativamente mayor en el seguimiento, lo cual es consistente con los hallazgos de volúmenes del hipocampo derecho mayores en adultos normales (Pedazra, Bowers \& Gilmore, 2004). Por tanto, el desarrollo cerebral subcortical desde la adolescencia temprana hasta la adolescencia media se caracteriza por la notable especialización hemisférica y los dimorfismos sexuales, y proporciona un marco para interpretar los cambios típicos y atípicos en la cognición, el afecto y el comportamiento (Dennison et al., 2013).

La mayoría de estudios publicados sobre el desarrollo cerebral han sido a partir de diseños transversales. Pocas investigaciones han abordado el desarrollo de regiones subcorticales utilizando diseños longitudinales. Wierenga et al. (2014), realizaron un estudio con un diseño de este tipo, sobre el volumen de 8 estructuras subcorticales en 147 participantes (rango de edad 7-24 años, 94 hombres y 53 mujeres). Los autores del estudio se interesaron por estas estructuras porque juegan un papel importante en el desarrollo cognitivo (Bunge, 2009; Diamond, 2000; Ito, 2008; Lavenex \& Banta 
Lavenex, 2013; Scherf et al., 2013) y porque han estado implicadas en diversos trastornos del desarrollo, como el autismo (Langen et al., 2013; Philip et al., 2012), el TDAH (Carmona et al., 2009, Krain \& Castellanos, 2006) y la esquizofrenia (Ballmaier et al., 2008, Mamah et al., 2008). En dicho estudio se analizaron un total de 223 imágenes de resonancia magnética (MRI) de las siguientes regiones: núcleo caudado, putamen, globo pálido, accumbens, tálamo, amígdala, hipocampo y corteza cerebelosa. Se observaron distintas trayectorias del desarrollo entre las diferentes estructuras subcorticales, de modo que encontraron patrones de desarrollo en forma de $\mathrm{U}$ invertida en el volumen de SG en el hipocampo, la amígdala, el globo pálido, el tálamo y córtex cerebelar, mientras que se observaron disminuciones lineales en el núcleo caudado, el putamen y el núcleo accumbens. El tálamo mostró un pequeño aumento inicial en el volumen seguido por una ligera disminución. Este es uno de los pocos estudios que ha captado cambios en el desarrollo del volumen del tálamo (Brown \& Jernigan, 2012; Dennison et al., 2013; Giedd et al., 1996a, 1996b; Ostby et al., 2009; Reiss et al., 1996). Esto puede estar relacionado con la pequeña magnitud del cambio (aproximadamente $2 \%$ ) el tálamo muestra un desarrollo prolongado en comparación con el volumen total de SG, pero el volumen máximo ocurre antes del hipocampo y amígdala. Por lo tanto, el tálamo puede madurar antes que el hipocampo y amígdala. Todas las estructuras tuvieron mayor volumen en los hombres que en las mujeres en todo el rango de edad, excepto para el cerebelo que tenía una trayectoria de desarrollo sexualmente dimórfica. La corteza cerebelosa fue la única estructura que presentó una interacción entre la edad y el sexo, así, para los hombres hubo una relación cuadrática entre la edad y el volumen con un pico máximo a la edad de 15,6 años, mientras que para las mujeres, la SG cerebelosa presentó un pico más temprano. Las estructuras subcorticales parecen todavía no estar completamente desarrolladas en la infancia y continúan mostrando cambios de maduración en la adolescencia (Wierenga et al., 2014).

Para concluir este apartado, una aportación interesante en el desarrollo cerebral humano fue la de Mutlu et al., (2013) quienes estudiaron las diferencias de sexo en el desarrollo del grosor cortical, y el desarrollo del plegado cortical en toda la corteza, en una muestra de sujetos con desarrollo típico, con un rango de edad de 6 a 30 años. Concluyeron que las trayectorias más complejas de grosor cortical estaban simétricamente localizadas en regiones cerebrales relacionadas con la cognición de orden superior, como la región prefrontal, la unión temporoparietal y el precúneo. Las 
regiones que presentaron trayectorias más complejas del grosor cortical cambiaban con la edad, presentando una trayectoria de desarrollo cuadrática. De hecho, la región prefrontal, la unión temporoparietal y el precúneo son regiones corticales conocidas por ser clave en la integración de la información proveniente de diferentes áreas. La corteza prefrontal es una gran región implicada en muchos procesos cognitivos superiores, como el funcionamiento socioemocional y el funcionamiento ejecutivo. Por ejemplo, la corteza prefrontal medial desempeña un papel en la empatía cognitiva (Shamay-Tsoory, 2011) y la región prefrontal dorsolateral es crucial para la planificación y la toma de decisiones. La región prefrontal madura más tarde que las otras regiones corticales (Teffer \& Semendeferi, 2012). Aparte de la región prefrontal, también observaron trayectorias de crecimiento cortical cuadrático en el surco temporal superior izquierdo, responsable de la interpretación de las acciones de los otros (Thompson \& Parasuraman, 2012), en la unión temporoparietal, implicada en la ToM y en la representación de los estados mentales de los demás (Samson et al., 2004; Saxe \& Wexler, 2005), y en el precúneo (relacionado con la autoconsciencia y autoimágenes mentales (Cavanna \& Trimble, 2006).

En resumen, los cambios observados en esta segunda etapa en las estructuras clave son menos pronunciados en general, y tendencia a desarrollarse en forma de $\mathrm{U}$ invertida $\mathrm{O}$ pequeños decrementos lineales.

\section{2- EL TRASTORNO DE ASPERGER: Un poco de historia}

"Desde 1938 me ha llamado la atención varios niños cuyo cuadro difiere de forma tan marcada y única de cualquier otro conocido hasta el momento, que cada caso merece una consideración detallada acerca de sus fascinantes peculiaridades" Leo Kanner, 1943. Con estas palabras empezaba, hace un poco más de siete décadas, un artículo que describía uno de los trastornos que más fascinación ha despertado en los investigadores que tratan de estudiarlo: el autismo.

Sin embargo, el término de "autismo" ya había sido introducido mucho antes por Paul Eugene Bleuler (1911), psiquiatra suizo, para referirse a una alteración relacionada con la esquizofrenia que implicaba aislarse de la realidad y encerrarse en sí mismo. En 1923, Carl Gustav Jung, psicólogo también suizo, introdujo los conceptos de personalidad 
extravertida e introvertida y definió el autismo como una forma de ser profundamente introvertida y centrada en el mundo interior. Así, durante unos años, el concepto de autismo se aceptó en el ámbito médico europeo como una forma de esquizofrenia. Ssucharewa, psiquiatra rusa, describió en 1926 a 6 pacientes similares a los que posteriormente describiría Hans Asperger. De hecho, ella fue quien introdujo el concepto de "psicopatía autista" para referirse al cuadro clínico del autismo (Artigas-Pallarés y Paula, 2017).

No obstante, la comunidad científica vinculada con el tema, consideraba la aportación de Kanner en su artículo Autistic disturbances of affective contact (Los trastornos autistas del contacto afectivo), como la primera descripción del trastorno, publicado por la revista Nervous Child (1943). Kanner trabajó durante años en el servicio de Psiquiatría Infantil del Hospital John Hopkins de Baltimore. Allí se centró y profundizó en el estudio de este trastorno e identificó con precisión un número elevado de niños que lo presentaban Kanner (1951). En su trabajo, describió las características conductuales observadas en once niños (8 niños y 3 niñas) e introduce el término early infantile autism (autismo infantil precoz). Estas características eran: incapacidad para relacionarse, alteraciones en los aspectos pragmáticos del lenguaje, insistencia obsesiva en mantener el ambiente sin cambios, presencia de habilidades especiales (en algunos casos), buena capacidad cognitiva (limitada a sus centros de interés) e inicio de los síntomas desde el nacimiento. En resumen, estos niños presentaban unas alteraciones en su desarrollo que se resumían en tres núcleos principales: problemas en la relación social, alteración en la comunicación y el lenguaje y espectro restringido de intereses (Kanner, 1943). Una de las aportaciones más interesantes de Kanner en aquella época fue la de considerar el autismo como un trastorno del neurodesarrollo y negaba rotundamente la idea de que dicho trastorno dependía de determinantes emocionales ligados al vínculo materno; estaba convencido de que no se trataba de una enfermedad rara ni que era un tipo de esquizofrenia. Así lo describía en su trabajo: "Por tanto, debemos asumir que estos niños han llegado al mundo con una incapacidad innata para formar el contacto afectivo normal, biológicamente proporcionado, con las personas; al igual que otros nacen con deficiencias intelectuales o físicas innatas. Si esta hipótesis es correcta, un estudio más profundo de nuestros niños puede ayudar a proporcionar unos criterios más concretos relativos a las todavía difusas relaciones sobre los componentes constitucionales de la respuesta emocional. Por el momento parece que tenemos ejemplos puros de trastornos 
autistas innatos del contacto afectivo". Probablemente el autismo ha existido siempre, pero es a partir de la descripción de Kanner cuando se reconoce como entidad (ArtigasPallarés y Paula, 2017).

El conocimiento del trastorno se fue extendiendo por América y también por Europa y se publicaron una serie de trabajos como los de Krevelen en Holanda (1952) y Stern en Francia (1952). Mientras tanto, en el continente europeo Hans Asperger, pediatra vienés que trabajaba en el Hospital Infantil de la Universidad de Viena, publicó en 1944 observaciones similares a las de Kanner, sin conocer el trabajo de éste. Asperger en su artículo describía a cuatro chicos que, a pesar de las diferencias entre ellos, mostraban unas características comunes: falta de contacto con las personas que le rodean, poca habilidad para hacer amigos, pobre empatía, intereses específicos, necesidad de que todo siga un mismo orden o se haga de una manera determinada, una manera de hablar peculiar y un lenguaje repetitivo o pedante, ausencia de contacto visual al conversar y mala coordinación motora. Utilizó el término autistic psychopathy (psicopatía autista) para referirse al trastorno que presentaban estos niños. En la obra de Asperger resaltan varios aspectos de indudable valor ya que, de alguna manera, se anticiparon a su época y coinciden con el actual concepto de espectro autista descrito en el DSM-5. Así, para Asperger, el autismo era una condición frecuente y de diagnóstico fácil, podían presentar problemas de atención, de aprendizaje y de procesamiento sensorial, algunos de ellos podían estar plenamente integrados en su entorno social y laboral e identificó que el trastorno tenía una base poligénica compleja. Además, fue un defensor tenaz de la integración social y laboral de estas personas y defendía la idea de una educación basada en la comprensión de la personalidad de cada niño y afirmaba que estos niños aprendían mejor cuando eran guiados por sus intereses especiales. (Artigas-Pallarés y Paula, 2012, 2017).

El trabajo de Asperger no tuvo mucha repercusión en la mayoría de países porque fue escrito en alemán y no fue traducido al inglés hasta casi cuatro décadas después, por Lorna Wing (a quien se le atribuye el término Síndrome de Asperger (SA) (Wing, 1981). Desde su descripción, se han llevado a cabo muchos estudios y bastantes esfuerzos para buscar una explicación de las causas del trastorno. Una de las primeras fue la "hipótesis psicogénica del autismo", desarrollada por Spitz en 1945, con una fuerte influencia del psicoanálisis (Spitz, 1945). Según este autor, se culpaba a los padres de la enfermedad que padecían sus hijos porque no se había establecido un vínculo afectivo adecuado entre 
la madre y el hijo desde el nacimiento de éste. La propuesta realizada por Spitz en esa época era considerar el autismo como una enfermedad (Muñoz Yunta, Palau, Salvadó y Valls, 2006; Muñoz Yunta et al., 2005). Debido a esta hipótesis, durante los primeros veinte años de estudio de TEA, éste ha sido considerado como una enfermedad estigmatizada y llena de mitos. Otro planteamiento que pretendía dar una explicación fue el propuesto por Bettelheim en 1967, quien propone "la teoría de la madre nevera" ("refrigerador mother"). Bettelheim sostenía que los primeros días de vida del bebé son críticos para el desarrollo y la falta de calor materno provocado por el rechazo de la madre hacia su hijo era la causa que provocaba la aparición de los síntomas del autismo.

En la década de los 60, se descarta la hipótesis citada anteriormente a medida que se va demostrando su falta de justificación experimental. Así, a lo largo de los años 70 se demuestran las primeras evidencias en las que se asocia el autismo con trastornos neurobiológicos (Schain \& Yannet, 1960; Deykin \& MacMahon, 1979; Chess, 1977).

En las últimas tres décadas, el enfoque del autismo ha experimentado cambios notables. Un cambio importante ha sido la consideración del autismo bajo la vertiente de la neurología evolutiva, clasificándolo como un trastorno del desarrollo. Esta modificación aparece reflejada en las definiciones diagnósticas, dónde se ha sustituido la consideración tradicional del autismo como psicosis infantil, por su categorización como trastorno generalizado del desarrollo. Otro gran avance experimentado en el estudio del autismo ha sido el auge de la investigación neurobiológica, que abarca distintos campos de estudio, tales como la neuropatología, la neuroquímica, la neurofisiología, la neuroimagen y la genética.

En la tercera edición del Diagnostic and Statistical Manual of Mental Disorders, DSM-III (American Psychiatric Association, 1980) es donde se separan por primera vez las denominaciones de autismo y esquizofrenia infantil y se introduce el concepto pervasive developmental disorder, que se ha traducido como trastorno generalizado del desarrollo, donde se agrupan distintas variantes del trastorno autista.

La fuente a partir de la cual se ha extraído la información histórica anterior ha sido de los artículos: "El autismo 70 años después de Leo Kanner y Hans Asperger" y "Deconstruyendo a Kanner" de Artigas-Pallarés y Paula-Pérez, (2012, 2017, respectivamente), del artículo “Autismo y epilepsia” de Muñoz Yunta, Palau, Salvadó y 
Valls, (2006) y del libro "Guía Médica y Neuropsicológica del Autismo" de Muñoz Yunta et al., (2005).

El SA era uno de los cuadros que componían el gran abanico de los trastornos generalizados del desarrollo o también conocido como espectro autista (Etchepareborda et al., 2007). Adquiere personalidad propia como trastorno diferenciado en 1981 cuando la psiquiatra inglesa Lorna Wing publica su trabajo "Asperger syndrome: a clinical account" (Síndrome de Asperger: un informe clínico), un texto de referencia que popularizó las investigaciones de Hans Asperger e introdujo el término Síndrome de Asperger (Wing, 1981). Proponía incluir tanto el autismo de Kanner como el Síndrome de Asperger en un grupo más amplio, como un continuo más que como una categoría diagnóstica, como un conjunto de síntomas que se puede asociar a distintos trastornos y niveles intelectuales, introduciendo así el concepto de espectro autista (Wing \& Gould, 1979). Además, Lorna Wing desarrolló la triada de Wing (dimensiones alteradas en el continuo autista): trastorno de la reciprocidad social, trastorno de la comunicación verbal y no verbal y ausencia de capacidad simbólica y conducta imaginativa. A estas características luego añadió los patrones repetitivos de actividad e intereses (Wing, 1988). A finales de los años 80, Uta Frith publica el libro "Autism: Explaining the Enigma" (Autismo: explicando el enigma), donde propone dos claves para entender la mente autista: la incapacidad para formular la teoría de la mente (para entender los propios pensamientos y los de los otros) y la falta de una coherencia central (capacidad de reunir diferentes piezas de conocimiento para formar un todo con significado propio) (Frith, 1989). También edita el libro "Autism and Asperger syndrome" (Autismo y síndrome de Asperger) donde incluye la primera traducción al inglés del trabajo original de Hans Asperger (Frith, 1991).

El reconocimiento oficial del SA como trastorno diferenciado del autismo clásico llegó poco después. Primero fue la Organización Mundial de la Salud, quien lo incluye en la décima edición de la Clasificación Internacional de Enfermedades (CIE-10, 1993); al año siguiente, la Asociación Americana de Psiquiatría hizo lo mismo incluyéndolo en su cuarta versión del Manual Estadístico y Diagnóstico de Trastornos Mentales (DSM-IV, 1994). En realidad, las versiones del DSM-I (1952) y DSM-II (1968), no contemplaron el autismo como un diagnóstico específico, sino más bien era considerado como una característica propia de la esquizofrenia infantil. En el DSM-III (1980) ya se incorpora como una categoría diagnóstica específica y se denomina Autismo infantil. En 1987, en 
la revisión del DSM-III-TR, se modifican tanto los criterios diagnósticos como la denominación, siendo considerado como Trastorno autista.

En la actualidad, se mantiene clasificado en la CIE-10 (Síndrome de Asperger) pero ha desaparecido como tal en el DSM-5 (APA, 2013) (Ver Tabla 1), donde se han incluido las tres categorías que aparecían en el manual anterior (Trastorno Autista, Trastorno de Asperger y Trastorno Generalizado del desarrollo no especificado) en una única categoría en la que se diferencian tres niveles de afectación (Ver Tabla 2). Esta determinación viene impulsada por la falta de evidencias respecto a las diferencias neurobiológicas consistentes entre ellas (Via, Radua, Cardoner, Happé, \& Mataix-Cols, 2011; Anagnostou \& Taylor, 2011; Ozonoff, South \& Miller, 2000; Howlin, 2003). El DSM-5 reduce a dos los tres criterios diagnósticos propuestos por el manual anterior. Así, agrupa los dos criterios de trastorno cualitativo de la relación social y trastorno cualitativo de la comunicación en uno solo, proponiendo un déficit persistente en la comunicación social y en la interacción social en distintos contextos (Déficits en reciprocidad socio-emocional, Déficits en conductas comunicativas no verbales usadas en la interacción social y Déficits para desarrollar, mantener y comprender relaciones). 
Tabla 1. Trastorno de Asperger en la Clasificación Internacional de Enfermedades (CIE-10, 1993) y el Manual Estadístico y Diagnóstico de Trastornos Mentales (DSM-5, 2013)

CIE-10 (1993) DSM-5 (2013)

Autismo infantil

Trastorno del espectro del autismo, nivel 1 (Trastorno Asperger y Autismo de alto funcionamiento)

Autismo atípico

Trastorno del espectro del autismo, nivel 2

Síndrome de Rett

Trastorno del espectro del autismo, nivel 3

Otro trastorno desintegrativo de la infancia

Síndrome de Asperger

Otro Trastorno generalizado del desarrollo

Trastorno generalizado del desarrollo, inespecífico

Trastorno hiperquinético con retraso mental y movimientos estereotipados

El otro criterio propuesto es: patrones repetitivos y restringidos de conductas, actividades e intereses (Movimientos motores, uso de objetos o habla estereotipados o repetitivos, Insistencia en la igualdad, adherencia inflexible a rutinas o patrones de comportamiento verbal y no verbal ritualizado, Intereses altamente restringidos, obsesivos, que son anormales por su intensidad o su foco) en el que introduce como novedad la Hiper- o hipo-reactividad sensorial o interés inusual en aspectos sensoriales del entorno. Los síntomas deben estar presentes en el período de desarrollo temprano (aunque pueden no manifestarse plenamente hasta que las demandas del entorno excedan las capacidades del niño, o pueden verse enmascaradas en momentos posteriores de la vida por habilidades aprendidas) (DSM-5, 2013). 
La evolución del concepto de autismo y su incorporación en el Diagnostic and Statistic Manual of Mental Disorders (DSM) ha sido la que aparece en la Tabla 3 (ArtigasPallarés y Paula, 2017).

Por tanto, el SA es un trastorno del desarrollo de base neurobiológica, que se incluye dentro de los Trastornos del Espectro Autista (TEA, nivel 1) y caracterizado por un complejo fenotipo en el que se observan déficits en la comunicación e interacción social, así como déficits sensoriomotores y afecta, aproximadamente, a 1 de cada 88-110 niños, con 4-5 veces mayor prevalencia en niños que en niñas (Kana, Libero \& Moore, 2011; Uddin et al., 2013). Presenta gran variabilidad de expresiones clínicas, producidas por disfunciones multifactoriales en el desarrollo del Sistema Nervioso Central. De modo que no se trata de un único espectro autista sino más bien de diferentes espectros autistas (Fernell, Eriksson \& Gillberg, 2013). Tal y como indica Cererols en su libro "Descubrir el Asperger”: “...se habla de espectro autista en el mismo sentido en el que hablamos del espectro de colores en el que se descompone la luz visible al pasar por un prisma. Podemos distinguir en él los colores, pero nos resulta difícil decidir en qué punto exacto un color cambia para convertirse en otro". Actualmente no existen marcadores biológicos diferenciados y el diagnóstico es clínico, por tanto, los marcadores diagnósticos son conductuales. Rara vez se presentan aislados porque coexisten con otros problemas neurológicos y de desarrollo. En general, los TEA coexisten (aparecen junto con otros trastornos) con Trastornos afectivos, Trastornos ansiosos, Trastorno obsesivocompulsivo, Trastorno por Déficit de Atención con Hiperactividad (TDAH), Trastornos motores y Trastornos de conducta (Artigas, 2001). Normalmente, los problemas de comportamiento, la irritabilidad y las conductas agresivas que pueden manifestar se deben a la inhabilidad para comunicar sus frustraciones, sus miedos y sus ansiedades (Artigas y Narbona, 2011). 
Tabla 2. Niveles de severidad del trastorno del espectro del autismo, según el Manual Estadístico y Diagnóstico de Trastornos Mentales (DSM-5, 2013).

\begin{tabular}{|c|c|c|}
\hline $\begin{array}{l}\text { Niveles de } \\
\text { severidad }\end{array}$ & Comunicación social & $\begin{array}{l}\text { Intereses restringidos y conducta } \\
\text { repetitiva. }\end{array}$ \\
\hline $\begin{array}{c}\text { Nivel } 3 \\
\text { Requiere } \\
\text { un apoyo } \\
\text { muy } \\
\text { sustancial }\end{array}$ & $\begin{array}{l}\text { Los déficits graves de las aptitudes de } \\
\text { comunicación social verbal y no verbal } \\
\text { causan alteraciones graves en el } \\
\text { funcionamiento, inicio muy limitado de } \\
\text { interacciones sociales y respuesta mínima a } \\
\text { la apertura social de otras personas. Por } \\
\text { ejemplo, una persona con muy pocas } \\
\text { palabras inteligibles que raramente inicia } \\
\text { interacciones sociales y cuando lo hace, } \\
\text { realiza aproximaciones inusuales únicamente } \\
\text { para satisfacer sus necesidades y únicamente } \\
\text { responde a aproximaciones sociales muy } \\
\text { directas. }\end{array}$ & $\begin{array}{l}\text { La inflexibilidad del } \\
\text { comportamiento, la extrema } \\
\text { dificultad de hacer frente a los } \\
\text { cambios u otros comportamientos } \\
\text { restringidos /repetitivos, interfieren } \\
\text { notablemente en el funcionamiento } \\
\text { en todos los ámbitos. Ansiedad } \\
\text { intensa, dificultad para cambiar el } \\
\text { foco de acción. }\end{array}$ \\
\hline $\begin{array}{l}\text { Nivel } 2 \\
\text { Requiere } \\
\text { un apoyo } \\
\text { sustancial }\end{array}$ & $\begin{array}{l}\text { Déficits notables de las aptitudes de } \\
\text { comunicación social verbal y no verbal; } \\
\text { problemas sociales aparentes incluso con } \\
\text { ayudas in situ; inicio limitado de } \\
\text { interacciones sociales y responden de manera } \\
\text { atípica o reducida a la apertura social de otras } \\
\text { personas. Por ejemplo, una persona que emite } \\
\text { frases sencillas, cuya interacción se limita a } \\
\text { intereses especiales muy concretos y tiene } \\
\text { una comunicación no verbal muy excéntrica. }\end{array}$ & $\begin{array}{l}\text { El inflexibilidad de } \\
\text { comportamiento, la dificultad de } \\
\text { hacer frente a los cambios u otros } \\
\text { comportamientos restringidos } \\
\text { /repetitivos, aparecen claramente } \\
\text { con frecuencia al observador casual } \\
\text { e interfieren con el funcionamiento } \\
\text { en diversos contextos. Ansiedad y / } \\
\text { o dificultad para cambiar el foco de } \\
\text { acción. }\end{array}$ \\
\hline $\begin{array}{c}\text { Nivel } 1 \\
\text { Requiere } \\
\text { apoyo }\end{array}$ & $\begin{array}{l}\text { Sin ayuda in situ, las dificultades en la } \\
\text { comunicación social causan problemas } \\
\text { importantes. Dificultad para iniciar } \\
\text { interacciones sociales y ejemplos claros de } \\
\text { respuestas atípicas o insatisfactorias en } \\
\text { respuesta a la apertura social de los otros. } \\
\text { Puede parecer que tiene poco interés en las } \\
\text { interacciones sociales. Por ejemplo, una } \\
\text { persona que es capaz de hablar con frases } \\
\text { completas y que establece comunicación pero } \\
\text { cuya conversación amplia con otras personas } \\
\text { falla y cuyos intentos de hacer amigos son } \\
\text { excéntricos y generalmente sin éxito. }\end{array}$ & $\begin{array}{l}\text { La inflexibilidad del } \\
\text { comportamiento causa una } \\
\text { interferencia significativa con el } \\
\text { funcionamiento en uno o más } \\
\text { contextos. Dificultad para alternar } \\
\text { actividades. Los problemas de } \\
\text { organización y planificación } \\
\text { dificultan la autonomía. }\end{array}$ \\
\hline
\end{tabular}


El perfil neurocognitivo característico que presentan los sujetos con TEA es el siguiente (Artigas y Narbona, 2011):

1. Tienen un cociente intelectual dentro de la media $(\mathrm{CI}>80)$;

2. Su memoria suele estar muy desarrollada pero es poco funcional;

3. El lenguaje está relativamente conservado en los aspectos semánticos y morfosintácticos pero está alterado en la vertiente pragmática;

4. Suelen asumir el rol de hablador exclusivo y se convierten en protagonista de la charla, prescindiendo del discurso del interlocutor;

5. Presenta dificultades para identificar los signos no verbales implícitos que funcionan como reglas tácitas de las conversaciones (miradas, pausas, gestos);

6. Suelen desviar la conversación hacia temas relacionados con sus intereses; su lenguaje es literal presentando dificultades para entender frases hechas, metáforas, mensajes irónicos, ...

A nivel de pensamiento y cognición social:

- Presentan dificultades en la percepción global y mayor habilidad en la percepción de detalles.

- Su pensamiento es visual (relatan su pensamiento en forma de imágenes, no incluyen ni sensaciones ni sentimientos).

- Sus funciones ejecutivas aparecen disminuidas (control inhibitorio, memoria de trabajo, flexibilidad al cambio y vigilancia).

- Presentan una falta de motivación notable hacia lo que no les interesa.

- Tienen el proceso de aprendizaje simultáneo menos desarrollado que el secuencial; finalmente, presentan dificultades para generalizar los aprendizajes.

Otras características a destacar serían:

- Dificultades en la interacción social, debido a desarrollo empobrecido de sus habilidades sociales, les cuesta captar las señales sociales y, por tanto, no dan respuestas sociales y emocionales adecuadas. 
- Preocupación u obsesión por determinados temas o por intereses restringidos a los que dedican mucho tiempo.

- Finalmente, suelen imponer a menudo rutinas rígidas para ellos y para todos los que les rodean, les gustan las mismas cosas y hacerlas de la misma manera una y otra vez. Esta falta de flexibilidad mental hace que se alteren de forma notable ante los mínimos cambios en su entorno y también origina dificultades respecto al pensamiento imaginativo y creativo.

La conducta de los sujetos que presentan el TEA es coherente con la percepción que tienen de la realidad. Se conoce bastante sobre este trastorno pero todavía falta mucho para llegar a la comprensión definitiva del mismo (Artigas, 2001).

Tabla 3. Evolución del concepto de autismo en el Diagnostic and Statistic Manual of Mental Disorders (DSM). (Artigas-Pallarés y Paula, 2017).

\begin{tabular}{|c|c|c|}
\hline DSM & Año & Denominación \\
\hline DSM-I & 1952 & Reacción esquizofrénica, tipo infantil. \\
\hline DSM-II & 1968 & Esquizofrenia de tipo infantil. \\
\hline DSM-III & 1980 & Autismo infantil. \\
\hline DSM-III-R & 1987 & Trastorno autista. \\
\hline \multirow[t]{2}{*}{ DSM-IV-TR } & $\begin{array}{l}1994 \\
2000\end{array}$ & $\begin{array}{l}\text { Trastorno Generalizado del Desarrollo: Trastorno } \\
\text { Autista, Trastorno de Asperger, Trastorno de Rett, } \\
\text { Trastorno desintegrativo infantil y trastorno } \\
\text { generalizado del desarrollo no especificado. }\end{array}$ \\
\hline & & Trastorno del Espectro del Autismo (TEA) \\
\hline DSM-5 & 2013 & Niveles: 1,2 y 3 \\
\hline
\end{tabular}


Respecto al diagnóstico, un diagnóstico válido y fiable posibilita una intervención más adecuada además de mejorar el bienestar de las familias (Noterdaeme \& HutzelmeyerNickels, 2010; Volkmar \& Pauls, 2003) y de las personas con TEA (Adelman, 2010; Canal-Bedia et al., 2015; Fountain, King \& Bearman, 2011; Klin, Klaiman \& Jones, 2015). Para mejorar el enfoque y la calidad de la práctica diagnóstica, se han desarrollado diferentes guías clínicas o de buenas prácticas, basadas en el consenso de expertos (Diez-Cuervo et al., 2005) y en la evidencia científica (Filipeck et al., 2000; NAPC, 2003; NICE, 2011; SIGN, 2007; SNS, 2009). Estos documentos recogen una serie de recomendaciones a modo de estándares de calidad desde un enfoque comprehensivo y multidisciplinar (Cervera, Martínez-Sanchis, Molla y Suárez, 2015). Las propuestas de estas guías sitúan al diagnóstico a medio camino entre la categorización clasificatoria de un modelo médico y la de un modelo educativo dirigido a la definición de perfiles de desarrollo y necesidades educativas (Cervera, MartínezSanchis, Molla y Suárez, 2015). En la Tabla 4 aparecen recogidas las principales guías mencionadas. 
Tabla 4- Selección de Guías de Buenas Prácticas (Cervera, Martínez-Sanchis, Molla y Suárez, 2015).

\begin{tabular}{lll}
\hline \multicolumn{1}{c}{ Autor } & \multicolumn{1}{c}{ Nombre } & Año \\
\hline & $\begin{array}{l}\text { Practise parameter: Screening and } \\
\text { diagnosis of autism Report of the Quality }\end{array}$ & \\
Filipeck et al. & $\begin{array}{l}\text { Standards Subcommitee of the American } \\
\text { Academy of Neurology and the Child } \\
\text { Neurology Society. }\end{array}$ & \\
\hline
\end{tabular}

National Autistic Society:Ann Le Couteur, National Autism Plan for Children (NAPC) 2003 Chair, Core Working Group.

Grupo de Estudios TEA del Guía de Buena Práctica para el Diagnóstico Instituto de Salud Carlos III de los TEA

(Diez-Cuervo et al., 2005).

Scottish Intercollegiate Assessment, diagnosis and clinical Guidelines Network (SIGN) interventions for children and Young people with autism spectrum disorders.

Ministries of Health and New Zeland Autism Spectrum Disorder Education Guideline.

Sistema Nacional de Salud Guía de Práctica Clínica para el Manejo de (SNS) Pacientes con TEA en Atención primaria. (SNS)

National Institute for Health Autism: recognition, referral and diagnosis and Care Excellence (NICE) of children and Young people on the autism spectrum. 


\section{3- ALTERACIONES EN LA TRAYECTORIA DEL DESARROLLO CEREBRAL EN NIÑOS CON TEA}

Muchos estudios de neuroimagen estructural y funcional se han centrado en la investigación de los cambios neuroanatómicos y en las posibles vías fisiopatológicas en los TEA. En los últimos años, estos métodos modernos de neuroimagen han aportado importantes conocimientos sobre las bases neurobiológicas de dicho trastorno. En el meta-análisis llevado a cabo por el grupo de Via (2011), no obtuvieron diferencias significativas en el volumen de sustancia gris entre el grupo de sujetos con Trastorno autista y el grupo de sujetos con Trastorno de Asperger. La conclusión a la que llegaron estos autores fue que ambos trastornos tenían los mismos sustratos neurales, de ahí que se haya considerado en el nuevo manual DSM-5 como una única entidad nosológica con diferentes grados de severidad.

Por otra parte, se han encontrado una serie de cambios cerebrales atípicos relacionados con la edad en las personas con TEA a partir de una serie de estudios longitudinales y transversales. A continuación vamos a exponer los resultados obtenidos en algunos de dichos estudios relacionados con las áreas y regiones de interés (ROI) que hemos utilizado en nuestro trabajo y donde esta población ha mostrado diferencias corticales, subcorticales y cerebelosas al compararla con sujetos con desarrollo típico. Las áreas y regiones cerebrales son las siguientes: Sistema Límbico (hipocampo, amígdala y otras zonas límbicas), ínsula, gánglios basales (núcleo caudado y putamen), tálamo, córtex frontal y cerebelo. Aunque no es un aspecto que vamos a tratar en este estudio, consideramos importante y necesario abordar a grandes rasgos qué datos aparecen en la literatura sobre el tema relacionados con del desarrollo cerebral en niños con TEA en los primeros años de vida.

\subsection{Desarrollo cerebral en los primeros años de vida}

La acumulación de evidencia de neuroimagen, así como de estudios post-mortem, sugiere que se produce un crecimiento acelerado en los primeros años de desarrollo en niños con TEA de manera que alcanzan el tamaño de un cerebro casi adulto considerablemente más temprano que en el caso de niños normotípicos (Bauman \& Kemper, 1985; Piven et al., 1995; Kemper \& Bauman 1998; Courchesne et al., 2001; 
Courchesne, Carper \& Akshoomoff, 2003). Esta ampliación en el tamaño del cerebro durante la infancia en el TEA sugiere que también puede haber más alteraciones estructurales específicas relacionadas con la edad en este trastorno (Courchesne et al., 2004; Schumann et al., 2010; Zielinski et al., 2014)

Los primeros estudios se centraron en el volumen total del cerebro para posteriormente evaluar las diferentes regiones e identificar estructuras cerebrales con mayor volumen. Los datos extraídos confirmaron un aumento en el volumen total del cerebro en estos niños al presentar un perímetro craneal mayor, debido a un crecimiento acelerado temprano del mismo que se producía durante los primeros años de vida. Los resultados sugirieron que en el nacimiento no existían diferencias en cuanto al perímetro craneal y que el inicio del crecimiento se produce alrededor de los 12 meses de edad, después continua hasta los 3 o 4 años de edad y, finalmente en la infancia, dicho crecimiento se reducía de forma gradual para no ser significativo en la adolescencia y en la edad adulta, al comparar los datos con controles con desarrollo típico (Courchesne et al., 2001; Sparks et al., 2001; Bartholomeusz et al., 2002; Courchesne et al. 2004; Courchesne \& Pierce, 2005; Courchesne et al., 2011; Yorbik et al. 2001; Lainhart et al. 1997; Bolton et al. 2001; Hazlett et al., 2005; Hazlett et al., 2011).

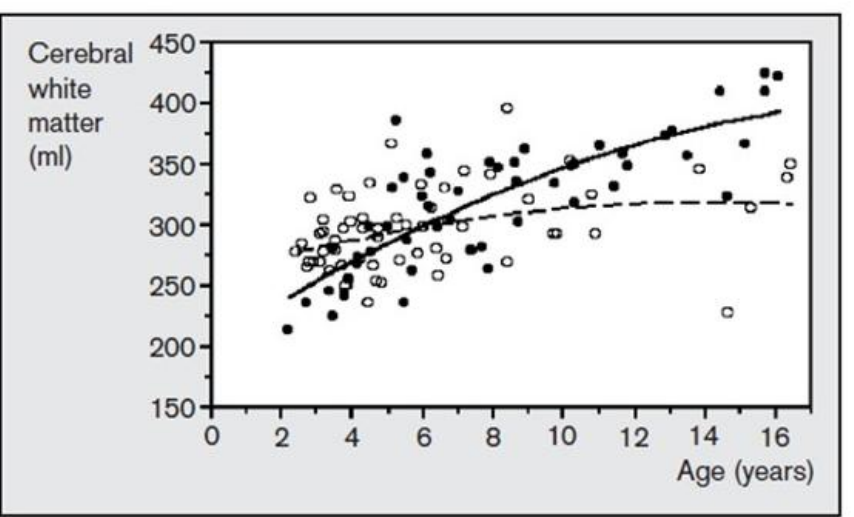

Figura 3. Volúmenes de la sustancia blanca cerebral: edad de 2-16 años, grupo con autismo (círculos blancos) y grupo con desarrollo típico (círculos negros), junto con las curvas de crecimiento: el grupo con autismo (línea discontinua) y el grupo control (la línea continua). E1 volumen de la SB cerebral fue mayor en el grupo con autismo entre los 2 y los 4 años de edad, (Courchesne et al.,2001)
Los primeros trabajos llevados a cabo sobre este crecimiento temprano partieron de estudios (longitudinales y transversales) realizados a partir de la medición del perímetro craneal. Uno de ellos, realizado por Courchesne et al., (2001) (Ver Figura 3) con un grupo de 60 varones con autismo y 52 con desarrollo típico (rango de 2 a 16 años, dividido en dos grupos de edad: 2-4 años y 5-16 años), encontró que en el grupo de menor edad con autismo tenía mayor volumen cerebral al compararlos con los controles, en contraste, el volumen del otro grupo de mayor edad (5-16 años) era más pequeño en el grupo con autismo que en los controles. Los resultados fueron consistentes con otros estudios, tales como el 
realizado por Sparks et al. (2002), quienes también encontraron mayor volumen cerebral en un grupo de niños (rango de edad 3-4 años) con el mismo trastorno o los realizados por Courchesne et al., (2003), por Dawson et al., (2007), por Dementieva et al., (2005) o por Hazlett et al., (2005).

Otros estudios realizados a partir de técnicas de Resonancia Magnética estructural (RMe), sugirieron que niños muy pequeños con autismo (18 meses hasta 4 años) tenían entre un 5\% -10\% más de volumen total cerebral (Hazlett et al., 2005; Courchesne et al., 2001; Sparks et al., 2002; Carper et al., 2002).

Por tanto, según los datos anteriores y según la propuesta de Courchesne et al., (2007), el TEA implicaría dos fases de crecimiento atípico temprano del cerebro: una fase sería el crecimiento acelerado del cerebro al principio de la vida y otra sería una ralentización o incluso detención del crecimiento en la primera infancia. Una explicación a este crecimiento rápido sería un exceso en el número de neuronas, particularmente un exceso de neuronas piramidales excitatorias. Dicho exceso podía significar un exceso de axones, dendritas, sinapsis y mielina, produciendo así un aumento del volumen de SG y de SB y un aumento del volumen del cerebro en general, tal y como se ha comprobado en los estudios de resonancia magnética estructural (MRe). Este exceso de neuronas también podría significar un aumento del peso del cerebro en niños pequeños con TEA y provocaría alteraciones en la formación de circuitos en regiones claves corticales frontales y temporales, implicados en el desarrollo de funciones de orden superior como la comunicación social, las emociones o el lenguaje (Courchesne et al., 2007).(Ver Figura 4).

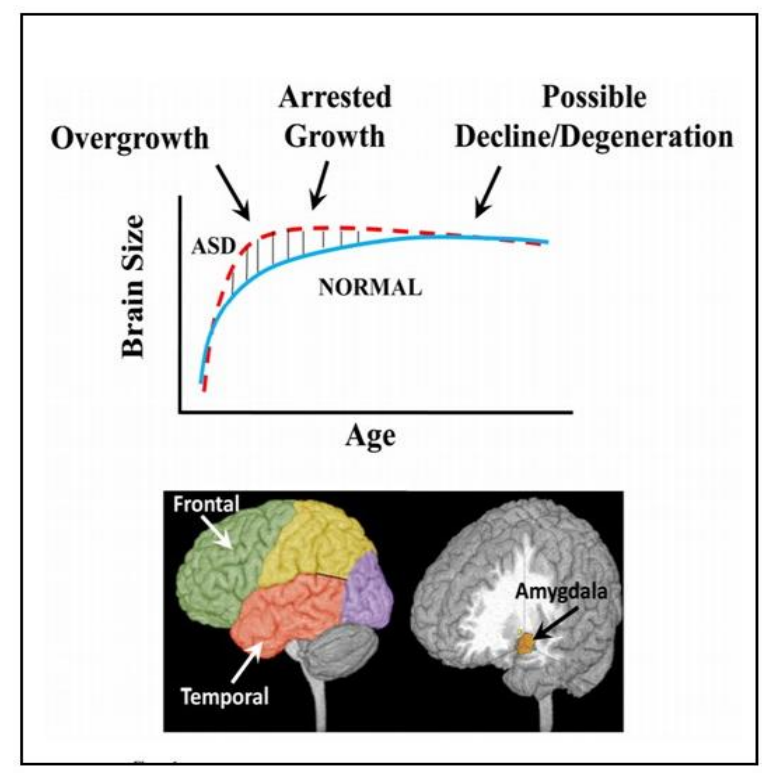

Figura 4. Patrón de crecimiento del cerebro: el grupo con TEA presenta un crecimiento acelerado en edades tempranas seguido de una detención (linea roja); el grupo control (línea azul), presenta un patrón típico. Regiones cerebrales donde se produce el sobrecrecimiento (Courchesne et al., 2007). 
Estos resultados indicaron que en el autismo, el cerebro sufre un período de crecimiento celerado en el período postnatal temprano (aproximadamente, 12 meses de edad) seguido por una deceleración en el crecimiento que se produce entre la infancia y adolescencia (Amaral, Schumann \& Nordahl, 2008).

\subsection{Estudios del volumen cerebral en TEA}

Respecto a los estudios acerca del volumen cerebral total, los resultados indican un aumento en el volumen de la SG y de la SB en la corteza cerebral entre 2-4 años de edad y el aumento era entre un 6\% - 10\% mayor que en los controles con desarrollo típico. En los años siguientes (6-16 años) se produce una disminución, incluso parada, en la tasa de aumento de dicho volumen, para ser similar a la población de la misma edad sin TEA (Aylward, Minshew, Field, Sparks \& Singh, 2002; Sparks et al. 2002; Courchesne et al. 2004; Courchesne \& Pierce, 2005). Este crecimiento volumétrico excesivo se observó en los lóbulos frontales y en los lóbulos temporales (Schumann et al., 2010; Courchesne et al., 2007; Courchesne, Webb \& Schumann, 2010; Carper, Moses, Tigue \& Courchesne, 2002; Courchesne, Campbell \& Solso, 2011a; Hazlett, Poe, Gerig, Smith \& Piven, 2006; Palmen et al., 2005) y en los lóbulos parietales (Carper \& Courchesne, 2000; Carper et al., 2002; Sparks et al., 2002; Herbert et al., 2004), aunque el mayor aumento de volumen se produce en el lóbulo frontal, especialmente, en la corteza frontal medial que incluye la corteza prefrontal dorsolateral y el córtex cingulado anterior (Carper et al., 2002; Carper \& Courchesne, 2005; Herbert et al., 2004). En general, el volumen de sustancia blanca era mayor que el de sustancia gris (Courchesne et al., 2001; Sparks et al., 2002; Carper et al., 2002; Hazlett et al., 2005), siendo menor el aumento de sustancia blanca en la corteza parietal y de sustancia gris en la corteza temporal. Estos resultados sugieren un gradiente de sobrecrecimiento del volumen del cerebro que se produce desde áreas anteriores hacia áreas posteriores (Carper et al., 2002).

Los resultados del primer estudio longitudinal del desarrollo cortical cerebral en niños con diagnóstico de TEA fueron los aportados por Schumann et al. (2010), quienes examinaron las imágenes de resonancia magnética de 41 niños con un diagnóstico de TEA y 44 controles con desarrollo típico. Se observó un aumento significativo del 7\% en el tamaño total del cerebro en los niños autistas, en comparación con los controles 
hasta los 2,5 años de edad, con un aumento del $10 \%$ y $5 \%$ en el total de la SB y SG, respectivamente. Esto apoya claramente las sugerencias de estudios previos que indicaron patrones alterados de crecimiento cortical en niños con TEA y que el crecimiento excesivo comienza antes de los 2 años de edad. Otro estudio que comparaba el desarrollo cerebral de niños con TEA y niños neurotípicos en una muestra amplia fue publicado por Courchesne et al. (2011a). En él se examinaron los cerebros de individuos entre 1 y 50 años de edad aportando evidencia de sobrecrecimiento temprano de la corteza frontal seguido de una marcada reducción en el tamaño cerebral en casos de TEA (Courchesne et al., 2011a).

Sin embargo, las mediciones volumétricas de las regiones lobulares no proporcionan información espacialmente localizada sobre alteraciones de la SG. Los avances en los análisis morfométricos cerebrales permiten ahora la medición directa del grosor cortical, un determinante del volumen de SG y pueden proporcionar información detallada sobre la extensión espacial y la ubicación de las diferencias corticales entre los grupos. Los estudios de desarrollo a gran escala en individuos con desarrollo típico, que incluyen tanto datos transversales como longitudinales, muestran que después de un período de crecimiento en la primera infancia, el adelgazamiento de la SG ocurre en toda la corteza, en la adolescencia (Raznahan et al., 2011; Shaw et al., 2008).Así, el desarrollo cortical puede evaluarse a través de tres componentes morfométricos interrelacionados: el volumen cortical, el grosor cortical y el área superficial (Ecker et al., 2014). Los estudios de imagen han explorado las trayectorias de la anatomía cortical (estudios iniciales con volumen de SG) con estudios recientes centrados en el grosor cortical a lo largo de la niñez y la adolescencia en el desarrollo típico y en el autismo (Courchesne et al., 2001; Doyle-Thomas et al. 2013; Ecker et al., 2014; Zielinski et al., 2014; Lange et al., 2015, Wallace et al., 2015).

Actualmente ningún estudio longitudinal en individuos con TEA ha examinado el desarrollo del grosor cortical a lo largo de una amplia gama de edad. Los estudios transversales sugieren cambios atípicos del grosor cortical entre la infancia y la edad adulta en individuos con TEA (Mak-Fan, Taylor, Roberts, \& Lerch, 2011; Raznahan et al., 2010; Scheel et al., 2011; Wallace, Dankner, Kenworthy, Giedd, \& Martin, 2010). Recientemente, Zielinski et al. (2014) han llevado a cabo un estudio longitudinal donde analizaron los cambios en el grosor cortical. El estudio abarcó varios períodos en el desarrollo posnatal en 97 varones con TEA (3-36 años) y 60 varones con desarrollo 
típico (4-39 años de edad). Sus resultados fueron consistentes con estudios previos, mostrando mayor grosor cortical en la primera infancia, seguido por una disminución en el crecimiento y detención del desarrollo en la infancia tardía que persistió hasta la adolescencia. Los resultados evidenciaron un adelgazamiento cortical acelerado predominantemente en las regiones frontal, parietal y occipital en la primera infancia en el grupo con autismo. Estos resultados fueron consistentes con estudios previos que describían la macrocefalia y el crecimiento acelerado en el volumen cerebral en niños muy pequeños, con una tendencia hacia la pseudonormalización más allá de los 4 años de edad (Courchesne et al., 2001, 2004, 2011a; Schumann et al., 2010; Hazlett et al., 2011). También encontraron un adelgazamiento cortical acelerado en este grupo durante la infancia media, reflejando una pseudonormalización del grosor cortical entre las edades de 8-18 años, dependiendo de la región del cerebro. Sin embargo, indicaron que la pseudonormalización del grosor cortical podía no reflejar una pseudonormalización estructural o funcional más amplia. Finalmente, indicaron que en el grupo experimental se observó un mayor adelgazamiento en regiones predominantemente frontales en la adolescencia, sugiriendo que dicho adelgazamiento se producía más temprano en estas áreas, mientras que las regiones posteriores mostraban una disminución más prolongada. Los datos aportados relacionados con el grosor cortical reducido y el adelgazamiento cortical atípico coincidían con estudios previos similares (Hadjikhani et al., 2006; Hyde, Samson, Evans \& Mottron, 2010; Jiao et al., 2010; Scheel et al., 2011; Mak-Fan et al., 2012; Ecker et al., 2013). Estos resultados apoyan la idea de que la trayectoria del crecimiento del cerebro está alterada en los TEA.

Otro estudio reciente realizado por Sussman et al. (2015) con una muestra de 72 participantes con TEA (61 varones y 11 mujeres) y 138 sujetos controles (116 varones y 22 mujeres) y una franja de edad de 4 hasta 18 años. El objetivo del estudio era realizar un examen completo del desarrollo cerebral de los niños con TEA. Respecto al volumen total del cerebro, los participantes del grupo control mostraron un aumento gradual durante la franja de edad citada mientras que los participantes con TEA mostraron sobrecrecimiento temprano: en la infancia aumentó a un ritmo más rápido y alcanzó su máximo volumen en la adolescencia temprana (edad aproximada 11 años). Este pico fue seguido por una disminución gradual en el volumen en la adolescencia, que es similar a los resultados de otros estudios con adolescentes (Courchesne et al., 2011) y con adultos participantes con el mismo trastorno (Mak-Fan et al., 2013; Stigler et al., 2011). Los 
resultados no mostraron ninguna diferencia de grupo respecto a la superficie cortical. Esto es consistente con los resultados de estudios previos sobre el tema pero con diferentes rango de edad: 12-64 años (Raznahan et al., 2010), 6-15 años (Mak-Fan et al., 2013) y 12-23 años (Wallace et al., 2013).

Otro estudio realizado por Lin, Ni, Lai, Tseng \& Gau (2015) partió de un enfoque de modelado estadístico en tres etapas, en el que consideraron la edad de desarrollo para determinar los patrones de crecimiento atípicos en el TEA. Para ello, utilizaron un grupo de 86 participantes varones con autismo de alto funcionamiento y 90 participantes neurotípicos (rango de edad de 7 a 29 años). Los resultados indicaron que los participantes con TEA tenían significativamente mayores volúmenes de SG que el grupo control en la corteza orbitofrontal inferior derecha y en el tálamo bilateral (núcleo dorsal medial izquierdo y núcleo dorsal lateral derecho). Además, en el estudio corroboraron los datos obtenidos en estudios previos de que la edad es un factor influyente en los patrones de crecimiento atípicos en el autismo (Nordahl et al., 2012; Scheel et al., 2011; Raznahan et al., 2010; Greimel et al., 2013; Zielinski et al., 2014; Langen et al., 2009; McAlonan et al., 2002).

En un metaanálisis muy reciente de varios estudios de imagen llevado a cabo por Khundrakpam, Lewis, Kostopoulos, Carbonell \& Evans, (2017) se selecciona un total de 294 participantes varones con desarrollo típico y 266 participantes con TEA (con un rango de edad 6-35 años) para valorar las diferencias específicas relacionadas con la edad en el grosor cortical de los participantes del grupo con TEA y la relación de dichas diferencias con los síntomas característicos del trastorno. El metaanálisis reveló un patrón dinámico de diferencias entre los dos grupos, con un aumento significativo del grosor cortical en niños con TEA en amplias regiones de la corteza, pero las diferencias desaparecían en la adolescencia donde presentaban un grosor cortical similar al que se presenta a los 35 años de edad. De modo que, el grupo con TEA mostraba un patrón de crecimiento atípico que se iniciaba en el primer año de vida, seguido de un período de crecimiento acelerado que continúa durante la primera infancia hasta la adolescencia para después lograr un tamaño cerebral cercano al del adulto más pronto que el grupo con desarrollo típico (Courchesne et al., 2003; Redcay \& Courchesne, 2005; Dementieva et al. 2005; Hazlett et al. Al., 2005). Las curvas de crecimiento del grosor cortical en cada una de las regiones mostraron diferencias significativas entre los dos grupos e indicaron que este patrón dinámico de diferencias de grupo se debía a un 
adelgazamiento cortical más rápido en el grupo experimental después de un retraso inicial en el adelgazamiento cortical visto en niños con desarrollo típico. Esto concuerda ampliamente con los estudios basados en la trayectoria del grosor cortical en el TEA (Zielinski et al., 2014; Hadjikhani et al. 2006; Ducharme et al., 2016; Mills et al., 2016; Walhovd, Fjell, Giedd, Dale \& Brown, 2016) y con otros resultados donde se indica que el sobrecrecimiento cerebral proviene de un retraso en los procesos regresivos del neurodesarrollo, como por ejemplo, la poda sináptica / axonal, y que el aumento del tamaño del cerebro en TEA puede conducir posteriormente a pérdidas neurales (Lewis \& Elman 2008; Tang et al., 2014). Finalmente, observaron más grupos de grosor cortical en el hemisferio izquierdo que en el derecho, lo que posiblemente indicó asimetría de las alteraciones observadas en el grosor cortical, explicando este resultado como consecuencia del desarrollo neurológico tardío en la población con TEA. (Ver Figura 5).

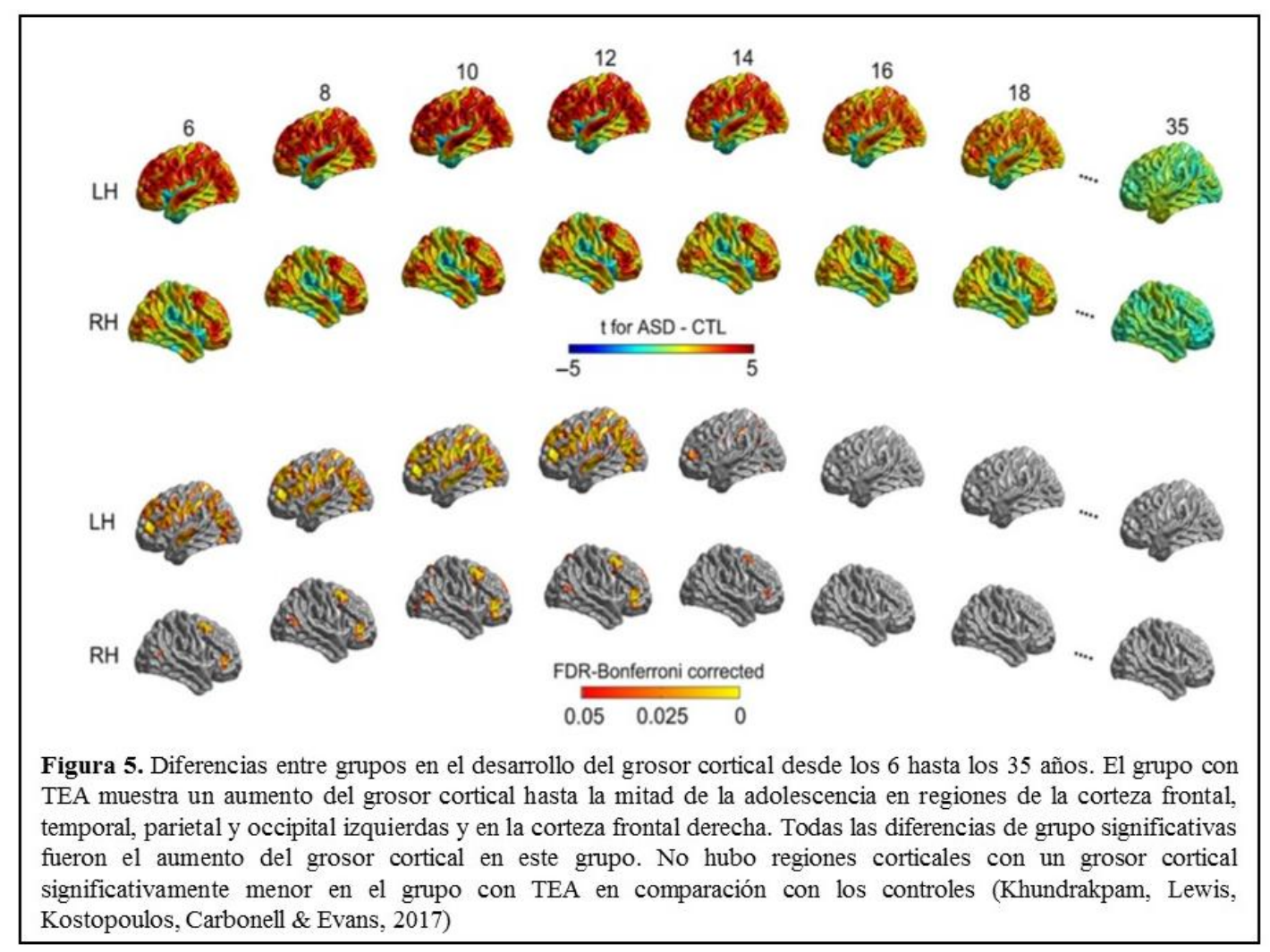




\subsection{Estudios de las Estructuras límbicas en TEA}

Los cambios anatómicos cerebrales aportador en la literatura centrada en el campo de los TEA, también han suscitado interés en estructuras subcorticales funcionalmente conectadas, especialmente en el Sistema Límbico (amígdala e hipocampo), los Gánglios basales (caudado y putamen) y el tálamo. Otro de los resultados más consistentes que aparecen publicados ha sido las alteraciones en el desarrollo del Sistema Límbico, ya que fueron una de las primeras hipótesis planteadas porque las estructuras de este sistema median funciones de memoria, sociales y afectivas y éstas suelen estar afectadas en este trastorno (Hauser et al., 1975; Bauman \& Kemper, 1985; Bachevalier, 1994; Sparks et al.,2002; Schumann et al.,2004, 2009).

\subsubsection{La amígdala}

Es una región cerebral del Sistema Límbico que han generado un enorme interés dentro del estudio del TEA. La amígdala ha sido una región bastante estudiada y presenta una vinculación estrecha con el autismo (emociones, juicio social, cognición social). Varias investigaciones utilizando técnicas de neuroimagen estructural han mostrado mayor volumen en la amígdala en sujetos con autismo, al compararlos con sujetos con desarrollo típico.

En una amplia variedad de estudios dentro del campo del autismo, la amígdala ha sido relacionada con déficits asociados con el mismo, entre ellos, cabe destacar, la cognición social, la percepción de la dirección de la mirada y la emoción (Conty \& Grezes, 2012; Fanselow \& Dong, 2010; Greicius et al., 2003; Kawashima et al., 1999). Hay evidencia creciente en los estudios transversales que sugieren que en comparación con los controles, el volumen de la amígdala se incrementa en los niños pequeños con autismo (Kim et al., 2010a, 2010b; Mosconi et al., 2009; Munson et al., 2006; Nordahl et al., 2012; Schumann et al., 2009; Sparks et al., 2002), no se modifica en jóvenes de mayor edad (Bigler et al., 2003; Haznedar et al., 2000, Palmen et al., 2006) y es menor en adultos (Aylward et al., 1999; Nacewicz et al., 2006, Pierce \& Courchesne, 2001; Rojas et al., 2004).

En un estudio realizado por Sparks et al. (2002) con un grupo de niños que presentaban TEA (3-4 años de edad), observaron que tenían una amígdala más grande que el grupo 
de niños con desarrollo típico. Concretamente, tenían la amígdala izquierda un 14\% mayor y la amígdala derecha un 22\% mayor (al realizar la corrección del volumen total cerebral). Este aumento de la amígdala correlacionó con mayor severidad en las puntuaciones de los tests clínicos que evaluaban factores sociales y de comunicación. Por su parte, Schumann et al. (2004) realizaron un estudio del hipocampo y de la amígdala en una muestra de niños y adolescentes con TEA. Encontraron que la amígdala en niños con TEA era inicialmente más grande y alcanzaba el tamaño del adulto antes de la adolescencia; no seguía el mismo patrón de desarrollo que tiene lugar en los niños con desarrollo típico donde la amígdala sufría un crecimiento progresivo hasta la adolescencia (a los 8 años tiene un tamaño aproximado de $1,7 \mathrm{~cm}^{3}$ y a los 18 años de $2,3 \mathrm{~cm}^{3}$ ). Sugirieron que el mayor volumen de la amígdala en el autismo era un fenómeno que dependía de la edad. La conclusión en el estudio de Schumann era que los niños con TEA presentaban mayor volumen en la amígdala bilateral respecto al grupo control, pero no había diferencias entre los dos grupos en la adolescencia. Por tanto, estos autores consideraban que los aspectos fundamentales de la organización neuroanatómica y funcional de la amígdala eran diferentes en los niños con autismo en comparación con los controles, de ahí los déficits sociales (Baron-Cohen et al., 2000a) y los déficits en otros procesos cognitivos que presenta esta población, como por ejemplo, déficits en el procesamiento de caras (Grelotti, Gauthier \& Schultz, 2002; Haxby, Hoffman \& Gobbini, 2002) o en el reconocimiento de emociones (Adolphs, 2002; Adolphs, Tranel \& Damasio, 2003).

Munson, Dawson \& Abbott (2006) encontraron mayor volumen en la amígdala derecha en niños con TEA (3-4 años), que se asociaba con déficits en la adquisición de habilidades sociales y de comunicación y que, además, estaba relacionado con un curso clínico más severo y peor pronóstico a los 6 años (incluso después de controlar la variable inteligencia y el volumen total del cerebro).

Una serie de estudios en la última década han explorado el papel de los patrones alterados en el crecimiento de la amígdala en niños y adolescentes con TEA (Gadad et al., 2013). Un estudio longitudinal realizado por Mosconi et al. (2009) examinó el volumen de la amígdala a los 2 años y realizó un seguimiento hasta los 4 años de edad en un grupo de 52 niños con autismo y 33 controles (22 con desarrollo típico y 11 con retraso en el desarrollo), además exploró la relación entre el volumen de la amígdala y las características del comportamiento propias del trastorno. Se recogieron imágenes a 
partir de RMe en dos momentos, el primero, cuando tenían 2 años de edad (18-35 meses) y, el segundo, con 4 años de edad (42-59 meses). Los resultados del estudio indicaron que la comparación del volumen de amígdala entre grupos mostró mayor volumen bilateral en niños con autismo a los 2 años de edad. Las trayectorias de crecimiento entre 2 y 4 años de edad no difirieron entre los niños con autismo y los controles. Los autores sugieren que, de acuerdo con las publicaciones anterior sobre las tasas de crecimiento del perímetro craneal en el autismo (Hazlett, Poe, Gerig, Smith \& Piven, 2006) y de acuerdo con los estudios del volumen de la amígdala en la infancia (Schumann et al., 2004; Sparks et al., 2002; Munson et al., 2006) las trayectorias de crecimiento de la amígdala se aceleran antes de los 2 años de edad en el autismo y se mantienen durante la primera infancia. Además, la ampliación de amígdala en niños de 2 años de edad con autismo es desproporcionada a la ampliación global del cerebro y sigue siendo desproporcionado a los 4 años de edad. (Ver Figura 6).

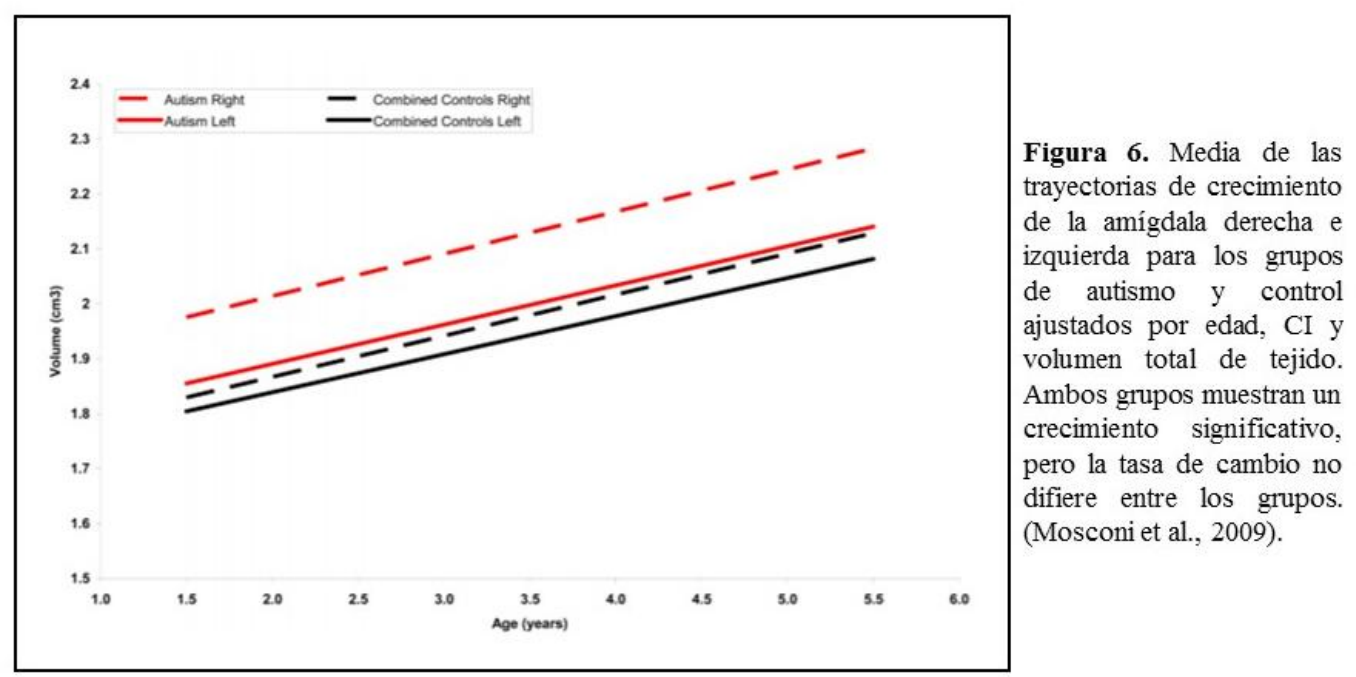

Una aportación interesante de este trabajo fue la relación que establecieron los autores entre la ampliación de la amígdala y la habilidad de atención conjunta a los 4 años, sugiriendo que las alteraciones de la amígdala en el autismo reflejan un comportamiento de orientación social disminuido y, más específicamente, una tendencia reducida a coordinar el contacto visual. El desarrollo alterado de esta habilidad en el autismo dificulta la posibilidad de experiencias sociales compartidas y, por lo tanto, puede provocar una serie de efectos negativos en el desarrollo cognitivo, comunicativo y social (Hazlett et al., 2005). 
Otro trabajo reciente donde se evaluaba el patrón de desarrollo de la amígdala y del hipocampo en un grupo de niños con TEA fue el realizado por Barnea-Goraly et al. (2014). La muestra estaba formada por 15 participantes con autismo y 22 participantes controles (rango de edad 8-16), a quienes se les realizaron unas pruebas de RMe dos veces, con un intervalo de dos años entre las mismas. Los resultados indicaron que los volúmenes de la amígdala así como los aumentos de volumen con la edad fueron similares en los dos grupos. Además, dentro del grupo con TEA, el cambio de volumen de la amígdala derecha correlacionó con la capacidad de establecer un contacto visual adecuado, que es una capacidad deteriorada en el autismo y que está relacionada con la función de la amígdala (Adams et al., 2011; Boll et al., 2011; Tazumi et al., 2010). Los resultados indicaron una correlación significativa entre el cambio en el volumen de la amígdala y el contacto visual durante la infancia y la adolescencia, indicando que los cambios en el volumen de la amígdala a lo largo del tiempo pueden estar relacionados con el comportamiento social asociado con la función de la amígdala. También concluyeron que su estudio proporcionaba evidencia acerca de la normalización de los volúmenes de amígdala en la última infancia y la adolescencia.

De acuerdo con estos resultados, la amígdala es una estructura importante que está implicada de forma considerable en el desarrollo de la cognición social y, además, ocupa un lugar destacado en el circuito de la empatía. Este circuito está formado por diversas áreas del cerebro que se encuentran interconectadas. Entre ellas, destacarían: la amígdala, las neuronas espejo, la ínsula anterior y la corteza cingulada caudal anterior (Ruggieri, 2013). La amígdala es esencial en el aprendizaje emocional y en la regulación de éste, siendo su principal función, según Tirapu, Pérez, Erekatxo y Pelegrín (2007), la de "convertir las representaciones perceptuales en cognición y conducta para dotar de valor emocional y social a dichos estímulos". La regulación de las emociones es fundamental para desarrollar correctamente nuestra conducta social. En el reconocimiento facial de las emociones también está implicada, especialmente en emociones básicas como el miedo o el asco. Las personas con TEA presentan dificultades en el reconocimiento de caras, en la percepción de expresiones faciales y en la percepción de las emociones. De modo que, presentan problemas a la hora de inferir segundas intenciones, comprender miradas, deseos y conductas de los demás (Ruggieri, 2013). Diversos autores han informado de que las personas con TEA presentan déficits en el reconocimiento facial (Dawson, Webb \& McPartland, 2005), en la detección de 
expresiones emocionales (Howard et al., 2000) y en la interpretación de la mirada (Calder, Lawrence \& Young, 2001). Todos estos déficits están relacionados con disfunción de la amígdala (Ruggieri, 2013). Estudios con Resonancia Magnética funcional (RMf) en población con TEA mostraron la falta de activación de la amígdala derecha en respuesta al estímulo social, en relación con la percepción de la mirada (Baron-Cohen et al., 1999a).

Los déficits en la interacción social, la predicción de la recompensa, la memoria emocional y el reconocimiento facial y emocional en los TEA pueden ser indicativos de un mal funcionamiento de la amígdala y las estructuras asociadas (Davis \& Whalen, 2001).

\subsubsection{El hipocampo}

Otra estructura del Sistema Límbico que ha generado un número considerable de estudios en el campo del autismo ha sido el hipocampo. Esta pequeña estructura cerebral ha sido implicada en déficits asociados con los TEA: la cognición social, la percepción de la dirección de la mirada y la emoción (Conty \& Grezes, 2012; Fanselow \& Dong, 2010; Greicius et al., 2003; Kawashima et al., 1999).

Una serie de estudios encontraron que en niños con autismo tanto el hipocampo derecho como el izquierdo presentaban mayor volumen al compararlos con niños que presentaban un desarrollo típico, incluso después de controlar el volumen total del cerebro. Los hallazgos de los estudios de Schumann et al. (2004) pusieron de relieve que había un programa atípico de desarrollo temprano de la amígdala en el autismo, donde el crecimiento excesivo comenzaba antes de los 3 años de edad cuando los síntomas se vuelvan clínicamente evidentes (Schumann, Barnes, Lord \& Courchesne, 2009) y un patrón también atípico de desarrollo del hipocampo que persistía hasta la adolescencia.

Por su parte, Sparks et al. (2002) examinaron las características cerebrales en una amplia muestra de niños con autismo (3-4 años) y los compararon con un grupo de niños con desarrollo típico y otro grupo con retraso en el desarrollo. Los resultados que obtuvieron indicaban que los niños con TEA presentaban mayor volumen del cerebro respecto a los otros dos grupos (tal como se ha indicado en la primera parte de este punto), además, presentaban mayor volumen tanto en la amígdala como en el 
hipocampo bilateral. El hipocampo era un $9 \%$ mayor que en los controles con desarrollo típico. Estos resultados estructurales sugerían un patrón de desarrollo cerebral alterado en el curso clínico del autismo desde edades muy tempranas.

En el estudio llevado a cabo por Barnea-Goraly et al. (2014), citado en el punto anterior, los autores también abordaron las trayectorias del desarrollo en el hipocampo en niños con autismo (rango de edad 8 a 16 años) y examinaron los correlatos clínicos del cambio de volumen en el mismo. En dicho estudio, los autores encontraron que el volumen del hipocampo derecho aumentó significativamente en el grupo con TEA, en comparación con los controles. Además, las diferencias encontradas en el cambio del volumen del hipocampo derecho entre los dos grupos se acercaron a la significación con el paso del tiempo. Los resultados de su estudio fueron concordantes con los obtenidos por Schumann et al. (2004). Finalmente, sugieren que los cambios hipocampales todavía están en curso en la última infancia y adolescencia y concluyeron a partir de los resultados que hay una relación entre la edad y los cambios de volumen en el hipocampo derecho. (Ver Figura 7).

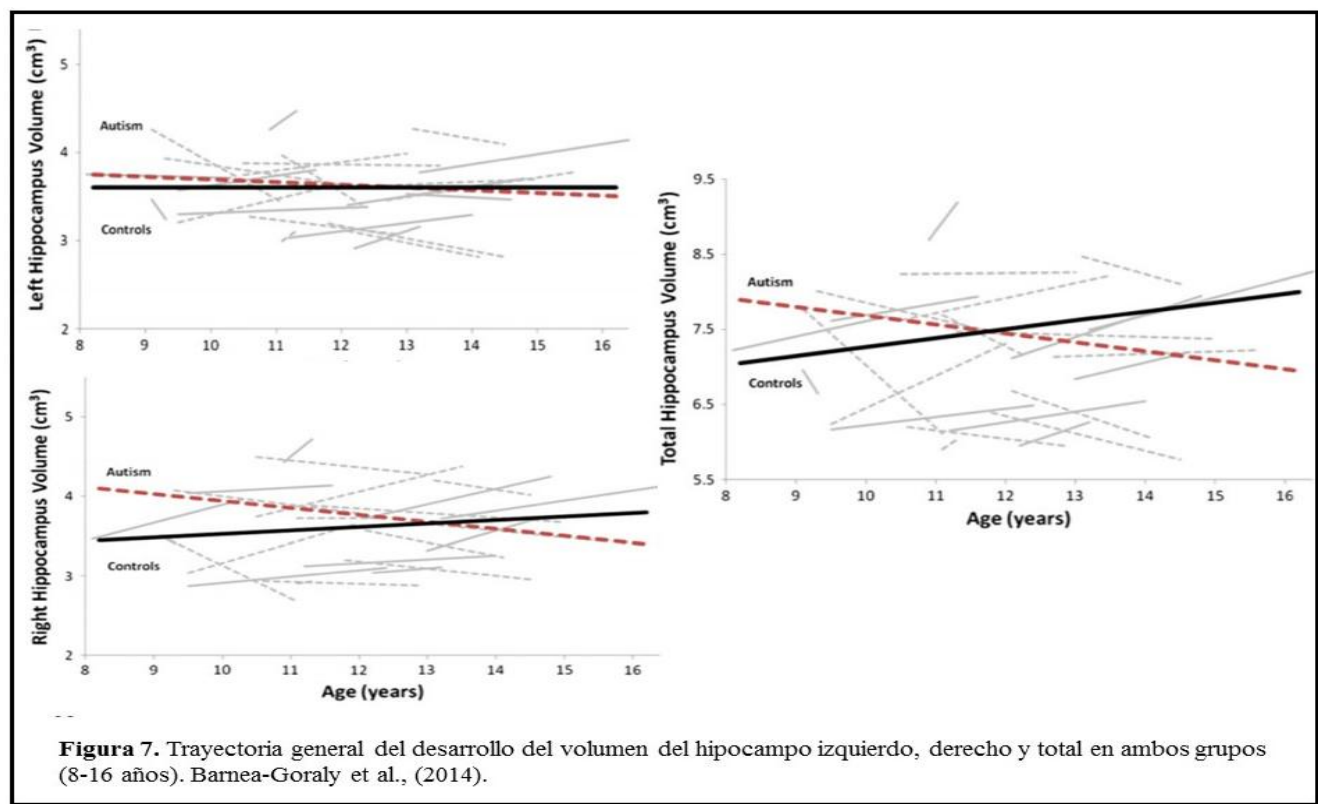

\subsubsection{Otras estructuras límbicas}

Duerden et al. (2012) mostraron que los niños con TEA en edad escolar presentaban un aumento de sustancia gris en áreas del Sistema Límbico, el córtex cingulado anterior derecho y la ínsula bilateral, en regiones del Lóbulo temporal (circunvolución fusiforme y giro temporal medio) y en varias áreas subcorticales de los ganglios basales (núcleo 
caudado derecho). Posiblemente, este aumento se debe a varios mecanismos como la neurogénesis, retraso en la poda sináptica y la muerte celular programada, o la migración inapropiada de las neuronas (Courchesne et al., 2001; Bauman \& Kemper, 2005; Kelly et al., 2009). El córtex cingulado está situado en el área media del cerebro y realiza funciones importantes en la actividad cerebral del Sistema Límbico. Está involucrado en la formación de las emociones y en el procesamiento de los datos relacionados con la conducta, el aprendizaje y la memoria (Kelly et al., 2008). La ínsula desempeña un rol importante como mediadora entre el componente frontal del Sistema de Neuronas Espejo y el Sistema Límbico (Dapretto et al., 2005). El aumento de SG en el córtex cingulado anterior y en la ínsula podría estar relacionado con los déficits que presentan en el procesamiento emocional visto en los TEA (Joseph, Ehrman, McNally \& Keehn, 2008), ya que ambas áreas juegan un papel importante en el procesamiento afectivo y en la motivación de la conducta (Bush, Luu \& Posner, 2000). También el aumento de SG en el córtex cingulado anterior podría estar relacionado con las alteraciones en los procesos cognitivos como la atención, que se ha observado en TEA (Solomon, Ozonoff, Cummings \& Carter, 2008). Esta zona cerebral también se ha relacionado con el desarrollo de la capacidad de monitoreo de la respuesta, que es una función ejecutiva alterada en niños que presentan este trastorno y que contribuye a la aparición de déficits socio-emocionales y socio-cognitivos (Henderson et al., 2006; Thakkar et al., 2008). El córtex cingulado anterior también contribuye a evaluar y modificar el comportamiento basado en sus consecuencias y el comportamiento flexible depende de estas funciones. Las alteraciones en la evaluación y el aprendizaje de los errores pueden conducir a un comportamiento rígido y repetitivo en lugar de un comportamiento guiado óptimamente por los resultados, y puede comprometer el rendimiento en una amplia gama de tareas (Thakkar et al., 2008). La corteza cingulada anterior, corteza cingulada media y la ínsula anterior están implicadas en la experiencia y reconocimiento de las emociones por lo que desempeñan un papel fundamental en el circuito de la empatía (Carr, Iacoboni, Dubeau, Mazziotta \& Lenzi, 2003; Moya-Albiol, Herrero y Bernal, 2010).

Las neuronas espejo, estudiadas por el grupo de Rizzolatti (1996), se activan cuando observamos a otros realizar una actividad o movimiento (mano, boca, pie,..) y cuando la realizamos nosotros mismos (Blakemore \& Decety, 2001). La imitación es fundamental para el desarrollo de pautas sociales, así, podemos imitar gestos, expresiones faciales, 
acciones, ..., tendemos a imitar a otros cuando interactúan socialmente. La ubicación de las neuronas espejo se encuentra en la parte inferior de la corteza frontal, la parte posteroinferior del giro frontal, la corteza ventral premotora adyacente y la parte rostral inferior del lóbulo parietal (Iacoboni \& Dapretto, 2006). Estas neuronas no solo se activan ante estímulos visuales, sino también del lenguaje (Aziz-Zadeh, Wilson, Rizzolatti \& Iacoboni, 2006). El sistema de neuronas espejo, mediante la imitación interna o la simulación, envía señales al Sistema Límbico a través de la ínsula, y dicho sistema nos permite sentir la emoción que vemos (Ruggieri, 2013).

Respecto al aumento de sustancia gris en el giro fusiforme, parece ser que está asociado con patrones atípicos de socialización en esta población. Esta área del cerebro está involucrada en el reconocimiento de rostros y de expresiones faciales, así, un aumento de SG en esta región podría contribuir a los déficits en el procesamiento de rostros, también vistos en niños con TEA (Corbett et al., 2009; Grupa, Giovannelli, Minshew \& Strauss, 2009).

\subsection{Estudios de los Gánglios Basales en TEA}

A partir de una serie de estudios se ha documentado que el volumen de los ganglios basales sigue un patrón de desarrollo atípico en el autismo. Varios estudios han demostrado un aumento del volumen estriatal en individuos con TEA (Haznedar et al., 2006; Hollander et al., 2005; Langen et al., 2009), así como un aumento en la conectividad cortico-estriatal en esta población (Cerliani et al., 2015; Delmonte et al., 2013; Di Martino et al., 2011; Padmanabhan et al., 2013). De manera que, las alteraciones en los circuitos cortico-estriatales podrían estar implicadas en los déficits nucleares de este trastorno (dificultades en las interacciones sociales y en la comunicación e intereses restringidos y comportamientos repetitivos).

Sears et al. (1999) realizaron un estudio de los ganglios basales en el autismo (edad 1229 años) y encontraron que el núcleo caudado tenía mayor volumen en este grupo al compararlo con los sujetos controles. También observaron que el volumen del núcleo caudado estaba asociado con las conductas rituales, las dificultades ante los cambios mínimos en el entorno y los manierismos motores complejos que presentan las personas afectadas por este trastorno. Cody Hazlett et al. (2005) también encontraron mayor volumen del núcleo caudado en una muestra de niños con TEA ( 2 años edad). Tanto 
Sears et al. (1999) como Cody Hazlett et al. (2005) concluyeron que el mayor aumento del núcleo caudado estaba asociado con las conductas repetitivas de orden superior observadas en el autismo (resistencia al cambio, conductas estereotipadas).

Langen et al. (2009) encuentran cambios en la trayectoria de desarrollo del estriado en el autismo y observaron que el volumen del núcleo caudado aumentaba con la edad, mientras disminuía en el grupo de sujetos con desarrollo típico. Además, este aumento de volumen estaba relacionado con la severidad de las conductas repetitivas y la resistencia al cambio. De forma similar, Hollander et al. (2005) mostraron que el aumento del volumen estriatal correlacionaba con el aumento de conductas repetitivas y restringidas en TEA. Estudios recientes en el campo del autismo han mostrado cambios específicos en la anatomía cerebral, así como cambios en las trayectorias de desarrollo de varias regiones cerebrales (Courchesne, Campbell \& Solso, 2011; Hardan, Libove, Keshavan, Melhem \& Minshew, 2009; Schumann et al., 2010), tales cambios pueden explicar las discrepancias en los estudios anteriores que no tuvieron en cuenta la importancia de la etapa de desarrollo a la hora de realizar el estudio. Desde esta perspectiva, Langen et al. (2014) realizan un estudio longitudinal con un grupo de 86 participantes, 49 niños con TEA y 37 niños con desarrollo típico (rango de edad: 7-17 años). El estudio se realiza en dos tiempos, con una diferencia de 2 años y 4 meses entre las primeras y las segundas RMe. Los objetivos del mismo eran, por un lado, determinar la trayectoria de desarrollo del estriado en el TEA y, por otro, examinar la relación entre el estriado y las conductas repetitivas en dicho trastorno. Encontraron que los niños con TEA presentaban una trayectoria de crecimiento del estriado diferente al compararla con sujetos con desarrollo típico, mostrando los primeros un aumento en la tasa de crecimiento de las estructuras estriadas, más específicamente, en el núcleo caudado donde dicha tasa se duplicó (4,6\% vs 2,3\% aumentó el volumen en 27 meses). Este aumento del crecimiento fue desproporcionado respecto al crecimiento global del cerebro y no se explicó por el uso de neurolépticos. Este crecimiento estriatal más rápido se relacionó con un comportamiento repetitivo más severo (insistencia en la igualdad y uniformidad) en la edad preescolar (Ver Figura 8). 
Respecto a la conectividad cortico-estriatal, Cerliani et al. (2015), encontraron que dicha conectividad decrecía con la edad en sujetos con desarrollo típico pero no cambiaba con la edad en sujetos con autismo. También demostraron que había una correlación entre el grado de hipoactivación en los circuitos cortico-estriatales y los síntomas propios del TEA (los déficits sociales y de comunicación y los comportamientos restringidos y repetitivos). Un estudio reciente realizado por Balters, Mantini \& Wenderoth (2017) mostró las diferencias en la organización del circuito cortico-estriatal en el TEA. Encontraron diferencias en la parcelación del estriado, especialmente en el putamen, que se dividió en dos partes (anterior y posterior) en los individuos neurotípicos, sin embargo, no sucedió lo mismo con el grupo con TEA, donde el putamen permaneció como una estructura simple. Al igual que en el estudio llevado a cabo por el grupo de Cerliani, estos autores también encontraron cambios en el desarrollo de la conectividad cortico-estriatal en el grupo de sujetos con desarrollo típico, mientras que el grupo con TEA no mostró ningún cambio relacionado con la edad en dicha conectividad. Por tanto, los circuitos córtico-estriados están organizados de manera diferente en el autismo, en comparación con los sujetos controles. Estos autores sugieren que el putamen anterior presente en los sujetos con desarrollo típico, pero no en el grupo con TEA, probablemente contribuye está implicado en los procesos sociales y lingüísticos.

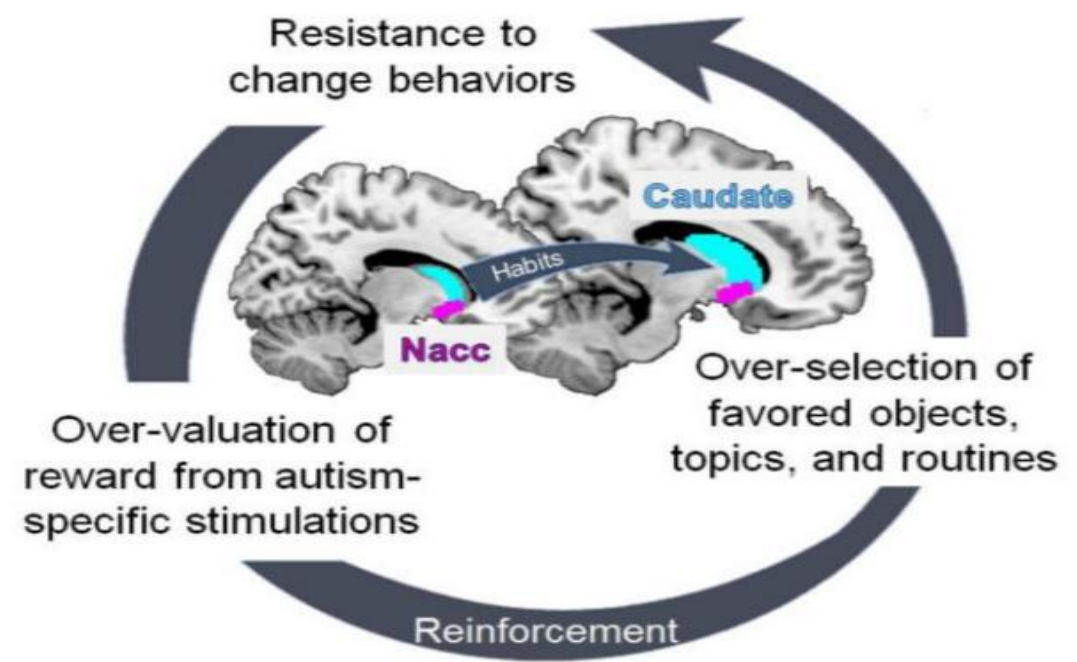

Figura 8. Modelo de trabajo basado en los datos del estudio longitudinal de Langen et al (2014) sobre la ontogénesis de comportamientos e intereses restringidos y repetitivos de orden superior, como la resistencia a los comportamientos de cambio, en niños con trastornos del espectro autista. Propuesto por Kohls, Yeris \& Schultz, (2014) 


\subsection{Estudios de la Corteza Frontal Medial en TEA}

La región frontal ha sido centro de atención en numerosos estudios realizados en la población con TEA. Las porciones más anteriores de la corteza prefrontal medial se encuentran involucradas en los procesos de mentalización y se sabe que está implicada frecuentemente en tareas de Teoría de la Mente (Shallice, 2001); de hecho, es una región crucial para resolver tareas como, por ejemplo, el engaño, especialmente el área del córtex frontal ventromedial, que conecta directamente con la amígdala y otras áreas límbicas cuando se deben procesar aspectos emocionales y motivacionales (Stuss, Gallup \& Alexander, 2001). En otras tareas como las falsas creencias de segundo orden, que requieren memoria de trabajo para su resolución, la intervención de áreas como el córtex frontal dorsolateral son fundamentales (Stone, Baron-Cohen \& Knight, 1999). La corteza prefrontal medial también está vinculada con el circuito de la empatía, de hecho, es el eje del procesamiento de la información social y muy importante en la comparación de nuestra propia perspectiva con la de los demás. Según Di Martino et al. (2009), los niños con autismo tienen una baja reactividad en la mayoría de las áreas implicadas en los circuitos de la empatía que varía de acuerdo con las pruebas realizadas y el paradigma utilizado. Frente a tareas como lectura de historias simples, donde deben valorar las intenciones o estados mentales de un personaje, se detecta reducción de la actividad en la corteza prefrontal dorsomedial (Happé et al., 1996; Wang, Lee, Sigman \& Dapretto, 2006). Si la tarea implica observar en una foto los ojos de una persona e inferir qué está pensando o sintiendo, los niños con autismo presentan dificultades para resolver con éxito la misma, mostrando menor actividad que los niños con desarrollo típico en el opérculo frontal, la amígdala y la ínsula anterior (Baron-Cohen et al., 1999a; Baron-Cohen \& Hammer, 1997a).

Los estudios de neuroimagen funcional han identificado áreas clave del "cerebro social" (corteza prefrontal medial, unión temporoparietal, giro cingulado anterior, ínsula y amígdala) que se activan específicamente durante las tareas de ToM en personas con desarrollo típico pero se activan escasamente en personas con autismo (Baron-Cohen et al., 1999a; Castelli, Frith, Happe, et al., 2002; Frith \& Frith 2003; Happe et al.1996). El córtex prefrontal medial y la región del córtex cingulado posterior, que son estructuras mediales de la Default Mode Network, están relacionados con los procesos de mentalización interna (pensamientos de autorreferencia y procesos de ToM) y además se encargan de supervisar las situaciones inesperadas del entorno. Cuando el desarrollo 
de la corteza prefrontal medial sufre algún tipo de alteración, como sucede en el caso de los TEA, se producen déficts considerables relacionados con los procesos de mentalización interna (Mantini \& Vanduffel, 2013). Otras regiones neurales clave para desarrollar adecuadamente las habilidades de mentalización son la amígdala, el córtex orbitofrontal y el córtex frontal medial (Baron-Cohen, 2001a).

\subsection{Estudios de la Corteza Frontal Lateral en TEA}

La corteza frontal controla muchas de las funciones ejecutivas del cerebro, incluidos los procesos cognitivos de orden superior, como la toma de decisiones, la planificación, la memoria de trabajo, las emociones, el comportamiento social, el aprendizaje y la comunicación. Debido a las alteraciones en la interacción social y en el desarrollo emocional que presentan las personas con TEA, la corteza frontal también ha sido una región del cerebro que ha recibido considerable atención en los últimos años. Las principales aportaciones sobre el tema incluyen patrones de crecimiento cortical atípicos, alteraciones en el grosor cortical y desorganización de las neuronas a través de las capas corticales y sus conexiones con otras regiones del cerebro (Donovan \& Basson, 2016).

Otro de los resultados más consolidados y donde los niños con TEA presentaban morfología cerebral atípica era en áreas frontoestriatales importantes para la comunicación (corteza prefrontal) y para las conductas repetitivas (putamen). Estos resultados pueden corroborar el deterioro de la función ejecutiva (Dawson \& Fernald, 1987), con déficits en la infancia que siguen presentes en la edad adulta (Bennetto, Pennington \& Rogers, 1996; Josef Nicolaas van der, Chantal, Gert, Marinus Nicolaas \& van Herman, 2001; Minshew \& Keller, 2010; Ozonoff et al., 2004; Volkmar, Chawarska \& Klin, 2005).

La función ejecutiva es un término general que se refiere a los procesos neuropsicológicos que permiten el autocontrol cognitivo, emocional y físico (Corbett et al., 2009). Por tanto, se refiere al comportamiento voluntario planificado que se logra mediante la presentación de una meta en la memoria de trabajo y la inhibición de las respuestas automáticas inadecuadas que podrían dificultar la consecución de dicha meta (O’Hearn, Asato, Ordaz \& Luna, 2008). La adquisición de las capacidades ejecutivas se 
inicia de manera temprana en el desarrollo (aproximadamente, desde un año de edad), se van desarrollando lentamente a lo largo de la infancia y en la adolescencia (Demetriou, Christou, Spanoudis \& Platsidou, 2002; Luciana, Conklin, Hooper y Yarger, 2005; Luna, Garver, Urban, Lazar \& Sweeney, 2004), con dos picos destacables, a los 4 años y a los 18 años, después se estabiliza y declina en la vejez (Diamond, 2002). La maduración prolongada de la función ejecutiva refleja los cambios de desarrollo en una amplia red de áreas, incluidas las áreas subcorticales y cerebelosas, y su conectividad en todo el cerebro (Goldman-Rakic, Chafee \& Friedman, 1993). Los componentes fundamentales de procesamiento de la función ejecutiva incluyen la conectividad funcional y anatómica entre el córtex prefrontal y el cuerpo estriado (Alexander, DeLong \& Strick, 2003). En el desarrollo del cerebro típico la maduración de las regiones que intervienen en las funciones ejecutivas se prolonga y las vías dorsofrontales continúan su desarrollo hasta la postadolescencia (Shaw et al., 2008; Sowell, Thompson, Tessner \& Toga, 2001). Tal y como se ha descrito en publicaciones previas, los lóbulos frontales muestran un desarrollo alterado en el TEA (Zilbovicius et al., 1995; Brambilla et al., 2003). Los estudios realizados con población infantil con TEA indican que presentan peor rendimiento en un amplio rango de tareas que miden las funciones ejecutivas, al compararlos con un grupo control (memoria de trabajo, control inhibitorio, flexibilidad al cambio y vigilancia) (Corbett \& Constantine, 2006; Geurts, Verte, Oosterlaan, Roeyers \& Sergeant, 2004; Goldberg et al., 2005; Just, Cherkassky, Keller, Kana \& Minshew 2007; Khosino et al., 2005, 2008; Kana, Keller, Minshew \& Just, 2007).

\subsection{Estudios del Cerebelo en TEA}

Los estudios de la estructura cerebral en el autismo, además de proporcionar suficientes pruebas de alteraciones en el desarrollo de la corteza cerebral y de las estructuras subcorticales, también han aportado una serie de datos relacionados con alteraciones en el cerebelo (O’Hearn, Asato, Ordaz \& Luna, 2008). Una abundante evidencia aportada de estudios postmortem (Bauman \& Kemper, 1985; Ritvo et al., 1986; Bailey et al., 1998), de estudios clínicos, genéticos y de imágenes (Courchesne et al., 1988; Becker \& Stoodley, 2013) sugieren que el cerebelo es parte de los circuitos neurales que son disfuncionales en el TEA. Uno de los datos más establecidos acerca del cerebelo es su implicación en la propiocepción y en el control motor fino. Estudios recientes también 
implican fuertemente al cerebelo en funciones cognitivas de orden superior como el lenguaje, el procesamiento cognitivo y la regulación afectiva (Strick, Dum \& Fiez, 2009; Stoodley \& Schmahmann, 2010; Basson \& Wingate, 2013, Becker \& Stoodley, 2013).

Los estudios relacionados con el cerebelo en el campo del autismo han sido poco consistentes a lo largo de los años. Tanto los aumentos como las disminuciones de la SG cerebelosa y de la SB se han descrito en estudios de morfometría cerebral. El grupo de Courchesne (1988) observó que el vermis (lóbulos VI y VII) mostraba una disminución específica en el tamaño en un grupo de sujetos con autismo $(n=18$, rango edad 6-30 años). Resultados similares obtuvieron Kaufmann et al. (2003) y Allen et al. (2005), quienes también observaron una reducción en el vermis de la línea media posterior en sus estudios. Por otro lado, Piven et al. (1997), observaron un aumento general del volumen cerebeloso en adolescentes y adultos con TEA. Hardan, Minshew, Harenski \& Keshavan (2001) encontraron mayor volumen total en el cerebelo, en una muestra de 22 adolescentes y adultos con autismo al compararlos con un grupo de controles, de la misma edad (rango 12- 51 años) y nivel medio de inteligencia (ajustando el TIV).

Courchesne et al. (2001) observaron que tanto la SG como la SB presentaban mayor volumen en una muestra pequeña de niños con autismo de 2-4 años y Sparks et al. (2002) sugirieron que el volumen total del cerebelo aumentó en proporción a los aumentos en el volumen total del cerebro entre 3-4 años de edad en niños con autismo. Por su parte, Ecker et al. (2009) encuentran disminuido el volumen cortical cerebelar bilateral en un grupo de 22 adolescentes y adultos con autismo (rango edad 18-42 años). También se ha informado de una menor integridad del pedúnculo cerebeloso superior en TEA (Sivaswamy et al., 2010) que se asoció con un grado de deterioro social (Catani et al., 2008). Se ha encontrado de forma consistente disminución de la SG en el lóbulo IX de la línea media, el Crus I derecho y el lóbulo VIII en el autismo, a la vez que se ha encontrado un aumento de la SG en el lóbulo VI (Cauda et al., 2011, Duerden et al., 2012; Nickl-Jockschat et al., 2012). Estas diferencias estructurales se correlacionaron con los puntajes obtenidos en las medidas de diagnóstico del autismo, así el aumento de SG en el lóbulo VI correlacionó con mayores dificultades sociales y de comunicación y la reducción de SG en el Crus I derecho se asoció con el aumento de comportamientos repetitivos y estereotipados (Rojas et al., 2006). 
Otro estudio reciente también encontró una reducción del volumen de SG en el lóbulo VII y Crus I / II (una región que muestra la conectividad estructural y funcional con la red frontoparietal y la red de modo por defecto) en sujetos con TEA y demostró una correlación entre estos cambios y la severidad de una serie de déficits conductuales y cognitivos, entre los que se incluyen las dificultades en la interacción social, en la comunicación y el aumento de los comportamientos repetitivos (D'Mello, Crocetti, Mostofsky et al., 2015) (Ver Figura 9). También se ha sugerido que regiones específicas del cerebelo influían en áreas neocorticales relacionadas con la interacción social y que un período sensible de interrupción de estos mecanismos de comunicación entre el cerebelo y la corteza podría explicar algunos de los fenotipos conductuales asociados con el TEA (Wang, Kloth \& Bandura, 2014). La participación del cerebelo en la cognición está ahora firmemente establecida. Los estudios de resonancia magnética funcional han identificado la activación cerebelosa en una serie de tareas cognitivas como el lenguaje, la memoria visual, espacial, ejecutiva y de trabajo (Stoodley, 2012).

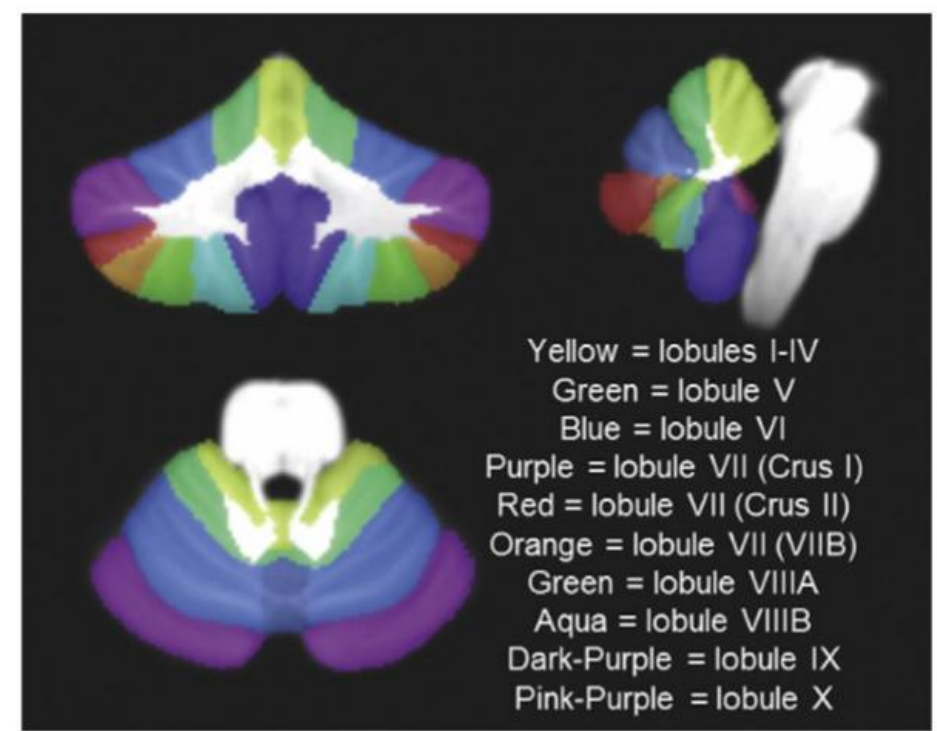

Figura 9. El cerebelo humano con lóbulos I-X codificados por colores. De la plantilla infratentorial espacialmente imparcial [SUIT] del cerebelo y el tronco encefálico (Diedrichsen etal.,2009; Diedrichsen,2006).

D'Mello, Crocetti, Mostofsky \& Stoodley, (2015)

Otra de las alteraciones neuroanatómicas más consistentes observadas en el análisis post-mortem de cerebros de personas con TEA es una disminución importante en el tamaño y en el número de células de Purkinje, principalmente en las cortezas posterolaterales neocerebelares y archicerebelares (Fatemi, Aldinger, Ashwood et al., 
2012). Los datos obtenidos en 24 estudios post mortem mostraron una disminución del 79\% de células de Purkinje en los hemisferios cerebelosos de los cerebros de individuos con este trastorno (Amaral, Schumann \& Nordahl, 2008).

El grupo de Wegiel et al., (2014b) llevó a cabo un análisis post mortem en el que describieron una reducción del $25 \%$ en el número total y una disminución del $24 \%$ en la densidad de células de Purkinje en el cerebelo de 14 sujetos con autismo frente a 14 controles de edad (4-60 años). Otro estudio llevado a cabo por el mismo grupo, también mostró reducciones significativas en el volumen de las células de Purkinje, de aproximadamente un $31 \%$ en niños de 4 a 8 años y de un $23 \%$ en adultos de 29 a 60 años.

En general, es evidente que existe una variación considerable entre los estudios centrados en el papel del cerebelo en los TEA y se han publicado muchos resultados aparentemente contradictorios. Sin embargo, actualmente están empezando a emerger estudios que tienen en cuenta la etapa del desarrollo y que pretenden relacionar las alteraciones en la estructura del cerebelo con distintos fenotipos conductuales dentro del autismo (D'Mello, Crocetti, Mostofsky et al., 2015).

\subsection{Estudios del Tálamo en TEA}

Finalmente, es necesario mencionar otra estructura cerebral de vital importancia que se ha estudiado en el autismo. Se trata del tálamo, dos estructuras cerebrales, simétricas y situadas en el centro del encéfalo. Las funciones principales del tálamo son: integrar datos procedentes de los órganos sensoriales, regular el ciclo del sueño-vigilia, regular la atención y la consciencia así como regular las emociones, además está implicado en funciones cognitivas como, por ejemplo, la memoria y el lenguaje. Hay evidencia de alteraciones talámicas en personas con autismo, sin embargo, hay pocos estudios sobre el papel de esta estructura cerebral en niños que presentan este trastorno. Además, se sabe poco sobre el vínculo entre las alteraciones neurobiológicas y las características clínicas del autismo (Say et al., 2014).

En la amplia variedad de publicaciones sobre el TEA, recientemente, ha aumentado el interés hacia el tálamo, de tal manera que se han encontrado alteraciones talámicas relacionadas con el trastorno. Algunos de estos estudios se centran en la investigación 
de aspectos estructurales y funcionales. Dos estudios morfométricos en individuos con autismo han observado una relación no lineal entre el tamaño total del cerebro y los volúmenes talámicos en el grupo con TEA, en ausencia de diferencias volumétricas entre ambos grupos (Tsatsanis et al., 2003; Hardan et al., 2006). Así, en el estudio de Tsatsanis et al. (2003) se examinó el tamaño del tálamo en 12 individuos con autismo de alto funcionamiento (rango de edad: 10,7-29,5 años) y 12 controles neurotípicos y encontraron diferencias significativas en la relación entre el volumen del tálamo y el volumen total del cerebro (en inglés, Total Brain Volume, TBV). La correlación positiva fue significativa en el grupo control pero no en el grupo con autismo. No se observó el aumento del volumen talámico con aumento de TBV en el grupo experimental (Tsatsanis et al., 2003). En el estudio de Hardan et al. (2006), examinaron a un grupo mucho mayor (40 individuos con autismo y 41 controles) con un rango de edad más amplio (8,8 a 45,7 años) observando resultados similares. No se observaron diferencias entre los dos grupos para los volúmenes talámicos no ajustados, sin embargo, tampoco se observó en el grupo con TEA la relación lineal esperada entre el TBV y el volumen talámico (Hardan et al., 2006).

En esta misma línea, Hardan et al. (2008b) combinaron dos métodos de neuroimagen para examinar la fisiopatología de las alteraciones talámicas en el autismo e identificar cualquier asociación con los déficits sensoriales que presentan en una muestra de 18 niños con autismo y 16 controles con desarrollo típico (rango de edad: 8 a 15 años). Los resultados indicaron que no había diferencias volumétricas en el tálamo entre sujetos con autismo y controles neurotípicos. La ausencia de alteraciones estructurales es consistente con varios estudios morfométricos de resonancia magnética, lo que sugiere que no existen alteraciones estructurales evidentes en el tálamo (Perich, Aduna de Paz, Valls \& Muñoz-Yunta, 2002; Haznedar et al., 2006; Hardan et al., 2006). Sin embargo, se observó una correlación positiva entre el volumen talámico y TBV en el grupo con autismo. Los resultados de este estudio apoyan el papel del tálamo en la fisiopatología del autismo y más específicamente en las anomalías sensoriales observadas en el mismo. El grupo de Hardan justifica la diferencia de sus resultados con los obtenidos en estudios previos por la diferencia en los rangos de edad de los sujetos y la aplicación de diferentes metodologías morfométricas y software.

Uno de los primeros estudios de RMe que mostró un aumento significativo de lateralidad del tálamo en niños y adolescentes con Síndrome de Asperger (SA) fue el 
llevado a cabo por Say et al. (2014). La muestra de participantes estaba formada por 15 niños con SA y 15 niños con desarrollo neurotípico (rango de edad: 7-18 años). El estudio mostró que los participantes con SA no presentaron diferencias significativas en volúmenes talámicos o TBV al compararlos con los niños del grupo control. Se observó una correlación positiva entre los volúmenes talámicos y TBV en el grupo con SA y también en el grupo de control. Estos resultados son consistentes con la mayoría de los estudios estructurales previos de resonancia magnética que examinan el volumen del tálamo en el autismo (Tsatsanis et al., 2003; Hardan et al., 2008; Haznedar et al., 2006). Otro resultado interesante en el estudio fue que el grupo con SA mostró una relación significativa entre el índice de lateralidad aumentado en el tálamo y el nivel de alteraciones en el lenguaje. La mayoría de los niños con SA tienen algún déficit en el desarrollo del lenguaje hablado, como problemas de articulación, dificultades pragmáticas, alteraciones en la prosodia y también problemas de comprensión del lenguaje (Gillberg, 2002). Este aumento de la asimetría en el tálamo y su relación con las alteraciones en el lenguaje en niños y adolescentes con SA, apoya el papel que desempeña esta estructura cerebral en los déficits del lenguaje observadas incluso en formas leves de autismo. (Say et al., 2014).

Las alteraciones en la estructura de las regiones subcorticales pueden sugerir un desarrollo atípico de estas redes, con implicaciones para entender la base neural de los síntomas de la TEA. En el trabajo de Schuetze et al. (2016) se investigó los efectos del diagnóstico de TEA y la interacción con la edad, el volumen, la superficie y la forma del tálamo y los ganglios basales. El estudio se suma a un creciente número de publicaciones que implican los circuitos ganglio-talámicos-corticobasales en la fisiopatología de los TEA. Estos circuitos están implicados en una gama amplia de funciones cognitivas, emocionales y motoras, y pueden tener un papel fundamental en el complejo perfil del autismo. Se llevó a cabo con 373 participantes varones con TEA y 384 varones neurotípicos (rango de edad de los participantes, entre 7-35 años). Los resultados indicaron mayor superficie bilateralmente y una forma más cóncava en el tálamo de los participantes con TEA en comparación con el grupo control. También encontraron en el grupo experimental que la forma del globo pálido derecho y del putamen tuvo un aumento más pronunciado con la edad en cuanto a la forma (mayor concavidad). Finalmente, encontraron asociaciones entre una parte del área talámica y la morfología del globo pálido y la gravedad de los síntomas del TEA. En conjunto, estos 
resultados sugieren que hay diferencias sutiles en la morfología subcortical en los TEA. Aunque este estudio fue transversal, estos resultados apoyan la idea de trayectorias atípicas de desarrollo en el autismo en la forma del globo pálido, del putamen y del tálamo desde la infancia hasta la edad adulta.

Los resultados obtenidos por Schuetze et al. (2016) son compatibles con el estudio realizado por Lin, Ni, Lai, Tseng \& Gau (2015) y descrito anteriormente, en el que los participantes con TEA obtuvieron significativamente mayores volúmenes de SG que el grupo control en la corteza orbitofrontal inferior derecha y también en el tálamo bilateral (núcleo dorsal medial izquierdo y núcleo dorsal lateral derecho).

A modo de conclusión, podemos afirmar que las personas con autismo presentan una trayectoria de crecimiento cerebral atípica que se puede apreciar prácticamente desde edades muy tempranas por el crecimiento acelerado del cerebro a partir del primer año de vida (especialmente por el aumento de SG y SB en los lóbulos frontales y temporales), una disminución de dicho crecimiento durante la infancia tardía hasta el inicio de la adolescencia, para no ser significativo en la vida adulta. Esto se evidencia a partir de los datos aportados por la infinidad de estudios que hay publicados sobre el tema, tanto estudios transversales como estudios longitudinales, en los que se indica que en esta población hay cambios cerebrales atípicos relacionados con la edad. Los niños con autismo han mostrado en dichos estudios que presentan diferencias en el desarrollo cerebral a nivel cortical (lóbulo frontal medial y lateral, y lóbulo temporal), subcortical (Sistema límbico, estriado, ínsula, tálamo, entre otras) y cerebelar, al compararlos con niños que presentan un desarrollo típico. Además, estas alteraciones observadas en el desarrollo de estas áreas cerebrales, que son claves y que están implicadas a su vez en el desarrollo de funciones cognitivas de orden superior como son la cognición y comunicación social, el desarrollo de las emociones, el lenguaje y la memoria, están implicadas y relacionadas con los síntomas principales que podemos observar en el autismo (déficits en la interacción social y en la comunicación social, intereses restringidos y conductas repetitivas). 


\section{4- ALTERACIONES NEUROPSICOLÓGICAS EN NIÑOS CON TEA}

\subsection{Desarrollo de la Teoría de la Mente en niños con desarrollo típico}

La cognición social incluye los mecanismos cognitivos basados en la capacidad de procesar el mundo social y se empieza a desarrollar desde edades muy tempranas a través del desarrollo de la "teoría de la mente" (ToM) (Astington \& Edward, 2010). Aunque el desarrollo de la ToM no es el tema central de nuestro estudio, consideramos importante conocer y entender cómo se adquieren estas habilidades de forma natural en un niño con desarrollo típico para posteriormente valorar cómo un desarrollo inadecuado de las mismas en las personas con TEA puede generar dificultades importantes a lo largo de la vida.

La ToM no es una habilidad que aparece de forma repentina, sino que sigue un proceso de desarrollo creciente a lo largo de los primeros años de vida, especialmente a lo largo de los 2 primeros años a través de los cuales se empieza a adquirir un nivel considerable de comprensión de la mente (Carpendale \& Lewis, 2006; Sodian, 2005). Desde el nacimiento observamos conductas en los niños que nos indican su interés por interactuar con las personas de su entorno obteniendo información social a partir de las expresiones faciales, de la mirada, de la voz,...imitando acciones sencillas (Hood, Willen \& Driver, 1998; Meltzoff, 2002).

Happé \& Frith (2014) realizaron una revisión sobre la cognición social en el desarrollo típico partiendo del nacimiento y dividiendo la trayectoria en grandes épocas de desarrollo definidas por hitos claves de la cognición social. Así, los recién nacidos comienzan a desarrollar varias competencias sociales de forma muy temprana y hacia los 3 meses, hay evidencia de que desarrollan la reciprocidad social relacionada con el reconocimiento de la relación entre uno mismo (su propio cuerpo) y otros (su madre). Desde los 3-6 meses de edad, se pueden observar los primeros indicios de procesamiento emocional y de sensibilidad hacia las señales sociales, principalmente a través del procesamiento de la mirada. Posteriormente, alrededor de los 6-18 meses, comienza a surgir el comportamiento social con el desarrollo de una fuerte reciprocidad y el intercambio de estados mentales con varias personas: atención conjunta, 
referenciación social, apego y atribución implícita del estado mental. En este período de tiempo, sobre los 9 meses, se desarrolla la atención conjunta y el niño entiende que él y el adulto están atendiendo de forma intencionada, es decir, no solo sigue la mirada de la otra persona sino que además presta atención al objeto que le interesa a ella (Scaife y Bruner, 1975; Tomasello, 1995, 1999; Tomasello \& Carpenter, 2007; Baron-Cohen, 2009; Happé \& Frith, 2014). También entre los 14 y 18 meses, los niños empiezan a comprender que detrás de una acción hay una intención y que ésta puede ser diferente a la de uno mismo (Tomasello, 1995). Hacia los 20 meses, el nivel de desarrollo que presenten en la atención conjunta, en la capacidad de imitación y en el desarrollo del juego simbólico determinará el rendimiento en ToM a los 4 años (Charman et al., 2000). Entre los 18 y los 24 meses empiezan a desarrollar juegos de ficción (Leslie, 1987). Este tipo de juego es fundamental para que desarrollen posteriormente la capacidad de comprender el estado mental de los demás (Leslie, 1988). A la edad de 24 meses, los niños claramente muestran conciencia de la diferencia entre los pensamientos de la mente y las cosas en el mundo. Son capaces de realizar juegos de simulación y utilizan sus habilidades de lectura mental para ser capaz de entender que la otra persona puede estar fingiendo. A esta edad, los niños también entienden que la gente se sentirá feliz si consigue lo que quiere o se sentirá triste si no lo hace (Leslie, 1987; Astington \& Edward 2010; Happé \& Frith, 2014).

Entre los 3-5 años se produce un cambio cualitativo en el funcionamiento mentalista de los niños de esta edad. Utilizan conceptos como "deseo" y lo relacionan con las creencias y con las emociones (Wellman, Cross \& Watson, 2001); empiezan a entender que las creencias o las intenciones de otras personas puede no ser ciertas. Esta capacidad se conoce como atribución de creencias falsas. También empiezan a comprender que el conocimiento está relacionado con la experiencia y que hay una relación estrecha entre ver y saber. Pueden pasar la prueba de "ver conduce a saber": comprender que simplemente tocando una caja no es suficiente para saber lo que hay dentro (Pratt \& Bryant, 1990; Baron-Cohen, Leslie \& Frith, 1985; Baron-Cohen, 2009). Con 4 años de edad realiza adecuadamente la tarea de la falsa creencia y es capaz de reconocer cuando alguien tiene una creencia equivocada sobre el mundo (Wimmer \& Perner, 1983). También a esta edad entienden con facilidad el engaño (Sodian \& Frith, 1992). Hacia los 4 o 5 años de edad, los niños ya empiezan a percibir que las personas hablan y actúan dependiendo de la forma en que piensan acerca del mundo (Astington 
\& Edward 2010; Happé \& Frith, 2014) y a los 5 años, la habilidad de ToM se ha desarrollado lo suficiente como para que los niños sean capaces de diferenciar sus propios estados internos de los de otros (Happé \& Frith, 2014). La comprensión y realización adecuada de tareas de ToM de mayor complejidad, como las creencias falsas de segundo orden, se produce entre los 5 ó 6 años, según indican varios estudios al respecto (Sullivan, Zaitchik \& Tager-Flusberg, 1994; Perner \& Howes, 1992; Leekman, 1990). Otro tipo de tareas que también presentan cierta complejidad serían "las meteduras de pata", diseñadas por el grupo de Baron-Cohen (1999b). Los niños con desarrollo típico empiezan a resolver este tipo de tareas hacia los 7 años de edad, aunque van mejorando la ejecución hasta los 11 años (Baron-Cohen, O’Riordan, Stone, Jones \& Plaisted, 1999b; Banerjee \& Watling, 2005; Banerjee, Watling \& Caputi, 2011). Respecto al tema de las mentiras, la edad de comienzo en la que los niños empiezan a utilizarla es bastante temprana, sobre 2 ó 3 años, pero no hay intencionalidad detrás; sobre los 3 y 4 años es cuando realmente empiezan a mentir con el fin de engañar a los demás. A estas edades, aun no son capaces de mantener la mentira a lo largo del tiempo pero aprenderán a hacerlo cuando se desenvuelvan bien resolviendo tareas de falsas creencias de segundo orden, entre 7 ó 8 años (Wilson, Smith \& Ross, 2003; Polak \& Harris, 1999; Talwar \& Lee, 2002a; Newton, Reddy \& Bull, 2000; Leekman, 1992).

A los 9 años saben que pueden hacer comentarios y realizar conductas que podrían ofender los sentimientos ajenos, qué se puede decir y qué otras cosas se deben callar. También a esta edad pueden interpretar las expresiones de los ojos de otra persona y averiguar qué puede estar pensando o sintiendo (Baron-Cohen, 2009).

Resumiendo, podemos considerar que la ToM sigue un desarrollo progresivo y secuencial en el que se van adquiriendo diferentes habilidades y logros cognitivos de complejidad creciente durante los primeros años de la etapa infantil (Steele, Joseph \& Tager-Flusberg, 2003; Wellman \& Liu, 2004). Muchos autores defienden la idea de que la ToM se va desarrollando a lo largo de la vida (Happé, Winner \& Brownell, 1998). 


\subsection{Desarrollo de la Teoría de la Mente en niños con TEA}

El TEA se caracteriza por una baja competencia social (Hamilton, Hoogenhout \& Malcolm-Smith, 2016). Los déficits en las habilidades sociales son una característica diagnóstica fundamental del TEA y, especialmente, los déficits en el desarrollo de la Teoría de la Mente (ToM) que son los que socavan la competencia social en estas personas generándoles una disfuncionalidad importante para desenvolverse en diferentes contextos sociales (American Psychiatric Association, 2013; Baron-Cohen, Leslie \& Frith 1985; Kanner, 1943). La investigación en la población con TEA ha sido numerosa y abundante en el ámbito de los déficits relacionados con el desarrollo de la ToM. Tales estudios se han llevado a cabo desde etapas muy tempranas del desarrollo y se ha postulado con frecuencia que tales déficits pueden subyacer en las dificultades sociales y las dificultades de la comunicación que presentan a lo largo de toda la vida (Baron-Cohen, Leslie \& Frith, 1985; Happe \& Frith 1996; Hoddenbach et al., 2012; Ozonoff \& McEvoy, 1994).

En las últimas décadas, varias aproximaciones teóricas se han propuesto para dar una explicación razonable sobre el fenotipo cognitivo-conductual propio del autismo (TEA). Desde una perspectiva cognitiva, que es la que nos interesa describir en este apartado, la conducta social en este trastorno está afectada por déficits en los mecanismos cognitivos innatos a partir de los cuales podemos imaginar y descifrar las intenciones, deseos y estados mentales de otros. Esta habilidad innata se conoce como Teoría de la Mente (Lampreia, 2004). La ToM es la capacidad y habilidad para inferir y representar los estados mentales y emocionales de los otros, y a su vez nos permite anticipar y predecir el comportamiento de los demás (Hare, 2007). Por tanto, es la base cognitiva en la que se sustenta la empatía. La ToM es un elemento fundamental para las habilidades sociocomunicativas y para lograr una integración social exitosa; por tanto, es una habilidad compleja que requiere la capacidad de formar conceptos mentales, de representar verbalmente construcciones complejas, de inhibir algunos estados mentales a favor de otros y de considerar y comparar múltiples perspectivas.

En parte de la literatura publicada sobre la ToM se ha sugerido que está formada por dos componentes: un componente más cognitivo y otro más afectivo (Baron-Cohen et al., 2015; Mazza et al., 2014; Pino et al., 2016; Shamay-Tsoory, Aharon-Peretz \& Perry, 2009). Específicamente, el componente cognitivo es la capacidad de entender lo que 
otros están pensando (es decir, sus estados mentales). Mientras que el componente afectivo es la capacidad de hacer inferencias con respecto a las emociones de otras personas (Franco et al., 2014; Mazza et al., 2014; Pino et al., 2016; Shamay-Tsoory, Tomer \& Aharon-Peretz, 2005).

Las personas con TEA a menudo presentan dificultades en estas áreas, aspecto que les dificulta poder integrarse socialmente, generándoles problemas de funcionamiento en el entorno familiar, en la escuela, en el lugar de trabajo y con los amigos (Baron-Cohen, Leslie \& Frith, 1985; Hamilton, Hoogenhout \& Malcolm-Smith, 2016). La ToM no se refiere a una sola habilidad, sino a una serie de destrezas que están presentes desde tan sólo 14 meses y se desarrollan en una trayectoria relativamente predecible durante toda la infancia (Low \& Perner, 2012; Wellman, Cross \& Watson, 2001; Wellman \& Liu, 2004).

\subsubsection{Primeros estudios de ToM en TEA}

El origen de este concepto se encuentra en los trabajos de Primatología llevados a cabo por Premack y Woodruf (1978) quienes intentaron demostrar que los chimpancés podían comprender la mente humana y eran capaces de atribuir al actor humano estados mentales como la intención y el conocimiento. Para ellos, la ToM era una habilidad que permitía atribuir estados mentales a otras personas, incluso a uno mismo, para poder comprender, predecir y explicar el propio comportamiento y el de los demás. Por tanto, era un proceso que se presentaba tanto en primates como en humanos, constituyendo un proceso importante y crucial en el desarrollo adecuado de la cognición socio-emocional y el desarrollo de una conducta social competente (Premack \& Woodruf, 1978). Posteriormente a la publicación de estos estudios, el concepto de ToM se fue introduciendo en el campo de la Psicología, especialmente en el campo del desarrollo socio-cognitivo infantil (Flavell, 2004), tanto en relación con el desarrollo típico como en relación con los trastornos del neurodesarrollo.

Autores como Baron-Cohen (1985, 1989b, 2000b), Leslie (1985, 1987) y Frith (1985), centraron sus investigaciones sobre ToM en el autismo. La mayor parte de personas con autismo tienen afectada esta capacidad de teoría de la mente, mostrarían una especie de "ceguera" ante las mentes de los demás e incluso ante la propia. Esta "ceguera" podría 
explicar muchos de los déficits que presentan a nivel social y comunicativo y, en este sentido, muchas investigaciones han tenido por objetivo comprobar la dificultad de mentalización en esta población. Para el grupo de Baron-Cohen, Leslie \& Frith, (1985), las personas que presentan este trastorno tienen serios problemas para teorizar acerca de la mente de los demás. Definieron la ToM como la capacidad de inferir toda la gama de estados (creencias, deseos, intenciones, imaginación, emociones, etc.) que causan la acción, es decir, la capacidad de reflexionar sobre el contenido de la mente de uno y de los demás. La dificultad para entender otras mentes es una característica cognitiva fundamental de las personas con TEA (Baron-Cohen, 2001a). Los déficits en la adquisición de una teoría de la mente proporcionaron una explicación aceptable de los principales síntomas del autismo, especialmente las dificultades en la reciprocidad social y la comunicación, proporcionando así la primera explicación integrada de los mecanismos cognitivos que podrían subyacer a varios comportamientos clave que definen el trastorno (Baron-Cohen, Leslie \& Frith, 1985). La ToM se desarrolla de manera gradual desde la infancia pero es una habilidad que es más evidente hacia los cuatro años de edad (Adolphs, 2003; Wilde, Astington \& Barriault, 2001; Butman \& Allegri, 2001; Mercadillo, Díaz \& Barrios, 2007). La terminología asociada a este concepto es variada: “ToM”, “cognición social”, “mentalización”, “psicología popular”, "psicología intuitiva" o "conducta intencional” (Tirapu-Ustárroz, Pérez-Sayes, Erekatxo-Bilbao y Pelegrín-Valero, 2007).

El aumento de investigaciones para valorar el desarrollo de las habilidades mentalistas en la infancia fue notable a partir de la década de los ochenta. En un principio, el interés se centró en valorar la comprensión de las creencias. Así, las primeras tareas diseñadas para evaluar las habilidades mentalistas se centraron en las creencias. La habilidad para distinguir entre las creencias y la realidad es fundamental para el desarrollo de la ToM. Las creencias son representaciones mentales que nos hacemos sobre la realidad y pueden ser verdaderas cuando corresponden con ella o falsas cuando no es así. Nuestra conducta está motivada por nuestra forma de ver la realidad (creencias). Entre los $3 \mathrm{y}$ los 4 años, los niños empiezan a utilizar las creencias para explicar o predecir la conducta de los demás. En este terreno, hay investigaciones centradas en el estudio de la comprensión de las creencias verdaderas y otros en la comprensión de las creencias falsas (Serrano, 2012). 
En nuestro trabajo nos centraremos en revisar los estudios que se han basado en evaluar el segundo tipo de creencias. Así, los primeros trabajos se inician de la mano de los psicólogos austriacos Heinz Wimmer \& Joseph Perner (1983), quienes crearon la clásica situación de falsa creencia a partir de una tarea experimental denominada cambio inesperado de objeto. Estas tareas se denominaron de primer orden porque permitían evaluar que diferentes personas podían tener diferentes pensamientos sobre la misma situación y sólo implicaban inferir el estado mental de una persona. Para comprender esta tarea, el niño debe diferenciar entre el mundo real y el mundo mental, y sólo entonces puede predecir las acciones de los otros a partir de los estados mentales. La demanda cognitiva de esta tarea requiere que el niño tome la perspectiva del personaje y se dé cuenta de que tiene una falsa creencia, distinguirla de la suya propia y ser capaz de predecir su conducta. Para estos autores, resolver con éxito la tarea era un marcador de la presencia de ToM.

Wimmer \& Perner (1983) crearon una historia, "Maxi y el Chocolate", que se le cuenta al niño de la siguiente manera: Maxi, el personaje, guarda una tableta de chocolate que le había comprado su madre en un armario verde de la cocina. Más tarde, Maxi sale a jugar al jardín y mientras permanece fuera, su madre coge el chocolate para hacer un pastel y lo guarda en el armario azul. Después la madre se marcha a comprar huevos y Maxi regresa a la cocina porque quiere un poco de chocolate. Se le pregunta al niño dónde cree que Maxi piensa que está el chocolate (Serrano, 2012). Los resultados variaron dependiendo de la edad, así, el 86\% de niños entre 6 y 9 años realizaron correctamente la tarea, el $57 \%$ de niños entre 4 y 6 años también contestaron de forma adecuada y ningún niño entre 3 y 4 años hizo bien la tarea. Según estos autores, la mayoría de los niños de 6 años la podían realizar sin dificultad mientras que los niños con 4 años las realizaban al azar. La conclusión fundamental de esta investigación fue la identificación de un aumento progresivo en la comprensión de las falsas creencias, con el aumento de la edad. Esta tarea de cambio inesperado de localización supuso un punto de partida y dió pie a una línea productiva de investigaciones acerca de la comprensión de la creencia falsa en el desarrollo evolutivo normotípico y en el alterado.

La tarea de falsa creencia de primer orden ha sido frecuentemente modificada con el fin de asegurarse de que la ejecución errónea en los niños menores de 4 años no fuera causada por la dificultad de representar la creencia del personaje de la historia. Sin embargo, la estructura de la tarea se ha conservado intacta. Una de las primeras 
modificaciones fue realizada por el grupo de Baron-Cohen, Leslie \& Frith (1985). Estos autores retomaron la tarea original de Wimmer \& Perner (1983) e idearon la tarea de "Sally y Anne", aunque la simplificaron para reducir las demandas cognitivas de la misma. Además, pretendían comparar la ejecución de la misma entre grupos de niños con autismo, niños con Síndrome de Down y niños con desarrollo típico. En este test, el niño ve a Sally (una muñeca) que esconde una canica en su cesta y se va; a continuación, Anne (otra muñeca) coge la canica de la cesta de Sally y la coloca en su propia cesta. Después regresa Sally y quiere coger su canica. A partir de aquí, al niño se le realizan una serie de preguntas de control de la memoria (¿Dónde está la canica realmente?, ¿Dónde estaba la canica al principio?) y la pregunta clave del test: “¿Dónde buscará Sally la canica?. Los resultados fueron que el $80 \%$ de niños con autismo contestaron incorrectamente (incluso los que presentaban un cociente intelectual promedio): Sally miraría en la cesta donde está realmente la canica. La mayor parte de los niños con 4 años con desarrollo típico (85\%) así como el $86 \%$ de niños con S. de Down contestaron correctamente que Sally miraría en su cesta al creer que la canica estaría allí. Este grupo de niños era capaz de entender que Sally tenía una creencia distinta a la suya y, por tanto, era falsa. Este estudio fue replicado por Leslie \& Frith (1988). Las conclusiones se mantuvieron constantes y en la misma dirección del estudio original: "los niños autistas tienen una dificultad en su capacidad metarrepresentacional y esto impide que tengan una teoría de la mente" (Leslie \& Frith, 1988). En el 2001, Wellman, Cross \& Watson realizaron un metaanálisis con 178 estudios con niños neurotípicos entre los años 1983 y 1998 en el que concluyeron que las tareas de evaluación de la ToM de primer orden ponen de manifiesto una mejora progresiva en la comprensión de la falsa creencia con la edad cronológica, que se extienden desde respuestas azarosas a los tres años a respuestas acertadas alrededor de los 4 años, edad en la que el rendimiento en este tipo de tareas es adecuado. En la literatura publicada sobre esta tarea hay gran número de estudios que evidencian las dificultades en este tipo de tarea mostradas por personas con autismo al compararlo con niños con desarrollo típico (Baron-Cohen, Leslie \& Frith, 1985; Baron-Cohen, Leslie \& Frith, 1986; Leekam \& Perner, 1991; Reed \& Peterson, 1990; Swettenham, 1996; Swettenham, Baron-Cohen, Gomez \& Walsh, 1996). 


\subsubsection{Estudios posteriores sobre ToM en TEA: tareas más complejas}

\subsubsection{Falsas creencias de segundo orden}

Otro tipo de tareas con mayor dificultad, más complejas, son las denominadas "creencias de segundo orden", que evalúan la atribución a segundos de creencias de un tercero (Portela et al., 2003), como por ejemplo, La prueba del Heladero diseñada por Perner \& Wimmer (1985). Estos autores, condujeron la primera investigación sistemática sobre la capacidad de reconocimiento de creencia falsa de segundo orden en niños y hallaron que los niños no infieren correctamente una creencia de este tipo antes de los 7- 8 años. Las creencias de segundo orden son necesarias para la comprensión de actos de habla complejos, como la ironía y la mentiras, entre otras. Como se podría esperar, al producirse un retraso en la adquisición de las competencias de ToM de primer orden, los niños con TEA suelen fracasar también en las pruebas de falsa creencia de segundo orden (Baron-Cohen, 1989b). La tarea diseñada consistía en una historia en la que participaban los siguientes personajes: "Es un día caluroso de verano. Juan y María están sentados en el parque cuando ven llegar una furgoneta de helados. Como no llevan dinero encima, María decide ir a buscar la cartera a su casa. El heladero le asegura que esperará en el parque, pero al cabo de unos minutos Juan ve cómo el heladero arranca la furgoneta para irse. Al preguntarle dónde va, el heladero contesta que se marcha a la zona de la iglesia porque en el parque apenas hay gente. Cuando el heladero va conduciendo camino de la iglesia, María le ve desde la puerta de su casa y le pregunta dónde va. Así, María también se entera de que estará en la iglesia. Por su parte, Juan, que no sabe que María ha hablado con el heladero, va a buscarla a su casa pero no la encuentra, ya no está. La madre de María le dice a Juan que ella se ha ido a comprar un helado. Pregunta: ¿Dónde piensa Juan que María habrá ido a buscar al heladero?". Las pruebas de segundo orden implican inferir el estado mental de dos personas, por ejemplo, “que piensa Juan que piensa María”. Mientras que las pruebas de primer orden corresponden a un nivel de edad mental de 4 años, las pruebas de segundo orden corresponden a un nivel de edad mental de 6 años. Los resultados del estudio indicaron que el $25 \%$ de los niños de 7 años dieron una respuesta correcta a la pregunta realizada y todos los niños con 10 años resolvieron la tarea también correctamente. En este caso, los resultados obtenidos también dependieron de la edad, así a los 8 años, el 
porcentaje de respuestas correctas fue del $67 \%$ y a los 9 años, del $57 \%$ concluyendo que la progresión del porcentaje de respuestas correctas entre los 7 y los 10 años no fue lineal (Serrano, 2012).

Estos resultados indican que las tareas de comprensión de falsas creencias de segundo orden tienen una mayor complejidad que las de primer orden y la capacidad para resolverlas correctamente se aprecia alrededor de los 6 años, mejorando su ejecución a lo largo del desarrollo. Por tanto, en la literatura publicada sobre el tema de las falsas creencias, los estudios indican que los niños con TEA fracasaban en la resolución de las mismas o, en algunos casos, podían resolverlas adecuadamente pero no eran capaces de generalizarlas a otras situaciones o a otras pruebas (Bowler, Stromm \& Urquhart, 2001; Oznoff \& Miller, 1995).

\subsubsection{Historias extrañas de Happé}

Posteriormente, los estudios empezaron a centrarse en niveles más avanzados de la comprensión de la ToM. Concretamente, en la comprensión de las intenciones comunicativas verbales ya que requerían ir más allá del lenguaje literal y atender aspectos como la intención del hablante. En 1994, Happé crea la prueba de "Historias extrañas", un tipo de historias que evaluarían un tercer nivel de complejidad de ToM, la capacidad de extraer un significado en función de una situación social particular, que implicaría la necesidad de una "coherencia central o global" donde el niño debe superar la literalidad para generar un significado determinado en un contexto concreto (TirapuUstárroz, Pérez-Sayes, Erekatxo-Bilbao y Pelegrín-Valero, 2007; Aguirre, 2013). El conjunto original fue de 24 historias (dos de cada tipo) que trataban sobre la comprensión de: la mentira, la mentira piadosa, el chiste, la ficción, el malentendido, la persuasión, la apariencia-realidad, la metáfora, el sarcasmo, el olvido, el doble engaño y las emociones opuestas. Estas historias iban acompañadas por un conjunto más pequeño de seis historias de control que exigían la comprensión de los estados físicos (White, Happé, Hill \& Frith, 2009). Con estas historias Happé pretendía evaluar la comprensión de los pensamientos y sentimientos de los personajes a partir de varias situaciones de la vida cotidiana. Por tanto, con dichas historias se podía evaluar la ToM de una forma más natural (Serrano, 2012). En cada una de ellas, el personaje decía algo que no se debía entender en sentido literal, debía tener en cuenta el estado mental del hablante así 
como su intencionalidad y se solicita al sujeto una explicación de por qué el personaje afirma eso. Un ejemplo sería: Mentira piadosa: "Hoy tía Amelia ha venido a visitar a Pedro. Pedro quiere mucho a su tía pero hoy lleva un nuevo peinado que Pedro encuentra muy feo. Pedro cree que su tía está horrorosa con este pelo y que le quedaba mucho mejor el que llevaba antes. Pero cuando tía Amelia le pregunta a Pedro: ‘¿Qué te parece mi nuevo peinado?’, Pedro dice ‘¡Oh, estás muy guapa!’. Pregunta: ¿por qué le dice eso Pedro?” (Tirapu-Ustárroz, Pérez-Sayes, Erekatxo-Bilbao y Pelegrín-Valero, 2007).

De modo que, el objetivo principal era evaluar esta habilidad en niños con autismo y valorar el grado de desarrollo en su capacidad de atribuir intenciones a los demás (Aguirre, 2013). Los resultados del estudio indicaron que las personas con autismo interpretaron las historias de forma incorrecta, al igual que ocurrió con las tareas de las creencias falsas de segundo orden. De hecho, los problemas de comprensión y los problemas con las inferencias son una característica común de los individuos de alto funcionamiento en el espectro del autismo (Jolliffe \& Baron-Cohen, 1999b; Norbury \& Bishop, 2002). Sin embargo, los participantes con desarrollo típico mostraron una mejor ejecución en esta prueba a partir de los 8 años de edad, orientando estos resultados a la conclusión de que los niños empiezan a comprender el lenguaje figurado a partir de esa edad (Baron-Cohen, 2001a). Otros estudios llevados a cabo con niños de 5 a 12 años con desarrollo típico mostraron que la comprensión de las intenciones comunicativas se iniciaría sobre 6 ó 7 años para desarrollarse completamente sobre los 11 años aproximadamente (Happé, 1994; Winner \& Leekman, 1991; Sullivan, Winner \& Hopfierld, 1995).

\subsubsection{Meteduras de pata (Faux pas)}

En 1999, el grupo de Baron-Cohen elaboró un nuevo test para evaluar la sensibilidad social (Faux pas) con el que pretendían valorar las diferencias en el rendimiento en la comprensión de la ToM avanzada entre niños con desarrollo típico y niños afectados por el SA. Esta será la primera prueba que evalúa aspectos relacionados con ToM en niños más mayores, siendo la franja de edad era de 7 a 11 años. Hasta este momento, la mayoría de las pruebas anteriores se diseñaron para una franja de edad de 4-6 años (Baron-Cohen, O’Riordan, Stone, Jones \& Plaisted, 1999b). El test de Meteduras de 
pata consistía en 10 historias en las que el protagonista "mete la pata" en distintos contextos sociales y 10 historias de control de tipo "aséptico" (Tirapu-Ustárroz, PérezSayes, Erekatxo-Bilbao y Pelegrín-Valero, 2007; Aguirre, 2013). Un ejemplo de este tipo de tarea sería el siguiente: "Julia compró a su amiga Esther un jarrón de cristal como regalo de bodas. Esther hizo una gran boda y había tal cantidad de regalos que le fue imposible llevar la cuenta de qué le había regalado cada invitado. Un año después, Julia estaba cenando en casa de Esther. A Julia se le cayó una botella de vino sin querer sobre el jarrón de cristal y éste se hizo añicos. 'Lo siento mucho. He roto el jarrón' dijo Julia. 'No te preocupes -dijo Esther-, nunca me gustó; alguien me lo regaló por mi boda." El niño debe determinar si alguien ha dicho algo inoportuno y las razones por las cuáles cree que lo ha dicho. Esta tarea es más compleja y se requiere que el niño haya comprendido la situación y sea capaz de ponerse en el lugar de los diferentes protagonistas de la historia (Tirapu-Ustárroz, Pérez-Sayes, Erekatxo-Bilbao y PelegrínValero, 2007). Los resultados obtenidos por el grupo de Baron-Cohen indicaron varios

aspectos: el primero, que la habilidad para detectar la metedura de pata se va desarrollando con la edad y que hay un perfil diferencial entre ambos sexos (superior en las niñas); el segundo, mientras el grupo de niños con desarrollo típico muestra un rendimiento adecuado entre 9 y 11 años, los niños con SA y Autismo de alto funcionamiento (AAF) no realizaron correctamente la tarea (Baron-Cohen, O'Riordan, Stone, Jones \& Plaisted, 1999b). Los trabajos realizados a partir de este test indicaron que la ejecución correcta de este tipo de tarea se relacionaba estrechamente con formas más avanzadas de comprensión social y que los niños con 7 años empiezan a entender las meteduras de pata, van mejorando esta capacidad hacia los 11 años y finalizan su comprensión hacia los 15 años (Banerjee \& Watling, 2005; Banerjee, Watling \& Caputi, 2011; Kaland et al., 2002).

\subsubsection{Test de la Mirada}

Otra tarea utilizada para evaluar la comprensión de los estados mentales más complejos fue a partir de expresiones faciales, especialmente la mirada. Baron-Cohen, Jolliffe, Mortimore \& Robertson (1997c) elaboraron "El Test de los ojos" para evaluar la detección de estados mentales complejos dentro de la ToM. La primera versión del test contenía 25 fotografías solo de la zona de los ojos, cejas y nariz. En cada fotografía 
había dos palabras y una de ellas expresaba el estado mental que expresaba la imagen. La tarea consistía escoger la palabra que mejor expresaba qué sentía o qué pensaba la persona de la fotografía. En 2001 el grupo de Baron-Cohen modifica la tarea para corregir algunos aspectos inadecuados de la misma. La nueva versión estaba formada por 36 fotografías y cada una de ellas estaba rodeada de cuatro palabras, en lugar de dos. Era una tarea para ser realizada por adultos. Posteriormente, realizan una versión para niños y adolescentes, con un número menor de fotografías, en este caso eran 28 , también rodeadas por cuatro palabras. En las dos versiones del test, sólo una palabra es la que indicaba el estado mental expresado en la imagen. Los participantes debían elegir la palabra que mejor expresa qué podía sentir o pensar la persona de la imagen. En la versión infantil incluye un vocabulario mental más simple (Baron-Cohen et al., 2001b). La tarea fue administrada a un grupo de niños de 6 a 13 años con desarrollo típico y a niños con SA con edades de 8 a 14 años. Los resultados indicaron que más del 50\% de niños del grupo control con edades entre 10 y 12 años realizaron correctamente la tarea, pero no alcanzaron el efecto techo. En otro estudio realizado por Peterson \& Slaughter (2009), los resultados fueron similares, los niños con desarrollo típico con edades comprendidas entre 6 y 13 años, obtuvieron mejores resultados en el desempeño de la tarea que los niños con autismo pero no alcanzaron tampoco el efecto techo (Serrano, 2012). Los niños con desarrollo típico de 9 años pueden interpretar las expresiones de los ojos de una persona, para averiguar lo que podría estar pensando o sintiendo, sin embargo, los niños con SA tienden a encontrar estas pruebas mucho más difíciles (Baron-Cohen et al., 2001b).

\subsubsection{Otros estudios relacionados con el tema}

En ocasiones, se ha cuestionado la idea de que las personas con TEA presentan déficits en el desarrollo de la ToM debido a que algunas de ellas, especialmente las personas con Autismo de Alto Funcionamiento o SA, eran capaces de solucionar adecuadamente las pruebas mentalistas de primer orden (aunque no lo hacían a la edad en la que lo hacían las personas con desarrollo neurotípico) (Happé, 1995). En muchos estudios sobre el tema se ha podido comprobar que, aunque sí realizaban bien las pruebas de ToM más sencillas, no lograban realizar correctamente las pruebas más complejas, como las falsas creencias de segundo orden (Baron-Cohen, 1989b), la tarea del Test de 
la Mirada (Baron-Cohen, Jolliffe, Mortimore \& Robertson, 1997c; Baron-Cohen, Wheelwright, Hill, Raste \& Plumb, 2001a; Baron-Cohen, Wheelwright \& Jolliffe, 1997d; Brent, Rios, Happé \& Charman, 2004), las tareas de comprensión de interacciones sociales complejas (Tager-Flusberg, 1999) o tareas que impliquen entender la mentira, la persuasión y los malentendidos (Brent, Rios, Happé \& Charman, 2004).

En 2005, el grupo de Peterson utilizó un conjunto de cinco tareas donde se incluían conceptos de ToM, desde el deseo hasta la falsa creencia y las emociones ocultas. Los niños con autismo encontraron la tarea de creencia falsa más difícil que las emociones ocultas. Por tanto, pueden en cierta manera desarrollar cierta comprensión del deseo y de la emoción pero presentan dificultades considerables para manejar y comprender las creencias y otros estados cognitivos de los demás (Peterson, Wellman \& Liu, 2005).

Los niños con desarrollo típico, realizan las tareas clásicas de ToM a partir de ideas sociales intuitivas en las personas o el conocimiento conceptual de los estados mentales, junto con las habilidades cognitivas generales que apoyan el procesamiento verbal, la memoria de los eventos narrativos claves y la inhibición de las respuestas espontáneas que son centrales para las tareas. Por el contrario, los estudios de niños con autismo sugieren que estos niños tratan las tareas de ToM como problemas de razonamiento lógico, basándose principalmente en el lenguaje y otros procesos cognitivos no sociales en lugar de la intuición social (Tager-Flusberg, 2007).

Los estudios originales han sido replicados muchas veces por diferentes equipos de investigación y no hay duda de que los niños con autismo tienen dificultades para atribuir estados mentales a ellos mismos y a otras personas (Baron-Cohen, Leslie \& Frith, 1985). Sin embargo, la investigación actual apoya la opinión de que los niños y adultos con autismo tienen problemas para procesar la información del estado mental, tanto suya como de los otros, y que cuando son capaces de inferir estados mentales, tienden a no usar los mismos sistemas neurocognitivos que las personas con desarrollo típico. Así, el desempeño en las tareas de la ToM puede explicar parte de los síntomas sociales y de comunicación que definen este trastorno.

Las personas usan ToM para entender y explicar su comportamiento o el de otras personas. Por lo tanto, el desarrollo adecuado de estas habilidades es un requisito previo para el procesamiento de la información social, es decir, primero necesitamos entender 
y reconocer las intenciones, creencias y emociones de otras personas para aprender a distinguir nuestros estados mentales de los estados mentales de otras personas. Posteriormente, procesamos esta información social para interactuar de manera adecuada con otras personas y el mundo que nos rodea (Mazza et al., 2017).

Como se ha podido comprobar, el desarrollo de la ToM es un proceso largo que se empieza a detectar experimentalmente en edades tempranas. A medida que continua su desarrollo, el niño logra llevar a cabo inferencias más complejas del contexto social. Así, es capaz de reconocer ironías, bromas, chistes, dobles sentidos, expresiones emocionales complejas. Aprende a diferenciar y a adaptarse a distintas situaciones y contextos sociales utilizando en cada ocasión la forma socialmente adecuada y aceptada de interacción. Por tanto, existen diferentes niveles de complejidad en ToM: las creencias de primer y segundo orden, relacionadas con la posibilidad de comprender las representaciones mentales de los otros. Las comunicaciones metafóricas e historias extrañas (ironía, mentira y mentira piadosa) permiten evaluar la habilidad de niños autistas para atribuir intenciones a los demás. Las meteduras de pata (Faux pas) permiten valorar la sensibilidad social, mientras que la expresión emocional a través de la mirada valora aspectos emocionales complejos que surgen en la interacción social, permitiendo que la persona se ponga en el lugar de la otra persona (Tirapu-Ustárroz, Pérez-Sayes, Erekatxo-Bilbao y Pelegrín-Valero, 2007). Por tanto, las dificultades que caracterizan a los niños con TEA en el desarrollo de la ToM están relacionadas con un comportamiento social inadecuado y con malas habilidades de comunicación social (Lerner et al., 2011; Ziv, Hadad, Khateeb \& Terkel-Dawer, 2014).

\subsubsection{Inteligencia, Lenguaje y ToM}

Otro aspecto importante relacionado con el tema que estamos abordando es la fuerte relación que existe entre ToM y el desarrollo del lenguaje así como la relación con el funcionamiento ejecutivo (Carlson, Moses \& Breton, 2002). Además, para que el desarrollo de la ToM sea adecuado, se requiere también de un cierto nivel de funcionamiento intelectual general (Baker, Peterson, Pulos \& Kirkland, 2014). A continuación vamos a analizar estos tres procesos cognitivos ya que su influencia es decisiva en el desarrollo de la ToM. Respecto a la inteligencia general (CI), un resultado que se ha encontrado con frecuencia en la literatura sobre el tema ha sido una 
correlación consistente entre las puntuaciones de ToM e CI en personas neurotípicas y en población con TEA (Baker, Peterson, Pulos \& Kirkland, 2014; Happé, 1995; Hoogenhout \& Malcolm-Smith, 2014; Steele, Joseph \& Tager-Flusberg, 2003).

El lenguaje está estrechamente relacionado con la ToM. Hay bastantes estudios que apoyan la relación existente entre ambos (Farrar \& Maag, 2002; Lind \& Bowler, 2009; Milligan, Astington \& Dack, 2007; Slade \& Ruffman, 2005, Thirion-Marissiaux \& Nader-Grosbois, 2008). Los resultados obtenidos en algunos estudios sobre el tema indican que los niños bilingües tienen mejor ToM que los niños monolingües (Goetz, 2003), los niños sordos presentan un retraso en el desarrollo de la ToM (Peterson, Wellman \& Liu, 2005; Schick, Villiers, Villiers \& Hoffmeister, 2007) y los niños con TEA que realizan adecuadamente las tareas de creencias falsas presentan un nivel de inteligencia verbal más alto que aquellos que fallan en la realización de las mismas (Happé, 1995). La habilidad temprana del lenguaje es un factor importante que predice la capacidad posterior de entender las creencias falsas (Slade \& Ruffman, 2005). Por tanto, algunas personas con TEA pueden utilizar sus habilidades de razonamiento cognitivo-lingüístico para compensar los déficits en la capacidad de ToM y así lograr la respuesta correcta en tareas explícitas (Lind \& Bowler, 2009). Las personas con TEA y con deterioro del funcionamiento intelectual y verbal muestran más déficits en las habilidades de ToM con la edad que aquellas con un funcionamiento cognitivo y verbal más avanzado (Hamilton, Hoogenhout \& Malcolm-Smith, 2016).

Cuando el TEA se presenta junto con un Trastorno del desarrollo intelectual aparecen dificultades más acentuadas en el desarrollo de la ToM que cuando el TEA va acompañado de un desarrollo intelectual promedio (Baker, Peterson, Pulos \& Kirkland, 2014; Happé, 1995; Hoogenhout \& Malcolm-Smith, 2014). Hay una relación entre ToM y la CI que es más fuerte que la relación entre ToM y el CI Verbal. Los niños neurotípicos son capaces de realizar adecuadamente las tareas de creencia falsa con tan sólo 3 años. Sin embargo, los niños con TEA generalmente requieren una edad mental verbal de 11 años 9 meses para ejecutar con cierta precisión las mismas tareas (Happé, 1995). Incluso niños con Trastorno del desarrollo intelectual sin TEA, en los que se creía que la capacidad de ToM estaba preservada, las pruebas más sensibles muestran déficits en el desarrollo de la ToM (Baurain \& Nader-Grosbois, 2013; ThirionMarissiaux \& Nader-Grosbois, 2008). Por lo tanto, el deterioro intelectual puede afectar a la adquisición de habilidades que forman la ToM, independientemente del TEA. 


\subsubsection{Funcionamiento ejecutivo y ToM}

Respecto a la relación entre el funcionamiento ejecutivo, hay bastantes publicaciones en la literatura acerca de este tema. La ToM requiere la construcción de conceptos mentales complejos, por tanto, es necesario cierto nivel de capacidad ejecutiva para que su desarrollo sea adecuado (Aboulafia-Brakha et al., 2011; Austin et al., 2014). Los datos que aparecen en los estudios publicados indican que hay dos áreas de funcionamiento ejecutivo que son particularmente importantes para el desempeño de ToM, por un lado, la memoria de trabajo (MT) y, por otro, la inhibición cognitiva. La MT se ha implicado constantemente en la adquisición y la expresión de ToM (Gordon \& Olson, 1998; Lin, Keysar \& Epley, 2010; Ozonoff, Pennington \& Rogers, 1991; Slade \& Ruffman, 2005). Cuando hablamos de esta función ejecutiva, nos referimos a la capacidad de mantener temporalmente cierta información en nuestra mente para procesarla. La ToM requiere la capacidad de tener en la mente perspectivas conflictivas, así como la capacidad de comparar estas perspectivas dentro de un contexto relevante (Hamilton, Hoogenhout \& Malcolm-Smith, 2016). Por ejemplo, varias tareas de ToM requieren que los niños consideren su propia perspectiva y la de otra persona (falsa creencia) o considerar la apariencia de un objeto frente a la realidad de la situación (por ejemplo, un objeto que parece una manzana pero es una vela, en forma de manzana). Cuando aparecen déficits en la MT se reduce el número de perspectivas que una persona puede tener en la mente y disminuye su capacidad de cambiar o comparar dichas perspectivas. Se ha podido comprobar que los niños que presentan déficits en la MT realizan con más esfuerzo y más lentitud las tareas de ToM, y suelen cometer más errores que los niños sin déficit en la misma, a pesar de invertir más tiempo en contestar las preguntas (Lin, Keysar \& Epley, 2010).

En cuanto a la otra función ejecutiva, también relacionada con la ToM, cabe decir que se trata de la capacidad para detener una respuesta prepotente o la capacidad de desplazar el foco de atención lejos de estímulos irrelevantes (Hamilton, Hoogenhout \& Malcolm-Smith, 2016). Un aspecto importante para realizar con éxito una tarea de engaño, de creencias falsas o de apariencia-realidad es que la respuesta inicial debe ser inhibida para considerar o bien otras perspectivas o bien otra información (por ejemplo, "parece que es una manzana, pero en realidad es una vela"). Así, es necesario que los niños inhiban su propia perspectiva o conocimiento de la situación para considerar las 
opiniones de los demás o para considerar otra perspectiva más precisa. La relación entre ToM e inhibición cognitiva persiste después de que la edad, el género, el CI, la habilidad verbal y la capacidad de MT se mantienen constantes (Carlson, Moses \& Breton, 2002; Perner, Lang y Kloo, 2002; Perner y Lang, 1999). Las dificultades que se han observado en los niños con déficits en la inhibición cognitiva a la hora de realizar tareas de ToM generan un bajo rendimiento provocado por la impulsividad e inexactitud en las respuestas y por el nivel atencional bajo (Hamilton, Hoogenhout \& MalcolmSmith, 2016).

A modo de síntesis, podemos concluir que la ToM es una habilidad innata a partir de la cual podemos inferir y representar los estados mentales y las emociones de los demás. Nos permite anticipar y predecir el comportamiento de los otros. Esta habilidad se desarrolla de forma gradual desde la infancia y es un proceso largo. Es fundamental para desarrollar habilidades socio-comunicativas y para lograr con éxito una integración social apropiada. Necesitamos entender y reconocer las intenciones, creencias y emociones de los demás para aprender a distinguir nuestros estados mentales de los estados mentales de los otros. La ToM fue la primera explicación sobre los mecanismos cognitivos subyacentes a varios comportamientos clave que definen el autismo. La abundante literatura publicada sobre el tema confirma que la mayoría de las personas que presentan este trastorno muestran dificultades en el desarrollo de la ToM y dichas dificultades están relacionadas con un comportamiento social desajustado e importantes déficits en las habilidades de comunicación social.

\subsection{Teoría de la Empatía-Sistematización}

En los últimos años han surgido otras teorías que pretenden dar una explicación global de los déficits nucleares que aparecen en el autismo. Baron-Cohen (2002) propone una nueva perspectiva basada en la Teoría de la Empatía-Sistematización (TE-S) que daría explicación a las dificultades mostradas por personas con autismo tanto en la comunicación y en las relaciones interpersonales como en las dificultades relacionadas con las características no sociales (intereses restringidos, conductas repetitivas, resistencia al cambio, excesiva atención al detalle,...). Baron-Cohen (2010) en su obra: "Autismo y síndrome de Asperger" indica que la TE-S explica un porcentaje muy 
superior de características que definen el autismo en relación con el resto de teorías propuestas.

Esta teoría resalta los déficits que presentan las personas con TEA en el desarrollo de la empatía pero a la vez destaca su habilidad intacta o superior a la media en cuanto a capacidad de sistematización (Baron-Cohen, Richler, Bisarya, Gurunathan \& Wheelwright, 2003; Baron-Cohen \& Wheelwright, 2004; Baron-Cohen, Wheelwright, Burtenshaw \& Hobson, 2007b; Baron-Cohen, Wheelwright \& Jolliffe, 1997d; BaronCohen, Wheelwright, Stone \& Rutherford, 1999c; Lai et al., 2011; Lawson, BaronCohen \& Wheelwright, 2004). De acuerdo con la TE-S, el autismo se explica mejor no sólo con referencia a la empatía (por debajo del promedio), sino también con referencia a un segundo factor psicológico (sistematización) (Baron-Cohen, 2002).

Hablar de empatización implica no solo identificar las emociones y los pensamientos de otra persona sino también responder con una emoción apropiada. La sistematización, es la tendencia a analizar, explorar y construir un sistema. La propuesta del grupo de Baron-Cohen se centra en dos aspectos fundamentales de la ToM: empatía cognitiva y empatía afectiva. Así, la empatía cognitiva implica identificar los estados mentales de otra persona o los suyos propios (atribuciones, reconocimiento de expresiones faciales o vocales,...). Por otro, la empatía afectiva implica tener una reacción emocional apropiada a los pensamientos y sentimientos de otra persona.

Respecto al concepto de sistematización, para Baron-Cohen (2006), lo que define un sistema es que sigue reglas y cuando sistematizamos estamos tratando de identificar las reglas que gobiernan el sistema, con el fin de predecir cómo se comportará ese sistema.

Una característica común en el autismo es que las personas que presentan este trastorno se convierten en expertos en el reconocimiento de patrones de repetición en los estímulos, sienten la necesidad de analizar o construir sistemas. Algunas de las conductas típicas que muestran las personas con autismo y que estarían explicadas por la buena capacidad de sistematización serían: insistir en la misma comida cada día, insistir en que ningún objeto cambie de posición en la habitación, insistir en el mismo juego cuando un amigo va a jugar, hacer girar repetidamente un objeto, repetir frases, golpear superficies, obsesión con horarios y calendarios. La empatía es considerada nuestra manera más poderosa de entender y predecir el mundo social y la sistematización es considerada nuestra forma más poderosa de entender y predecir el 
universo inanimado gobernado por la ley (Baron-Cohen, Richler, Bisarya, Gurunathan \& Wheelwright, 2003).

Esta teoría, al igual que la teoría de la Coherencia Central Débil (Frith, 1989; Happé \& Vital, 2009) defiende que en el autismo se da un estilo cognitivo diferente (Happé, 1996) en el cual la atención hacia los pequeños detalles tiene mucho peso. Esta característica cognitiva se ha demostrado repetidamente en bastantes estudios (Shah \& Frith 1983, 1993; Jolliffe \& Baron-Cohen 2001; O'Riordan, Plaisted, Driver \& BaronCohen, 2001; Mottron, Burack, Iarocci Belleville \& Enns, 2003). Para la primera teoría, esta atención hacia el pequeño detalle es una característica negativa para suplir la incapacidad de percibir los estímulos globalmente. Para la segunda, TE-S, la atención al detalle es una característica positiva que lleva a las personas cognitivamente sistemáticas a intentar entender los sistemas. Por otro lado, no defiende que las personas con autismo, y por lo tanto más sistemáticas, no puedan dar coherencia y percibir globalmente dichos estímulos (Baron-Cohen, Ashwin, Ashwin,Tavassoli \& Chakrabarti, 2009).

Para medir estas capacidades (empatía y sistematización) Baron-Cohen, Richler, Bisarya, Gurunathan \& Wheelwright (2003) diseñaron el Cociente de sistematización (SQ) y el Cociente de Empatía (CE). El objetivo de esta herramienta fue la necesidad de tener un instrumento que pudiera evaluar el interés de un individuo en los sistemas a través de la gama de diferentes clases de sistema. El objetivo de sus estudios ha sido, primero probar una diferencia de sexo en la sistematización en la población general y, en segundo lugar, probar la superioridad en la sistematización en adultos con SA o AAF. Ambos son cuestionarios de autoaplicación con un formato sencillo y constan de 60 preguntas, 40 relacionadas con la capacidad de sistematización y 40 relacionadas con la capacidad de empatía y 20 preguntas de relleno (control) en cada uno de ellos. Los resultados de varios estudios en los que se utilizaron ambos cuestionarios indicaron, respecto al primer objetivo planteado en la población general, indicaron que las mujeres eran más empáticas y los hombres tenía mayor tendencia a ser sistemáticos. Respecto al segundo objetivo, los participantes con SA y AAF obtuvieron puntuaciones significativamente más bajas en el CE (nivel bajo de empatía) y más altas en el CS (nivel alto de sistematización) que los controles con desarrollo típico con los que se compararon. De manera que la población con TEA es más propensa a tener un cerebro extremadamente sistematizador (Goldenfeld, Baron-Cohen \& Wheelwright, 2005). 
Baron-Cohen, Auyeung et al., (2009) elaboran un cuestionario para niños en el que unificaron y adaptaron los dos cuestionarios anteriores en uno solo para facilitar y simplificar la administración de los mismos a los padres, que eran quienes iban a rellenar el cuestionario en relación a las conductas observadas en sus hijos. Así, el cuestionario constaba de 55 preguntas, 27 preguntas corresponden al CE y 28 preguntas al CS, siendo el rango de puntuación del primer cuestionario 0-54 y el rango del segundo cuestionario 0-56. Los resultados obtenidos por el grupo de Baron-Cohen fueron similares a los obtenidos con muestras de adultos. En la población de niños con desarrollo típico mostró que las niñas exhibían conductas más empáticas y los niños presentaron mayores habilidades visuoespaciales y puntuaciones más altas en el CS, es decir, eran más sistematizadores. Respecto al grupo de niños con SA y AAF, los patrones de puntuación observados indicaron que no empatizaban en la misma medida que la población típica y que eran más propensos a participar en comportamientos o actividades que implican sistemas y procesos (Baron-Cohen, 2009; Auyeung et al., 2009; Baron-Cohen, Richler, Bisarya, Gurunathan \& Wheelwright, 2003). En una serie de pruebas que miden la empatía, como por ejemplo, las Meteduras de pata (donde los niños deben reconocer que alguien ha dicho algo inoportuno), las niñas con desarrollo típico desarrollan esta habilidad antes que los niños mientras que en la población infantil con TEA, dicha habilidad se desarrolla de forma más tardía (Baron-Cohen et al., 1999b). Resultados similares ocurren cuando se utiliza el Test de la Mirada, en la población con desarrollo típico, las mujeres puntúan más que los hombres y la población con autismo, puntúan incluso menos que los hombres con desarrollo típico (Baron-Cohen et al., 1997c).

Para Baron-Cohen (2009), la TE-S tiene varios puntos fuertes. El primero, es que se trata de una teoría de dos factores que puede explicar el conjunto de características sociales y no sociales en las condiciones del espectro autista. La empatía por debajo del promedio es una manera sencilla de explicar las dificultades sociales y de comunicación, mientras que la sistematización media o incluso superior a la media es una forma de explicar las dificultades no sociales observadas también en esta población, es decir, los intereses restringidos, el comportamiento repetitivo y la resistencia al cambio. Esto se debe a que cuando se sistematiza, es más fácil mantener todo constante, y sólo varían una cosa a la vez. De esta manera, el mundo es más predecible. El segundo punto fuerte apoyaría la idea de que esta teoría puede ayudar a caracterizar el perfil 
único de las condiciones del espectro autista. El tercero, esta teoría permite un enfoque diferente en las intervenciones, utilizando la fuerte sistematización para enseñar la empatía, por ejemplo, presentar emociones en un formato favorable al autismo (BaronCohen, 2009; Baron-Cohen 2007b; Golan et al., 2006). El cuarto punto fuerte indica que la teoría de E-S podría explicar la dificultad de "generalizar" en las condiciones del espectro autista (Plaisted, O'Riordan, \& Baron-Cohen 1998; Wing 1997).

Otra aportación interesante realizada por el grupo de Baron-Cohen (2009) es la idea de que la excelente atención al detalle se relaciona con la hipersensibilidad sensorial. Aunque el tema del procesamiento sensorial lo abordaremos con más profundidad en el apartado siguiente, nos parece oportuno tratarlo de forma superficial en este punto por la relación que implica las habilidades de sistematización con aspectos relacionados con el procesamiento sensorial. Los estudios que utilizan cuestionarios como el perfil sensorial han revelado anormalidades sensoriales en más del 90 por ciento de los niños con TEA (Leekam et al., 2001; Kern et al. 2006; Tomchek \& Dunn 2007). En el contexto de la sistematización y excelente atención al detalle, las diferencias en cuanto al funcionamiento sensorial que presentan las personas con TEA pueden estar afectando al procesamiento de la información en una etapa temprana (en términos de sensación / cognición y desarrollo) de forma que o bien podría provocar angustia o bien podría predisponer al talento inusual (Baron-Cohen, Ashwin, Ashwin,Tavassoli \& Chakrabarti, 2009). 


\section{5- PROCESAMIENTO SENSORIAL EN NIÑOS CON TEA}

\subsection{Alteraciones sensoriales en niños con TEA}

Cuando hablamos de procesamiento sensorial nos referimos a la manera en que el sistema nervioso central y periférico maneja la información sensorial entrante desde los órganos sensoriales (Visual, auditivo, táctil, gustativo, olfativo, propioceptivo y vestibular) (Fernández-Andrés, Pastor-Cerezuela, Sanz-Cervera \& Tárraga-Minguez, 2015). La Teoría de la Integración Sensorial defiende la idea de que el procesamiento y la integración de estímulos sensoriales es un proceso neuroconductual importante que afecta en gran medida al desarrollo (Ayres, Robbins \& McAtee, 1979). Este procesamiento incluye varios aspectos: registrar el estímulo, modulación del estímulo, discriminarlo y práctica del nuevo acto motor. Cualquier alteración que afecte a uno de estos procesos puede provocar déficits considerables en funciones integrativas de nivel superior (Tomchek, 2001).

Desde la primera caracterización del autismo, propuesta por Kanner (1943), se han observado alteraciones en el procesamiento sensorial en el trastorno del espectro autista. En el pasado, estos síntomas se han visto como periféricos al trastorno más bien que como característica del núcleo. Estos trastornos de procesamiento sensorial, aunque estaban bien documentados en la literatura relacionada con el tema en el pasado (Ornitz, 1989; Ornitz, Lane, Sugiyama \& Traversay, 1993; Yeung, Courchesne \& Courchesne, 1997; Ermer \& Dunn, 1998; Watling, Deitz \& White, 2001), no se han tenido muy en cuenta en el campo del autismo. De hecho, los problemas sensoriales no habían sido incluidos directamente en los criterios diagnósticos.

Los primeros trabajos sobre el autismo ya incluyeron descripciones de respuestas poco comunes a los estímulos sensoriales por parte de las personas que presentaban este trastorno (Kanner, 1943; Asperger, 1944, citados por Frith, 1991). Los estudios en este ámbito se fueron realizando de forma esporádica ya que los adultos con TEA sí autodescribían la importancia de los problemas sensoriales en su día a día, y consideraban que eran los causantes de los problemas sociales y de comunicación que presentaban (Grandin, 1996; O’Neil, 1999; Williams, 1992; Cesaroni \& Garber, 1991). Según estos informes autobiográficos, las alteraciones sensoriales encontradas en el autismo no se limitaban únicamente a la hipersensibilidad o hiposensibilidad (O'Neill \& 
Jones, 1997) sino que también incluían las fluctuaciones entre estos estados, las distorsiones sensoriales, la sobrecarga sensorial y las dificultades de procesamiento de información de más de un canal sensorial al mismo tiempo (Bogdashina, 2003).

Sin embargo, en los últimos años se ha reconocido cada vez más la importancia central de los síntomas sensoriales en el TEA (Hazen et al., 2014). Un creciente número de investigaciones ha demostrado la frecuencia de estos síntomas y el papel que pueden desempeñar en la contribución a las características y los déficits funcionales en el autismo. Así, la investigación sobre los déficits sensoriales en el autismo ha experimentado en estos últimos años un auge creciente. Además de las características básicas del autismo (desarrollo alterado en la interacción y en la comunicación social y un repertorio restringido de conductas e intereses), los investigadores han informado que los niños y adolescentes con trastornos del espectro autista responden a las experiencias sensoriales de manera diferente a la población de su misma edad con desarrollo típico.

Hasta la aparición del Diagnostic and Statistical Manual of Mental Disorders, 5th edition (DSM-5, 2013), los criterios diagnósticos para el TEA no tenían en cuenta los problemas sensoriales, así, en todas las ediciones anteriores del DSM, no se mencionaban. En este nuevo manual se proponen unas modificaciones en los criterios diagnósticos, entre los cuales se incluyen la hiper-hiporreactividad a los estímulos sensoriales y el interés inusual por aspectos sensoriales del entorno.

La literatura actual sobre el tema sugiere que la prevalencia de los problemas sensoriales en esta población es relativamente alta; así, entre un 70-80\% de personas con TEA presentan este tipo de síntomas (Costa \& Lampreia, 2012; Harrison \& Hare, 2004) y las diferencias sensoriales pueden observarse en la infancia temprana antes del momento en que se reconozcan síntomas clínicamente significativos de TEA (Baranek, 1999; Clifford et al., 2013). De hecho, la aparición inicial de estos síntomas a menudo es previa al diagnóstico (Adrien et al., 1993; Baranek, 1999; Dahlgren \& Gillberg, 1989, Lord, 1995). Actualmente, sabemos que los problemas sensoriales, además de ejercer un impacto considerable en la configuración del trastorno, también influye directamente en la vida cotidiana de las personas con TEA, generando alteraciones considerables en su funcionamiento diario y agravando los síntomas que acompañan al trastorno. (Costa \& Lampreia, 2012). 
Entre los síntomas sensoriales más comunes observados y estudiados en el TEA están los trastornos de la modulación sensorial, que pueden definirse como respuestas anormales a los estímulos sensoriales que conducen al deterioro funcional (Miller, Anzalone, Lane, Cermak \& Osten, 2007). Este tipo de trastorno se divide en tres categorías. La primera es la hiperresponsividad sensorial, en la cual se experimenta mucha angustia o aparece una respuesta negativa exagerada, que a menudo conduce a la evitación y a la hipervigilancia relacionada con el estímulo (Miller, Anzalone, Lane, Cermak \& Osten, 2007). Es decir, se trataría de una reacción a estímulos sensoriales desproporcionadamente intensa, rápida o prolongada (Martínez-Sanchis, 2015). Sería el caso de un niño con TEA especialmente sensible a las sensaciones táctiles asociadas con determinadas prendas de ropa o con partes de las mismas, como las etiquetas. Esta sensibilidad puede llevar al niño a empezar a sentir angustia y ansiedad excesivas al usar tal prenda, a tener una fuerte rabieta cuando la lleva puesta o negarse a usar determinada ropa. La segunda categoría de trastorno de la modulación sensorial es la hiporresponsividad, en la que parece que se ignora o se tarda en responder a un estímulo que normalmente provocaría una respuesta (Miller, Anzalone, Lane, Cermak \& Osten, 2007). Un ejemplo, podría ser que algunos niños con TEA no responden al dolor, lo que podría provocar lesiones considerables si se tocara una estufa caliente, al no reaccionar con rapidez. La tercera categoría de trastorno de la modulación sensorial es el comportamiento de búsqueda sensorial, en el que se persigue ciertas experiencias sensoriales prolongadas e intensas (Martínez-Sanchis, 2015). Por ejemplo, un niño con TEA puede oler repetidamente sus dedos, oler el cabello de las personas con las que está, o determinado objeto. Los trastornos de la modulación sensorial son muy prevalentes en las personas con TEA, con estimaciones en los estudios en niños que van del 56\% al 70\% (Baranek, David, Poe, Stone \& Watson, 2007; Ben-Sassonet al., 2007). Además, los presentan en varias modalidades sensoriales (Baranek, David, Poe, Stone y Watson, 2007; Tomchek y Dunn, 2007; Baker, Lane, Angley y Young, 2008; BenSasson et al., 2009; Lane, Molloy \& Bishop, 2014), entre otras, visuales, táctiles y auditivas. Así, hay personas con autismo que evitan las luces brillantes y otras son capaces de mirar fijamente a un estímulo luminoso intenso (Behrmann \& Humphreys, 2006; Simmons et al., 2009). La hiperresponsividad a la estimulación táctil, en situaciones como por ejemplo cortarse las uñas o cortarse el cabello, pueden provocar problemas de conducta y ansiedad (Cascio et al., 2008; Güçlü, Tanidir, Mukaddes \& Unal, 2007). Los niños con niveles más altos de hipersensibilidad táctil en un estudio 
también mostraron comportamientos inflexibles, verbalizaciones repetitivas, estereotipias visuales y atención enfocada anormal (Baranek et al., 1997).

Respecto a la responsividad a estímulos auditivos, hay casos de hiperresponsividad a sonidos neutros y casos de hiporresponsividad a estímulos auditivos lingüísticos (Ceponiene et al., 2003; Dunn, Gomes \& Gravel, 2008; Ludlow et al., 2014).

Estudios recientes, en la línea de los trastornos de la modulación sensorial, han aportado datos interesantes sobre el tema, indicando que las personas con TEA podían presentar déficits en más de una modalidad sensorial (Leekam, Nieto, Libby, Wing, \& Gould, 2007; Baker, Lane, Angley \& Young, 2008) y que los niños presentan respuestas sensoriales poco comunes a partir de edades tempranas. La evidencia sugiere que los problemas sensoriales en esta población son más comunes durante la infancia que durante la edad adulta (Baranek, Foster, \& Berkson, 1997). Kern et al. (2006) informaron que los problemas sensoriales en el autismo mejoraban con la edad. Según los autores, esto está en concordancia con los informes de los padres y cuidadores que con frecuencia describen un mayor número de signos de problemas sensoriales en su hijo durante la infancia.

Estudios previos también han encontrado que niños con TEA presentan comportamientos y respuestas emocionales asociadas con diferencias sensoriales, tales como hiperreactividad auditiva (por ejemplo, reaccionan con lloros o con rabietas ante sonidos inesperados), hiporreactividad sensorial (por ejemplo, no reaccionar ante estímulos dolorosos) y búsqueda sensorial (por ejemplo, lamer u oler objetos) (Rogers \& Ozonoff, 2005; Baranek, Boyd, Poe, David \& Watson, 2007; Tomchek \& Dunn, 2007; Baker, Lane, Angley, \& Young, 2008). Estas diferencias no se deben a problemas de pérdida sensorial (es decir, pérdida auditiva, deterioro visual, etc.) y son significativamente más frecuentes en niños con TEA que en niños con desarrollo típico (Ben-Sasson et al., 2009).

Recientemente, una serie de estudios han relacionado los patrones de diferencias sensoriales con los déficits nucleares de los TEA (Boyd et al., 2010; Hilton, Graver, \& LaVesser, 2007). Boyd et et al. (2010) concluyeron en su estudio que se daba una correlación entre niveles altos de hiperreactividad sensorial con mayores niveles de conductas repetitivas en los TEA y la búsqueda sensorial, también estaba asociada con la tendencia a la uniformidad. Otros estudios relacionaron el estilo sensorial 
hiperresponsivo con la menor participación en actividades (Little, et al., 2015; BenSasson, 2009). Otros estudios han observado asociaciones significativas entre la hiperreactividad sensorial y la comunicación social, la motivación social y el desempeño de las actividades sociales (Hilton, Graver \& LaVesser, 2007; Reynolds, Bendixen, Lawrence \& Lane, 2011).

Los estudios centrados en el procesamiento sensorial en niños con TEA coinciden en que presentan una amplia prevalencia de alteraciones en estos procesos (Costa \& Lampreia, 2012; Kientz \& Dunn, 1997; Liss, Saulnier, Fein \& Kinsbourne, 2006; Baranek, David, Poe, Stone \& Watson, 2005). La forma habitual de evaluar el procesamiento sensorial en niños con TEA ha sido a partir de cuestionarios o informes estandarizados para padres o para maestros. En tales estudios, se ha comparado cómo es el procesamiento sensorial en niños con TEA y en niños con desarrollo típico y se ha podido comprobar que en el caso de los primeros, presentan alteraciones importantes en este tipo de procesamiento (Kern et al., 2006; Lai, Chung, Chan \& Li-Tsang, 2011; Watling, Deitz \& White, 2001; Tomchek \& Dunn, 2007; Ben-Sasson et al., 2007; Ashburner, Ziviani \& Rodger, 2008), especialmente las diferencias eran más significativas en dos modalidades (auditiva y táctil) aunque en otras modalidades se han encontrado algunas diferencias (Kientz \& Dunn, 1997; Rogers, Hepburn \& Wehner, 2003; Tomchek \& Dunn, 2007; Wiggins, Robins, Bakeman \& Adamson, 2009; Ashburner, Ziviani \& Rodger, 2008). Las diferencias en el procesamiento auditivo son una de las alteraciones en el procesamiento sensorial más comúnmente documentadas. En una revisión retrospectiva de patrones de desarrollo en 200 casos con autismo, Greenspan \& Weider (1997) informaron que el 100\% de los participantes demostraron dificultades con la respuesta auditiva. Varios autores han reportado hipersensibilidad auditiva (Bettison, 1994; Dahlgren \& Gillberg, 1989; Gillberg \& Coleman, 1996; Rimland \& Edelson, 1995; Vicker, 1993). Además, Dahlgren \& Gillberg (1989) encontraron que la sensibilidad a los estímulos auditivos en la infancia era un poderoso discriminador entre los niños con y sin autismo. Otros estudios han informado de un bajo procesamiento auditivo (Baranek, 1999; Osterling \& Dawson, 1994; Wing, 1966). Esta hiporreactividad (por ejemplo, una respuesta disminuida al nombre) ha sido una consideración diagnóstica temprana en que los niños que parecían ser sordos en su infancia han sido posteriormente diagnosticados con autismo (Wing, 1966). 
La respuesta visual también ha sido documentada en la literatura sobre el tema. Se ha descrito la evitación del contacto visual y el uso inadecuado de la mirada como características sociales tempranas del autismo (Baranek, 1999; Gillberg \& Coleman, 2000; Kientz \& Dunn, 1997). Varios autores han propuesto que estas características son un mecanismo autorregulador que compensa las dificultades con la modulación de la entrada visual. Otros informes han señalado que los niños con TEA inspeccionan a menudo los objetos (por ejemplo, las manos, los objetos en movimiento) de una manera inusual con su visión periférica (LeCouteur et al., 1989; Lord, Rutter \& LeCouteur, 1994).

Los problemas sensoriales pueden aportar una nueva comprensión de los déficits observados en el autismo. Una afirmación razonable extraída de estudios previos sobre el tema es que el aparato sensorial permite que el bebé sea sensible y receptivo a las emociones de los demás, se involucre emocionalmente e interactúe con su entorno habitual. Si los niños con TEA experimentan el mundo de manera diferente desde edades tempranas debido a los déficits que presenta en el procesamiento sensorial, sus experiencias no les proporcionarán los aprendizajes necesarios para establecer relaciones interpersonales e integrarse en la vida social (Costa \& Lampreia, 2012). Así, en el área de la interacción social, durante el desarrollo temprano, los problemas sensoriales pueden causar dificultades en las interacciones sociales en los niños que presentan este trastorno. Estos déficits en las relaciones sociales y emocionales reflejan, a su vez, déficits en el desarrollo adecuado de las habilidades de comunicación. Las personas con TEA además de presentar un procesamiento sensorial diferente respecto a la población con desarrollo típico en uno o varios canales sensoriales, frecuentemente tienen problemas para integrar adecuadamente la información proveniente de distintos sistemas sensoriales. Estas dificultades en la integración afectan directamente al desarrollo del lenguaje y de la comunicación, ya que la correcta percepción del lenguaje requiere la integración de señales tanto auditivas como visuales (Martínez-Sanchis, 2015).

Los patrones de comportamiento, intereses y actividades restringidos y repetitivos se pueden explicar mejor a partir de los déficits sensoriales. Así, estos patrones parecen reflejar intentos de manejar y controlar un ambiente percibido como caótico por las personas con TEA y la capacidad de manejar y controlar estos entornos empeora debido 
a la falta de habilidades sociales y de comunicación apropiadas (Costa \& Lampreia, 2012).

Para evaluar los síntomas sensoriales en el autismo se han utilizado diversos instrumentos. A continuación, se numeran varios de ellos, pero dedicaremos un apartado para detallar con más precisión el Sensory Profile, la medida que utilizaremos en este trabajo. La mayoría de los estudios que investigan los problemas sensoriales en esta población se han basado en cuestionarios que han realizado los padres, cuidadores y maestros. Varios instrumentos se han utilizado para identificar, a través de cuestionarios, problemas sensoriales, con el objetivo de crear un perfil sensorial individual. Entre ellos, los más utilizados han sido: el Sensory Profile (Dunn \& Westman, 1995), el Short Sensory Profile (Dunn, 1999), Sensory Profile ChecklistRevised (Bogdashina, 2003), Sensory Sensitivity Questionnaire-Revised (Talay-Ongan \& Wood, 2000), Sensory Experiences Questionnaire (Baranek, David, Poe, Stone \& Watson, 2005) y Evaluation of Sensory Processing (Johnson-Ecker \& Parham, 2000). Otro cuestionario que evalúa la disfunción sensorial es el Sensory Integration and Praxis Test (SIPT, Ayers,1989). Esta herramienta proporciona una evaluación completa del funcionamiento sensorial para niños de 4 años a 8 años, 11 meses de edad y es diferente al resto de cuestionarios. Es más largo porque implica la observación directa del comportamiento de un niño por parte de un terapeuta profesional, además, requiere que el niño entienda y siga las instrucciones, por lo que puede no ser válido para niños con déficits cognitivos. Varios instrumentos también estandarizados de evaluación sensorial son el Sensory Processing Measure (Parham, 2007) y el DeGangi-Burk Test of Sensory Integration (DeGangi \& Burk, 1983).

Además, muchas medidas estandarizadas de la sintomatología del espectro autista contienen elementos relacionados con las alteraciones en el procesamiento sensorial. Entre ellas, destacan la Childhood Autism Rating Scale (Schopler, Reichler, DeVellis \& Daly, 1980), Autism Behavior Checklist (Krug, Arick \& Almond, 1980) y Gilliam Autism Rating Scale (Gilliam, 1995).

Todos estos instrumentos han sido desarrollados y estandarizados con poblaciones de niños con desarrollo típico. Si bien muchas de estas herramientas se han utilizado en estudios de niños con TEA, actualmente no se han desarrollado instrumentos publicados para esta población en particular (Hazen, Stornelli, O’Rourke, Koesterer \& McDougle, 2014). 


\subsection{Estudios sobre procesamiento sensorial en TEA que han utilizado el Cuestionario Sensory Profile}

Existen varios instrumentos de evaluación estandarizados para evaluar las dificultades de procesamiento sensorial. Uno de los instrumentos más utilizados en investigación y en el campo de la clínica es el Sensory Profile (Dunn, 1999). En 1997, Dunn propuso un modelo de cuatro tipos de patrones de procesamiento sensorial: sensibilidad sensorial, evitación de sensaciones, bajo registro sensorial y búsqueda de sensaciones. Los dos primeros evaluaban aspectos relacionados con la hipersensibilidad y los dos últimos, aspectos relacionados con la hiposensibilidad. A partir de su modelo, diseña un cuestionario específico que le permitía elaborar un perfil sensorial individual. Este tipo de cuestionario permitía obtener un perfil sensorial individual y bastante detallado de cada niño y se basa en la descripción de conductas observables a partir de la información dada por parte de los adultos. Estaba dirigido a los padres y cuidadores y se consideraba apropiado para evaluar el procesamiento sensorial de niños entre 7 y 12 años de edad. Se han desarrollado otras variaciones del cuestionario, entre las que se incluyen un cuestionario más abreviado el Short Sensory Profile (Dunn, 1999), el Sensory Profile para bebés y niños pequeños (Dunn, 2002a) y el Sensory Profile para adolescentes y adultos (Brown, 2002).

La mayoría de estudios que se han llevado a cabo han comparado los comportamientos de procesamiento sensorial entre niños con y sin autismo. Así, Watling, Deitz \& White (2001) realizaron un estudio para valorar si había diferencias en el procesamiento sensorial y en qué ámbitos, entre niños con autismo y niños con desarrollo típico. Compararon un grupo de 40 niños con autismo y 40 niños con desarrollo típico, de 3 a 6 años de edad. En este estudio se utilizó la versión completa del Sensory Profile (Dunn \& Westman, 1995). El cuestionario constaba de125 ítems y 10 factores, era similar a la versión del cuestionario publicado de Dunn (1999), excepto los cambios gramaticales en la redacción de los ítems. Los 10 factores del Perfil Sensorial son Búsqueda de sensaciones, Reactividad emocional, Baja Resistencia/Tono, Sensibilidad Oral, Inatención/Distractibilidad, Registro pobre, Sensibilidad Sensorial, Inactividad, Psicomotricidad fina $\mathrm{y}$ otros. El resultado principal de este estudio fue que las puntuaciones de los niños con autismo eran significativamente diferentes a las obtenidas por los niños con desarrollo típico en 8 Factores del Perfil Sensorial: Búsqueda de 
sensaciones, Reactividad emocional, Baja Resistencia/Tono, Sensibilidad Oral, Inatención/Distractibilidad, Registro pobre, Psicomotricidad fina y otros. Estos resultados eran consistentes con la literatura publicada sobre el tema, que describe hiposensibilidad e hipersensibilidad a los estímulos sensoriales (factor de Registro pobre), Sensibilidad a los estímulos auditivos y visuales (factor de Sensibilidad sensorial), hábitos alimenticios selectivos (factor de Sensibilidad oral), poca atención y habilidades de juego (factor de Inatención / Distractibilidad), una mala respuesta y variabilidad en las respuestas emocionales (factor de Reactividad emocional), hiperactividad (factor de Búsqueda sensorial) y una variedad de otras respuestas perceptuales anormales, en niños con autismo o retrasos generalizados del desarrollo (Baranek, \& Berkson, 1997; O'Neill \& Jones, 1997; Wing \& Wing, 1971).

Usando medidas fisiológicas junto con la versión corta del Sensory Profile (McIntosh et al., 1999a), Miller et al. (2005) demostraron la existencia de distintos patrones de procesamiento sensorial entre los niños con autismo de alto funcionamiento y el síndrome de Asperger. Cuando examinaron los datos del cuestionario, el análisis factorial reveló tres grupos diferentes de procesamiento sensorial: hiperresponsividad sensorial, hiporresponsividad sensorial y búsqueda sensorial. El análisis preliminar de los autores del informe combinado de los padres y los datos fisiológicos indicaron que puede haber congruencia entre los subgrupos fisiológicos y de comportamiento.

Kern et al. (2006) realizaron un estudio para valorar la mayor incidencia que presentaban las personas con autismo relacionada con la disfunción táctil, oral, auditiva y visual en comparación con un grupo control. Además, también abordaron en el estudio la expresión de tal disfunción sensorial en diferentes edades. De ahí que seleccionaron una muestra de 104 personas con un diagnóstico de autismo, de edades comprendidas entre 3 y 56 años y un grupo control de 104 participantes. Todos los participantes fueron reclutados en siete categorías de edad $(3-7 ; 8-12 ; 13-17 ; 18-22 ; 23-$ $27 ; 28-32 ;$ y $33+$ ) con el fin de asegurar una gama completa de edades y un equilibrio de participantes en las siete categorías. Cada categoría tenía 12 o más participantes. Para cada uno de los 104 participantes del grupo de autismo, se completó el Sensory Profile (Dunn, 1999) y la Escala de Evaluación del Autismo Infantil (CARS: Schopler et al., 1994). Para el grupo de control, sólo se completó el Sensory Profile. Este cuestionario fue completado por un maestro, un entrenador de trabajo o un terapeuta que estaba muy familiarizado con el participante. Para los participantes con autismo, el Sensory Profile 
fue completado por un miembro de la familia. En el grupo control, el cuestionario fue completado por un miembro de la familia si los participantes eran menores de 21 años de edad. Hubo diferencias de grupo significativas en las cuatro modalidades: auditiva, visual, táctil y gusto. En el grupo con autismo, las alteraciones observadas en los cuatro tipos de procesamiento sensorial cambiaron y mejoraron con la edad, obteniendo puntuaciones similares a las obtenidas por los controles de mayor edad. Hubo una interacción significativa en el bajo umbral auditivo y bajo umbral visual, lo que sugiere que los dos grupos cambian de forma diferente sobre estas variables. El grupo con autismo mostró una disminución en la sensibilidad auditiva y visual y el grupo control mostró un aumento en la sensibilidad auditiva y visual con la edad. Estos resultados indicaron que los sujetos con desarrollo típico se vuelven más sensibles a la audición y a la luz con la edad. Muchos informes aportados por los padres en estudios previos mostraban que su hijo tenía más signos de dificultades de procesamiento sensorial cuando eran más jóvenes.

Resultados similares obtuvieron Tomchek \& Dunn (2007), quienes realizaron un estudio para valorar si existían diferencias significativas en el procesamiento sensorial entre un grupo de niños con TEA y un grupo de niños con desarrollo típico y para averiguar qué dominios del procesamiento sensorial eran también significativamente diferentes en el grupo de niños con TEA. Para ello, utilizaron la versión corta del Cuestionario Sensory Profile (McIntosh, Miller \& Shyu, 1999a). Los 7 ámbitos del cuestionario fueron: Sensibilidad Táctil, Sensibilidad al Sabor / Olor, Sensibilidad al Movimiento, Baja Respuesta / Búsqueda de sensaciones, Filtrado Auditivo, Baja Energía y Sensibilidad Visual / Auditiva. Los resultados indicaron que 83,6\% ( $\mathrm{n}=235$ de 281) de los participantes con TEA obtuvieron puntuaciones de diferencia significativa en el procesamiento sensorial en comparación con el 3,2\% ( $n=7$ de 221) en los participantes del grupo control. Las secciones de procesamiento sensorial del cuestionario donde el grupo TEA obtuvo las diferencias fueron: Baja respuesta / Búsqueda de sensaciones $(86.1 \%, \mathrm{n}=242)$, Filtrado auditivo $(77.6 \%, \mathrm{n}=218)$, Sensibilidad táctil $(60.9 \%, \mathrm{n}=171)$ y Sensibilidad al sabor / olor $(54.1 \%, \mathrm{n}=152)$. En los otros factores evaluados, el grupo TEA presentó también porcentajes mayores que el grupo control, pero las diferencias no fueron significativas entre las puntuaciones obtenidas por ambos grupos. La conclusión final del estudio indicaba que el $95 \%$ ( $\mathrm{n}=$ 267) de la muestra de niños con TEA mostró diferencias en el procesamiento sensorial. 
Un estudio piloto australiano realizado por el equipo de Baker, Lane, Angley \& Young, 2008) reveló patrones de deterioro marcado en el procesamiento sensorial en niños con trastorno autista $(n=22)$ usando la versión corta del Cuestionario Sensory Profile (McIntosh, Miller, Shyu \& Dunn, 1999a). Específicamente, se mostraron diferencias definidas en el Filtrado Auditivo y una alta incidencia de comportamiento de Búsqueda sensorial. El rendimiento en el grupo con desarrollo típico indicó mayor puntuación en Sensibilidad Visual / Auditiva y Sensibilidad de Movimiento. Además, las puntuaciones de procesamiento sensorial para esta muestra se agruparon de manera similar a la descrita por el grupo de Miller (2005), un grupo que indica hiperresponsividad sensorial y otro sensorial hiporresponsividad sensorial.

Ashburner, Ziviani y Rodgers (2008), utilizando también la versión corta del mismo cuestionario (McIntosh, Miller, Shyu \& Dunn, 1999a), encontraron que las dificultades presentadas en los factores Sensibilidad táctil, Sensibilidad al movimiento y Filtrado auditivo en niños con ASD estaban asociadas con la falta de atención, la hiperactividad, el comportamiento de oposición y el bajo rendimiento académico.

Lane, Young, Baker \& Angley (2010) realizaron un estudio con el objetivo de describir las dificultades en el procesamiento sensorial dentro del autismo y examinar la relación entre los patrones de dicho procesamiento sensorial en este grupo y el comportamiento adaptativo. Para realizar el estudio, utilizaron la versión corta del Sensory Profile (McIntosh, Miller, Shyu \& Dunn, 1999a) en una muestra de 54 niños con autismo. Los resultados indicaron que la mayoría de los participantes presentaron diferencias significativas respecto al patrón de procesamiento típico en los factores Baja sensibilidad / Busqueda de sensaciones y Filtrado auditivo. Además, los resultados sugirieron que los dominios sensoriales de Filtrado Auditivo, Sensibilidad al Sabor / Olor y Baja Energía podían ser de particular interés en la comprensión del procesamiento sensorial de los niños con autismo. Las alteraciones en el dominio Filtrado auditivo fueron evidentes en el 92,6\% de los participantes. (Ashburner, Ziviani \& Rodgers, 2008; Dunn, Gomes \& Gravel, 2008; Tecchio et al. 2003). El dominio de Baja Energía indicaba la falta de respuesta en los dominios sensoriales vestibular y proprioceptivo, lo que da como resultado la aparición de debilidad, fatiga y estabilidad postural básica deficiente. Los retrasos en la coordinación motora son un posible resultado de la falta de respuesta en los sistemas vestibular y propioceptivo (Miller et al., 2007). La dispraxia y las dificultades en la imitación y en las acciones dirigidas a 
objetivos se han encontrado con frecuencia en otros estudios también con niños con TEA (Dziuk et al., 2007; Piek \& Dyck 2004) y se ha demostrado que están asociados con déficits en la comunicación social (Hilton, Graver \& LaVesser, 2007a; Hilton et al., 2007b). Los resultados sugirieron que tanto la hiperresponsividad sensorial como la hiporresponsividad sensorial pueden coexistir en niños con autismo. Este estudio apoya la opinión predominante en la literatura de que los niños con TEA experimentan diferencias significativas en el patrón de desarrollo del procesamiento sensorial comparado con sus niños neurotípicos.

En otro estudio realizado por el grupo de Lane (2014) realizaron un estudio para examinar si las diferencias sensoriales se podrían utilizar para clasificar subgrupos significativos de niños con trastorno del espectro autista. Para ello, utilizaron una versión corta del cuestionario Sensory Profile, que fue rellenado por los padres. El cuestionario constaba de 38 ítems diseñados para medir los comportamientos asociados con las diferencias en la modulación de estímulos sensoriales ambientales diarios y se utilizó en una muestra amplia de 228 niños de 3 a 10 años (McIntosh, Miller \& Shyu, 1999a). Las puntuaciones obtenidas mostraban siete dominios diferentes de modalidad sensorial: (a) sensibilidad táctil; (B) sensibilidad gustativa/olfativa; (C) sensibilidad al movimiento; (D) sensibilidad visual / sensibilidad auditiva; (E) baja respuesta / búsqueda de sensación; F) filtrado auditivo; y (g) baja energía. Las puntuaciones obtenidas en cada uno de los dominios evaluados se compararon con los datos normativos de 1.200 niños con desarrollo típico. Así, las puntuaciones más altas se relacionaron con un rendimiento más típico, mientras que las más bajas indicaron una diferencia probable o definida en la función sensorial. Los resultados indicaron cuatro subtipos sensoriales distintos: función adaptativa sensorial típica, sensibilidad al sabor y al olor, desatención postural y diferencia sensorial generalizada. Los subtipos sensoriales diferían entre sí en dos dimensiones, por un lado, la gravedad de las diferencias sensoriales reportadas $y$, por otro, el enfoque de las diferencias entre los dominios auditivo, gustativo, olfatorio, vestibular y propioceptivo. Por tanto, propusieron dos posibles mecanismos de alteración sensorial en los TEA: uno, la hiperreactividad sensorial y, otro, las dificultades con el procesamiento multisensorial. En estos resultados no influyeron otras variables como la edad, el sexo, el CI y la gravedad de los síntomas del autismo. La conclusión principal a la que llegó el grupo de Lane fue que la clasificación de los niños utilizando las diferencias sensoriales ofrece un 
método prometedor para identificar los fenotipos en los TEA. Los fenotipos basados en la sensibilidad permiten un examen más sistemático de los perfiles conductuales y de los síntomas y pueden ser más útiles en la identificación de características de comportamiento que responden a intervenciones específicas, mejorando así la eficacia de la intervención.

La propuesta de Lane, Molloy \& Bishop (2014) incorpora y racionaliza la nosología actual de la diferencia sensorial, expresada como: trastorno de la modulación sensorial (hiperreactividad, hiporreactividad y búsqueda de sensaciones), trastorno del movimiento sensorial y trastorno de la discriminación sensorial (Ausderau et al., 2013; Miller, Anzalone, Lane, Cermak, \& Osten, 2007). Además, los resultados de este estudio, y de estudios previos, apoyan la hipótesis de que la reactividad sensorial atípica (hipersensibilidad y / o hipo-reactividad) puede ser un rasgo diferenciador útil en la identificación temprana de TEA en niños pequeños (Lane, Young, Baker \& Angley, 2010; Lane, Dennis \& Geraghty, 2011; Lane, Molloy \& Bishop, 2014).

\subsection{Correlatos clínicos de la disfunción sensorial en TEA}

Gran parte de la literatura reciente relacionada con los síntomas sensoriales en el TEA se ha centrado en la correlación entre éstos y otros síntomas propios del trastorno. Los comportamientos restrictivos y repetitivos son parte de los criterios diagnósticos en DSM-IV y DSM-5, y por lo tanto están presentes en la gran mayoría de personas con autismo. Cuando hablamos de este tipo de comportamientos nos referimos al aleteo de las manos, al balanceo del cuerpo, taparse los ojos y las orejas, la organización de las cosas siguiendo un orden y la insistencia en colocar los elementos en el mismo lugar (Bodfish, Symons, Parker \& Lewis, 2000).

Los niños con TEA tienen más probabilidad de presentar conductas repetitivas si muestran alteraciones en el procesamiento sensoriales (Baker, Lane, Angley \& Young, 2008; Chen, Rodgers \& McConachie, 2009; Gabriels et al., 2008). Así, cuanto más severas son dichas alteraciones sensoriales más conductas repetitivas y restrictivas aparecen (Chen, Rodgers \& McConachie, 2009). Esta relación ha llevado a algunos investigadores a proponer que este tipo de comportamientos tienen un origen sensorial subyacente (Lovaas, Newsom \& Hickman, 1987; Rogers \& Ozonoff, 2005) y la 
evidencia disponible sugiere que tales comportamientos tienen una función autoestimuladora (Cunningham \& Schreibman, 2008). Una revisión reciente de Leekam, Prior \& Uljarevic (2011) sugiere que los comportamientos repetitivos proporcionan estrategias de afrontamiento para que los niños con TEA regulen el nivel de excitación o manejen la ansiedad. En los casos de hiperreactividad, los comportamientos repetitivos pueden ser tranquilizantes, mientras que en los casos de hiporreactividad, los comportamientos repetitivos pueden actuar para aumentar la estimulación sensorial. La disfunción en el procesamiento sensorial en personas con TEA se asocia con niveles más bajos de habilidades adaptativas (Rogers, Hepburn \& Wehner, 2003; Jasmin et al., 2009) y más problemas conductuales (Lane, Young, Baker \& Angley, 2010; Jasmin et al., 2009; O’Donnell, Deitz, Kartin, Nalty \& Dawson, 2012) especialmente cuando presentan disfunción sensorial más severa (Lane, Young, Baker \& Angley, 2010). El grupo de Lane (2010) encontraron que la subescala de Comportamiento Maladaptive Behaviors subscale de Vineland Adaptative Scale (Sparrow, Balla y Cicchetti, 1984) se asoció significativamente con disfunción sensorial severa.

En la última década, una serie de estudios han informado del aumento de la coocurrencia entre el TEA y el TDAH, así como de los sustratos neurobiológicos comunes y similaridades en el perfil neuropsicológico en personas que presentan ambos trastornos (Gargaro, Rinehart, Bradshaw, Tonge \& Shepard, 2011; Rommelse, Geurts, Franke, Buitelaar \& Hartman, 2011). Un porcentaje significativo de niños con TEA presentan síntomas comórbidos de TDAH con tasas que oscilan entre un $37 \%$ y un $85 \%$ (Gadow, DeVincent \& Pomeroy, 2006; Lee \& Ousley, 2006; Rao \& Landa, 2013). Las dificultades de atención que se observan en los niños con TEA tienden a ser muy diferentes de las personas con TDAH. En general, mientras que los niños con TDAH tienen dificultades para mantener la atención en la tarea, los niños con TEA tienen problemas para cambiar la atención (Hazen, Stornelli, O’Rourke, Koesterer \& McDougle, 2014). Esta dificultad para cambiar la atención podría atribuirse a hiposensibilidad a estímulos externos junto con bajos niveles de excitación. Aunque la excitación y la activación sensorial a los estímulos externos son fisiológicamente diferentes, la baja reactividad a menudo coocurre con la baja excitación (Miller, Coll \& Schoen, 2007). 
También se ha encontrado una asociación entre la hiperresponsividad observada en los individuos con TEA y la atención excesiva (Liss, Saulnier, Fein \& Kinsbourne, 2006). En otros estudios se ha encontrado que la hiporresponsividad, la búsqueda de sensaciones y el filtrado auditivo se asociaban comúnmente con dificultades de atención (Ermer \& Dunn, 1998; Watling, Deitz \& White, 2001). Sin embargo, un bajo nivel de activación produce dificultades en la asignación de recursos de atención para el procesamiento de los estímulos ambientales (Schoen, Miller, Brett-Green \& Nielsen, 2009; Schell et al., 2005). Además de las dificultades en el cambio de la atención, algunos niños con TEA tienen dificultades en la atención selectiva. Ésta nos permite determinar qué información del entorno debe ser atendida y qué información debe ser ignorada. Los niños con autismo han demostrado dificultades en la atención selectiva cuando se encuentran en un ambiente sensorial muy estimulante, como por ejemplo, un patio de recreo (Marco, Hinkley, Hill \& Nagarajan, 2011).

Finalmente, a modo de síntesis, añadir que en los últimos años se han llevado a cabo una serie de investigaciones sobre los déficits en el procesamiento sensorial y su relación con el autismo, así como las repercusiones que causan en la vida diaria de las personas que padecen este trastorno, agravando los síntomas del mismo. Se ha podido demostrar que las alteraciones en el procesamiento sensorial se dan en un porcentaje alto de personas con TEA (70-80\%), se manifiestan desde edades muy tempranas y provocan que los aprendizajes que deben realizar a partir de sus experiencias cotidianas no sean ni adecuados ni suficientes para establecer de forma apropiada relaciones interpersonales, además dificultan la integración en su entorno social. Las personas con TEA no sólo tienen este tipo de dificultades sensoriales, también tienen problemas para integrar la información que procede de diferentes sistemas sensoriales. Estos déficits en la integración sensorial afectan de forma considerable al desarrollo del lenguaje y de la comunicación. Según los resultados aportados por diferentes estudios, las dificultades tanto en el procesamiento sensorial como en la integración de la información de varios sistemas sensoriales podrían generar mayor número de comportamientos restrictivos y repetitivos, menos habilidades adaptativas y más problemas conductuales, dificultades para cambiar el foco de atención o bien mostrar una atención excesiva hacia un estímulo concreto. 


\section{III- PLANTEAMIENTO EXPERIMENTAL Y OBJETIVOS}

El desarrollo del cerebro humano empieza ya en la vida prenatal y continúa desarrollándose de manera sorprendente durante los primeros años de vida. Esta etapa es fundamental y crítica ya que una maduración cerebral adecuada acompañada de un ambiente favorable y enriquecedor va a permitir la adquisición y el desarrollo progresivo de funciones cognitivas de orden superior. Datos extraídos de una variedad amplia de estudios sobre el tema indican que el volumen cerebral total sigue una trayectoria de crecimiento en forma de $U$ invertida, al igual que el volumen total cerebral de SG que sigue una trayectoria similar. Sin embargo, el volumen de SB sigue una trayectoria casi lineal a lo largo de las dos primeras décadas de vida (Lenroot et al., 2007; Gogtay et al., 2004). Cualquier tipo de alteración en estos patrones de desarrollo cerebral pueden provocar la aparición de un trastorno del neurodesarrollo.

El estudio del desarrollo cerebral típico en la etapa infantil se ha centrado en temas como la plasticidad cerebral, la sinaptogénesis, los procesos de mielinización, el desarrollo de estructuras corticales y de estructuras subcorticales (Matsui et al., 2016). Una serie de mecanismos cerebrales básicos van a permitir que el sistema nervioso se forme a partir de la experiencia durante la infancia. La plasticidad cerebral es un mecanismo importante que facilita al cerebro en desarrollo una adaptación adecuada ante las demandas del entorno (Lau \& Zukin, 2007). Durante los dos primeros años de vida, las conexiones entre las neuronas se multiplican rápidamente gracias a la sinaptogénesis, posteriormente le sigue un proceso de poda sináptica que va a permitir una mayor especialización en la sinapsis además de lograr un funcionamiento cerebral más eficiente (O’Hearn, Asato, Ordaz \& Luna, 2008). A lo largo del desarrollo diferentes partes del cerebro sufrirán este proceso. Respecto al proceso de mielinización, estudios volumétricos de RM indican un aumento constante del volumen de la SB desde la primera infancia hasta la edad adulta con tasas similares en los diferentes lóbulos cerebrales (Giedd et al., 1999).

Durante la infancia tardía y la adolescencia, en el desarrollo cerebral se produce una disminución de SG y un aumento de SB. Así, el volumen cortical total crece durante la infancia y empieza a disminuir a partir de los 12 años, el grosor cortical disminuye linealmente en todas las regiones corticales y la superficie cortical varía de forma lineal con la edad, aumentando en todas las regiones. 
Los resultados que aparecen en estudios centrados en el desarrollo de estructuras subcorticales indican que el volumen de la SG muestra diferentes trayectorias de desarrollo, de manera que estructuras como el tálamo, el núcleo caudado y el putamen disminuyen su volumen con la edad, mientras que el hipocampo y la amígdala presenta más bien una trayectoria en forma de $U$ invertida (aunque con los cambios más relevantes en los primeros 5 años de vida) y el cerebelo presenta una trayectoria de desarrollo más compleja, con tendencia lineal o cuadrática dependiendo de los lóbulos (Sussman, Leung, Chakravarty, Lerch \& Taylor, 2016).

En la última década, los conocimientos aportados por los estudios sobre la trayectoria de desarrollo típico en el cerebro infantil han incrementado considerablemente el interés por comprender y abordar los trastornos del neurodesarrollo, especialmente por el estudio de los TEA. Desde el campo de las neurociencias, más concretamente desde la neuroimagen estructural y funcional, se han aportado interesantes conocimientos sobre las bases neurobiológicas del autismo. Las evidencias aportadas en la literatura publicada sobre el tema indican que las personas con autismo presentan una trayectoria de crecimiento cerebral atípica relacionada con la edad, que se puede apreciar prácticamente desde edades muy tempranas a partir del crecimiento acelerado del cerebro que se inicia a partir del primer año de vida, seguido de un período de crecimiento acelerado que continúa durante la primera infancia hasta la adolescencia para después lograr un tamaño cerebral cercano al del adulto más pronto que el grupo con desarrollo típico (Courchesne et al., 2001, 2003; Dementieva et al. 2005; Hazlett et al., 2005; Dawson et al., 2007; Amaral, Schumann \& Nordahl, 2008). Posiblemente este aumento se debe a varios mecanismos como la neurogénesis, retraso en la poda sináptica y la muerte celular programada, o la migración inapropiada de las neuronas (Courchesne et al., 2001; Bauman \& Kemper, 2005; Kelly et al., 2009).

Los niños con autismo han mostrado diferencias en el desarrollo cerebral a nivel cortical, subcortical y cerebelar, áreas cerebrales claves que están implicadas en el desarrollo de funciones cognitivas de orden superior como son la cognición y comunicación social, y el desarrollo de las emociones. Estas alteraciones están relacionadas con los síntomas clínicos principales que podemos observar en este trastorno: déficits en la interacción y en la comunicación social, intereses restringidos y conductas repetitivas. Respecto a las alteraciones observadas en estructuras subcorticales como el sistema límbico (amígdala e hipocampo), los ganglios basales 
(caudado y putamen) y el tálamo, cabe decir que también siguen una trayectoria de desarrollo atípica en los TEA. Hay una serie de resultados consistentes que también aparecen publicados indicando que el patrón de crecimiento de la amígdala se acelera antes de los 2 años de edad en el autismo, se mantiene durante la primera infancia para posteriormente producirse una normalización de los volúmenes de la misma en la última infancia y en la adolescencia (Mosconi et al., 2009; Barnea-Goraly et al., 2014). Resultados similares se obtuvieron en el estudio del hipocampo, indicando que los niños con TEA presentaban mayor volumen al compararlos con niños neurotípicos. Las disfunciones de estas estructuras cerebrales se han relacionado con la cognición social, la percepción de la dirección de la mirada y la emoción (Conty \& Grezes, 2012; Fanselow \& Dong, 2010). En relación con los ganglios basales, la trayectoria de crecimiento del estriado ha sido la más abordada y los resultados han indicado que también sigue un desarrollo atípico, presentando mayor volumen el núcleo caudado. Este rápido crecimiento estriatal se relacionó con un comportamiento repetitivo más severo (insistencia en la igualdad y uniformidad) en la edad preescolar (Langen et al., 2014). Las disfunciones de los ganglios basales podrían relacionarse con la aparición de conductas repetitivas.

La corteza prefrontal ha sido otra región del cerebro que ha recibido considerable atención en los últimos años, especialmente la corteza prefrontal medial y la lateral. Las principales aportaciones sobre el tema incluyen patrones de crecimiento cortical atípicos, alteraciones en el grosor cortical y desorganización de las neuronas a través de las capas corticales y sus conexiones con otras regiones del cerebro (Donovan \& Basson, 2016). Se sabe que esta región cerebral está implicada frecuentemente en tareas de ToM. Así, el área del córtex prefrontal ventromedial conecta directamente con la amígdala y otras áreas límbicas cuando se procesan aspectos emocionales y motivacionales. La corteza prefrontal medial también está vinculada con el circuito de la empatía y se encarga del procesamiento de la información social y de comparar nuestra propia perspectiva con la de los demás. Estos niños también presentaban morfología cerebral atípica en las regiones que intervienen en las funciones ejecutivas (córtex prefrontal lateral). Los estudios realizados con esta población infantil indican que presentan peor rendimiento en un amplio rango de tareas que miden las funciones ejecutivas, al compararlos con un grupo control: memoria de trabajo, control inhibitorio, flexibilidad al cambio y vigilancia (Just, Cherkassky, Keller, Kana \& Minshew 2007; Khosino et al., 2005, 2008). 
Los estudios de la estructura cerebral en el autismo, además de proporcionar suficientes pruebas de alteraciones en el desarrollo de la corteza cerebral y de las estructuras subcorticales, también han aportado una serie de datos relacionados con alteraciones en el cerebelo (O’Hearn, Asato, Ordaz \& Luna, 2008). Uno de los datos más establecidos acerca del cerebelo es su implicación en la propiocepción y en el control motor fino. Estudios recientes también implican fuertemente al cerebelo en funciones cognitivas de orden superior como el lenguaje, el procesamiento cognitivo y la regulación afectiva (Basson \& Wingate, 2013; Becker \& Stoodley, 2013).

Todas las alteraciones en el desarrollo cerebral de los niños y adolescentes descritas anteriormente están implicadas en los déficits nucleares propios del TEA. Así, se ha observado a menudo que tienen dificultades en el desarrollo adecuado de las habilidades relacionadas con la cognición social, aspecto que dificulta su integración en distintos ambientes sociales, generándoles problemas de funcionamiento en el entorno familiar, en la escuela, en el lugar de trabajo y con los amigos (Baron-Cohen, Leslie \& Frith, 1985; Hamilton, Hoogenhout \& Malcolm-Smith, 2016). La ToM es una habilidad que se desarrolla de forma gradual desde la infancia y es un proceso largo. Es fundamental para desarrollar habilidades socio-comunicativas y para lograr con éxito una integración social apropiada. Se trata de una serie de destrezas que están presentes desde tan sólo 14 meses y se desarrollan durante toda la infancia (Low \& Perner, 2012; Wellman \& Liu, 2004). La ToM fue la primera explicación sobre los mecanismos cognitivos subyacentes a varios comportamientos clave que definen el autismo. La abundante literatura publicada sobre el tema confirma que la mayoría de los niños que presentan este trastorno muestran dificultades en el desarrollo de estas habilidades mentalistas y tales dificultades están relacionadas con un comportamiento social desajustado e importantes déficits en las habilidades de comunicación social.

Finalmente, cabe señalar que los niños y adolescentes con trastornos del espectro autista responden a las experiencias sensoriales de manera diferente a la población de su misma edad con desarrollo típico. Los problemas sensoriales, además de ejercer un impacto considerable en la configuración del trastorno, también influye directamente en la vida cotidiana de las personas con TEA, generando alteraciones considerables en su funcionamiento diario y agravando los síntomas que acompañan al trastorno. (Costa \& Lampreia, 2012). A partir de los estudios realizados, se ha podido demostrar que las alteraciones en el procesamiento sensorial se dan en un porcentaje alto de personas con 
TEA (70-80\%), se manifiestan desde edades muy tempranas y prácticamente se desvanecen en la vida adulta. Entre los síntomas sensoriales más comunes observados y estudiados en el TEA están los trastornos de la modulación sensorial, que pueden definirse como respuestas anormales a los estímulos sensoriales que conducen al deterioro funcional (Miller, Anzalone, Lane, Cermak \& Osten, 2007). Los patrones de comportamiento, intereses y actividades restringidos y repetitivos propios del TEA se pueden explicar mejor a partir de los déficits sensoriales que presentan.

Los objetivos generales del presente estudio son los siguientes:

1. Confirmar la presencia de alteraciones estructurales en el TEA en regiones frontales, temporales, límbicas y subcorticales en la etapa de la niñez tardía.

2. Relacionar las alteraciones cerebrales encontradas con las características nucleares del TEA.

3. Analizar las relaciones existentes entre una serie de variables neuropsicológicas utilizadas en el estudio y las áreas y regiones que presentan una trayectoria de crecimiento atípica.

4. Establecer un modelo general de retraso en el desarrollo cerebral de niños con TEA. 


\section{IV-METODOLOGÍA}

Empezaremos describiendo las características principales de la muestra utilizada junto con los criterios usados en la selección de los sujetos participantes. Posteriormente, explicaremos qué medidas hemos empleado y el procedimiento (diseño) que hemos seguido

\section{1- PARTICIPANTES}

En el presente estudio se reclutaron 39 niños con TEA (32 varones y 7 mujeres) y 25 controles con desarrollo típico (17 varones y 8 mujeres), con un rango de edad de 8 a 12 años. Los niños con TEA fueron reclutados en la Asociación Asperger de Castellón y la Asociación Asperger de Valencia, mientras que los niños del grupo control proceden de diferentes centros escolares de Castellón. Para determinar los participantes de la muestra de niños con TEA, se tuvo en cuenta tres criterios de exclusión:

1. Tener un CI total inferior a 80;

2. Tener un trastorno genético asociado al TEA (Síndrome X Frágil, Esclerosis tuberosa,..) u otra condición médica que afecte a la función cerebral (p.e., epilepsia);

3. Llevar algún tipo de prótesis dental metálica.

La mayoría de los diagnósticos fueron realizados en centros privados a partir de los criterios del DSM-IV-TR (diagnósticos realizados antes de la publicación de la nueva edición del DSM) y del DSM-5. Como herramientas diagnósticas, se utilizaron el ADOS, Autism Diagnostic Observation Schedule (Lord, Rutter, DiLavore \& Risi, 1999) y el ADI-R, Autism Diagnostic Interview, Revised, (Rutter, LeCouteur \& Lord, 2003). Los criterios diagnósticos del DSM-5 aparecerán en el punto siguiente. Los diagnósticos fueron realizados por profesionales expertos en el diagnóstico de trastornos del neurodesarrollo con más de 30 años de experiencia en el manejo de instrumentos de evaluación clínica y neuropsicológica. 
Los criterios de exclusión para el grupo control serían:

1. Tener un CI inferior a 80 .

2. Presentar algún tipo de problema neurológico (p.e., epilepsia, ...)

3. Presentar antecedentes familiares relacionados con el Espectro autista

4. Llevar prótesis dental.

Ambos grupos no difirieron en las variables de edad, género y dominancia manual, encontrándose diferencias en cuanto a CI (Ver Tabla 5).

La muestra final fue de 39 participantes con TEA y 25 niños en el grupo control. De los 39 niños del primer grupo, sólo 24 realizaron con éxito las pruebas de RM (5 no consiguen hacer la prueba porque se asustaron al ver el escáner y decidieron abandonar y 10 no se incluyeron por exceso de movimiento durante la realización de las RM). Del grupo control, 24 niños realizan con éxito la RM y 1 niño no puede participar porque se detectó un quiste en el cerebro. Los análisis mostrados en la sección de resultados neuropsicológicos y de neuroimagen sólo se refieren a los niños que completaron la prueba.

Respecto al grupo con TEA, un total de 19 participantes presentaban además un TDAH, de los cuales 13 seguían tratamiento farmacológico: 12 seguían tratamiento con metilfenidato (3 además tomaban risperidona) y 1 niño solo tomaba atomoxetina. Dentro de este grupo, 19 niños presentaban otro trastorno del neurodesarrollo (TDAH, equivalente a 79\%) y 5 niños presentaban dos trastornos del neurodesarrollo: TDAH y Trastorno Específico del Aprendizaje (lectura y expresión escrita) (equivalente a un $21 \%)$. 
Tabla 5. Datos de todos los participantes en el estudio.

\begin{tabular}{|c|c|c|c|c|c|}
\hline & $\begin{array}{l}\text { Niños TEA } \\
\qquad(n=24)\end{array}$ & $\begin{array}{l}\text { Niños DT } \\
(n=24)\end{array}$ & $t$ & $p$ & $\mathbf{X}^{2}$ \\
\hline \multirow[t]{2}{*}{ Edad (años) } & $10,29 \pm 1,70$ & $10,19 \pm 1,47$ & & & \\
\hline & (8-12 años) & (8-12 años) &,- 21 &, 834 & \\
\hline \multicolumn{6}{|l|}{ Género } \\
\hline Niños & 18 & 16 & & & 8,333 \\
\hline Niñas & 6 & 8 & & & \\
\hline CIT & $98,21 \pm 14,77$ & $114,63 \pm 13,98$ & 3,96 &, $000 * *$ & \\
\hline \multicolumn{6}{|c|}{ Dominancia manual } \\
\hline Diestros & 20 & 24 & & & 33,333 \\
\hline Zurdos & 4 & 0 & & & \\
\hline
\end{tabular}

Los valores de $X^{2}$ no son significativos. 


\section{2- CRITERIOS DIAGNÓSTICOS DEL MANUAL DIAGNÓSTICO Y ESTADÍSTICO DE LOS TRASTORNOS MENTALES, QUINTA EDICIÓN (DSM-5)}

\section{Trastorno del espectro del autismo, 299.00 (F84.0)}

A. Déficits persistentes en la comunicación social y en la interacción social en diversos contextos, manifestados por los siguientes síntomas, actualmente o por los antecedentes (los ejemplos son ilustrativos pero no exhaustivos):

1. Déficits en reciprocidad socio-emocional; varían, por ejemplo, desde un acercamiento social inusual y fracaso para mantener una conversación recíproca; una conducta reducida a la hora de compartir intereses, emociones y afectos; un fracaso para iniciar o responder a interacciones sociales.

2. Déficits en conductas comunicativas no verbales utilizadas en la interacción social; varían, por ejemplo, desde una comunicación verbal y no verbal poco integrada pasando por alteraciones del contacto visual y del lenguaje corporal o déficits en la comprensión y el uso de gestos, hasta una falta total de expresión facial y de comunicación no verbal.

3. Déficits en el desarrollo, mantenimiento y comprensión de las relaciones, varían, por ejemplo, desde dificultades para ajustar el comportamiento en diversos contextos sociales pasando por dificultades para compartir juegos imaginativos o para hacer amigos, hasta la ausencia de interés por otras personas.

\section{Especificar la gravedad actual:}

La gravedad se basa en deterioros de la comunicación social y en patrones de comportamiento restringidos y repetitivos (Véase Tabla 2 que aparece en el marco teórico)

B. Patrones restringidos y repetitivos de comportamiento, intereses o actividades, que se manifiestan en dos o más de los siguientes puntos, actualmente o por los antecedentes (los ejemplos son ilustrativos pero no exhaustivos): 
1. Movimientos, utilización de objetos o habla estereotipados o repetitivos (por ejemplo, estereotipias motoras simples, alineación de los juguetes o cambio de lugar de los objetos, ecolalia, frases idiosincrásicas).

2. Insistencia en la monotonía, excesiva inflexibilidad de rutinas o patrones ritualizados de comportamiento verbal o no verbal (por ejemplo, gran angustia frente a pequeños cambios, dificultades con las transiciones, patrones de pensamiento rígidos, rituales de saludo, necesidad de tomar el mismo camino o de comer los mismos alimentos cada día).

3. Intereses muy restringidos y fijos que son inusuales en cuanto a su intensidad o foco de interés (por ejemplo, fuerte apego o preocupación por objetos inusuales, intereses excesivamente circunscritos o perseverantes).

4. Hiper- o hipo-reactividad a los estímulos sensoriales o interés inhabitual por aspectos sensoriales del entorno (por ejemplo, indiferencia aparente al dolor/temperatura, respuesta adversa a sonidos o texturas específicos, olfateo o palpación excesiva de objetos, fascinación visual por las luces o el movimiento).

\section{Especificar la gravedad actual:}

La gravedad se basa en deterioros de la comunicación social y en patrones de comportamientos restringidos repetitivos (Véase Tabla 2 que aparece en el marco teórico).

C. Los síntomas han de estar presentes en las primeras fases del período de desarrollo temprano (pero pueden no manifestarse totalmente hasta que la demanda social supera las capacidades del niño, o pueden estar enmascarados por estrategias aprendidas en fases posteriores de la vida).

D. Los síntomas causan un deterioro clínicamente significativo a nivel social, laboral o en otras áreas importantes del funcionamiento habitual.

E. Estas alteraciones no se explican mejor por la presencia de una discapacidad intelectual (trastorno del desarrollo intelectual) o por un retraso global del desarrollo. La discapacidad intelectual y el trastorno del espectro del autismo con frecuencia coinciden; para hacer diagnósticos de comorbilidades de un trastorno del espectro de autismo y discapacidad intelectual, la comunicación social ha de estar por debajo de lo previsto para el nivel general de desarrollo. 


\section{3- DESCRIPCIÓN DE LAS VARIABLES NEUROPSICOLÓGICAS}

Todos los participantes realizan pruebas de inteligencia y una serie de test neuropsicológicos.

\subsection{Inteligencia: Wechsler Intelligence Scale for Children (Wechsler, 2005)}

Se valora a partir de la Escala de Inteligencia Wechsler para Niños- WISC-IV (Wechsler Intelligence Scale for Children, Fourth Edition WISC-IV, Wechsler, 2005, última revisión del test en su adaptación española). Evalúa la capacidad cognitiva global y cuatro dominios específicos de la inteligencia, cuyos coeficientes de fiabilidad por grupos de edad, en la adaptación española, son los indicados en la Tabla 6. Esta batería de pruebas se organiza en cuatro índices que representan habilidades intelectuales generales, dos de ellos evalúan la inteligencia general verbal (Comprensión Verbal) y la no verbal (Razonamiento Perceptivo) y los otros dos índices evalúan habilidades de procesamiento cognitivo (Memoria de Trabajo y Velocidad de procesamiento).

El índice de Comprensión Verbal está formado por tres subpruebas:

1. Semejanzas: evalúa las capacidades de formación de conceptos, de razonamiento verbal abstracto y pensamiento lógico así como la distinción de características esenciales y secundarias. Consta de 23 ítems que se puntúan dependiendo de la respuesta con 0, 1, 2 puntos (excepto los dos primeros ítems que solo se pueden puntuar con 0,1$)$. La puntuación máxima es de 44. Se finaliza la prueba con 5 puntuaciones consecutivas de 0 .

2. Vocabulario: evalúa el nivel de desarrollo del lenguaje, el conocimiento léxico, la expresión verbal y el bagaje de conocimientos. Consta de 36 ítems, que también tiene tres posibles puntuaciones dependiendo de la respuesta $(0$, 1, 2 puntos; excepto los cuatro primeros ítems que solo tienen dos puntuaciones 0,1$)$. La puntuación máxima es 68 . Se finaliza la prueba con 5 puntuaciones consecutivas de 0 .

3. Comprensión: evalúa la capacidad de razonamiento, de juicio social y de conocimiento de normas de conducta convencionales para resolver problemas cotidianos. Consta de 21 ítems, todos ellos con tres posibles puntuaciones $(0,1,2$ puntos). La puntuación máxima es de 42 puntos. Se 
finaliza la prueba con 4 puntuaciones consecutivas de 0 o bien con 4 puntuaciones de 0 en 5 items consecutivos.

El índice de Razonamiento Perceptivo está formado también por tres subpruebas:

1. Cubos: evalúa la capacidad de comprender la integración espacial, de organizar y la planificar el espacio así como la coordinación visomotora durante un intervalo de tiempo dado. Consta de 14 ítems que van a tener puntuaciones diferentes dependiendo del tiempo invertido en la realización de cada uno. Los tres primeros ítems tienen puntuaciones de 0, 1, 2 puntos; los 5 siguientes pueden puntuar 0 o 4 puntos y los 6 últimos tienen puntuaciones que van desde 4 hasta 7 puntos dependiendo del tiempo de ejecución y 0 puntos si no lo realiza bien o en el tiempo exigido. La puntuación máxima es de 68 puntos. Se finaliza la prueba con 3 puntuaciones consecutivas de 0 .

2. Conceptos: evalúa la capacidad de razonamiento abstracto y de formación de categorías a partir de material visual. Consta de 28 ítems que se puntúan con 1 si la respuesta es correcta o con 0 si es incorrecta. La puntuación máxima es de 28 puntos. Se finaliza la prueba con 5 puntuaciones consecutivas de 0.

3. Matrices: evalúa la capacidad de razonamiento por analogías visuales e implica integración de información visual. Consta de 35 ítems que se puntúan con 1 punto si la respuesta es correcta o con 0 si no lo es. La puntuación máxima es de 35 puntos. Se finaliza la prueba con 4 puntuaciones consecutivas de 0 o bien 4 puntuaciones de 0 en cinco ítems consecutivos.

El índice de Memoria de Trabajo está formado por dos subpruebas:

1. Dígitos: evalúa la capacidad de memoria auditiva inmediata, la memoria secuencial, la atención y la flexibilidad cognitiva. Se evalúan dígitos en orden directo y dígitos en orden inverso. Consta de 8 ítems en orden directo y 8 en orden inverso (cada ítem tiene dos elementos) que se van a puntuar con 1 punto si se realiza correctamente o con 0 puntos si fallan. La puntuación máxima es de 32 puntos. Se finaliza la prueba con dos puntuaciones consecutivas de 0 en los dos elementos del mismo ítem. 
2. Letras y Números: evalúa la capacidad de retener y combinar dos tipos de información para organizarla de acuerdo con unas consignas. Consta de 10 ítems y cada uno de ellos tiene tres elementos. Se puntúa cada elemento con 1 punto si se realiza correctamente o 0 puntos en caso contrario. La puntuación máxima es de 30 puntos. Se finaliza la prueba con tres puntuaciones consecutivas de 0 puntos si son los tres elementos de un mismo ítem.

El índice de Velocidad de Procesamiento está formado por dos subpruebas:

1. Claves: evalúa la destreza visomotora, la velocidad y precisión ante una tarea de copiar figuras simples, memoria visual a corto plazo. La puntuación de esta prueba va a depender del número de símbolos que copian en el tiempo dado ( 2 minutos), por cada símbolo bien copiado se concede 1 punto. La prueba se finaliza cuando se ha acabado el tiempo o si el niño termina antes de copiarlos todos.

2. Búsqueda de símbolos: evalúa la coordinación visomotora y la rapidez asociativa, la discriminación visual, la concentración y la resistencia ante una tarea repetitiva. La prueba consta de 60 ítems y se concede 1 punto por cada uno bien resuelto y 0 puntos si no es correcto. La puntuación máxima es de 60 puntos. Se finaliza la prueba cuando han transcurrido los 2 minutos de tiempo o si el niño ha terminado antes.

Tabla 6. Coeficientes de fiabilidad (consistencia interna) de los índices de las pruebas de inteligencia.

\begin{tabular}{l|c}
\hline & Promedio \\
\hline Índice Comprensión Verbal (CV) & $\mathbf{9 2}$ \\
Índice Razonamiento Perceptivo (RP) & $\mathbf{9 1}$ \\
Índice Memoria trabajo (MT) & $\mathbf{, 8 9}$ \\
Índice velocidad procesamiento (VP) & $\mathbf{, 8 6}$ \\
\hline CI Total (CIT) & $\mathbf{9 5}$ \\
\hline
\end{tabular}




\subsection{Teoría de la Mente}

El término Teoría de la Mente (ToM), tal y como se ha explicado en el marco teórico de este estudio, se refiere a la capacidad de atribuir pensamientos e intenciones a otras personas, de comprender sus intenciones, sus pensamientos, sus creencias,...En nuestra investigación, utilizamos diferentes tareas para evaluar dicha capacidad. Las pruebas utilizadas han sido seleccionadas porque en publicaciones aportadas en estudios previos han demostrado ser eficaces a la hora de evaluar las habilidades implicadas en el desarrollo de la ToM. A continuación, se realiza una breve descripción siguiendo el orden utilizado en la evaluación. En la Tabla 7 aparece un resumen de las diferentes pruebas que se han utilizado en esta parte de la evaluación.

Tabla 7. Resumen de las diferentes tareas que evalúan aspectos relacionados con la cognición social (Teoría de la Mente).

\section{Tareas}

ToM -1 $\quad$ Test de la Mirada para niños (Baron-Cohen et al., 2001)

ToM -2 $\mathbf{2}^{\mathbf{a}} \quad$ Historias de Meteduras de pata (Faux Pas Recognition Test) de Baron-Cohen et al., 1999: Historia del avión e Historia del pastel (version adaptada de Serrano, 2012).

ToM - $\mathbf{3}^{\mathbf{a}} \quad$ Falsas Creencias de $2^{\circ}$ Orden: Historia del heladero ( Perner \& Wimmer 1985) e Historia de los hermanos y la tableta de chocolate (Sullivan et al., 1994)

ToM $\mathbf{~ - 4}^{\mathbf{a}} \quad$ Historias Extrañas (Happé, 1994): Mentira piadosa, El malentendido, Emociones contrarias y Forma de hablar. 


\subsubsection{Test de la Mirada (Baron-Cohen et al., 2001)}

Utilizamos la versión infantil del Test de la Mirada o Test de la lectura de los ojos (Baron-Cohen et al., 2001b) para valorar la habilidad de identificar una emoción a partir de una expresión determinada (empatía) en todos los niños que participan en el presente estudio. Empleamos la versión infantil que consta de 28 fotografías para niños en las que se observan las miradas de hombres y mujeres que expresan un pensamiento o una emoción. Cada fotografía tiene cuatro posibles respuestas y el niño debe elegir una de ellas, un ejemplo se puede observar en la Figura 10.

La tarea se realiza siguiendo las instrucciones establecidas por los autores. Se inicia mostrando una fotografía de prueba con cuatro palabras alrededor, se le pide al niño que mire atentamente la fotografía (previamente, le pedimos que diga si cree que es un hombre o una mujer, así conseguimos que se fije más y centre la atención en la tarea), se leen las palabras en voz alta y se le pide que elija qué palabra describe mejor lo que esa persona está pensando o sintiendo. A partir de aquí, se pasan las 28 fotos de la prueba de la misma forma. Se refuerzan todas las respuestas, sean o no correctas.

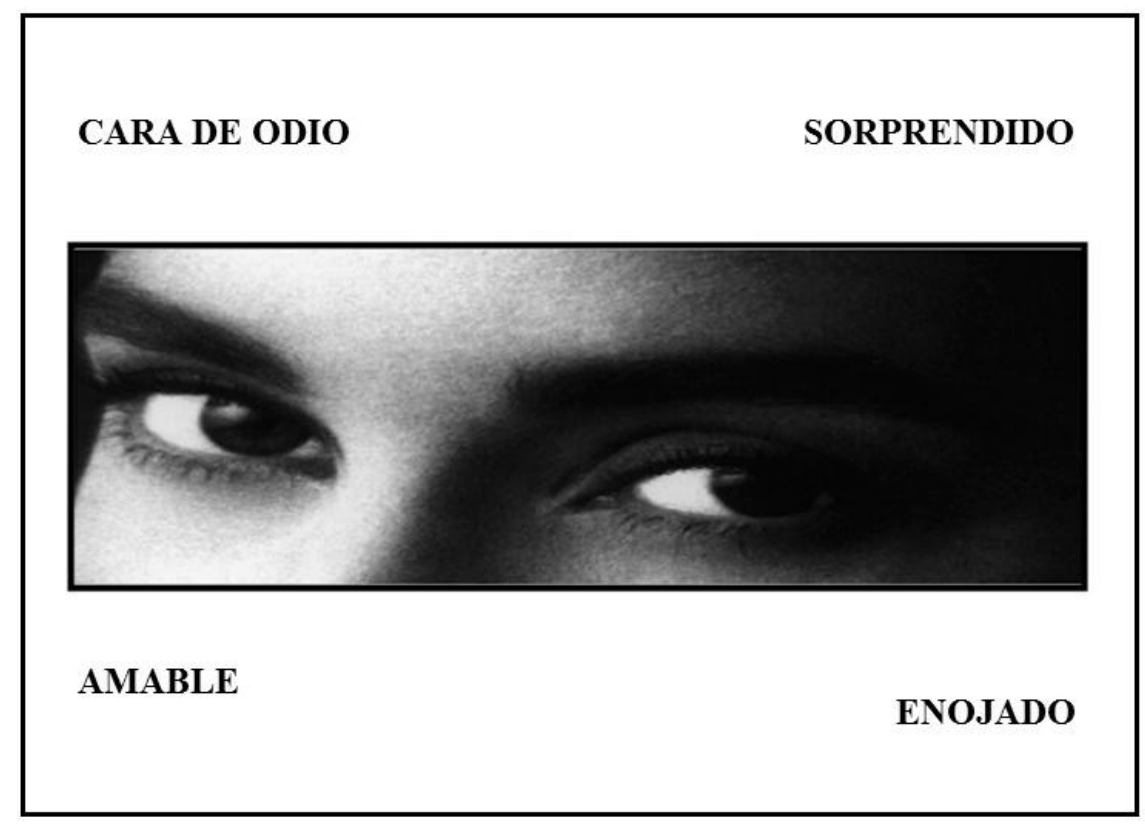

Figura 10. Test de la Mirada para niños (Baron-Cohen et al., 2001) 


\subsubsection{Historias Meteduras de pata (Baron-Cohen et al., 1999)}

Otra tarea que incluimos en nuestra evaluación de la ToM es la comprensión de meteduras de pata (Faux pas Recognition Test, Baron-Cohen et al., 1999b), con el objetivo de valorar aspectos más complejos en el desarrollo de la ToM así como para obtener una medida de la sensibilidad social. De las 10 historias propuestas por BaronCohen y su equipo en las que el protagonista mete la pata, elegimos dos historias extraídas de la tesis doctoral de Jéssica Serrano Ortiz (Serrano, 2012) y adaptadas por ella.

El procedimiento seguido con las dos historias es el siguiente: se lee al niño una historia despacio y tranquilamente en la que participan dos personas y se realizan 7 preguntas. Las tres primeras preguntas están relacionadas con la identificación y detección de la metedura de pata: “AAlguien ha dicho alguna cosa que no debería haber dicho?”, “¿Quién ha dicho alguna cosa que no debería haber dicho?” y “¿Qué ha dicho que no debería haber dicho?”. (Ver Figura 11).

Martina regaló un avión a Albert por su cumpleaños. Meses más tarde, Martina y Albert están jugando con el avión y sin querer Martina lo rompe. "Lo siento", dijo Martina. Y Albert le dijo: "No te preocupes. Nunca me ha gustado este avión. Alguien me lo regaló para mi cumpleaños".

- ¿Alguien ha dicho alguna cosa que no debería haber dicho o alguna cosa inoportuna?

- ¿Quién ha dicho alguna cosa que no debería haber dicho?

- ¿Qué ha dicho alguna cosa que no debería haber dicho?

- ¿Quería Albert hacer sentirse mal a Martina?

- ¿Cómo se sintió Martina?

- ¿Qué regaló Martina a Albert por su cumpleaños?

- ¿Albert se acordó que Martina le había regalado el avión?

Figura 11. Historias de Meteduras de pata (Faux Pas Recognition, Baron-Cohen, 1999). Adaptada por Serrano, (2012). 
A continuación, se realiza una pregunta para que valore la intención del protagonista y otra pregunta para valorar el estado emocional del otro protagonista. Finalmente, se realizan dos preguntas de control para comprobar si el niño ha entendido realmente la historia.

La forma de puntuar las historias se realiza siguiendo las mismas pautas de Serrano (2012), es decir, otorgando un punto por cada respuesta correcta en las tres primeras preguntas relacionadas con la identificación de las meteduras de pata y dando dos puntos más si contestaban correctamente las dos preguntas siguientes, intención del protagonista principal y estado de ánimo del otro protagonista.

\subsubsection{Falsas Creencias de $2^{\circ}$ Orden (Perner \& Wimmer, 1985; Sullivan et al., 1994).}

Las tareas de creencias falsas ocupan un lugar central en la investigación de ToM. Existen dos tipos de tareas de creencias falsas, las de primer orden que hacen referencia al conocimiento que el niño tiene de los estados mentales del personaje de una historia y las tareas de segundo orden, con mayor complejidad, que hacen referencia al conocimiento que el niño tiene sobre los estados mentales de un personaje de la historia en relación a los estados mentales de un segundo personaje implicado en la narración.

En estas tareas se pone de relieve la habilidad de los niños para atribuir falsas creencias a distintas personas en una interacción social, distinguiendo que cada persona puede tener estados mentales distintos unos de otros y esos estados son diferentes a los suyos.

Seleccionamos dos historias para evaluar la capacidad de pensar sobre los pensamientos de una persona sobre una tercera, es decir, "mentalizar". Una es la historia clásica de María, Juan y el heladero diseñada por Perner y Wimmer (1985) y la otra es la tarea de Los hermanos y la tableta de chocolate (Sullivan et al., 1994). La primera tarea es algo más compleja porque intervienen más personajes en la historia. En ambas tareas se van mostrando unas tarjetas realizadas en blanco y negro a medida que se les va leyendo la historia, cinco tarjetas en la primera y cuatro tarjetas en la segunda. Las 5 tarjetas de la primera historia han sido elaboradas y adaptadas por la autora del presente estudio. 
El procedimiento es el siguiente: se muestra la primera tarjeta donde se presentan a Juan y María sentados en un parque y donde acaba de llegar la furgoneta de los helados. A continuación, como no llevan dinero, María decide ir a su casa a por la cartera (segunda tarjeta) porque el heladero le ha dicho que la espera en el parque. Mientras se marcha, el heladero arranca la furgoneta para cambiar de lugar (tercera tarjeta) y Juan se acerca a preguntarle dónde va, a lo que responde el heladero que como no hay gente en el parque, se va a la zona de la iglesia. Cuando el heladero va hacia la iglesia, María lo ve desde la puerta de su casa (cuarta tarjeta) y le pregunta a dónde va. De modo que ella también sabe dónde estará el heladero. Juan va a buscar a María a su casa y no sabe que ella ha hablado con el heladero. Finalmente, la madre de María le dice a Juan que se ha ido a comprar un helado (quinta tarjeta) (Ver Figura 12). 


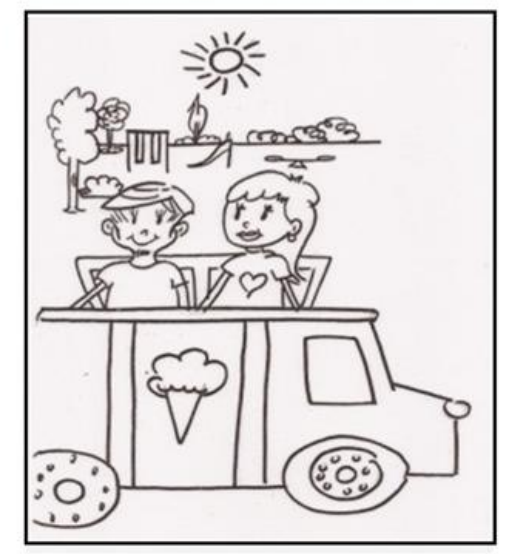

Tarjeta 1

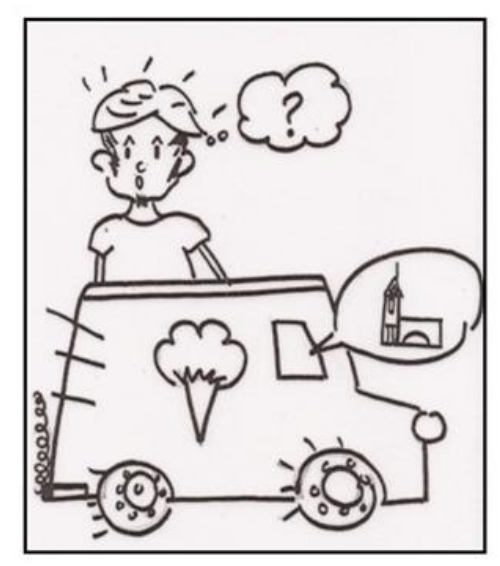

Tarjeta 3

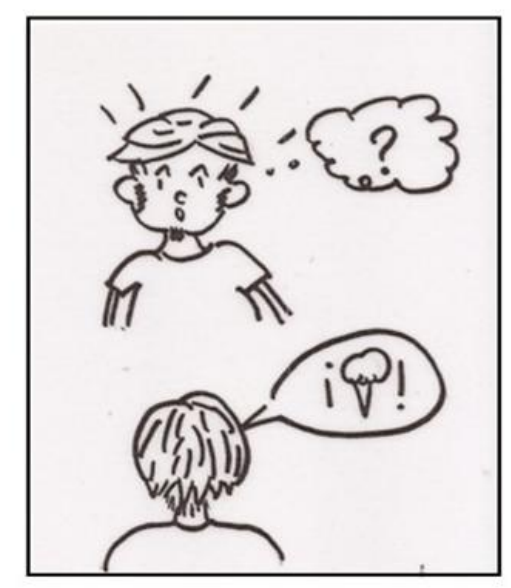

Tarjeta 5

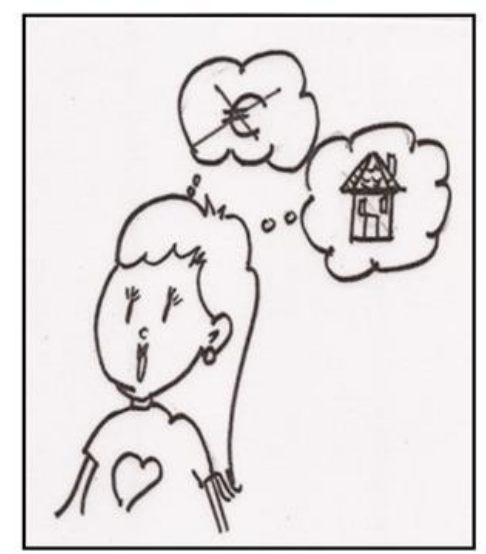

Tarjeta 2

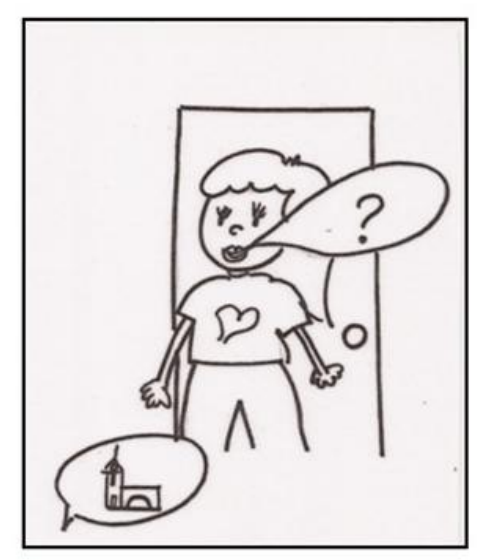

Tarjeta 4

Figura 12. Falsas creencias de $2^{\circ}$ orden: Historia del Heladero, Perner \& Wimmer (1985). Tarjetas adaptadas por la autora de la tesis. 
A continuación, se les formula a los niños la pregunta de atribución de falsa creencia de segundo orden: “¿Dónde piensa Juan que María habrá ido a buscar al heladero?” Y su correspondiente justificación: “¿Por qué crees que piensa eso?”. Para puntuarlas, se otorga 1 punto para la respuesta correcta en la atribución de la creencia falsa de segundo orden y 1 punto por la respuesta correcta de la justificación sobre la creencia falsa de segundo orden.

\subsubsection{Historias Extrañas (Happé, 1994)}

Las Historias extrañas fueron diseñadas en un principio por el grupo de Francesca Happé (1994) con el objetivo de evaluar las habilidades mentalistas de niños con autismo. Dichas historias permiten evalúan la capacidad para extraer un significado en función de un contexto social particular, lo que implica la necesidad de una "coherencia central o global" que debe superar la literalidad para generar un significado determinado en un contexto concreto. En todas las historias el personaje dice algo que no debía entenderse en sentido literal y se solicita al niño una explicación de por qué el personaje afirma eso. Se seleccionan 4 historias de las 24 historias originales: mentira piadosa, malentendido, emociones contrarias y forma de hablar. Para cada una de las historias se ha elaborado unas tarjetas con ilustraciones en blanco y negro elaboradas por la autora de la tesis. Hemos seleccionado una historia como ejemplo (Ver Figura 13).

\section{El malentendido (Guante)}

Un ladrón que acaba de robar una tienda se da a la fuga. Cuando corre hacia su casa, un policía que está haciendo su ronda ve caer su guante. Él no sabe que el hombre es un ladrón, solo quería decirle que se le había caído el guante. Pero cuando el policía grita al ladrón: “¡Eh tú, para!”, el ladrón se da la vuelta, ve al policía y se entrega. Levanta las manos y admite que él robó la tienda.

1. ¿Se sorprende el policía por lo que hizo el ladrón?

2. ¿Por qué el ladrón hace esto, cuando el policía solo quería devolverle el guante?

Figura 13. Historia extraña de Happé, (1994). 
El procedimiento seguido es el siguiente, la evaluadora relata la historia presentando las tarjetas con ilustraciones y. tras finalizar el relato, se hacen a los participantes dos preguntas. La primera pregunta: “¿Es cierto lo que dice X?”, para evaluar la comprensión de la veracidad del enunciado. Se concede 1 punto si el niño reconoce la falsedad del enunciado y 0 puntos si considera que es verdadero. La segunda pregunta: “¿Por qué X ha dicho eso?”, para evaluar la comprensión del niño sobre la intencionalidad del hablante. Aquí, el niño debe deducir por qué el personaje utiliza una frase con doble sentido, cuál es la intención comunicativa del personaje. La forma de evaluar esta segunda pregunta no sigue el baremo utilizado por la tarea original. Se concede 1 punto si reconoce y explica la intención del hablante de forma adecuada al contexto y 0 puntos en caso contrario, si no reconoce ni explica la intención del hablante o si simplemente reconoce pero no sabe dar una explicación adecuada (Ver Figura 14).

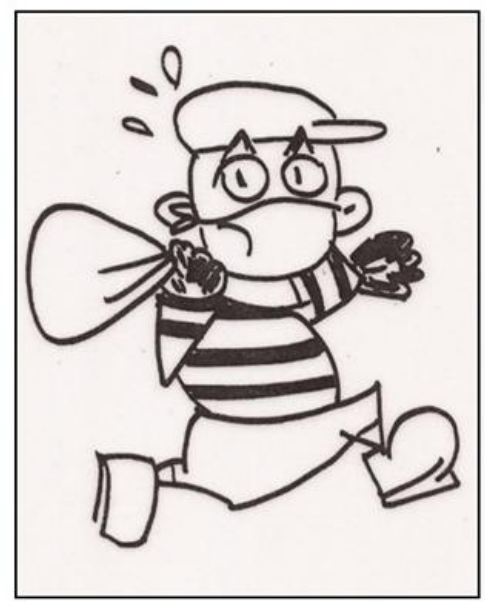

Tarjeta 1

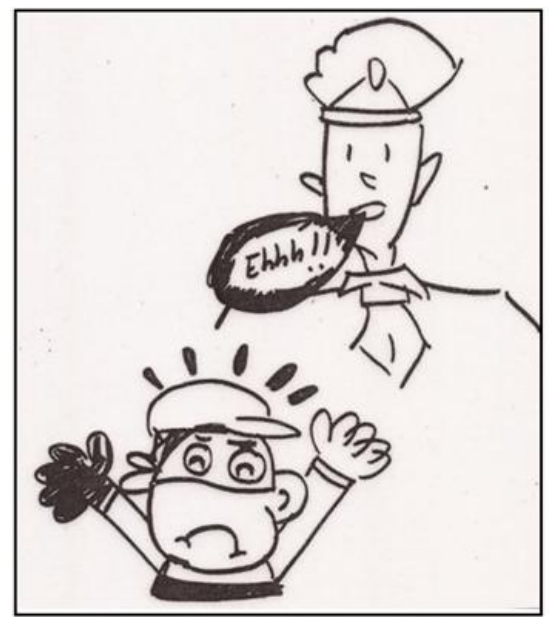

Tarjeta 3

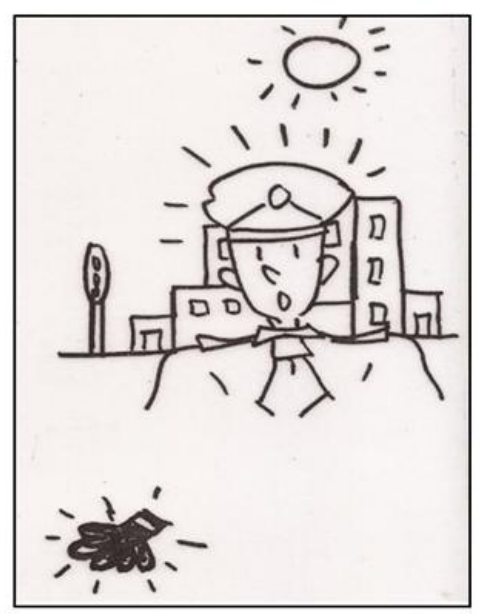

Tarjeta 2

Figura 14. Historia extraña: El malentendido. Happé, (1994).Tarjetas adaptadas por la autora de la tesis. 


\subsection{Cuestionario Sensory Profile, (Dunn, 1999)}

En este estudio hemos utilizado la versión corta del Cuestionario Sensory Profile (CSP) para medir el nivel de reactividad sensorial a partir de la información aportada por los padres. Esta versión se deriva del Cuestionario Sensory Profile más largo, de 125 ítems, que fue estandarizado en una muestra de más de unos 1.307 niños con desarrollo típico (Dunn, 1999). La versión corta consta de 38 ítems en los cuales los padres evalúan la frecuencia con la que su hijo muestra un comportamiento particular (por ejemplo, prefiere estar en la oscuridad), usando una escala Likert de cinco puntos que varía desde siempre (1) a nunca (5). Se considera apropiado para evaluar el procesamiento sensorial de niños entre 7 y 12 años de edad y evalúa las diferentes respuestas a estímulos táctiles, olfatorios, gustativos/orales, vestibulares, auditivos y visuales. Las puntuaciones obtenidas se organizan en tres grupos (desempeño típico, diferencia probable o diferencia definitiva), de tal manera que las puntuaciones más bajas refieren mayor gravedad de los síntomas (pudiendo indicar tanto hipersensibilidad como hiposensibilidad) y las puntuaciones más altas reflejan un comportamiento más típico. Así, una diferencia probable podría indicar dificultades en diferentes áreas del procesamiento sensorial, y correspondería a puntuaciones mayores que $1 \mathrm{SD}$ y menores que $2 \mathrm{SD}$ de la media. La diferencia definitiva, por su parte, indicaría problemas en el procesamiento sensorial, y se refiere a resultados mayores que $2 \mathrm{SD}$ de la media normativa. Dicho cuestionario tiene alta confiabilidad interna (0,90-0,95) (Dunn, 1999) y muestra diferencias sensoriales en hasta el $90 \%$ de niños y adultos con ASD en comparación con los controles (Crane, Goddard \& Pring, 2009; Dunn, Myles \& Orr, 2002b; Kern et al., 2007b; Kientz \& Dunn, 1997; Leekam, Nieto, Libby, Wing \& Gould, 2007; Tomchek \& Dunn, 2007; Wiggins, Robins, Bakeman \& Adamson, 2009). Este cuestionario lo han contestado todos los padres de los dos grupos de niños que han participado en el estudio, grupo control y grupo con TEA (Ver Figura 15). 


\begin{tabular}{|c|c|c|c|c|c|}
\hline & Siempre & $\begin{array}{l}\text { Frecuen: } \\
\text { temente }\end{array}$ & A veces & $\begin{array}{l}\text { Casi } \\
\text { Nunca }\end{array}$ & Nunca \\
\hline \multicolumn{6}{|l|}{$\begin{array}{l}\text { 16. Busca todo tipo de movimiento, y esto interfiere con las } \\
\text { actividades rutinarias (por ejemplo, no se puede quedar } \\
\text { quieto) }\end{array}$} \\
\hline \multicolumn{6}{|l|}{ 17. Se emociona demasiado en las actividades móviles. } \\
\hline \multicolumn{6}{|l|}{ 18. Toca a gente y objetos. } \\
\hline \multicolumn{6}{|l|}{ 19. No parece notar cuando tiene la cara o manos sucias. $(*)$} \\
\hline \multicolumn{6}{|l|}{$\begin{array}{l}\text { 20. Brinca de una actividad a otra al punto de interferir con el } \\
\text { juego. }\end{array}$} \\
\hline \multicolumn{6}{|l|}{ 21. Se deja puesta la ropa que viste de forma retorcida. } \\
\hline \multicolumn{6}{|l|}{$\begin{array}{l}\text { 22. Se distrae o tiene dificultades para funcionar } \\
\text { normalmente si hay mucho ruido a su alrededor. }\end{array}$} \\
\hline \multicolumn{6}{|l|}{$\begin{array}{l}\text { 23. Parece no oir lo que usted le diga (por ejemplo, parece no } \\
\text { hacerle caso). }\end{array}$} \\
\hline \multicolumn{6}{|l|}{$\begin{array}{l}\text { 24. No puede trabajar si hay ruido ambiental (por ejemplo, } \\
\text { ventilador, nevera). }(*)\end{array}$} \\
\hline $\begin{array}{l}\text { 25. Tiene dificultades para completar las tareas cuando esta } \\
\text { puesta la radio. }\end{array}$ & & & & & \\
\hline
\end{tabular}

Figura 15. Ejemplos de preguntas del Cuestionario Sensory Profile. Dunn, (1999).

\subsection{Cociente de Empatía y Sistematización para niños (Baron-Cohen et al., 2009)}

Este cuestionario, elaborado por Baron-Cohen et al., (2009), se encuentra en la siguiente página web: (http://www.autismresearchcentre.com/arc_tests), versión castellana realizada por Mauricio Martínez (Universidad de Buenos Aires). También, todos los padres de los niños que participan en el presente estudio rellenan el cuestionario. La versión para niños consta de 55 preguntas, 27 preguntas corresponden al Cociente de Empatía y 28 preguntas al Cociente de Sistematización, siendo el rango de puntuación del primer cuestionario 0-54 y el rango del segundo cuestionario 0-56. Los autores no han establecido puntos de corte para valorar los resultados obtenidos en ambos cuestionarios, por tanto, no es posible clasificar a los participantes dependiendo de la puntuación obtenida. La forma de interpretar la puntuación obtenida en cada cuestionario es compararlas con las medias que obtienen los autores en el proceso de validación del cuestionario. De lo que disponemos es del resultado obtenido al enfrentar el cuestionario a grupos de población normal (típica) y de afectados por trastornos del espectro autista. Las medias obtenidas por los autores en el proceso de validación del cuestionario se encuentran en la Figura 16. 
La forma de interpretar la puntuación obtenida consiste en compararla con las medias presentadas en la tabla. Como resultado complementario, y mediante la combinación de las dos puntuaciones obtenidas usando una formula proporcionada por los autores de los cuestionarios, es posible determinar el "tipo de cerebro" de la persona evaluada.

\begin{tabular}{|c|c|c|}
\hline & C.Empatía & C.Sistematización \\
\hline Grupo desarrollo típico & $37,70( \pm 9,81)$ & $24,11( \pm 8,02)$ \\
\hline Niñas & $40,16( \pm 8,89)$ & $22,64( \pm 7,94)$ \\
\hline Niños & $34,84( \pm 10,07)$ & $25,81( \pm 7,79)$ \\
\hline Grupo TEA & $13,97( \pm 6,82)$ & $27,43( \pm 9,20)$ \\
\hline Niñas & $15,43( \pm 6,27)$ & $26,11( \pm 9,11)$ \\
\hline Niños & $13,66( \pm 6,90)$ & $27,71( \pm 9,22)$ \\
\hline
\end{tabular}

Figura 16. C. Empatía y C. Sistematización para niños. Tabla con las medias obtenidas por los autores en el proceso de validación del cuestionario. Entre paréntesis aparece la desviación estándar. Baron-Cohen et al., (2009). 


\section{4- ANÁLISIS ESTADÍSTICOS CONDUCTUALES}

Los análisis estadísticos fueron realizados mediante el programa Statistical Package for the Social Sciences (SPSS, IBM, USA). Se realizó un análisis descriptivo de las variables conductuales para ambos grupos (control y TEA). Los análisis de comparación de grupos se calcularon mediante un ANOVA en el que la variable grupo era el factor entre sujetos, y la edad el covariante. En las pruebas de inteligencia, se llevó a cabo un análisis de la varianza mediante el prodecimiento ANOVA con la finalidad de realizar una comparación de medias entre los grupos. Un análisis de correlación de Pearson se llevó a cabo para estudiar las relaciones existentes entre las variables de interés.

Finalmente, se realizó un Análisis Factorial mediante el método de rotación Oblimin con Kaiser, en el que se incluyeron 6 variables utilizadas en el estudio (CE, CS, CSP, ToM, CI Verbal, CI No Verbal).

\section{5- DATOS DE NEUROIMAGEN}

Las técnicas de neuroimagen permiten ver imágenes en vivo del sistema nervioso central en general y del cerebro en particular. Estas técnicas no son invasivas y permiten evaluar los procesos de áreas y estructuras del cerebro en funcionamiento. La RM consiste en la utilización de campos magnéticos intensos para la creación de imágenes de tejido biológico. Dichos campos magnéticos son generados por el electroimán del escáner de resonancia y su unidad de medida es el Tesla. La intensidad de estos campos magnéticos en estudios con humanos está entre 0,5 y 9,4 Teslas. Los escáneres aplican las denominadas secuencias de RM para detectar propiedades y tipos de tejidos. En el cerebro estos tipos de tejidos son fundamentalmente la SG, la SB y el líquido cefalorraquídeo (LCR) (Ventura-Campos, 2013).

La RM nos permite realizar estudios de la estructura del cerebro a partir de imágenes, aportándonos información anatómica del mismo (RMe). Este tipo de técnica nos permite obtener representaciones estáticas del cerebro y una característica principal de las imágenes obtenidas para el estudio de la estructura cerebral es la resolución espacial. 


\subsection{Adquisición de las imágenes de $\mathrm{RMe}$}

Las imágenes de RM fueron adquiridas en un escáner Philips Achieva de 3T de 32 canales. Se adquirieron imágenes en 3D de todo el cerebro potenciadas en $\mathrm{T} 1$ en un escáner con los siguientes parámetros de adquisición: TR=8,558 ms; TE=3,8 ms; 250 volúmenes con una matriz 268 x 268; tamaño vóxel 0,75 x 0,75 x 0,8 mm. Durante la sesión de RM los niños del grupo experimental no tomaron psicoestimulantes (metilfenidato) ni atomoxetina (24 horas antes de la prueba). Para la realización de las pruebas de neuroimagen, se dieron instrucciones a los padres para que entrenaran a los niños en casa (se explicará con más detalles en el apartado de Procedimiento). Este entrenamiento favoreció bastante la realización de la misma en los niños con TEA.

\subsection{Preprocesado de imágenes de RMe}

Para el preprocesado de las imágenes de RMe se utilizó el programa SPM (Statistical Parametric Mapping 12; Wellcome Trust Centre for Neuroimaging, London, uk. http://www.fil.ion.ucl.ac.uk/spm) mediante la técnica morfométrica de VBM (Voxel Based Morphometry, por sus siglas en inglés). Esta técnica se llevó a cabo utilizando la herramienta CAT12 (A Computational Anatomy Toolbox for SPM, http://www.neuro.uni-jena.de/cat/) implementada para el programa SPM12. Hay que tener en cuenta que todas los templates (plantilla o cerebro de referencia) proporcionados por el SPM son de cerebros adultos, por lo que es necesario realizar un preprocesado previo de las imágenes de nuestra muestra de niños/as antes del análisis de VBM: 1) Reorientación de las imágenes de RMe a la comisura anterior (CA)- comisura posterior (CP); 2) Segmentación de las imágenes en SG, SB y LCR, y en el tejido de intensidades no uniformes (bias correction) mediante los mapas de probabilidad de los tejidos (TPM) que proporciona el SPM; 3) las imágenes segmentadas para cada participante se utilizaron para crear un template de toda la muestra de niños/as mediante la herramienta Template-O-Matic (TOM) (https://irc.cchmc.org/software/tom.php). La herramienta TOM utiliza el modelo lineal general para tener en cuenta las variables externas de interés en la estructura del cerebro, como son la edad y el género, permitiendo generar un template de alta calidad. De aquí obtendremos el TPM de nuestra propia muestra para el procesado del VBM. 4) El último paso conllevaba la creación de un 
template personalizado DARTEL (Ashburner, 2007) usando un registro afín de las imágenes segmentadas, este template se normalizó al espacio MNI (ICBM). Una vez creados los templates de nuestra muestra se utilizó la herramienta CAT12 para el análisis de VBM. Este procesado se basó en la segmentación de los tejidos cerebrales en SG, SB y LCR utilizando el TPM personalizado obtenido del TOM, a continuación, el volumen de SG fue normalizado utilizando el template Dartel personalizado y modulado mediante el escalado por la cantidad de cambios de volumen debidos al registro espacial, de manera que la cantidad total de volumen de SG de la imagen modulada-normalizada permanece igual que en la imagen original. Finalmente, se aplicó un suavizado con un kernel Gaussiano FWHM (Full With at Half Maximm) de $8 \mathrm{~mm}$. El último paso se basó en la obtención del volumen intracraneal (TIV) de cada participante que se utilizó en el posterior análisis estadístico con el fin de eliminar las diferencias individuales debidas a este volumen.

\subsection{Análisis estadístico de imágenes de RMe}

Los análisis estadísticos fueron realizados usando el programa SPM12. Los volúmenes de SG procesados en el análisis de VBM para cada participante, se utilizaron para el análisis estadístico de segundo nivel. Se realizó una Prueba T para muestras independientes para observar las diferencias en volumen de SG entre grupos, desarrollo típico y TEA. Por otro lado, se estudiaron las diferencias entre grupos de volumen de SG asociadas a las variables neuropsicológicas (WISC-IV, ToM, Cociente de Empatía y Sistematización y el Cuestionario Sensory Profile.), mediante un análisis de regresión múltiple a partir del cual se estudió la interacción de las variables de interés entre grupos. Por último, para conocer qué áreas cerebrales estaban relacionadas con la ejecución de cada una de las variables neuropsicológicas se realizó un análisis de regresión múltiple para grupo de participantes. Todos estos análisis estadísticos fueron covariados por TIV y edad, y calculados a nivel de todo el cerebro con un umbral corregido por múltiples comparaciones a nivel de clúster de $\mathrm{p}<, 05 \mathrm{FWE}$ (Family-wise error, siglas en inglés) con un umbral a nivel de vóxel de $\mathrm{p}<, 001$ con un criterio de clúster (Forman et. al., 1995) determinado por la simulación de Montecarlo. Se realizaron las mismas comparaciones covariando también con el CI manteniéndose los mismos resultados. 
En la introducción de esta tesis hemos realizado un estado de la cuestión revisando las áreas cerebrales en las que se han obtenido diferencias estructurales y/o funcionales en estudios con personas con TEA. Basándonos en estos estudios, se realizó un análisis post hoc tomando estas áreas cerebrales como regiones de interés (ROI). Las pruebas estadísticas para la comparación e interacción entre grupos y correlación asociada a las variables de interés fueron las mismas que hemos descrito en el párrafo anterior a nivel de todo el cerebro. La metodología para llevar a cabo este análisis post hoc conllevaba la creación a priori de las ROIs definidas mediante el atlas AAL (Automatic Atlas Labeling; con la herramienta WFU-PickAtlas; Maldjiang et al., 2003) y utilizando un umbral corregido por múltiples comparaciones con SVC (small volumen correction) a nivel de vóxel de $\mathrm{p}<.05$ FWE. La aproximación del análisis post hoc mediante ROIs, utilizando la corrección SVC, se realizó debido a que las correcciones a nivel de clúster con FWE en todo el cerebro son menos sensibles para detectar regiones anatómicas pequeñas tales como son nuestras áreas de interés: hipocampo, amígdala, ínsula, núcleo caudado, putamen, giro cingulado y tálamo (Woo, Krishnan \& Wager, 2004). 


\section{6- PROCEDIMIENTO}

Para la presente investigación se recogieron los datos de los participantes basándonos en dos modalidades de evaluación. Por un lado, datos dentro del ámbito cognitivo a partir de pruebas neuropsicológicas como la Escala Wechsler para Niños, WISC-IV y una serie de pruebas que nos permitieran evaluar el desarrollo de algunos aspectos relacionados con la cognición social, como son los test para evaluar la Teoría de la Mente (ToM) y una serie de cuestionarios cumplimentados por los padres para valorar el perfil sensorial y el desarrollo de las habilidades empáticas de los participantes (Ver Tabla 8). Por otro lado, datos obtenidos mediante la recogida de imágenes de RM estructural.

Un requisito imprescindible para poder participar en el estudio era que los participantes tuvieran un CI igual o superior a 80, habiendo utilizado el WISC-IV. Se aplica esta batería a todos los participantes del grupo control y a los participantes del grupo experimental. La distribución de las sesiones de evaluación fue la siguiente. Para los niños del grupo con desarrollo típico, se realizan dos sesiones: la primera para realizar el WISC-IV y la segunda para realizar las pruebas de ToM. Para los niños con TEA, se requieren más sesiones ya que, en general, por las características propias del trastorno que presentan, les costaba más centrar la atención, mantener el interés y un grado adecuado de motivación; además, se ponían más nerviosos, se angustiaban e incluso se enfadaban cuando era necesario controlar el tiempo o cuando se daban cuenta de que no lo habían hecho bien. Así, fueron necesarias dos sesiones o tres para realizar las subpruebas del WISC-IV y una o dos sesiones para las pruebas de ToM.

Por otro lado, se pide a los padres que rellenen dos tipos de cuestionarios. Los realizan ambos padres en su casa y se les da una semana de plazo para que los rellenaran con tranquilidad. Uno de ellos es el Cuestionario Sensory Profile (Dunn, 1999), para realizar un perfil sensorial individual de cada niño, y otro es el Cociente de Empatía y el Cociente de Sistematización para niños (Baron-Cohen, 2009), cuestionario para valorar el nivel de desarrollo de la empatía y de sistematización.

Después de haber finalizado la evaluación neuropsicológica, todos los niños que participaron en el estudio realizaron las pruebas de neuroimagen. Las sesiones se llevaron a cabo los sábados por la mañana. Previamente, la autora de la tesis, explicó a 
cada uno de ellos (de forma individual) qué pasos se iban a seguir el día de la sesión y les mostró una imagen con el escáner que se iba a utilizar, con el objetivo de anticipar la situación (ya que ante situaciones nuevas estos niños suelen alterarse fácilmente). En algunos casos, la explicación se realizó varias veces para anticipar la situación y tranquilizar al niño. Además, antes de acudir a las pruebas de neuroimagen, se dieron instrucciones a los padres de los niños con TEA para que entrenaran en casa durante 30 minutos, tumbados en su cama, escuchando un vídeo que reproducía el sonido del escáner, con unos cascos e incluso con tapones y practicando la respiración abdominal, así, simulaban una situación parecida a la del día en el que debían realizar la prueba y, de alguna manera, podían estar familiarizados con el sonido y con la situación. El entrenamiento fue progresivo y durante varias semanas antes de realizar la prueba y el objetivo era que a los niños con TEA no les molestara el sonido ya que muchos de ellos presentan cierta hipersensibilidad a los ruidos fuertes, inesperados y desconocidos. El video fue extraído del siguiente enlace de internet (https://www.youtube.com/watch?v=6Aj2QspPf7s). Se siguió el mismo procedimiento con los niños del grupo control para que conocieran en qué consistía la prueba, pero no necesitaron un entrenamiento tan sistemático como el otro grupo. El día que hacían la resonancia, se le preguntaba al niño con quién quería entrar en la sala del escáner para que le acompañara hasta el final de la misma y podía elegir entre uno de sus padres o la autora de la tesis. Las instrucciones que se les dieron era que debían estar quietos, no podían mover la cabeza ni hacer gestos con la cara y debían recordar cómo lo habían hecho durante el entrenamiento con sus padres. Algunos niños del grupo experimental tuvieron que repetir la prueba varias veces por exceso de movimiento. 
Tabla 8. Variables conductuales evaluadas.

Teoría de la Mente

*Test de la Mirada, versión niños (Baron-Cohen et al., 2001).

*Historia Meteduras de pata (Faux Pas

Recognition, Baron-Cohen et al., 1999).

*Falsas creencias de $2^{\circ}$ Orden (Perner \& Wimmer, 1985; Sullivan et al., 1994).

*Historias extrañas (Happé, 1994).

Procesamiento sensorial

*Cuestionario Sensory Profile (Dunn, 1999, versión corta).

*Cociente de Empatía y Cociente de

Empatía y Sistematización Sistematización, versión niños (Baron-Cohen et al., 2009). 


\section{V- $\underline{\text { RESULTADOS }}$}

\section{1- COMPARACIÓN ENTRE GRUPOS}

Los resultados de la comparación de ambos grupos de participantes no revelaron ninguna diferencia significativa en el volumen total del cerebro, en el volumen de SG, en el volumen de SB ni en el líquido cefaloraquídeo, aun utilizando un nivel de significación inferior al establecido (FWE p <,05 corregido a nivel de cluster, con un umbral a nivel de vóxel de $\mathrm{p}<, 005, \mathrm{k}=300$ ). Por lo que podemos concluir con mayor fiabilidad que no existían diferencias significativas globales en volumen de SG entre los dos grupos de participantes en el estudio (ver Tabla 9).

Tabla 9. Volumen medio $\left(\mathrm{en} \mathrm{cm}^{3}\right.$ ) de sustancia gris, sustancia blanca y líquido cefalorraquídeo para los dos grupos de participantes: grupo de niños con Trastorno del Espectro del Autismo (TEA) y grupo control.

\begin{tabular}{|c|c|c|c|c|}
\hline & $\begin{array}{c}\text { Grupo TEA } \\
\text { Media (desviación típ.) } \\
\mathrm{N}=\mathbf{2 4}\end{array}$ & $\begin{array}{c}\text { Grupo control } \\
\text { Media (desviación típ.) } \\
\qquad \mathbf{N}=\mathbf{2 4}\end{array}$ & $\mathbf{t}$ & $p$ \\
\hline TIV & $1607,97(153,03)$ & $1570,80(101,76)$ &,- 991 & ,328 \\
\hline SG & $794,06(71,88)$ & $782,87(49,52)$ &,- 628 &, 533 \\
\hline SB & $496,17(66,03)$ & $486,98(41,23)$ &,- 578 & ,567 \\
\hline CSF & $317,74(32,84)$ & $300,96(27,35)$ & $-1,924$ & ,061 \\
\hline
\end{tabular}

\section{2- VARIABLES NEUROPSICOLÓGICAS: DIFERENCIAS CONDUCTUALES Y REGRESIONES}

Para cada una de las pruebas neuropsicológicas administradas se aplicó una misma estrategia de análisis. En primer lugar, se estudiaron las diferencias entre grupos de las variables conductuales mediante ANOVAs, covariadas por la edad. En segunda instancia, se llevaron a cabo una serie de análisis de regresión múltiple entre las 
diferentes variables de las pruebas cognitivas y el volumen de SG calculado mediante la morfometría cerebral, para cada grupo. Así como un análisis de interacción usando como variables de interés las pruebas cognitivas, con el objetivo de ver las diferencias en volumen de SG entre grupo debidas a dichas variables. En todos los análisis de morfometría se utilizó la edad y el TIV como variable de no interés. A continuación, se detallan los resultados obtenidos para cada una de las variables de las pruebas cognitivas

\subsection{Pruebas de inteligencia: Escala de Inteligencia Wechsler para Niños - IV (WISC-IV)}

Al comparar las medias obtenidas en esta batería de pruebas por ambos grupos, el grupo con TEA y el grupo con desarrollo típico, se observó que presentaban diferencias significativas en las distintas medias globales de la batería utilizada (ver Tabla 10).

Tabla 10. Resultados de la ANOVA para la comparación de grupos en las pruebas de inteligencia.

\section{Grupo TEA Grupo control}

\begin{tabular}{lcccc} 
& Media (desviación típ.) & Media (desviación típ.) & $\mathbf{F}(\mathbf{1 , 4 5})$ & $\boldsymbol{p}$ \\
\hline CI Verbal & $105,17(14,27)$ & $115,88(11,82)$ & 7,79 &, $008^{* *}$ \\
\hline CI N Verbal & $100,29(17,30)$ & $111,54(14,93)$ & 5,67 &, $022^{*}$ \\
\hline MT & $96,96(17,16)$ & $108,71(14,51)$ & 6,54 &, $014^{*}$ \\
\hline VP & $93,17(15,12)$ & $107,96(12,77)$ & 13,30 &, $001^{* *}$ \\
\hline CI Total & $98,21(14,76)$ & $114,63(13,98)$ & 15,30 &, $000^{* *}$
\end{tabular}

$* p<, 05 ; * * p<, 01$

Los resultados de morfometría obtenidos mediante el análisis de regresión múltiple, realizado para cada una de las variables de la batería WISC-IV y para cada grupo, sólo obtuvieron en el grupo control una correlación significativa positiva entre la variable 
velocidad de procesamiento y el volumen en el giro cingulado posterior derecho ( $\mathrm{r}$ $(23)=, 49, \mathrm{p}=, 014 ; k=682 ; Z=4,18$; coordenadas $x=23, y=-54, z=-2)$ y una correlación negativa entre la misma variable y el cerebelo izquierdo ( $\mathrm{r}(23)=-, 61, \mathrm{p}=$ ,002; $k=747 ; Z=3,82$; coordenadas $x=-21, y=-77, z=-27$ ) a nivel de volumen total del cerebro (FWE $\mathrm{p}<, 05$ corregido a nivel de clúster, con un umbral $\mathrm{p}<0,001$ a nivel de vóxel) (Ver Figura 17). No se mostraron correlaciones significativas en el grupo con TEA con ninguna de las variables de estudio, a nivel de volumen total cerebral. Sin embargo, basándonos en hipótesis previas, se realizó un análisis a partir de las ROIs descritas en la introducción (SVC, FWE p $<, 05$ a nivel de vóxel) encontrando, en el grupo con autismo una correlación positiva entre CI Total y la región del núcleo caudado izquierdo $(\mathrm{r}(23)=, 94, \mathrm{p}=, 014 ; k=36 ; Z=4,33$; coordenadas $x=-9, y=-5, z=$ 18) (Ver Figura 18).

En cuanto al análisis de interacción realizado para cada una de las variables en la comparación de grupos, se encontraron diferencias significativas en la variable velocidad de procesamiento relacionada con un mayor volumen de SG en niños con TEA respecto a los niños con desarrollo típico, en el cerebelo derecho (TEA: $r$ (23)= ,45, p= ,029, control: $\mathrm{r}(23)=-, 50, \mathrm{p}=, 012 ; k=1548 ; \mathrm{Z}=4,32$; coordenadas $\mathrm{x}=24, \mathrm{y}$ $=-77, \mathrm{z}=-33$ ) y cerebelo izquierdo (TEA: $\mathrm{r}(23)=, 23, \mathrm{p}=, 285$, control $\mathrm{r}(23)=-, 58, \mathrm{p}=$ ,003; $k=847 ; Z=3,96$; coordenadas $x=-24, y=-77, z=-30$ ) a nivel de volumen total del cerebro (FWE $\mathrm{p}<, 05$ corregido a nivel de clúster, con un umbral $\mathrm{p}<0,001, \mathrm{k}=1548$ a nivel de vóxel) (Ver Figura 19). 
A)
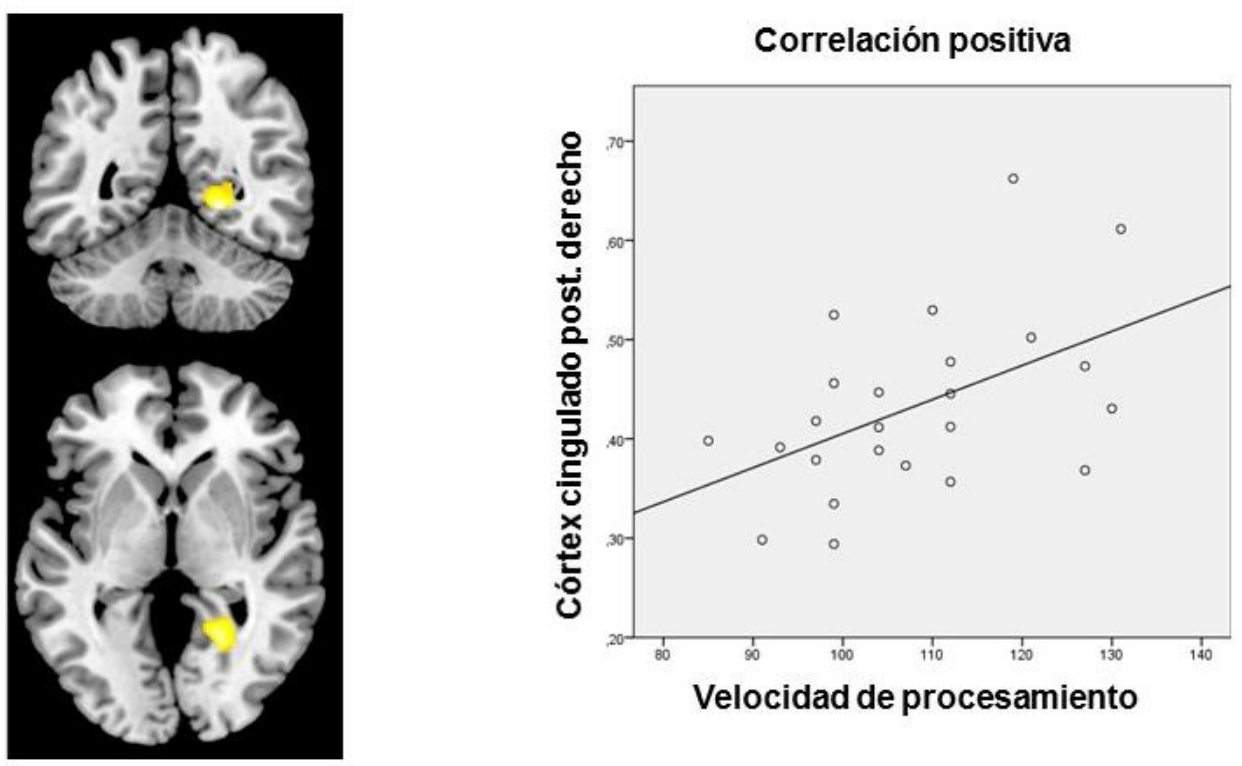

I

D

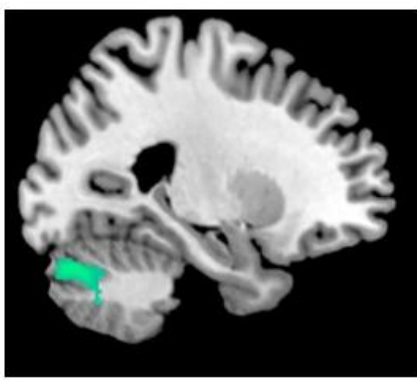

B)

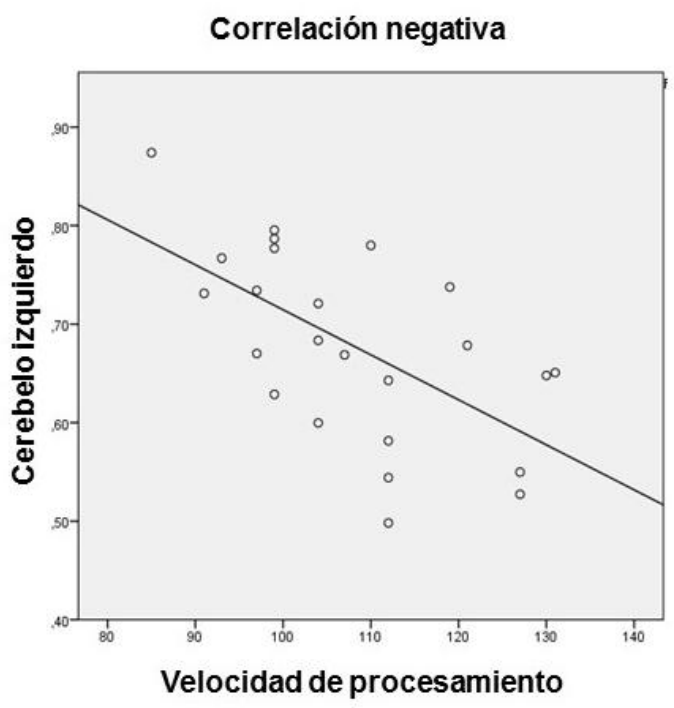

I

D

Figura 17. Regresión múltiple entre la variable Velocidad de procesamiento y el volumen en SG para el grupo control (FWE p <,05 corregido a nivel de clúster). A) Correlación significativamente positiva entre la variable conductual y el cingulado posterior derecho B) Correlación significativamente negativa entre la variable conductual y el cerebelo izquierdo 

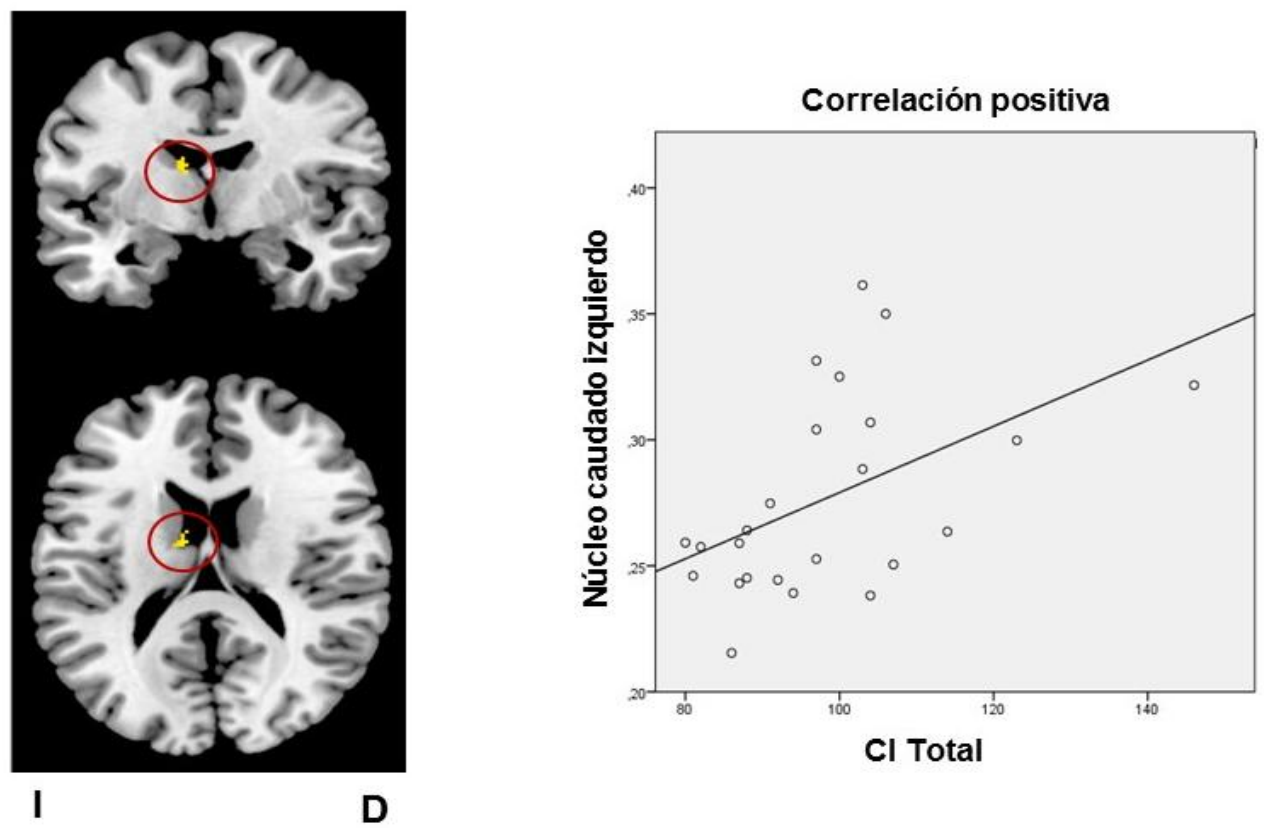

Figura 18. Correlación significativamente positiva en el grupo TEA entre la variable CI Total y el volumen del núcleo Caudado (SVC, FWE $\mathrm{p}<0,05$ corregido a nivel de vóxel).
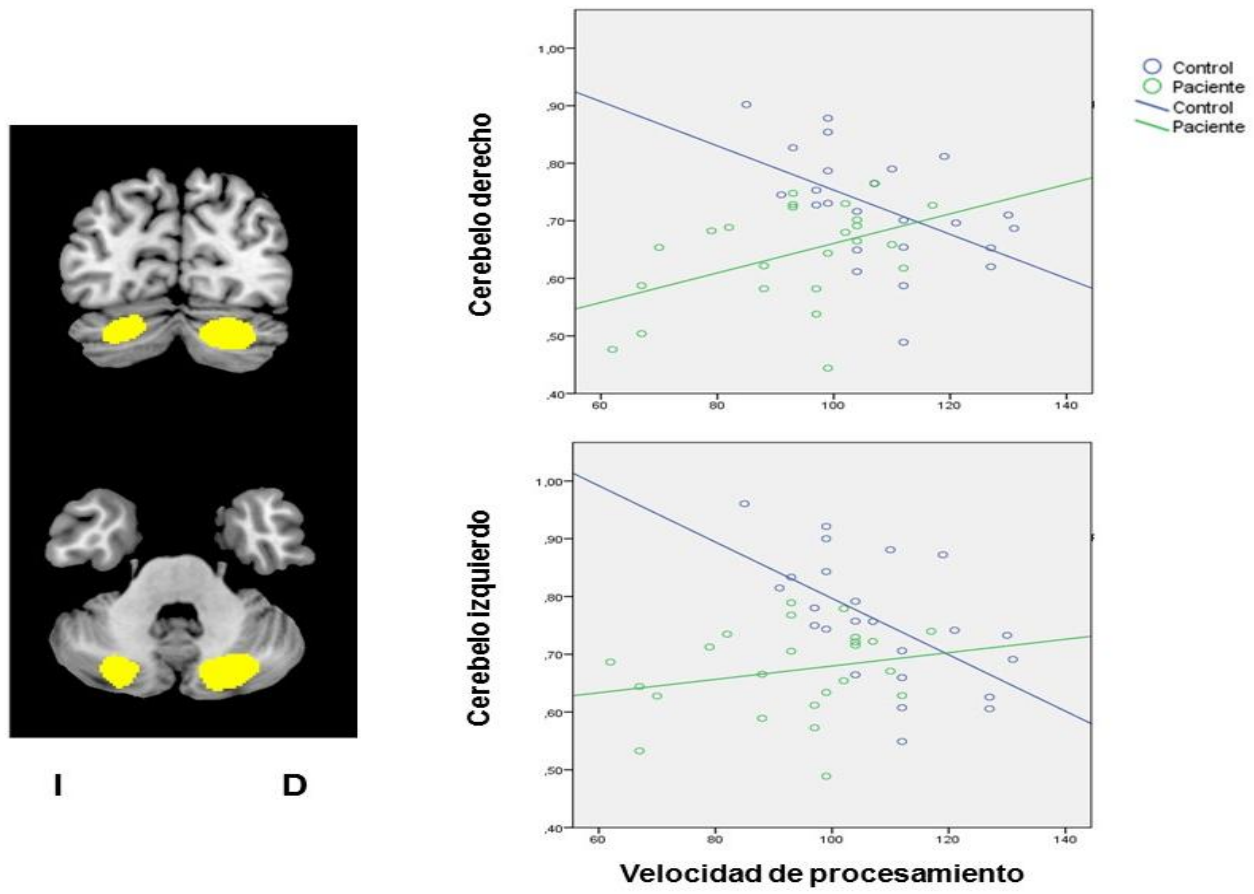

Figura 19. Análisis de interacción mostrando mayor volumen de SG en el cerebelo bilateral asociado a la variable de Velocidad de procesamiento, para el grupo TEA respecto del grupo control (FWE $\mathrm{p}<, 05$ corregido a nivel de clúster). 
Por otra parte, encontramos otros resultados en la interacción entre grupos obtenidos a partir del análisis de las ROIs (SVC; FWE p<,05 a nivel de vóxel), en los cuales la variable CI No Verbal se relacionaba con un mayor volumen de SG en el grupo con TEA respecto a los niños con desarrollo típico en el tálamo izquierdo (TEA: $r$ $(23)=, 26, \mathrm{p}=, 213$, control: $\mathrm{r}(23)=-, 52, \mathrm{p}=, 009 ; k=52 ; Z=3,96$; coordenadas $x=-23$, $y=-29, z=6$ ), y tálamo derecho(TEA: $\mathrm{r}(23)=, 38, \mathrm{p}=, 065$, control: $\mathrm{r}(23)=-, 54, \mathrm{p}=$ ,006; $k=97 ; Z=3,73$; coordenadas $x=20, y=-26, z=9$ ) (Ver figura 20).

No se obtuvieron diferencias significativas utilizando el umbral estadístico preestablecido para las variables CI Verbal, MT y CI Total en ninguno de los dos grupos.
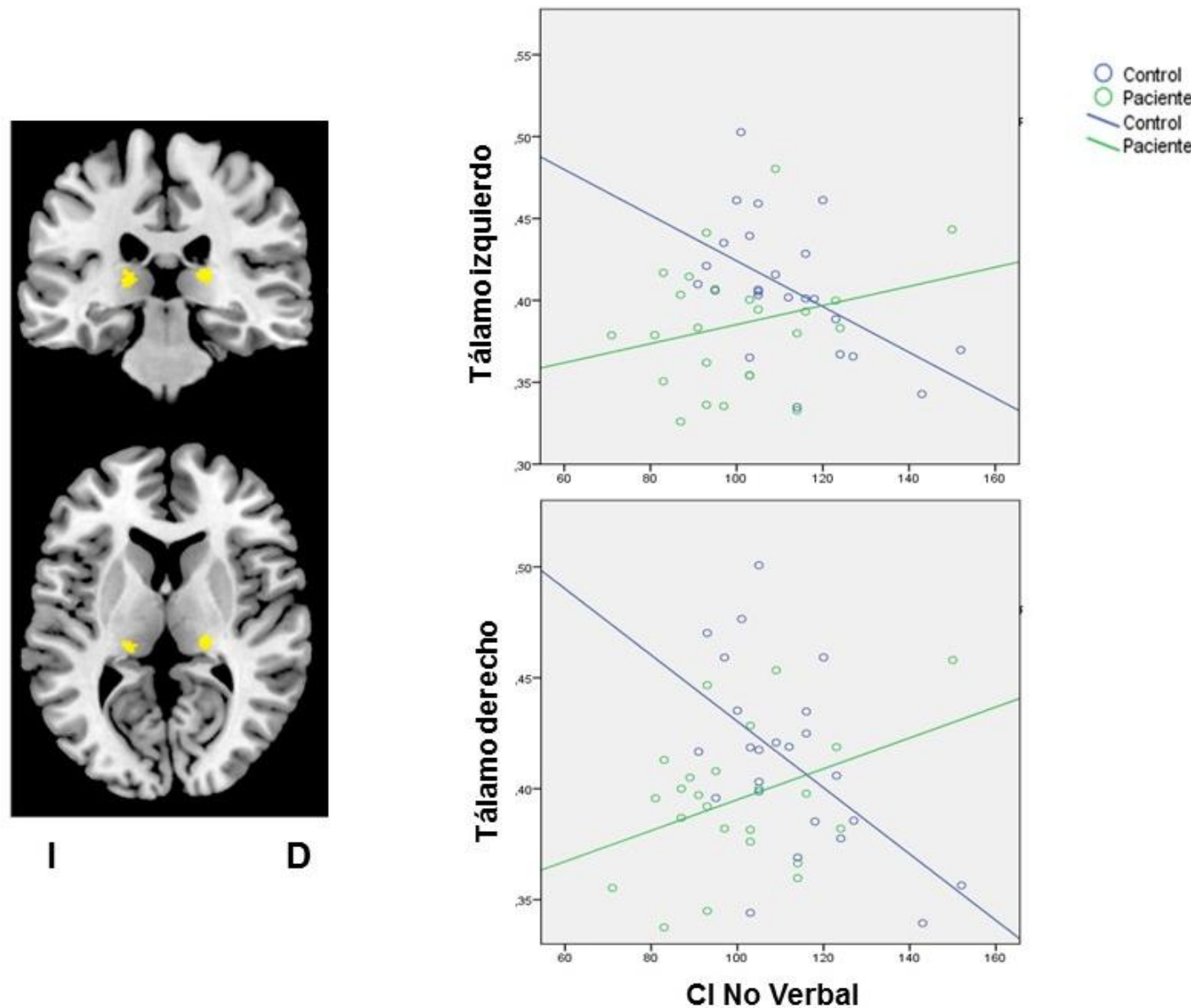

Figura 20. Análisis de interacción mostrando mayor volumen de SG en el tálamo bilateral asociado a la variable de CI no verbal, para el grupo TEA respecto del grupo control (SVC, FWE $p<, 05$ corregido a nivel de vóxel). 


\subsection{Pruebas de Teoría de la Mente (ToM)}

Los resultados obtenidos en la puntuación global de ToM y en cada una de las pruebas que evaluaban las habilidades mentalistas indicaron que los niños con desarrollo típico tenían mejor rendimiento en general, mostrando diferencias muy significativas en la valoración global y en las Historias de Happé y significativas en el Test de la Mirada, en Meteduras de pata y en Falsas creencias de $2^{\circ}$ Orden (Ver Tabla 11).

Tabla 11. Resultados de la ANOVA para la comparación de grupos en la puntuación global y cada una de las subpruebas de Teoría de la Mente.

\begin{tabular}{lcccc}
\hline & $\begin{array}{l}\text { Grupo TEA } \\
\text { Media (desviación típ.) }\end{array}$ & $\begin{array}{c}\text { Grupo Control } \\
\text { Media (desviación típ.) }\end{array}$ & F (1, 45) & $\boldsymbol{p}$ \\
\hline Punt. global ToM & $32,98(7,34)$ & $37,54(4,78)$ & 14,12 &, $000^{* *}$ \\
\hline Test Mirada & $17,00(3,91)$ & $18,33(2,56)$ & 4,40 &, $042^{*}$ \\
\hline H. Happé & $5,75(1,54)$ & $6,67(1,05)$ & 8,12 &, $007^{* *}$ \\
\hline Meteduras pata & $7,42(2,41)$ & $8,83(1,58)$ & 7,20 &, $010^{*}$ \\
\hline F. creencias & $2,85(1,51)$ & $3,71(1,41)$ & 5,55 &, $023^{*}$ \\
$\mathbf{2}^{\mathbf{0}}$ orden & & & & \\
\hline
\end{tabular}

$* p<, 05 ; * * p<, 01$

Los análisis de correlación parcial (eliminando el efecto de la edad) entre la puntuación global ToM y las puntuaciones globales de cada una de pruebas de inteligencia (WISCIV) mostraron una correlación significativa en CI Total y muy significativa con el CI Verbal, en ambos grupos (Ver Tabla 12).

Tabla 12. Resultados de la correlación parcial entre la puntuación global de ToM y cada una de las pruebas de inteligencia, para cada grupo.

\begin{tabular}{|c|c|c|c|}
\hline CI Total & CI Verbal & $\begin{array}{c}\text { CI No } \\
\text { Verbal }\end{array}$ & $\begin{array}{c}\text { Memoria } \\
\text { Trabajo }\end{array}$ \\
\hline
\end{tabular}

$\begin{array}{cccccc}\text { Grupo } & r=, 44 & r=, 60 & r=, 35 & r=, 28 & r=-, 16 \\ \text { TEA } & p=, 034^{*} & p=, 002 * * & p=, 099 & p=, 200 & p=, 478 \\ \text { Grupo } & r=, 50 & r=, 58 & r=, 37 & r=, 31 & r=, 20 \\ \text { Control } & p=, 015^{*} & p=, 003^{* *} & p=, 085 & p=, 146 & p=, 350\end{array}$

$* p<, 05 ; * * p<, 01$ 
Los resultados de morfometría de los análisis de regresión múltiple con la variables de ToM (covariado con el CI total debido a la correlación con esta variable) mostraron una correlación positiva significativa para el grupo de niños con desarrollo típico en la región del giro frontal medio/inferior derecho $(\mathrm{BA} 46)(\mathrm{r}(23)=, 38, \mathrm{p}=, 065 ; k=725 ; \mathrm{Z}$ $=4,24$; coordenadas $\mathrm{x}=50, \mathrm{y}=42, \mathrm{z}=29$ ), realizado a nivel de volumen total del cerebro (FWE $\mathrm{p}<, 05$ corregido a nivel de clúster, con un umbral $\mathrm{p}<0,001, \mathrm{k}=725$ a nivel de vóxel) (Ver Figura 21), no encontrando correlaciones significativas para el resto de las pruebas que evaluaban las habilidades mentalistas. En el caso del grupo de niños con TEA, los resultados de morfometría no mostraron correlaciones significativas en las variables de ToM y las diferentes pruebas incluidas en este apartado, a nivel de volumen total del cerebro.

Los resultados del análisis a partir de las ROIs (SVC, FWE $\mathrm{p}<, 05$ a nivel de vóxel), indicaron la existencia de una correlación positiva en el grupo con TEA entre la variable Test de la Mirada y la región de la amígdala derecha $(\mathrm{r}(23)=, 65, \mathrm{p}=, 001 ; k=28 ; \mathrm{Z}=$ 3,36; coordenadas $\mathrm{x}=30, \mathrm{y}=0, \mathrm{z}=-14$ ) (Ver Figura 22).

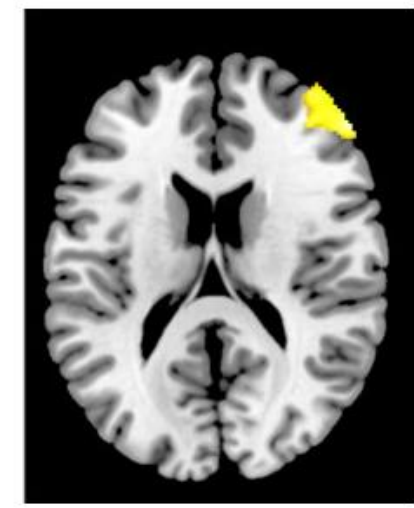

I

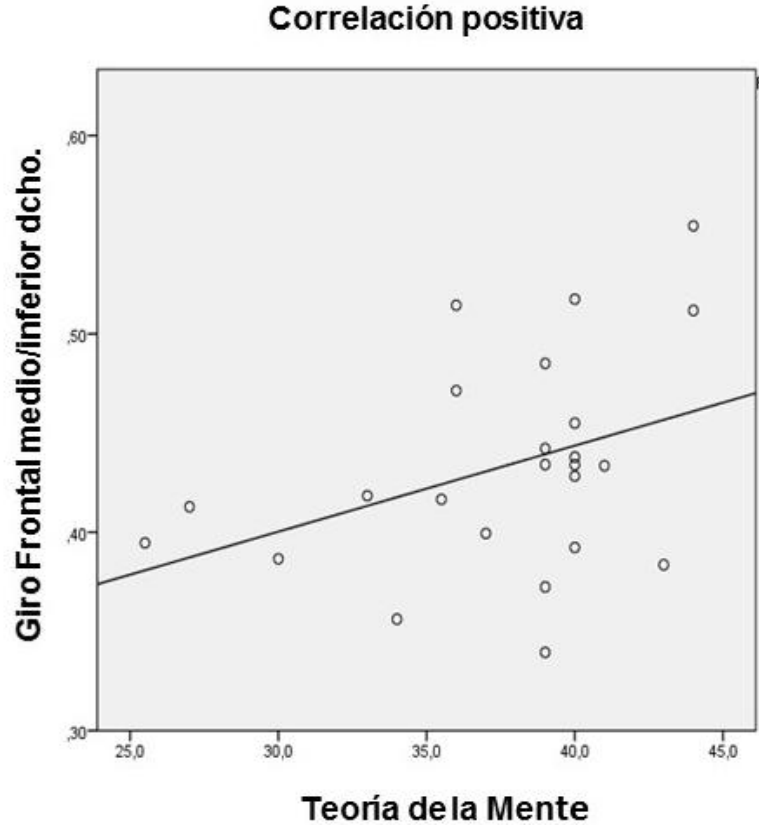

Teoría de la Mente

Figura 21. Resultado de la regresión múltiple para el grupo de niños con desarrollo típico con la variable ToM. Correlación positiva entre el giro frontal medio/inferior derecho y dicha variable (FWE $\mathrm{p}<, 05$ corregido a nivel de clúster) 

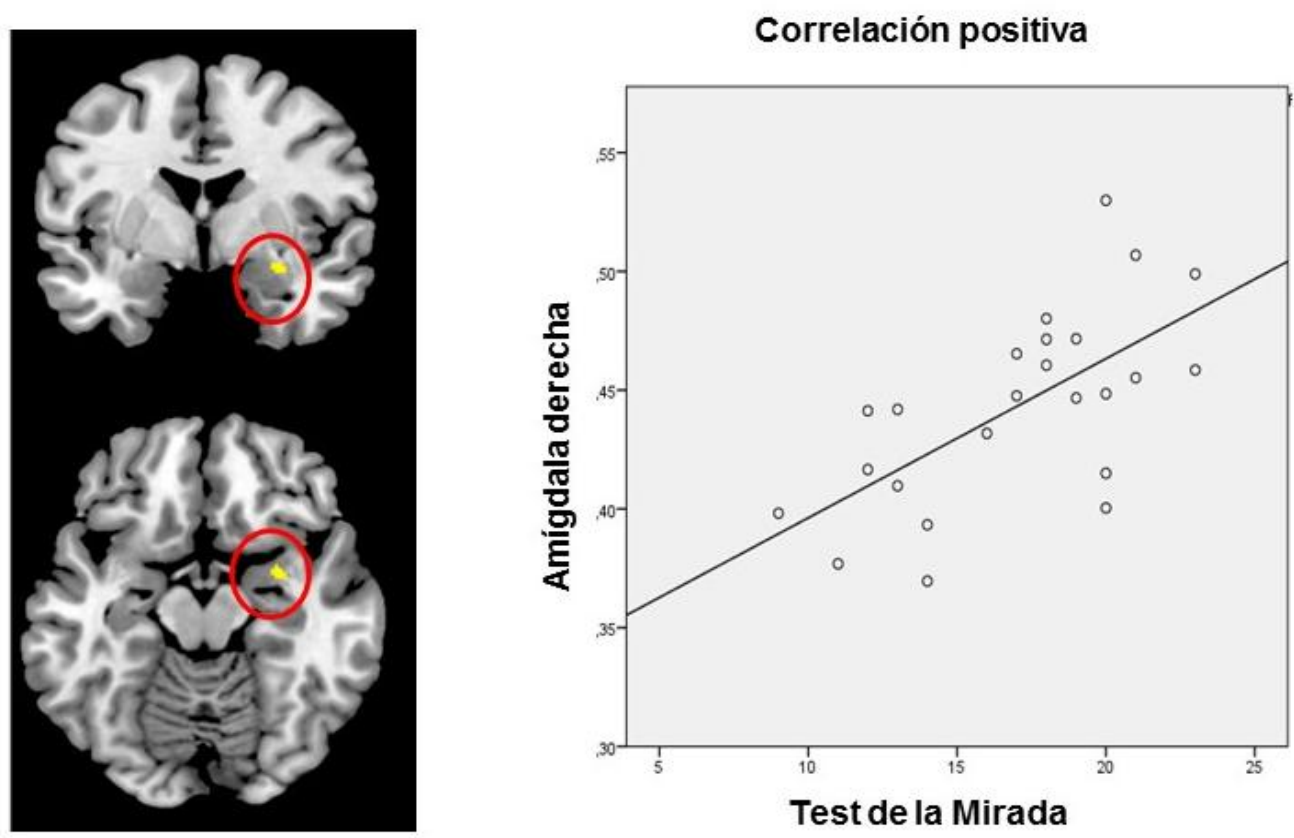

I

D

Figura 22. Regresión múltiple entre la variable Test de la mirada y el volumen en SG, para el grupo de niños con TEA, (SVC, FWE $p<0,05$ corregido a nivel de vóxel).

Respecto al análisis de interacción, que indican las diferencias de grupo en volumen de SG en relación con las variables de las diferentes pruebas incluidas en este apartado, a nivel de cerebro entero (FWE p<,05 corregido a nivel de clúster, con un umbral $\mathrm{p}<$ 0,001 a nivel de vóxel) no se encontraron diferencias significativas. No obstante, en el análisis de ROIs (SVC, FWE $\mathrm{p}<, 05$ a nivel de vóxel) el resultado de la interacción con la variable ToM global (covariada con CI) mostró mayor volumen de SG en el grupo de niños con TEA respecto al grupo control en el putamen izquierdo TEA: $\mathrm{r}(23)=, 45$, $\mathrm{p}=$ ,027, control: $\mathrm{r}(23)=-, 55, \mathrm{p}=, 006 ; k=165 ; \mathrm{Z}=3,95$; coordenadas $\mathrm{x}=-30, \mathrm{y}=-12, \mathrm{z}=$ -3) y putamen derecho $(\mathrm{r}(23)=, 48, \mathrm{p}=, 018$, control: $\mathrm{r}(23)=-, 49, \mathrm{p}=, 016 ; k=38 ; \mathrm{Z}=$ 3,34; coordenadas $\mathrm{x}=32, \mathrm{y}=-12, \mathrm{z}=-2)$ ) (Ver Figura 23). 

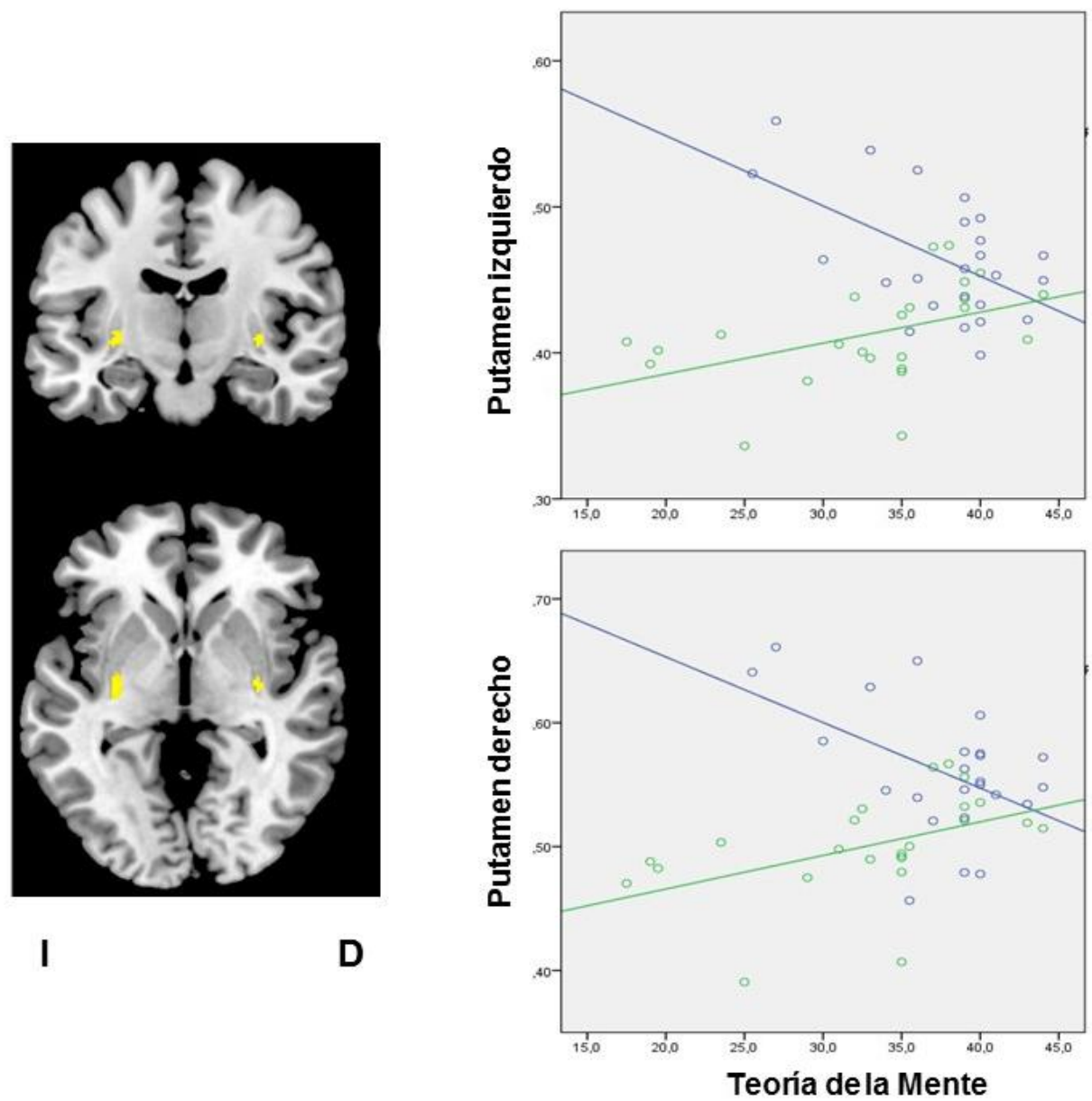

Figura 23. Análisis de interacción que muestra diferencias significativas en volumen de SG entre el grupo de niños con TEA y grupo control asociada a la puntuación global de ToM (SVC, FWE p < ,05 corregido a nivel de vóxel).

No se encontraron diferencias significativas entre grupos para el resto de variables del ToM (Historias de Happé, Meteduras de pata y Falsas creencias de $2^{\circ}$ orden).

\subsection{Cuestionario Sensory Profile, versión corta (CSP)}

Los resultados de comparación de medias para la variable CSP indicaron que los niños con TEA presentaban dificultades considerables en el procesamiento sensorial respecto a los controles, tal y como se ha reportado en estudios anteriores sobre el tema. A partir de estos resultados, se realizó una evaluación más exhaustiva y se compararon todos los factores que componían el CSP, para concretar con más precisión en qué factores se producían las diferencias entre los dos grupos. Los resultados mostraron que existían 
diferencias significativas entre los niños con TEA y los niños con desarrollo típico en los 7 ámbitos que evaluaba el CSP (Ver Tabla 13).

Tabla 13. Resultados de la ANOVA para la comparación de grupo en los diferentes factores del Cuestionario Sensory Profile, versión corta.

\begin{tabular}{lcccc} 
& $\begin{array}{c}\text { Grupo TEA } \\
\text { Media (Desv.típ.) }\end{array}$ & $\begin{array}{c}\text { Grupo Control } \\
\text { Media (Desv. típ.) }\end{array}$ & $\boldsymbol{F}(\mathbf{1 , 4 5})$ & $\boldsymbol{p}$ \\
\hline Puntuación global CSP & $121,08(25,09)$ & $173,75(13,12)$ & 82,53 &, $000^{* *}$ \\
\hline Sensibilidad táctil & $27,46(5,72)$ & $33,46(1,84)$ & 24,52 &, $000^{* *}$ \\
\hline $\begin{array}{l}\text { Sensib.gustativa/olfativa } \\
\text { Sensibilidad }\end{array}$ & $13,08(5,22)$ & $18,67(2,08)$ & 24,50 &, $000^{* *}$ \\
\hline movimiento & $12,29(2,71)$ & $14,46(0,93)$ & 13,36 &, $001^{* *}$ \\
\hline $\begin{array}{l}\text { Búsqueda sensaciones } \\
\text { Filtrado auditivo }\end{array}$ & $18,67(7,35)$ & $28,38(2,95)$ & 72,32 &, $000^{* *}$ \\
\hline $\begin{array}{l}\text { Baja energía } \\
\text { Sensib. visual/auditiva }\end{array}$ & $14,50(5,34)$ & $26,96(2,69)$ & 105,13 &, $000^{* *}$ \\
\hline *p <,05; ** $<, 01$ & $18,67(7,35)$ & $28,38(2,95)$ & 35,63 &, $000^{* *}$ \\
\hline
\end{tabular}

También se realizó un análisis para valorar si este cuestionario correlacionaba con la inteligencia, por lo que se llevó a cabo una serie de correlaciones de Pearson para explorar la relación entre el rendimiento general obtenido en el CSP y los diferentes índices específicos de las pruebas de inteligencia (WISC-IV). Cuando se analizaron las correlaciones obtenidas por los dos grupos, los resultados indicaron que no era significativa en ninguno de ellos (Ver Tabla 14). 
Tabla 14. Correlaciones entre el Cuestionario Sensory Profile y las pruebas de inteligencia.

\section{Total CI Verbal CI No Memoria Velocidad

Verbal Trabajo Procesam.

$\begin{array}{cccccc}\text { Grupo } & r=-, 18 & r=, 22 & r=-, 16 & r=-, 30 & r=-, 36 \\ \text { TEA } & p=, 394 & p=, 293 & p=, 459 & p=, 150 & p=, 084 \\ \text { Grupo } & r=-, 03 & r=, 01 & r=, 02 & r=, 04 & r=-, 10 \\ \text { Control } & p=, 890 & p=, 985 & p=, 921 & p=, 850 & p=, 647\end{array}$

$* p<, 05 ; * * p<, 01$

Los resultados de morfometría para valorar las correlaciones entre el volumen de SG y la puntuación global, así como con los factores que componen el cuestionario de CSP, indicaron que no había diferencias significativas a nivel de cerebro entero (FWE p<,05 corregido a nivel de clúster, con un umbral p<0,001 a nivel de vóxel) para ninguno de los dos grupos. Sin embargo, en el análisis de ROIs (SVC, FWE $\mathrm{p}<, 05$ corregido a nivel de vóxel) el grupo control presentó una correlación negativa significativa entre la variable Filtrado auditivo y el tálamo bilateral (tálamo izquierdo: $\mathrm{r}(23)=-, 56, \mathrm{p}=, 005$; $k=27 ; \mathrm{Z}=3,62 ;$ coordenadas $\mathrm{x}=-9, \mathrm{y}=-12, \mathrm{z}=5$; tálamo derecho: $\mathrm{r}(23)=-, 64, \mathrm{p}=$ $, 001 ; k=135 ; \mathrm{Z}=4,15 ;$ coordenadas $\mathrm{x}=12, \mathrm{y}=-12, \mathrm{z}=15)$. Presentaron también una correlación positiva significativa entre la variable Sensibilidad visual/auditiva y la región de la ínsula derecha $(\mathrm{r}(23)=, 72, \mathrm{p}=, 000 ; k=39 ; \mathrm{Z}=3,99 ;$ coordenadas $\mathrm{x}=39$, $\mathrm{y}=9, \mathrm{z}=-14)$ (Ver Figura 24). 
A)
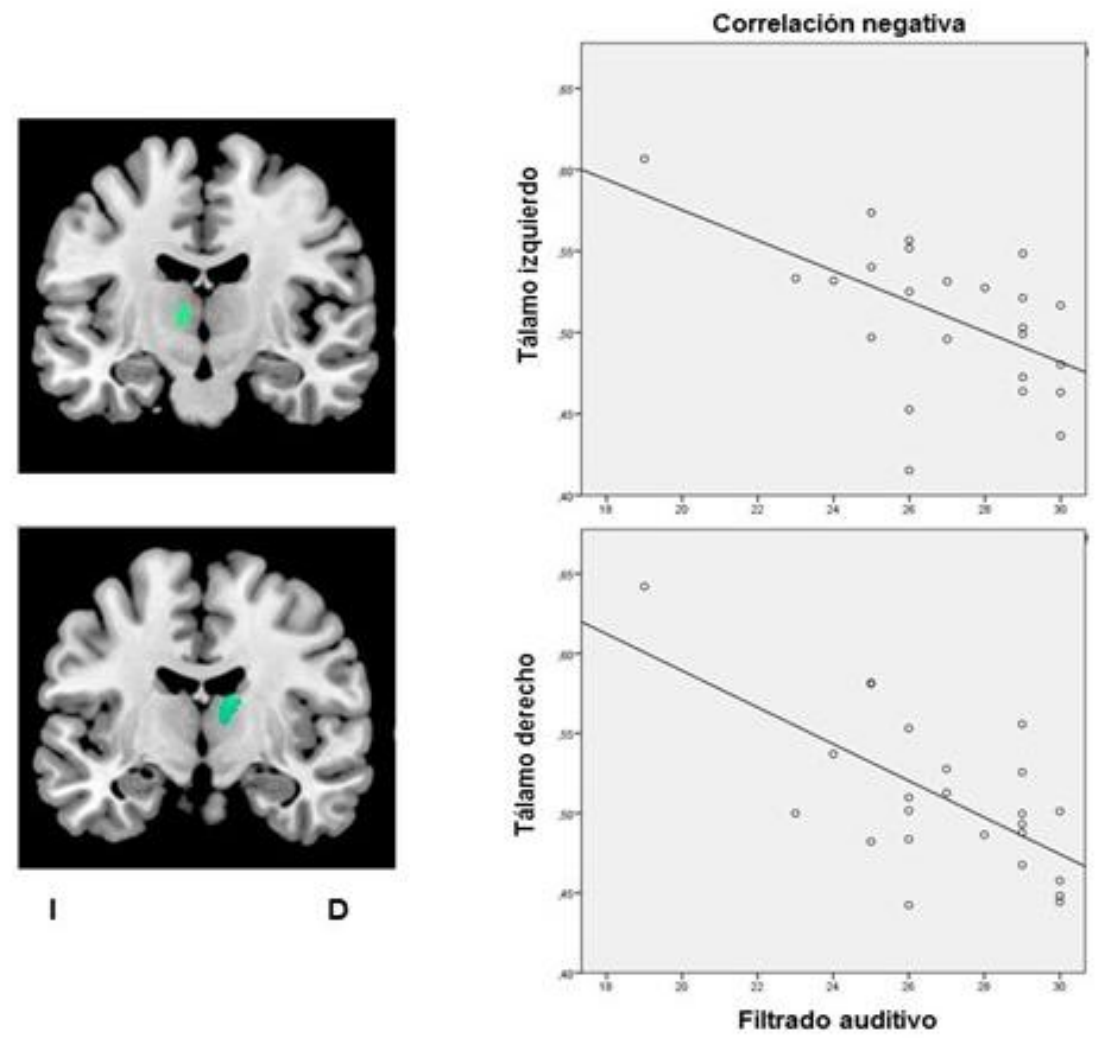

B)
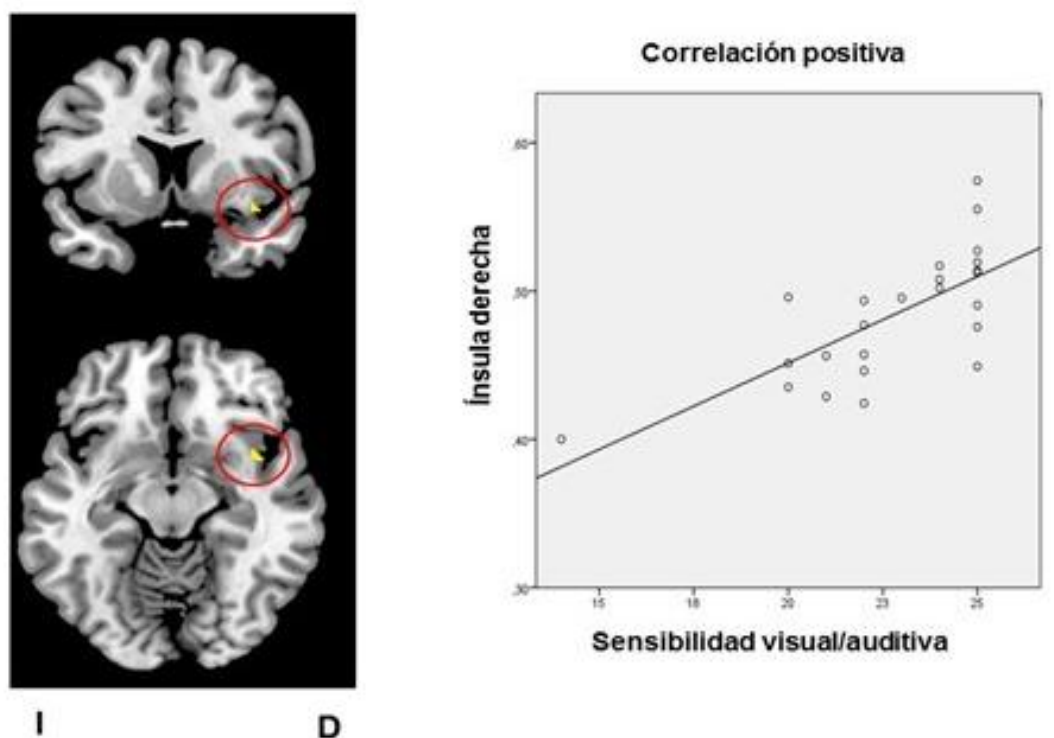

Figura 24 Análisis de Regresión múltiple entre el volumen de SG y las variables del cuestionario CSP, para el grupo de niños con desarrollo típico. A) Correlación negativa significativa entre la variable Filtrado auditivo y talamo bilateral; B) correlación positiva significativa entre la variable Sensibilidad visual/auditiva e ínsula derecha de sustancia gris respecto al grupo de niños con TEA (SVC, FWE $p<, 05$ corregido a nivel de vóxel). 
Respecto al grupo de niños con TEA, para el análisis de ROIs (SVC, FWE p< ,05 corregido a nivel de vóxel) los resultados indicaron una correlación positiva significativa entre la región del hipocampo derecho y las siguientes variables: la variable global de CSP $(\mathrm{r}(23)=, 35, \mathrm{p}=, 094 ; k=112 ; \mathrm{Z}=4,29$; coordenadas $\mathrm{x}=33$, y $=-21, \mathrm{z}=-11)$, la variable Filtrado auditivo $(\mathrm{r}(23)=, 48, \mathrm{p}=, 018 ; k=13 ; \mathrm{Z}=3,53$; coordenadas $\mathrm{x}=33, \mathrm{y}=-20, \mathrm{z}=-14$ ), la variable Sensibilidad al movimiento ( $\mathrm{r}(23)=$ $, 35, \mathrm{p}=, 093 ; k=50 ; \mathrm{Z}=3,70$; coordenadas $\mathrm{x}=38, \mathrm{y}=-20, \mathrm{z}=-14)$ y la variable Sensibilidad táctil $(\mathrm{r}(23)=, 66, \mathrm{p}=, 000 ; k=13 ; \mathrm{Z}=3,67$; coordenadas $\mathrm{x}=35, \mathrm{y}=-6, \mathrm{z}$ $=-21$ ). También se encontró una correlación positiva significativa entre el área de la amígdala y las variable Sensibilidad al movimiento (amígdala derecha: $\mathrm{r}(23)=, 26, \mathrm{p}=$ ,224; $k=30 ; \mathrm{Z}=3,53$; coordenadas $\mathrm{x}=29, \mathrm{y}=0, \mathrm{z}=-29$; amígdala izquierda: $\mathrm{r}(23)=$ ,45, $\mathrm{p}=, 028 ; k=28 ; \mathrm{Z}=3,91$; coordenadas $\mathrm{x}=-29, \mathrm{y}=0, \mathrm{z}=-27) \mathrm{y}$ Sensibilidad táctil (amígdala izquierda: $\mathrm{r}(23)=, 59, \mathrm{p}=, 002 ; k=14 ; \mathrm{Z}=3,58$; coordenadas $\mathrm{x}=-30, \mathrm{y}=2$, $\mathrm{z}=-23)$ (Ver Figura 25). 
A)

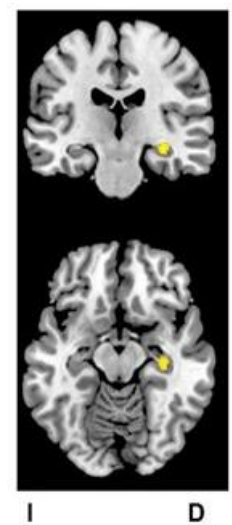

C)

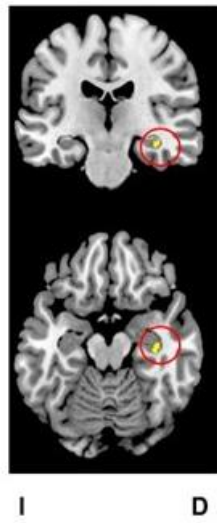

E)

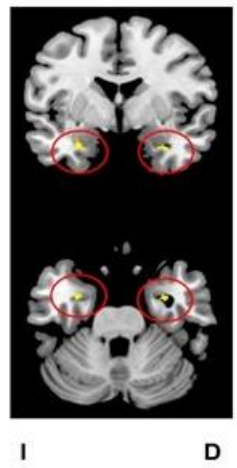

B)
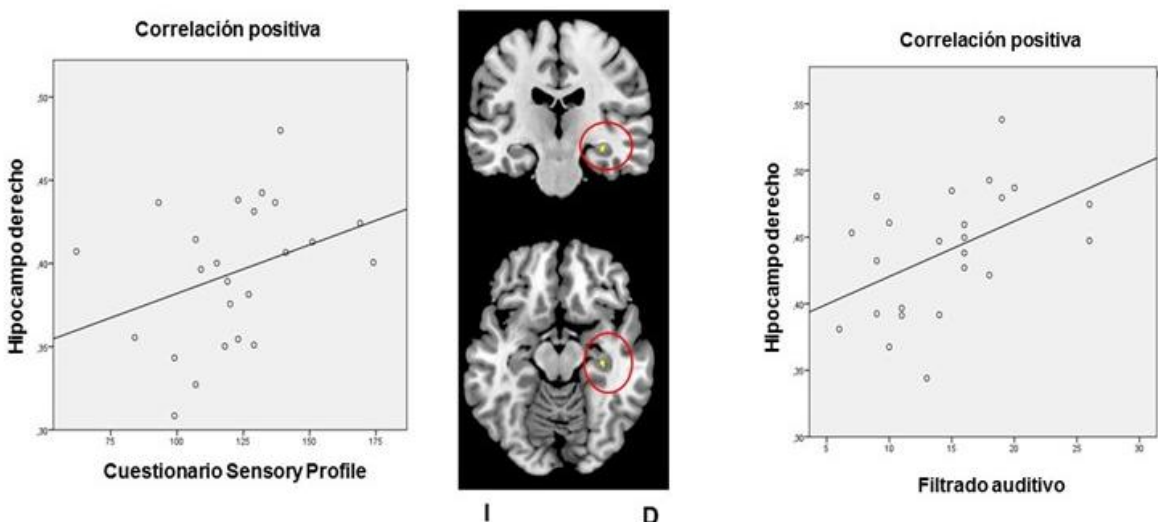

D)
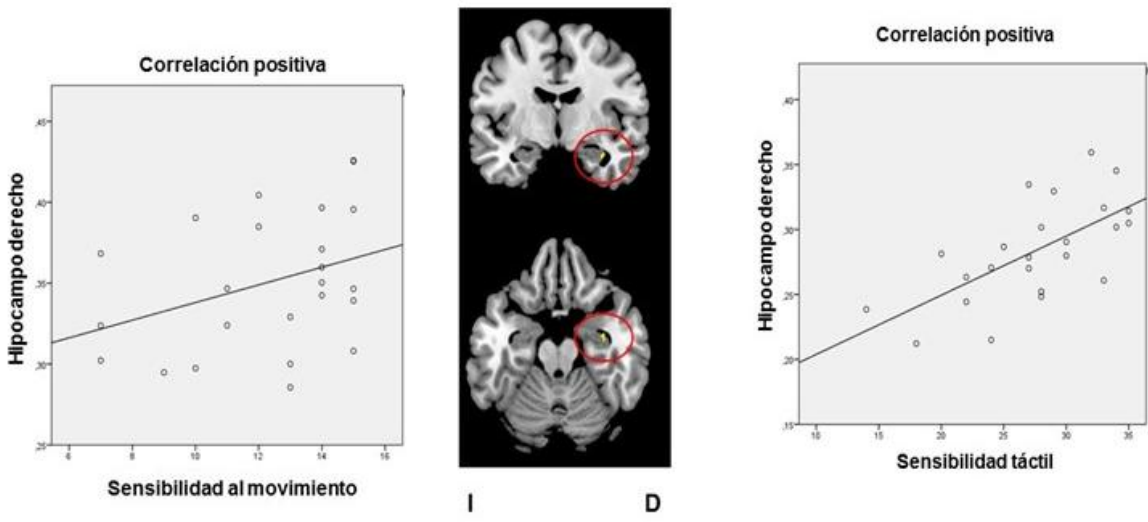

F)
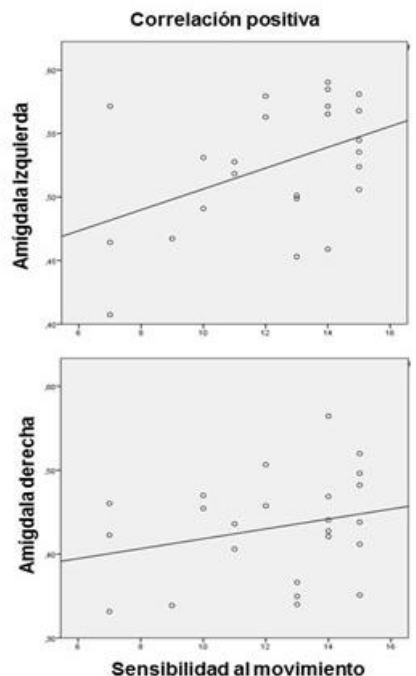
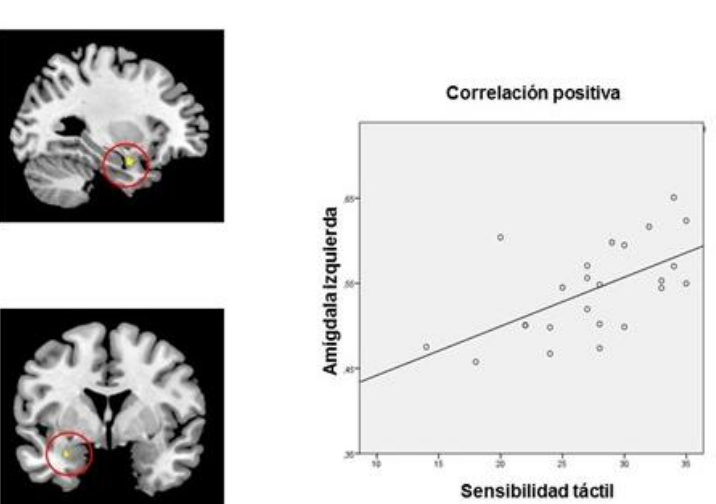

Figura 25. Regresión múltiple entre el volumen de SG y las variables del cuestionario CSP, para el grupo de niños con TEA. Los resultados mostraron un mayor volumen de SG en el hipocampo derecho correlacionado positivamente con las variables A) puntuación global de CSP; B) Filtrado auditivo; C) Sensibilidad al movimiento y D) Sensibilidad táctil. E) correlación positiva entre la amígdala bilateral y Sensibilidad al movimiento; F) correlación positiva entre la amígdala izquierda y Sensibilidad táctil. (SVC, FWE $\mathrm{p}<, 05$ corregido a nivel de vóxel). 
En el análisis de interacción, para evaluar las diferencias de grupo en cuanto a volumen de SG con las variables incluidas en este apartado, la variable Sensibilidad al movimiento mostró un mayor volumen de SG en el grupo con TEA respecto al grupo control en el cerebelo (TEA: $\mathrm{r}(23)=, 28, \mathrm{p}=, 177$, control: $\mathrm{r}(23)=-, 59, \mathrm{p}=, 002 ; k=$ 1922; $\mathrm{Z}=4,79$; coordenadas $\mathrm{x}=-14, \mathrm{y}=-51, \mathrm{z}=-44$ ), a nivel de cerebro entero (FWE $\mathrm{p}<, 05$ corregido a nivel de clúster, con un umbral $\mathrm{p}<0,001, \mathrm{k}=1922$ a nivel de vóxel).

Por otra parte, en el análisis de ROIs (SVC, FWE p<,05 a nivel de vóxel), los resultados mostraron diferencias significativas con un mayor volumen de SG en el grupo con TEA respecto al grupo control en el hipocampo izquierdo asociado a las siguientes variables: puntación global de CSP (TEA: $r(23)=, 56, p=, 004$, control: $r$ (23) $=-, 46, \mathrm{p}=, 240 ; k=48 ; Z=3,64$; coordenadas $x=-35, y=-24, z=-14)$ y Filtrado auditivo (TEA: $\mathrm{r}(23)=, 63, \mathrm{p}=, 001$, control: $\mathrm{r}(23)=-, 48, \mathrm{p}=, 019 ; k=47 ; Z=3,56$; coordenadas $x=-35, y=-24, z=-12$ ). Así mismo, también se encontró un mayor volumen de SG en el grupo con TEA comparado con el grupo control, en el núcleo cingulado anterior derecho relacionado con la variable Sensibilidad visual/auditiva (TEA: $\mathrm{r}(23)=, 05, \mathrm{p}=, 836$, control: $\mathrm{r}(23)=-, 57, \mathrm{p}=, 004 ; k=29 ; Z=3,52$; coordenadas $x=9, y=36, z=26$ ) (Ver Figura 26).

No se obtuvieron diferencias significativas para las variables Sensibilidad gustativa/olfativa, Sensibilidad táctil, Búsqueda de sensaciones y Baja energía en ninguno de los dos grupos. 
A)

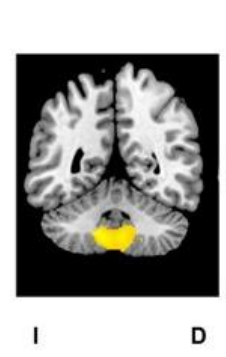

C)

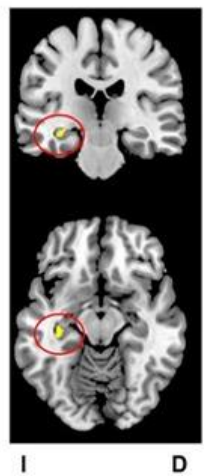

B)
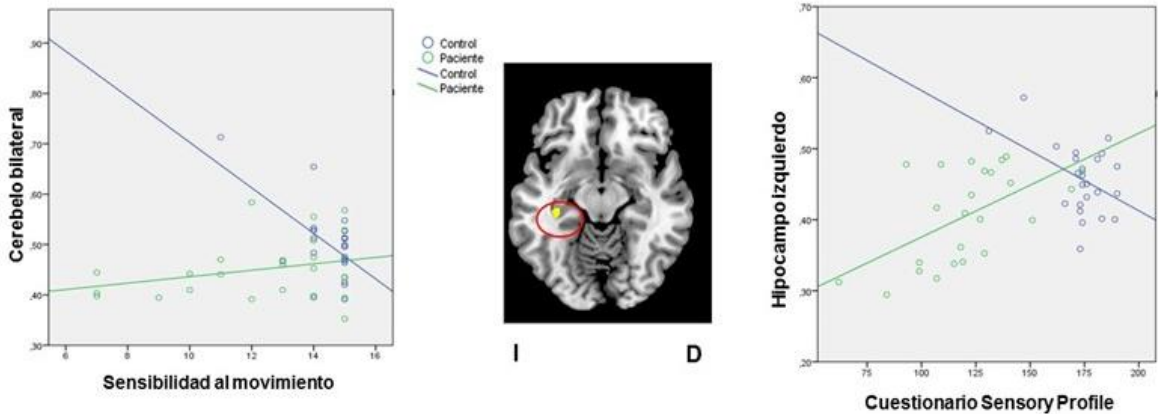

D)
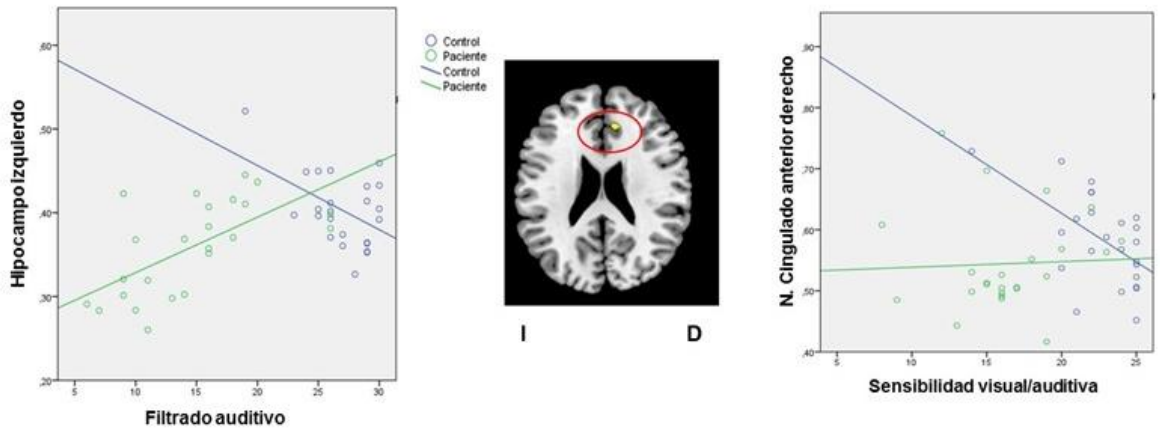

Figura 26. Análisis de interacción donde el grupo de niños con TEA presenta mayor volumen de SG respecto al grupo de niños controles A) en el cerebelo bilateral asociado a la Sensibilidad al movimiento (FWE p<,05 corregido a nivel de clúster); en el hipocampo izquierdo asociado a B) la puntuación global de CSP y C) a Filtrado auditivo; y D) en cingulado anterior derecho con la variable Sensibilidad visual/auditiva (SVC, FWE $p<, 05$ corregido a nivel de vóxel).

\subsection{Cuestionarios: Cociente Empatía (CE) y Cociente Sistematización (CS)}

Respecto al CE (Baron-Cohen et al., 2009) se obtuvieron diferencias muy significativas en la comparación de medias entre ambos grupos, confirmándose así las dificultades que presentan los niños con TEA en el desarrollo de la empatía. Sin embargo, en el CS se observó una ligera diferencia entre las medias de los dos grupos que no era significativa. (Ver Tabla 15). 
Tabla 15. Resultados de la ANOVA para la comparación de grupos en los dos cuestionarios.

$\begin{array}{cccc}\text { Grupo TEA } & \text { Grupo Control } & \text { F }(1,45) & p \\ \text { Media (Desv.típ.) } & \text { Media (Desv. típ.) } & & \end{array}$

\begin{tabular}{llccc} 
C. Empatía & $21,08(8,65)$ & $41,67(5,83)$ & 94,24 &, $000^{* *}$ \\
\hline C. Sistematización & $24,63(6,07)$ & $28,04(5,77)$ & 3,86 &, 056 \\
\hline
\end{tabular}

$* p<, 05 ; * * p<, 01$

Se analizó la relación entre el rendimiento general obtenido en el ambos cuestionarios, CE y CS, y los diferentes índices específicos de las pruebas de inteligencia (WISC-IV), al igual que se realizó este análisis con las anteriores pruebas neuropsicológicas. Los resultados obtenidos utilizando la correlación de Pearson indicaron que no había correlaciones significativas en el grupo control con ninguno de los dos cuestionarios. Sin embargo, en el grupo de niños con TEA, las correlaciones fueron significativas con el CS (Ver Tabla 16).

Tabla 16. Correlaciones entre los cuestionarios que evalúan el CE y el CS con las pruebas de inteligencia, para cada grupo.

\begin{tabular}{|c|c|c|c|c|c|c|}
\hline & & CI Total & $\begin{array}{c}\text { CI } \\
\text { Verbal }\end{array}$ & $\begin{array}{c}\text { CI No } \\
\text { Verbal }\end{array}$ & $\begin{array}{c}\text { Memoria } \\
\text { Trabajo }\end{array}$ & $\begin{array}{l}\text { Velocidad } \\
\text { Procesam. }\end{array}$ \\
\hline $\begin{array}{c}\text { Grupo } \\
\text { TEA }\end{array}$ & $\mathrm{CE}$ & $\begin{array}{c}r=-, 13 \\
p=, 554\end{array}$ & $\begin{array}{c}r=, 30 \\
p=, 154\end{array}$ & $\begin{array}{c}r=-, 16 \\
p=, 458\end{array}$ & $\begin{array}{l}r=-, 30 \\
p=, 150\end{array}$ & $\begin{array}{l}r=-, 26 \\
p=, 209\end{array}$ \\
\hline & $\mathrm{CS}$ & $\begin{array}{c}r=, 51 \\
p=, 010^{*}\end{array}$ & $\begin{array}{c}r=, 24 \\
p=, 251\end{array}$ & $\begin{array}{c}r=, 42 \\
p=, 041 *\end{array}$ & $\begin{array}{c}r=, 30 \\
p=, 157\end{array}$ & $\begin{array}{c}r=, 48 \\
p=, 018^{*}\end{array}$ \\
\hline $\begin{array}{l}\text { Grupo } \\
\text { control }\end{array}$ & $\mathrm{CE}$ & $\begin{array}{c}r=, 11 \\
p=, 599\end{array}$ & $\begin{array}{c}r=, 07 \\
p=, 741\end{array}$ & $\begin{array}{c}r=, 03 \\
p=, 887\end{array}$ & $\begin{array}{c}r=, 11 \\
p=, 601\end{array}$ & $\begin{array}{c}r=, 19 \\
p=, 370\end{array}$ \\
\hline & $\mathrm{CS}$ & $\begin{array}{c}r=, 07 \\
p=, 756\end{array}$ & $\begin{array}{c}r=-, 09 \\
p=, 683\end{array}$ & $\begin{array}{c}r=, 13 \\
p=, 535\end{array}$ & $\begin{array}{l}r=-, 04 \\
p=, 865\end{array}$ & $\begin{array}{c}r=, 20 \\
p=, 348\end{array}$ \\
\hline
\end{tabular}


Se realizó también una exploración para determinar las posibles correlaciones que podría haber entre cada uno de estos cuestionarios y la morfometría cerebral, para cada grupo de participantes. En primer lugar, se realizó un análisis a nivel de cerebro entero (FWE $\mathrm{p}<, 05$ corregido a nivel de clúster, con un umbral $\mathrm{p}<0,001$ a nivel de vóxel) y no se obtuvo ningún resultado significativo. Posteriormente, se realizó un análisis a nivel de ROIs (SVC, FWE p<,05 a nivel de vóxel) y, únicamente, se encontró una correlación positiva significativa en el grupo de niños con TEA entre el CE y la amígdala bilateral (amígdala derecha: $\mathrm{r}(23)=, 57, \mathrm{p}=, 004 ; k=38 ; \mathrm{Z}=3,78$; coordenadas $\mathrm{x}=32, \mathrm{y}=-3, \mathrm{z}=-18$; amígdala izquierda: $\mathrm{r}(23)=, 54, \mathrm{p}=, 006 ; k=24 ; \mathrm{Z}$ $=3,64$; coordenadas $\mathrm{x}=-30, \mathrm{y}=-5, \mathrm{z}=-17)$. No se encontraron correlaciones significativas para el grupo control en ninguno de los dos cuestionarios (Ver Figura 27).
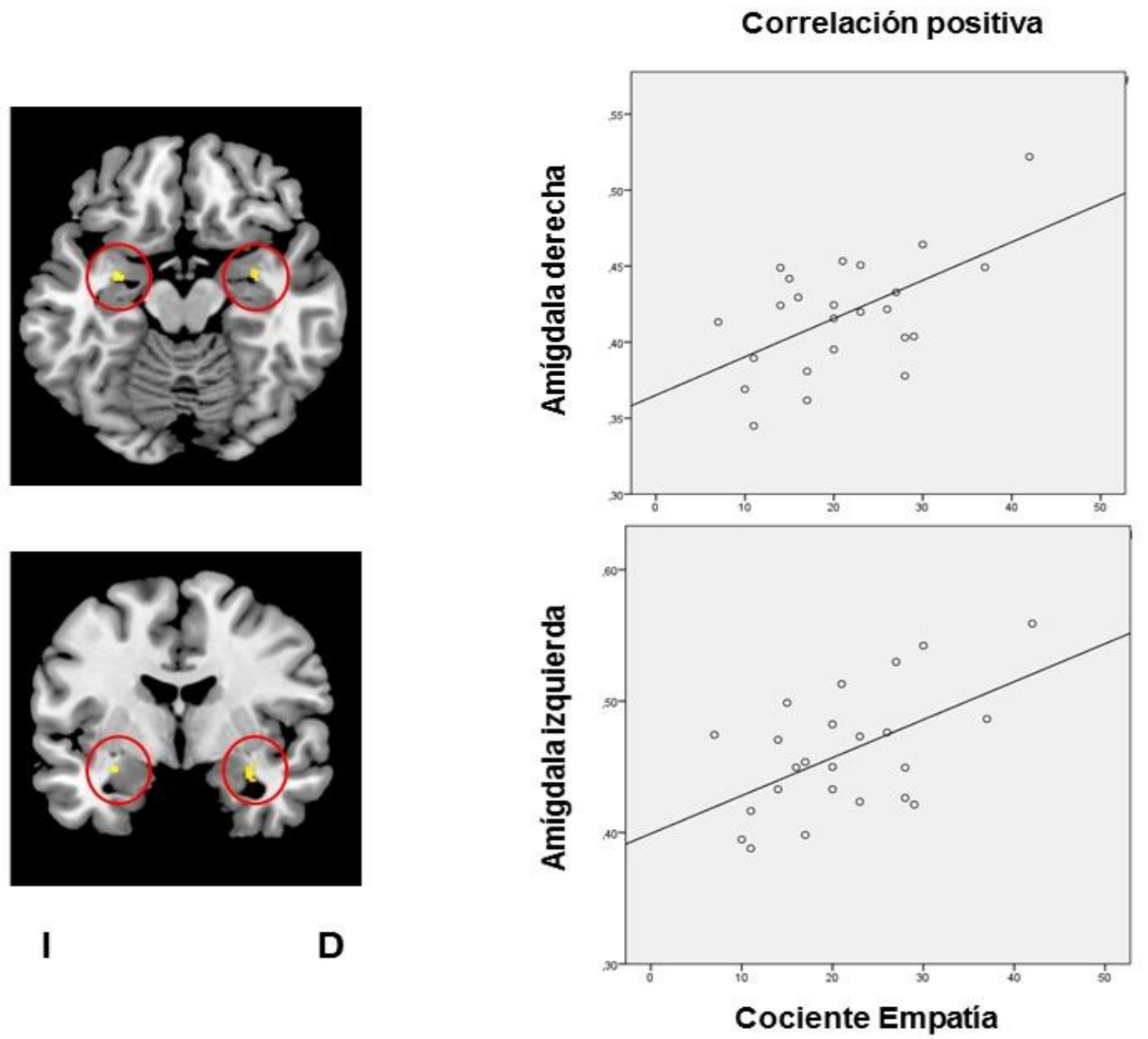

Figura 27. Regresión múltiple entre el volumen de SG y la variable CE para el grupo de niños TEA. Los resultados muestran una correlación positiva con la amígdala bilateral (SVC, FWE $\mathrm{p}<, 05$ corregido a nivel de vóxel). 
Respecto al análisis de interacción, para evaluar las diferencias de grupo en volumen de SG relacionado con cada uno de los cuestionarios incluidos en este apartado, no se obtuvo ningún resultado significativo ni a nivel de análisis del cerebro entero (FWE $\mathrm{p}<, 05$ corregido a nivel de clúster, con un umbral $\mathrm{p}<0,001$ a nivel de vóxel) ni en el análisis de ROIs (SVC, FWE p< ,05 a nivel de vóxel).

\subsection{Análisis factorial}

Se realizó un análisis factorial en el que se introdujeron 6 variables utilizadas en el presente estudio (CE, CS, CSP, ToM, CI Verbal, CI No Verbal) para valorar la relación existente entre ellas. El método de rotación utilizado fue el Oblimin con Kaiser, a partir del cual se obtuvieron dos factores: Factor 1 (CE, CSP y ToM) y Factor 2 (CI Verbal, CI No Verbal y CS). El porcentaje de varianza explicado por el Factor 1 era de 46,95\% y por el Factor 2 era de 20,22\% (Ver Tabla 17).

Tabla 17. Resultados obtenidos en el análisis factorial (Matriz de configuración).

FACTOR 1

FACTOR 2

Cuestionario Sensory Profile

Cociente de Empatía

Teoría de la Mente (punt. global)

CI No Verbal

Cociente de Sistematización

CI Verbal

, 885
$-, 028$ ,879 , 072 , 738 $-, 066$ , 023 , 867 $-, 105$ , 744

, 435
, 562

Cuando se utilizaron las puntuaciones factoriales, no se encontraron correlaciones significativas en las regresiones para cada grupo. Al realizar el análisis de interacción, el análisis a nivel de volumen total del cerebro (FWE $\mathrm{p}<, 05$ corregido a nivel de clúster, con un umbral $\mathrm{p}<0,001$ a nivel de vóxel) no mostró diferencias significativas, pero en el análisis de ROIs (SVC, FWE p <,05 a nivel de vóxel) los resultados de la interacción 
con la variable Factor 1 mostraron un mayor volumen de SG en el grupo de niños con TEA comparado con el grupo de control en el hipocampo izquierdo (TEA: r $(23)=, 59$, control: $\mathrm{r}(23)=-, 48, \mathrm{p}=, 018 ; \mathrm{p}=, 002 ; k=16 ; \mathrm{Z}=3,39 ;$ coordenadas $\mathrm{x}=-20, \mathrm{y}=-21, \mathrm{z}$ $=-14)$ y en el putamen izquierdo (TEA: $\mathrm{r}(23)=, 29, \mathrm{p}=, 168$, control: $: \mathrm{r}(23)=-, 56, \mathrm{p}=$ , $005 ; k=32 ; \mathrm{Z}=3,44$; coordenadas $\mathrm{x}=-33, \mathrm{y}=-14, \mathrm{z}=-3$ ) (Ver Figura 28).

No se obtuvieron diferencias significativas entre grupos utilizando el umbral estadístico preestablecido para el Factor 2.

A)
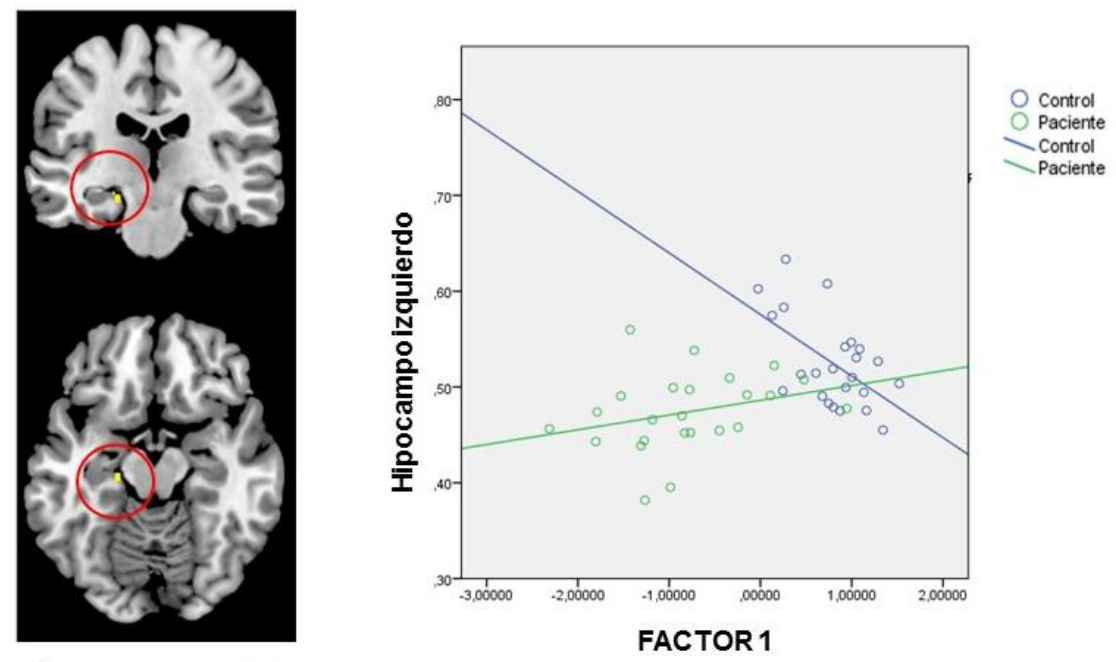

B)
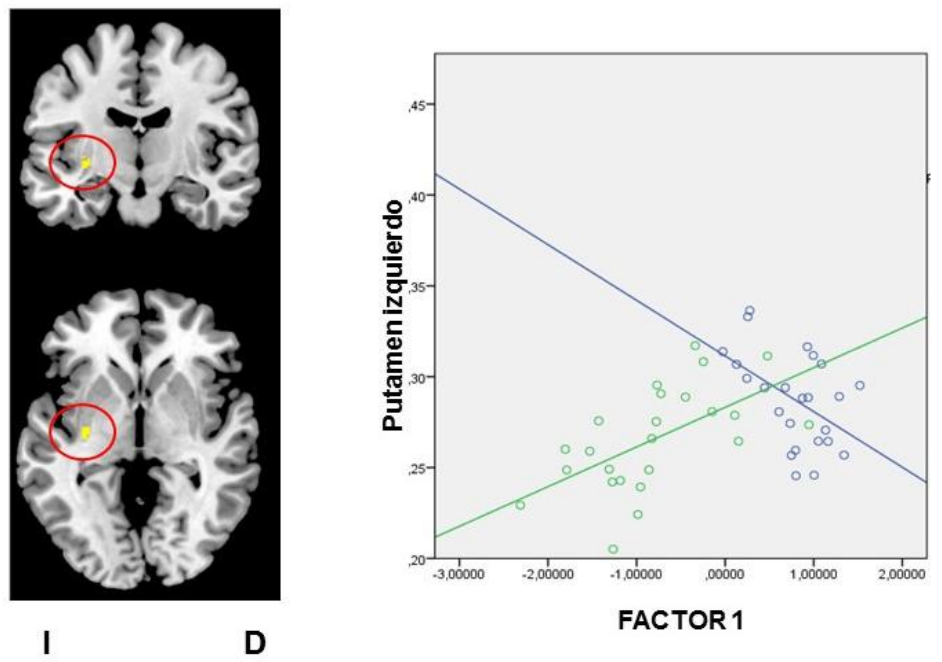

Figura 28. Análisis de interacción donde el grupo de niños con TEA presenta mayor volumen de SG respecto al grupo de niños controles asociado al Factor 1 en A) hipocampo izquierdo y B) putamen izquierdo, (SVC, FWE $\mathrm{p}<, 05$ corregido a nivel de vóxel). 
Tabla 18. Resumen de las correlaciones del grupo de niños con TEA entre el volumen de SG y variables de las diferentes pruebas neuropsicológicas y cuestionarios utilizados en el estudio. Se muestra el valor del estadístico Z, la extensión de los vóxeles del clúster $(k)$ y las coordenadas de la máxima local (coordenadas MNI: $x, y, z$ ).

\begin{tabular}{|c|c|c|c|c|}
\hline Variables & ROI & $\boldsymbol{k}$ & $\mathbf{Z}$ & $\begin{array}{l}\text { Coordenadas } \\
\quad(\mathbf{x}, \mathbf{y}, \mathbf{z})\end{array}$ \\
\hline \multicolumn{5}{|l|}{ CI Total } \\
\hline & N.Caudado izquierdo & 36 & 4,33 & $-9,-5,18$ \\
\hline $\begin{array}{l}\text { Test de la } \\
\text { Mirada }\end{array}$ & Amígdala derecha & 28 & 3,36 & $30,0,-14$ \\
\hline $\begin{array}{c}\text { Cuestionario } \\
\text { Sensory } \\
\text { Profile }\end{array}$ & Hipocampo derecho & 112 & 4,29 & $33,-21,-11$ \\
\hline \multirow[t]{2}{*}{$\begin{array}{c}\text { Sensibilidad } \\
\text { táctil }\end{array}$} & Amígdala izquierda & 14 & 3,58 & $-30,2,-23$ \\
\hline & Hipocampo derecho & 13 & 3,67 & $35,-6,-21$ \\
\hline \multirow[t]{3}{*}{$\begin{array}{l}\text { Sensibilidad } \\
\text { Movimiento }\end{array}$} & Hipocampo derecho & 50 & 3,70 & $38,-20,-14$ \\
\hline & Amígdala izquierda & 28 & 3,91 & $-29,0,-27$ \\
\hline & Amígdala derecha & 30 & 3,53 & $29,0,-29$ \\
\hline $\begin{array}{l}\text { Filtrado } \\
\text { auditivo }\end{array}$ & Hipocampo derecho & 13 & 3,53 & $33,-20,-14$ \\
\hline \multirow[t]{2}{*}{$\begin{array}{l}\text { Cociente } \\
\text { Empatía }\end{array}$} & Amígdala izquierda & 24 & 3,64 & $-30,-5,-17$ \\
\hline & Amígdala derecha & 38 & 3,78 & $32,-3,-18$ \\
\hline
\end{tabular}


Tabla 19. Resumen de las correlaciones del grupo de niños con desarrollo típico entre el volumen regional de sustancia gris y variables de las diferentes pruebas neuropsicológicas y cuestionarios utilizados en el estudio. Se muestra el valor del estadístico Z, la extensión de los vóxeles del clúster $(k)$ y las coordenadas de la máxima local (coordenadas MNI: $x, y, z$ ).

\begin{tabular}{|c|c|c|c|c|}
\hline Variables & ROI & $k$ & $\mathbf{Z}$ & $\begin{array}{c}\text { Coordenadas } \\
\quad(\mathbf{x}, \mathbf{y}, \mathbf{z})\end{array}$ \\
\hline \multirow[t]{2}{*}{$\begin{array}{c}\text { Velocidad } \\
\text { Procesamiento }\end{array}$} & $\begin{array}{l}\text { Giro Cingulado } \\
\text { posterior derecho }\end{array}$ & 682 & $\begin{array}{l}4,18 \\
4,03\end{array}$ & $\begin{array}{l}23,-54,-2 \\
24,-60,8\end{array}$ \\
\hline & Cerebelo izquierdo* & 747 & $\begin{array}{l}3,82 \\
3,71 \\
3,66\end{array}$ & $\begin{array}{l}-21,-77,-27 \\
-23,-66,-41 \\
-11,-63,-32\end{array}$ \\
\hline ToM & $\begin{array}{l}\text { Giro Frontal } \\
\text { medio/inferior derecho } \\
\text { (BA46) }\end{array}$ & 725 & $\begin{array}{l}4,24 \\
4,09 \\
3,53\end{array}$ & $\begin{array}{l}50,42,29 \\
56,35,26 \\
39,44,21\end{array}$ \\
\hline $\begin{array}{l}\text { Filtrado } \\
\text { auditivo }\end{array}$ & $\begin{array}{l}\text { Tálamo izquierdo* } \\
\text { Tálamo derecho* }\end{array}$ & $\begin{array}{c}27 \\
135\end{array}$ & $\begin{array}{l}3,62 \\
4,15\end{array}$ & $\begin{array}{c}-9,-12,5 \\
12,-12,15\end{array}$ \\
\hline $\begin{array}{c}\text { Sensibilidad } \\
\text { visual/auditiva }\end{array}$ & Ínsula derecha & 39 & 3,99 & $39,9,-14$ \\
\hline
\end{tabular}

*correlación negativa 
Tabla 20. Resumen del estudio de la interacción en volumen de SG, asociada a las variables de las diferentes pruebas neuropsicológicas y cuestionarios utilizados, entre el grupo de niños con TEA y los niños con desarrollo típico. Se muestra el valor del estadístico Z, la extensión de los vóxeles del clúster $(k)$ y las coordenadas de la máxima local (coordenadas MNI: $x, y, z$ ).

\begin{tabular}{|c|c|c|c|c|}
\hline Variables & ROI & $\boldsymbol{k}$ & $\mathbf{Z}$ & $\begin{array}{c}\text { Coordenadas } \\
\quad(\mathbf{x}, \mathbf{y}, \mathbf{z})\end{array}$ \\
\hline \multicolumn{5}{|l|}{ CI No Verbal } \\
\hline & Tálamo izdo. & 52 & 3,96 & $-23,-29,6$ \\
\hline & Tálamo dcho. & 97 & 3,73 & $20,-26,9$ \\
\hline \multirow{5}{*}{$\begin{array}{c}\text { Velocidad } \\
\text { Procesamiento }\end{array}$} & & & & \\
\hline & Cerebelo izdo. & 847 & 3,96 & $-24,-77,-30$ \\
\hline & & & 3,41 & $-21,-68,-39$ \\
\hline & Cerebelo dcho. & 1548 & 4,32 & $24,-77,-33$ \\
\hline & & & 4,01 & $18,-71,-38$ \\
\hline \multicolumn{5}{|l|}{ ToM } \\
\hline & Putamen izdo. & 165 & 3,95 & $-30,-12,-3$ \\
\hline & Putamen dcho. & 38 & 3,34 & $32,-12,-2$ \\
\hline \multicolumn{5}{|l|}{ Cuestionario } \\
\hline $\begin{array}{l}\text { Sensory } \\
\text { Profile }\end{array}$ & Hipocampo izdo. & 48 & 3,64 & $-35,-24,-14$ \\
\hline $\begin{array}{l}\text { Filtrado } \\
\text { auditivo }\end{array}$ & Hipocampo izdo. & 47 & 3,56 & $-35,-24,-12$ \\
\hline \multirow[t]{3}{*}{$\begin{array}{l}\text { Sensibilidad } \\
\text { movimiento }\end{array}$} & Cerebelo bilateral & 1922 & 4,79 & $-14,-51,-44$ \\
\hline & & & 4,47 & $5,-51,-47$ \\
\hline & & & 3,80 & $20,-56,-45$ \\
\hline $\begin{array}{c}\text { Sensibilidad } \\
\text { visual/auditiva }\end{array}$ & $\begin{array}{l}\text { N. Cingulado } \\
\text { anterior dcho. }\end{array}$ & 29 & 3,52 & $9,36,26$ \\
\hline \multicolumn{5}{|l|}{ Factor 1} \\
\hline & Hipocampo izq. & 16 & 3,39 & $-20,-21,-14$ \\
\hline & & 11 & 3,39 & $-17,-29,-11$ \\
\hline & Putamen izdo. & 32 & 3,44 & $-33,-14,-3$ \\
\hline
\end{tabular}




\section{VI- DISCUSIÓN Y CONCLUSIONES}

En este estudio pretendíamos analizar, por un lado, mediante técnicas de morfometría cerebral, la trayectoria de desarrollo cerebral atípica de determinadas regiones específicas (corticales, límbicas, estriatales y cerebelares) implicadas en el procesamiento socioemocional y conductual en una muestra de 24 niños con autismo de 8 a 12 años. Por otro lado, examinar las relaciones existentes entre el rendimiento obtenido en una serie de pruebas cognitivas utilizadas en el estudio y el desarrollo de las regiones cerebrales citadas anteriormente que están implicadas en el trastorno. Además, pretendíamos explicar las características nucleares del TEA a partir de dichas áreas cerebrales durante la franja de edad indicada. En el estudio también participó un grupo de 24 niños con desarrollo típico.

Los participantes de ambos grupos realizaron una serie de pruebas neuropsicológicas para evaluar la capacidad cognitiva y las habilidades relacionadas con el desarrollo de la ToM y una prueba de RMe. Asimismo, se recogieron datos a partir de una serie de cuestionarios cumplimentados por los padres de los niños participantes. En concreto, cuestionarios para evaluar el perfil sensorial y el nivel de desarrollo de la empatía y de la sistematización.

Los resultados obtenidos a partir del análisis estadístico indicaron que los niños con autismo obtuvieron peor rendimiento en las pruebas que evaluaban ToM, obtuvieron puntuaciones más bajas en empatía y presentaban déficits significativos en el procesamiento sensorial, cuando se compararon los resultados con el grupo control. En cambio, y de forma inesperada, no mostraron puntuaciones superiores en índices de Sistematización. Respecto al análisis morfométrico, los niños con TEA con una media de 10,29 años de edad no presentaron diferencias globales en volumen de sustancia gris, sustancia blanca o de líquido cefaloraquídeo en relación con el grupo control. Tampoco se encontraron diferencias específicas en sustancia gris en las diversas regiones cerebrales implicadas en el desarrollo de la cognición social y de las emociones (estructuras límbicas como el hipocampo y la amígdala, el tálamo y cerebelo) ni en regiones cerebrales relacionadas con conductas repetitivas, intereses restringidos y resistencia al cambio (putamen, núcleo caudado). En cambio, nuestros datos mediante correlaciones entre el volumen de sustancia gris y las variables neuropsicológicas muestran una relación diferente en estas estructuras clave en la manifestación del TEA. 
Una de las principales contribuciones de nuestro trabajo ha sido la confirmación de que el patrón de desarrollo atípico, iniciado en los primeros años de vida en niños con autismo en una serie de estructuras cerebrales implicadas en el desarrollo de la cognición social y de las emociones, sigue siendo evidente en la franja de edad utilizada. En estudios previos sobre el tema, se ha descrito la trayectoria de desarrollo cerebral atípica en los primeros años de vida o durante la adolescencia y la etapa adulta. Nosotros aportamos datos concretos sobre la trayectoria de desarrollo desde los 8 hasta los 12 años en un grupo de niños con TEA. Otra contribución interesante de esta tesis son los resultados obtenidos en el estudio correlacional realizado a partir del cual podemos indicar que en los niños con TEA a mayor volumen en las estructuras cerebrales estudiadas mejor funcionamiento cognitivo y emocional mientras que en el grupo control la tendencia es la opuesta, es decir, a mayor maduración cerebral menor volumen de sustancia gris.

Antes de iniciar una reflexión sobre las aportaciones y conclusiones finales de nuestro trabajo, consideramos interesante comentar dos aspectos novedosos del mismo. Por un lado, el planteamiento llevado a cabo a partir de un estudio correlacional en un grupo de niños con TEA combinando una serie de variables morfométricas y otras variables conductuales para poder determinar la relación existente entre determinadas regiones cerebrales y el rendimiento obtenido en una serie de pruebas neuropsicológicas. De esta manera, pretendíamos comprobar si la variedad conductual observada en dicho grupo era debida a las diferencias individuales en determinadas áreas cerebrales relacionadas con funciones importantes que aparecen alteradas en esta población. Las ROIs que hemos utilizado en nuestro trabajo son aquellas que han mostrado en niños con autismo diferencias significativas en las trayectorias de desarrollo (respecto a niños con desarrollo típico) a nivel cortical (córtex prefrontal medial y lateral), subcortical (hipocampo, amígdala, núcleo caudado, putamen y tálamo) y a nivel cerebelar.

El segundo aspecto, que consideramos relevante está relacionado con la muestra de participantes. La mayoría de investigaciones anteriores que han utilizado neuroimagen estructural en el campo del TEA han incluido adolescentes y adultos con autismo (Doyle-Thomas et al., 2013; Raznahan et al., 2010; Hadjikhani, Joseph, Snyder \& Tager-Flusberg, 2006; Hyde, Samson, Evans \& Mottron, 2010; Ecker et al., 2013) de modo que los resultados no se podían extrapolar a la etapa infantil. Otros estudios se han centrado en los primeros años de vida (Hazlett et al., 2011; Raznahan et al., 2012; 
Schumann et al., 2010), por lo que tampoco proporcionan una imagen completa de las trayectorias neuroanatómicas del desarrollo en el autismo a lo largo de toda la etapa infantil posterior. Pocos estudios se han centrado en la franja de edad previa a la adolescencia. Los niños que participan en el presente estudio tienen edades comprendidas entre 8 y 12 años, etapa importante porque aún no se han producido cambios significativos estructurales $y$ funcionales en el desarrollo cerebral característicos de la adolescencia (por ejemplo, cambios en la poda sináptica, en la mielinización, cambios volumétricos en estructuras subcorticales, diferencias sexuales en la conducta y en la cognición) (Giedd et al., 2009; Yang, Beam, Pelphrey, Abdullahi \& Jou, 2016; Lenroot et al., 2007; Dennison et al., 2013).

Según hemos podido comprobar en los datos aportados en el marco teórico, un amplio conjunto de estudios previos utilizando técnicas de neuroimagen estructural han señalado que individuos con autismo presentan trayectorias de desarrollo cerebral atípicas desde edades muy tempranas. Los modelos de desarrollo cerebral atípicos en el TEA descritos indican que uno de los resultados más consolidados ha sido el crecimiento acelerado del cerebro a partir del primer año de vida, especialmente el aumento de SG y SB en los lóbulos frontales y temporales, seguido de una ralentización de dicho crecimiento durante la infancia tardía hasta el inicio de la adolescencia, para ser similar y no presentar diferencias significativas en la vida adulta, cuando han sido comparados con sujetos con desarrollo típico (Courchesne et al., 2001, 2004, 2011; Sparks et al., 2001; Bartholomeusz et al., 2002; Courchesne \& Pierce, 2005;; Yorbik et al. 2001; Lainhart et al. 1997; Bolton et al. 2001; Hazlett et al., 2005, 2011).

Quizá el dato más notable sea la existencia de cambios volumétricos relacionados con la edad en el volumen total cerebral así como en regiones específicas. Estas regiones específicas corresponden a aquellas cuyo desarrollo se produce en personas neurotípicas en los primeros 4 años de vida, e incluyen zonas frontales mediales, zonas límbicas y zonas subcorticales. En concreto, estas zonas relevantes en el autismo son la corteza frontal medial (Carper et al., 2002; Carper \& Courchesne, 2005; Herbert et al., 2004), el lóbulo temporal, áreas límbicas como el hipocampo (Sparks et al., 2002; Barnea-Goraly et al., 2014), la amígdala (Mosconi et al., 2009; Munson et al., 2006; Nordahl et al., 2012; Schumann et al., 2009; Sparks et al., 2002), y el córtex cingulado (Joseph, Ehrman, McNally \& Keehn, 2008; Bush, Luu \& Posner, 2000; Thakkar et al., 2008), y 
zonas subcorticales como el estriado (Sears et al., 1999; Hazlett et al., 2005; Langen et al., 2014), y el tálamo (Say et al., 2014; Schuetze et al., 2016). El cerebelo también ha sido una región ampliamente estudiada ya que forma parte de los circuitos neurales que son disfuncionales en el TEA (O’Hearn, Asato, Ordaz \& Luna, 2008; Stoodley \& Schmahmann, 2010; Basson \& Wingate, 2013). Además, otro dato interesante es que se han relacionado las áreas mencionadas con el desarrollo de funciones cognitivas de orden superior que están afectadas en este trastorno, tales como, por ejemplo, el desarrollo de la cognición social o la aparición de conductas e intereses restringidos o repetitivos.

Por tanto, la trayectoria de desarrollo cerebral observada en individuos con TEA indica un patrón de crecimiento acelerado durante la infancia, seguido de una ralentización en la adolescencia temprana para igualarse al final de la adolescencia y durante la edad adulta. Este proceso madurativo es diferente en el desarrollo cerebral humano típico, donde el volumen cerebral total presenta una trayectoria en forma de $\mathrm{U}$ invertida, con un crecimiento rápido en la infancia y con un punto máximo sobre 10-12 años para empezar a declinar sobre la adolescencia tardía (Lenroot et al., 2007) logrando el tamaño del volumen de adulto más tarde que el grupo con TEA.

Todos los resultados obtenidos en el presente estudio siguen el mismo patrón: las estructuras cerebrales involucradas mantienen una relación positiva con la función cognitiva en el grupo con TEA mientras que esa correlación tiene tendencia negativa en el grupo control. De alguna manera, parece que el grupo con TEA muestre un retraso madurativo en relación con el grupo control a la edad concreta de los niños de este estudio (aproximadamente 12 años) en estructuras clave para el desarrollo como las límbicas, estriatales y el cerebelo. De modo que, mientras los niños con desarrollo normotípico aprovecharían la poda sináptica como elemento de desarrollo de las funciones cognitivas y emocionales, en los niños con TEA se demostraría una relación positiva por la que a mayor volumen de sustancia gris en estas estructuras clave, mejor funcionamiento cognitivo y emocional. Este patrón general se ejemplifica en la Figura 17. 


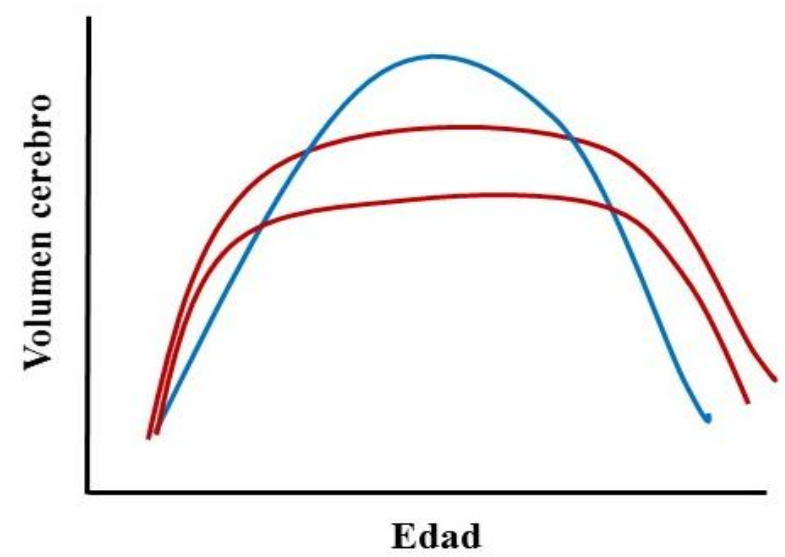

Figura 17. Grafica con el modelo de desarrollo cerebral para cada grupo de participantes: grupo de niños con TEA, de alto funcionamiento (línea roja superior) y de bajo funcionamiento (línea roja inferior) y grupo control (línea azul).

Tras haber abordado brevemente el patrón de desarrollo cerebral que hemos obtenido en nuestro trabajo, a continuación comentaremos los resultados conseguidos en las diferentes pruebas neuropsicológicas. Así, respecto a las medias globales obtenidas en las pruebas de inteligencia, los resultados indicaron que había diferencias significativas entre ambos grupos en los cuatro índices obtenidos (CI Verbal, CI No Verbal, MT y VP) y en el CI Total. Esta discrepancia entre el CI Total también aparece publicada en otros trabajos al comparar grupos con TEA y grupos con desarrollo típico (Hardan et al., 2009; Lange et al., 2015; Lin, Ni, Lai, Tseng \& Gau, 2015; Zielinski et al., 2014; Barnea-Goraly et al., 2014). Una posible explicación podría ser la influencia de varios factores que estarían afectando al rendimiento de los niños con TEA, tales como la atención a la tarea, (dificultades para centrar la atención, mayor facilidad de distracción, comorbilidad con TDAH), la motivación para obtener el logro, la conformidad, y otras conductas características del trastorno que pueden influir en el proceso de evaluación (Goldberg, 2004; Nedelcu y Bruceta, 2012).

En relación con las medias obtenidas por ambos grupos en las pruebas de ToM, los resultados indicaron diferencias muy significativas en la realización de este tipo de tareas tal y como ha aparecido en los estudios relacionados con el tema. La investigación en la población con TEA ha sido numerosa y abundante en el ámbito de 
los déficits relacionados con el desarrollo de la ToM y las conclusiones propuestas al respecto indican que tales déficits pueden estar en la base de las dificultades sociales y de la comunicación que presentan a lo largo de toda la vida (Baron-Cohen, Leslie \& Frith, 1985; Happe \& Frith 1996; Hoddenbach et al., 2012; Ozonoff \& McEvoy, 1994). Si analizamos una a una las diferentes subpruebas, podemos observar que los estudios relacionados con las Falsas creencias de segundo orden indican que los niños con TEA fracasan en la resolución de las mismas, sin embargo, si en algunos casos las resuelven adecuadamente, después no son capaces de generalizarlas a otras situaciones similares (Bowler, Stromm \& Urquhart, 2001; Oznoff \& Miller, 1995). Las Historias de Happé también les resultan complicadas de resolver ya que tienden a interpretarlas de forma literal debido a los problemas que presentan en la comprensión (pragmática del lenguaje) y en la atribución de intenciones a los demás. (Jolliffe \& Baron-Cohen, 1999b; Norbury \& Bishop, 2002). Los niños con desarrollo típico pueden realizarlas correctamente a partir de los 8 años, cuando empiezan a comprender el lenguaje figurado (Baron-Cohen, 2001). La realización correcta de las Meteduras de pata, requiere un desarrollo adecuado de la comprensión social que alcanzan los niños neurotípicos con 7 años, por eso, pueden realizar con éxito este tipo de historias (Banerjee \& Watling, 2005; Banerjee, Watling \& Caputi, 2011; Kaland et al., 2002). Resolver tareas que requieren la interpretación de la mirada resulta complejo para los niños con TEA, de ahí que encuentren muchas más dificultades a la hora de resolver la prueba del Test de la Mirada, puesto que la capacidad de realizar inferencias a partir de una imagen la desarrollan más tarde. Sin embargo, esta capacidad la presentan los niños con desarrollo típico a los 9 años, pudiendo interpretar correctamente las expresiones de los ojos de una persona y saber qué está pensando o sintiendo (Baron-Cohen, Wheelwright, Scahill, et al., 2001).

En nuestros resultados también obtuvimos una correlación significativa en los dos grupos entre el rendimiento obtenido en las pruebas de ToM y el CI Total, resultado que se ha encontrado con frecuencia en la literatura sobre el tema, tanto en personas neurotípicas como en población con TEA (Baker, Peterson, Pulos \& Kirkland, 2014; Happé, 1995; Hoogenhout \& Malcolm-Smith, 2014; Steele, Joseph \& Tager-Flusberg, 2003). Otra correlación más significativa que obtuvimos en ambos grupos fue entre las puntuaciones en ToM y el CI Verbal. Al respecto, hay bastantes estudios que apoyan esta relación (Farrar \& Maag, 2002; Lind \& Bowler, 2009; Milligan, Astington \& Dack, 
2007; Slade \& Ruffman, 2005, Thirion-Marissiaux \& Nader-Grosbois, 2008). De esta forma, se puede interpretar que algunas personas con TEA utilizan sus habilidades lingüísticas para compensar los déficits en la capacidad de ToM y así lograr un mejor rendimiento en la realización de este tipo de tareas (Lind \& Bowler, 2009). De hecho, hay evidencias de que cuando muestran un funcionamiento cognitivo y verbal más avanzado resuelven mejor este tipo de pruebas (Hamilton, Hoogenhout \& MalcolmSmith, 2016). En definitiva, podemos concluir que los niños con TEA presentan un rendimiento inferior en aquellas tareas que implican evaluar habilidades relacionadas con la ToM, como por ejemplo, inferir los estados mentales de los otros.

A continuación, analizaremos los datos obtenidos en los dos cuestionarios que fueron rellenados por los padres de los niños que participaron en la presente investigación. El primero de ellos es el Cuestionario Sensory Profile (Dunn, 1999). El tema de los déficits en el procesamiento sensorial, su alta prevalencia y su contribución en el cuadro sintomático del autismo ha cogido fuerza en los últimos años provocando un número considerable de estudios. Acorde con publicaciones previas, donde se ha evaluado el procesamiento sensorial utilizando, como nosotros, la forma abreviada del Cuestionario Sensory Profile, los resultados de nuestro estudio muestran diferencias muy significativas entre los dos grupos en los 7 factores incluidos en el cuestionario: Sensibilidad táctil, Sensibilidad gustativa/olfativa, Sensibilidad al movimiento, Búsqueda se sensaciones, Filtrado auditivo, Baja energía y Sensibilidad visual/auditiva. En un estudio realizado por Kern et al. (2006), los resultados indicaron diferencias significativas en cuatro modalidades sensoriales: auditiva, visual, táctil y gustativa, aunque utilizaron la versión original del cuestionario. Por su parte, Tomcheck \& Dunn (2007) llevaron a cabo un estudio similar al nuestro pero con una muestra más amplia de sujetos con autismo, quienes obtuvieron también diferencias significativas en 4 de los factores evaluados al compararlos con un grupo control: Búsqueda de sensaciones, Filtrado auditivo, Sensibilidad táctil y Sensibilidad al sabor/olor. En el resto de factores hubo también diferencias pero no llegaron a ser significativas. El grupo de Lane (2010), utilizando la versión corta del mismo cuestionario, concluyó que los participantes con autismo presentaron diferencias significativas en los factores de Búsqueda de sensaciones y Filtrado auditivo. Se han relacionado dichos déficits sensoriales con los patrones de comportamiento, intereses y actividades restringidos y repetitivos así como con la comunicación social y el desempeño de actividades sociales propios de las 
personas con TEA (Hilton, Graver \& LaVesser, 2007; Costa \& Lampreia, 2012; Reynolds, Bendixen, Lawrence \& Lane, 2011). Por tanto, podemos concluir que los déficits en el procesamiento sensorial tienen una alta prevalencia en las personas que presentan este tipo de trastorno, además de contribuir de forma decisiva a la presentación de los síntomas característico que lo definen, en especial, dichos déficits parecen estar implicados en las conductas e intereses restringidos y repetitivos. Asimismo, la presencia temprana y persistente de estas dificultades afecta a la organización y regulación de la conducta, el pensamiento y el lenguaje con serias implicaciones en la interacción social tanto en la persona con TEA como en su interlocutor que con frecuencia mal interpreta como rechazo las conductas secundarias al perfil sensorial anómalo (pobre contacto ocular y elevada latencia de respuesta frente a requerimientos verbales) (Martínez-Sanchis, 2015).

El segundo cuestionario que rellenaron todos los padres cuyos hijos participaron en el estudio fue el Cociente de Empatía y de Sistematización. Nuestros resultados indicaron que había diferencias muy significativas en cuanto al CE entre ambos grupos, de modo que el grupo control presentaba más conductas empáticas que los niños con TEA, que mostraron una capacidad pobre de empatía; sin embargo, en el CS se observó una ligera diferencia entre grupos pero no fue significativa. Estos resultados coinciden en parte con los obtenidos en el estudio llevado a cabo por el grupo de Auyeung (2009), donde el grupo de sujetos con desarrollo típico obtuvo mejores puntuaciones en el CE respecto al grupo con TEA y éste último puntuó más alto en el CS respecto a los controles. En otro trabajo que realizaron Goldenfeld, Baron-Cohen \& Wheelwright (2005), los resultados fueron similares a los obtenidos por Auyeung et al., (2009), el grupo con TEA logró puntuaciones altas en sistematización y bajas en empatía. Nuestros resultados y los obtenidos en estudios previos evidencian las dificultades que presentan las personas con autismo a la hora de desarrollar la empatía, aspecto que explicaría los déficits que presentan en la interacción social y en la comunicación. Nuestro grupo de niños con TEA se caracteriza por déficits considerables en la empatía. La alta sistematización explicaría la resistencia al cambio, las conductas repetitivas y los intereses restringidos, sin embargo, en nuestro trabajo el resultado obtenido no difiere respecto a los controles. Tal vez la diferencia entre nuestro estudio y los otros estribe en la franja de edad de los participantes ya que en la mayoría de ellos son adolescentes o adultos. 
Un resultado interesante encontrado en nuestro trabajo fue la correlación positiva obtenida entre el CS y el CI Total y CI No Verbal en el grupo con TEA. Este hecho es destacable ya que esta correlación surge de dos fuentes de información distintas como son los padres para CS y el propio niño para el CI. En el grupo de participantes neurotípicos no hubo correlación entre las puntuaciones obtenidas en el CE-CS y el CI. No hemos encontrado otros estudios previos en los que se haya obtenido un resultado similar al obtenido en nuestro grupo con autismo, pero sí hemos encontrado dos estudios donde no existe correlación entre CE- CS y CI en un grupo de sujetos con desarrollo típico (Auyeung et al., 2006; Capman et al., 2006). Una posible explicación del resultado obtenido en el grupo con autismo sea el hecho de que una mayor capacidad cognitiva resulte más eficaz a la hora de buscar y encontrar reglas o patrones que permitan a estos sujetos controlar y manipular su entorno para lograr que todo permanezca igual y no haya cambios. Sistematizar les permite predecir los cambios y controlarlos, hecho que les da seguridad. No obstante, es necesario realizar más estudios en esta línea y con muestras más amplias para valorar de forma más precisa nuestro resultado.

En conjunto, los resultados obtenidos en las pruebas neuropsicológicas que hemos utilizado en nuestro estudio son acordes, en líneas generales, con la literatura publicada sobre el tema. Los niños con TEA presentan dificultades a la hora de desarrollar las habilidades implicadas en la ToM, les cuesta predecir e inferir pensamientos, ideas, creencias, sentimientos y emociones de los demás y su rendimiento es más bajo en tareas que requiere utilizar este tipo de habilidades. Respecto al desarrollo de la empatía, las personas con autismo también presentan déficits considerables que les dificulta entender y predecir el mundo social; su rendimiento en este tipo de pruebas se sitúa por debajo del obtenido por los sujetos con desarrollo típico. De igual modo, presentan déficits considerables en el procesamiento sensorial en varias modalidades sensoriales (auditivas, visuales, táctiles, gustativas, entre otras), de ahí las dificultades que muestran a la hora de desenvolverse en situaciones que requieren integrar información más compleja, como por ejemplo, en las relaciones interpersonales. No obstante, los resultados en sistematización no han corroborado resultados previos ya que los niños con TEA no han obtenido puntuaciones superiores a los niños neurotípicos, lo que quizá sea la razón para la falta de resultados neurales en relación a esta medida. Por último, destacar que las diferencias halladas entre grupos en relación con el CI se 
explicarían por la influencia de una serie de factores que podrían haber afectado el rendimiento de los niños con TEA, tales como la atención a la tarea o el nivel de motivación.

Con las puntuaciones globales en estas dimensiones, llevamos un análisis factorial con 6 variables utilizadas en el estudio obteniéndose dos factores bien diferenciados. De forma relevante, ambos factores mezclan variables en las que se juntan datos aportados por los padres y por los propios niños. Por un lado, el Factor 1 principal que explica el $46,95 \%$ de la varianza formado por las variables relacionadas con el desarrollo social y emocional (ToM, CE y CSP) y, por otro lado, el Factor 2 que explica el 20,22\% de la varianza formado por variables relacionadas con conductas e intereses restringidos (CI Verbal, CI No Verbal y CS). Esta organización es importante ya que refleja una cierta independencia de dos aspectos relevantes en el TEA como son el mundo socioafectivo y la parte cognitiva y de sistematización.

Una vez comentados los resultados obtenidos en las pruebas neuropsicológicas, pasaremos a explicar los resultados morfométricos. Los datos obtenidos en la comparación de ambos grupos de participantes respecto al TIV no revelaron ninguna diferencia significativa, resultado también aportado en otros estudios (Langen et al., 2014; Hollander et al., 2005; Schumann et al., 2004; Say et al., 2014; Hardan et al., 2008a; Yang, Beam, Pelphrey, Abdullahi \& Jou, 2016). De manera que, a nivel de TIV, en nuestro estudio tampoco se encontraron diferencias entre grupos ni en el volumen total cerebral, ni en el volumen de SG, volumen de SB pero sí una tendencia hacia la significación en el líquido cefalorraquídeo. El patrón de resultados es similar al encontrado en estudios previos sobre comparaciones globales en volumen del cerebro. Así, en un estudio reciente con 417 participantes con TEA y 459 controles de todas las edades (Katuwal et al., 2016), se encontró, utilizando un análisis similar de VBM, que el grupo con autismo tenía un 1,49\% más de volumen de sustancia gris $(1,41 \%$ en nuestro estudio), un $0,71 \%$ más de volumen de sustancia blanca $(1,88 \%$ en nuestro estudio) y un 3,09\% más de líquido cefaloraquídeo (un 5,57\% más en nuestro estudio). Aunque las diferencias en sustancia gris y líquido cefaloraquídeo fueron significativas en el estudio citado de Katuwal et al., por la elevada muestra utilizada, en nuestro estudio no fue así. De hecho, al ser una muestra más joven se observaron diferencias mayores en líquido cefaloraquídeo probablemente como consecuencia de los efectos del desarrollo inicial. Estudios recientes muestran que el autismo se asocia a un mayor 
volumen de líquido durante los primeros años de vida (Shen et al., 2017) y estudios en muestras de similar edad han encontrado diferencias significativas (McAlonan et al., 2005).

De forma relevante, el análisis VBM realizado también ha mostrado la ausencia de diferencias parciales en alguna de las estructuras cerebrales. Los resultados de la comparación entre grupos no han producido ninguna diferencia parcial al umbral establecido ni incluso a niveles de significación más laxos. Estos datos son coincidentes con estudios previos en adultos con TEA con alto funcionamiento (Riedel et al., 2014). En este sentido, el meta-análisis comentado en la introducción sobre los estudios morfométricos también ofrece resultados en esta línea (Via, Radua, Cardoner, Happé \& Mataix-Cols, 2011). Este estudio no muestra diferencias globales en el cerebro pero si decrementos de volumen en individuos con autismo en hipocampo/amígdala y en áreas parietales así como incrementos en áreas prefrontales laterales. Sin embargo, cuando se analiza el efecto de la edad, los datos muestran que las diferencias se deben a los estudios en adultos, y que por tanto no se puede descartar que las diferencias se deban al hecho de convivir muchos con el trastorno. En este sentido, la evidencia contrastada hasta la fecha muestra que el autismo se asocia a un mayor volumen cerebral en los primeros años, seguidos de un periodo hasta la adolescencia en los que los cerebros de sujetos con autismo y controles son parecidos para acabar en la edad adulta con diferencias quizá debidas al propio trastorno.

En resumen, las diferencias estructurales globales y locales entre individuos con TEA y controles no parecen ser relevantes en niños preadolescentes con dicho trastorno. Sin embargo, no ocurre lo mismo si atendemos a los correlatos cognitivos de estas diferencias estructurales, que es el objeto de esta tesis. En ese contexto emerge el patrón de la Figura 17, de manera que son diversas las relaciones encontradas en estructuras y variables cognitivas clave en los TEA. A continuación las analizaremos una a una.

\section{Núcleo Putamen}

Respecto al núcleo putamen, se ha visto su papel diferencial entre grupos tanto para la medida global de Teoría de la Mente como para las puntuaciones del factor 1 (que engloba ToM, CSP y CE). En el primer caso, la influencia del putamen posterior es bilateral mientras que en el segundo se reduce al posterior izquierdo. Estudios previos han mostrado que el putamen sigue una trayectoria diferente en niños con TEA, de tal 
forma que tiende a crecer con los años mientras que en los niños neurotípicos tiende a decrecer (Langen et al., 2009, 2013). Un trabajo reciente conducido por el grupo de Balsters et al. (2017) mostró una división funcional en el putamen en dos partes (anterior y posterior) en los sujetos neurotípicos pero no en el grupo con TEA, donde se presentó como una estructura única. Utilizando la técnica de la resonancia magnética funcional en estado de reposo, comprobó que en el grupo control existía una conectividad funcional diferente para las partes anterior y posterior del putamen. De esta forma, la parte anterior se comunicaba con zonas de lenguaje (zonas frontal inferior, ínsula anterior y frontal medial) y parietales inferiores, mientras que la posterior se asocia zonas motoras. De forma relevante, esta diferencia no se daba en el grupo de niños con autismo, lo que podría asociar a los déficits en las esferas semántica, del lenguaje en general o a la empatía. Estos resultados podrían significar la falta de regulación del lenguaje en sujetos con TEA y la posible relación que existiría con un mayor desarrollo en putamen posterior para compensar los déficits del putamen anterior. En el caso de la ToM, estos datos avalarían el resultado de que la ejecución en ToM estuviera mediada por la inteligencia verbal, es decir, que aquellos niños con mayor inteligencia verbal realicen mejor este tipo de tareas.

\section{Núcleo Caudado}

Respecto al grupo de niños con TEA, éstos presentaron mayor volumen de SG en la región del núcleo caudado izquierdo en relación con la variable CI Total. Esta estructura subcortical, que forma parte de los ganglios basales, sigue un patrón de desarrollo cerebral de forma lineal y el volumen de la SG disminuye con la edad tal como se ha indicado en la literatura reciente en relación con población neurotípica (Ostby et al, 2009; Sussman, Leung, Chakravarty, Lerch \& Taylor, 2016; Dennison et al., 2013). Nuestro resultado es consistente con estudios previos realizados con niños que presentan autismo, en los que se indican la presencia de una trayectoria de desarrollo atípica en las estructuras del estriado, concretamente en el núcleo caudado. Sears et al. (1999) y Langen et al., (2014) indicaron que los niños con este trastorno presentaban mayor volumen de SG en esta estructura, incluso su crecimiento era casi el doble que en el grupo control. Esta alteración en el desarrollo del núcleo caudado en los niños con TEA la relacionaron con conductas repetitivas y con resistencia al cambio, una de las características nucleares que definen el trastorno. 


\section{Tálamo}

En el análisis de la interacción, a partir de las ROIs, el grupo con TEA presentó mayor volumen de SG en el tálamo bilateral asociado con la variable CI No verbal. En sujetos con desarrollo típico, el volumen del tálamo sigue una trayectoria de desarrollo lineal y disminuye con la edad, según indicaron los estudios llevados a cabo por Dennison et al. (2013) y por el grupo de Sussman (2016). Los resultados obtenidos en nuestro trabajo coinciden con los realizados por Schuetze et al. (2016) y por Lin y su equipo (2015), donde los participantes con TEA obtuvieron significativamente mayores volúmenes de SG que el grupo control en el tálamo bilateral, sustentando la idea de una trayectoria atípica de desarrollo en el tálamo en las personas que presentan este trastorno. El núcleo mayormente involucrado es el núcleo que tiene funciones de filtrado atencional de información y que participa con ello en la selección de los estímulos relevantes. Estudios recientes ilustran importantes diferencias en el patrón de conectividad del tálamo en niños con TEA, ya que parece hiperrelacionado con áreas de procesamiento emocional/social pero menos conectado con áreas de procesamiento heteromodales que sustentarían el procesamiento cognitivo (Nair et al., 2015). Estos autores relacionan estas diferencias en conectividad con la maduración temprana de estructuras límbicas en autismo junto con la ralentización posterior de las áreas cerebrales de procesamiento cognitivo de orden superior. En este sentido, un estudio reciente ha comprobado como el autismo se asocia a una conectividad aberrante del núcleo pulvinar con el córtex cerebral mientras se filtran estímulos relevantes. Los déficits en la modulación de la conectividad talamocortical en los jóvenes con TEA pueden reflejar la reducción de la inhibición tálamo-cortical en respuesta a la estimulación sensorial, lo que podría conducir a dificultades en el filtrado y en la integración de información sensorial. Un aumento de la conectividad de la amígdala con el pulvinar podría ser parcialmente responsable de los déficits en la atención selectiva (Green, Hernández, Bookheimer \& Dapretto, 2016).

\section{Cerebelo}

Cuando se combinaron las variables de las pruebas de inteligencia con el análisis de morfometría cerebral, a nivel de volumen total cerebral, el grupo control mostró menor volumen de SG en el cerebelo izquierdo (Crus I) con la variable velocidad de procesamiento. Este resultado es consistente con los datos obtenidos en el estudio de 
Wierenga et al. (2014) realizado con sujetos con desarrollo típico, en el que se indica que el córtex cerebelar presenta una trayectoria de desarrollo en forma de U invertida en el volumen de SG, con un pico máximo en los hombres a la edad de 15,6 años y en las mujeres más temprano. Estudios recientes también han implicado al cerebelo en funciones cognitivas de orden superior como, por ejemplo, el procesamiento cognitivo (Strick, Dum \& Fiez, 2009; Stoodley \& Schmahmann, 2010; Basson \& Wingate, 2013; Becker \& Stoodley, 2013). Estudios sobre conectividad cerebral de la Crus I muestran su amplia conectividad con la mayoría de las áreas de asociación del córtex cerebral, lo que le otorga una función de participación en los procesos cognitivos superiores incluyendo los motores y los de planificación (Buckner et al., 2011). Además esta zona del cerebelo está relacionada con las áreas cerebrales que forman la red por defecto, áreas que participan en el procesamiento interno de funciones y que facilita la toma de decisiones rápidas. En este sentido las tareas de velocidad de procesamiento requieren tomar estas decisiones y el incremento de volumen de sustancia gris en esta zona facilitará el proceso.

De forma relevante, el lóbulo IX del cerebelo se ha relacionado con la Sensibilidad al Movimiento, es decir, con la hiper/hiposensibilidad al movimiento externo. Estudios previos muestran que este lóbulo se considera esencial para la guía visual del movimiento (Glickstein et al., 1994). En este sentido, datos recientes muestran que el lóbulo IX se activa cuando se observa un movimiento animado de estímulos (con un objetivo intencional que se puede comprender en términos sociales) en relación a un movimiento aleatorio. Al respecto, se ha interpretado esta zona del cerebelo como la relacionada con la parte socioemocional del cerebelo más interconectada con el sistema límbico (Schmahmann, 2000; Blatt, Oblak \& Schmahmann, 2013), y que media especialmente en emociones negativas de enfado o malestar (Baumann \& Mattingley, 2012; Schienle \& Scharmüller, 2013). Por ello, aunque el cerebelo participa en dos funciones distintas en los resultados de esta tesis, cabe decir que son dos zonas diferentes una más relacionada con el procesamiento cognitivo (Crus I) y otra con el emocional/social (Crus IX). 


\section{Hipocampo}

Siguiendo con el análisis de las ROIS, el grupo con TEA mostró mayor volumen de SG en el hipocampo derecho con las variables: CSP global, Filtrado auditivo, Sensibilidad al movimiento y Sensibilidad táctil. El mayor volumen de SG en el hipocampo de estos niños concuerda con los resultados obtenidos en un estudio reciente realizado por Barnea-Goraly (2014), donde encontraron que esta estructura límbica aumentaba significativamente en un grupo de niños con TEA al compararlos con otro grupo de niños controles. Como hemos indicado anteriormente, el hipocampo está implicado en déficits característicos de los sujetos con TEA, tales como la cognición social y las emociones (Conty \& Grezes, 2012; Fanselow \& Dong, 2010; Greicius et al., 2003; Kawashima et al., 1999). Tal y como aparece publicado en la literatura, los niños con autismo tienen más probabilidad de presentar conductas repetitivas si presentan alteraciones en el procesamiento sensorial (Baker, Lane, Angley \& Young, 2008; Chen, Rodgers \& McConachie, 2009; Gabriels et al., 2008), de modo que cuanto mayor son estas alteraciones, más conductas de este tipo aparecen (Chen, Rodgers \& McConachie, 2009). También se ha encontrado, en otros estudios, una relación entre Filtrado auditivo y dificultades en la atención (Ermer \& Dunn, 1998; Watling, Deitz \& White, 2001). La trayectoria de desarrollo atípica en el hipocampo de las personas que presentan este trastorno podría contribuir a los déficits comentados en la cognición social, conductas repetitivas y en la atención. Otras variables analizadas indicaron que los niños con TEA presentaron mayor volumen de SG en la amígdala bilateral (Sensibilidad al movimiento) y la amígdala izquierda (Sensibilidad táctil). En un apartado posterior explicaremos con más detalle la relación entre el desarrollo atípico presentado por la amígdala y los déficits que produce en el autismo, relacionados con la cognición social y las emociones.

Sin embargo, en el análisis de las ROIs los resultados de la interacción con la variable Factor 1 mostró mayor volumen de SG en el grupo de niños con autismo en el hipocampo izquierdo, al compararlo con el grupo control. En relación con el hipocampo izquierdo, una serie de estudios han encontrado alteraciones en el desarrollo de esta estructura límbica que van en la misma dirección que nuestro resultado. De este modo, Schumann et al. (2004) describieron en su trabajo que el hipocampo seguía un patrón atípico en el desarrollo en un grupo de niños con TEA y que dicho patrón seguía hasta la adolescencia. Por su parte, Sparks et al. (2002) encontraron mayor volumen de SG en 
el hipocampo bilateral, en una amplia muestra de niños con autismo (3-4 años), indicando que el hipocampo era un $9 \%$ mayor en este grupo en relación con el grupo control. El desarrollo anómalo de esta estructura ha sido implicado en los déficits relacionados con la cognición social, la percepción de la dirección de la mirada y la emoción que presentan las personas con TEA (Kawashima et al., 1999; Greicius et al., 2003; Fanselow \& Dong, 2010; Conty \& Grezes, 2012).

\section{Cingulado Posterior Derecho}

En el presente estudio, el grupo control mostró mayor volumen de SG en el giro cingulado posterior derecho en relación con la variable cognitiva Velocidad de procesamiento. Esta estructura cerebral forma parte del Sistema Límbico y recibe proyecciones del hipocampo, formando así el componente emocional de la memoria. Además, es un núcleo importante de la Red por Defecto que, junto con el córtex prefrontal medial, están implicados en los procesos de mentalización interna (pensamientos de autorreferencia y procesos de ToM) y se encargan de supervisar las situaciones inesperadas del entorno (Mantini \& Vanduffel, 2013).

\section{Amígdala}

Nuestros análisis de morfometría cerebral con las variables de ToM no mostraron datos significativos a nivel de volumen total cerebral en el grupo con autismo, pero sí revelaron a nivel de ROIs en dicho grupo mayor volumen de SG en la región de la amígdala derecha al relacionarla con variable Test de la Mirada. Tal y como se ha constatado en estudios previos, la amígdala está implicada de forma considerable en el desarrollo de la cognición social, la percepción de la dirección de la mirada, el aprendizaje emocional (Conty \& Grezes, 2012; Fanselow \& Dong, 2010; Greicius et al., 2003; Kawashima et al., 1999; Tirapu, Pérez, Erekatxo y Pelegrín, 2007). Además, ocupa un lugar destacado en el circuito de la empatía (amígdala, neuronas espejo, ínsula anterior y corteza cingulada caudal anterior) (Ruggieri, 2013). Las personas con TEA presentan dificultades en el desarrollo de estas habilidades de forma que obtienen un bajo rendimiento en tareas que evalúan la ToM, como se ha indicado anteriormente. Estas dificultades se pueden explicar a partir del desarrollo atípico de esta estructura subcortical desde edades tempranas. En el estudio realizado por Sparks et al. (2002), los niños con TEA (3-4 años) ya presentaban una amígdala bilateral más grande pero con la característica de que la amígdala derecha (22\% mayor) era mayor que la izquierda ( $14 \%$ 
mayor), respecto al grupo control, indicando peor ejecución en las pruebas que implicaban habilidades sociales y de comunicación. Munson et al. (2006) encontraron mayor volumen de la amígdala derecha en un grupo de niños con TEA (3-4 años), además de dificultades en el desarrollo de habilidades sociales y comunicativas. Resultados similares obtuvieron Schumann et al. (2004), un mayor volumen de la amígdala bilateral en niños y adolescentes con TEA y una pobre ejecución en tareas de cognición social (reconocimiento de caras y de emociones). Los estudios previos revelan que la población con autismo muestra una trayectoria de desarrollo atípica en la amígdala, presentando un crecimiento acelerado antes de los 2 años que se mantiene durante toda la infancia y que se normaliza durante la infancia tardía y la adolescencia (Mosconi et al., 2009; Barnea-Goraly et al., 2014).

Nuestros resultados están en esta línea, así, el grupo de niños con TEA presentó un rendimiento mucho más bajo que los controles en las pruebas de ToM debido a los problemas que presentan a la hora de inferir intenciones en los otros, de comprender miradas, de entender los deseos y las conductas de los demás,..., problemas relacionados con la trayectoria de desarrollo atípica de la amígdala y de las estructuras relacionadas con la misma. Hay suficiente certeza de que en la base de los déficits que presentan las personas con TEA en el desarrollo de la ToM, la amígdala y una serie de estructuras asociadas juegan un papel fundamental. Entre ellas, el córtex orbitofrontal y el córtex frontal medial, son regiones cerebrales clave para desarrollar adecuadamente las habilidades mentalistas (Baron-Cohen, 2001a).

\section{Giro frontal medio}

Los participantes del grupo control mostraron, en el análisis de morfometría cerebral con las variables de ToM, mayor volumen de SG en la región del giro frontal medio/inferior derecho (BA46), a nivel de volumen total cerebral. Esta región corresponde con la corteza prefrontal dorsolateral y está relacionada con el mantenimiento de la atención y con la memoria de trabajo, con el funcionamiento ejecutivo en general. De acuerdo con las aportaciones dadas por una serie de estudios, durante la maduración cerebral típica, las capacidades ejecutivas se adquieren de manera temprana desde un año de edad y se van desarrollando lentamente durante la infancia y la adolescencia (Demetriou, Christou, Spanoudis \& Platsidou, 2002; Luciana, Conklin, Hooper y Yarger, 2005; Luna, Garver, Urban, Lazar \& Sweeney, 2004). A continuación, las vías dorsofrontales prolongan su desarrollo hasta la postadolescencia 
(Shaw et al., 2008; Sowell, Thompson, Tessner \& Toga, 2001). En nuestro estudio, los niños del grupo control mostraron una mejor ejecución en las tareas que evaluaban la ToM. Una serie de trabajos previos, por ejemplo, han evidenciado que la intervención de áreas como el córtex frontal dorsolateral son fundamentales para resolver tareas como las falsas creencias de segundo orden, que requieren memoria de trabajo para su resolución (Stone, Baron-Cohen \& Knight, 1999).

\section{Visión integrada}

Como resumen de todas estas interacciones, señalar que existe un patrón común de resultados por los que en niños con TEA, a mayor volumen en la estructura, mejor ejecución, mientras que en el grupo control la tendencia es la opuesta. En general, este patrón tiende a asociarse a un desarrollo anómalo de las estructuras involucradas en el procesamiento emocional y social que por la literatura previa parece producirse en los primeros años de vida. Este desarrollo anómalo no parece afectar de forma similar a todas las zonas límbicas, sino que afecta de forma diferencial en cada caso. De esta manera, la preservación de la sustancia gris en las diversas zonas parece asociarse en niños con TEA a un mejor funcionamiento, mientras que en el grupo control sigue el patrón de desarrollo típico por el que a mayor maduración, menor volumen de sustancia gris.

\section{Limitaciones del estudio}

En el presente estudio hay una serie de limitaciones que comentamos a continuación. La primera de ellas estaría relacionada con la muestra utilizada en el grupo con TEA. Al inicio del estudio la muestra era mayor $(\mathrm{N}=39)$, pero algunas características propias de los niños que presentan este trastorno, como la hipersensibilidad al ruido o el miedo a situaciones nuevas y, en otros casos, la dificultad para permanecer quieto durante un período breve de tiempo, dificultaron de forma considerable la realización de pruebas como la resonancia magnética. Aunque los niños tuvieron una fase de entrenamiento durante varias semanas tanto con la autora de esta tesis (anticipándoles la situación a partir de imágenes) como con sus padres en su casa (escuchando el ruido del escáner y practicando la respiración), un grupo de 15 niños no lograron superar esta prueba. Quizá con un entrenamiento real en la sala del escáner, adaptada para niños, además del entrenamiento que utilizamos nosotros, sería posible ampliar la muestra y tener un 
mayor número de participantes. Esto sería una propuesta interesante en futuros estudios con población infantil con autismo.

Otra limitación sería el hecho de que los participantes tenían una capacidad cognitiva superior o igual a 80, es decir, es un grupo considerado de alto funcionamiento, por tanto, nuestros resultados podrían no ser aplicables a los niños con un funcionamiento cognitivo más bajo.

La tercera limitación estaría relacionada con las diferencias significativas en cuanto a las pruebas del CI ya que dichas diferencias aparecían en todos los índices obtenidos en la batería de pruebas (CI Verbal, CI No verbal, MT y VP) y en el CI Total. Este rendimiento más bajo es un factor a tener en cuenta. Y la cuarta limitación que plantea nuestro trabajo estaría relacionada con la alta tasa de co-ocurrencia que presenta el TEA, especialmente con el TDAH. Cuando aparecen juntos estos dos trastornos del neurodesarrollo, aumentan las dificultades en el día a día de los niños que los padecen. Esta es la razón por la cual, muchos de ellos siguen un tratamiento farmacológico con el objetivo de disminuir y mejorar la sintomatología propia del TDAH (hiperactividad, impulsividad y déficit atencional). En nuestra muestra 12 niños tomaban metilfenidato (3 de ellos además tomaban risperidona) y 1 atomoxetina. A pesar de la falta de información sobre los efectos del metilfenidato sobre las estructuras cerebrales en el TEA, la literatura previa proporciona pruebas de que el tratamiento con estimulantes puede normalizar algunas anomalías cerebrales estructurales en el TDAH (Lin, Ni, Lai, tseng \& Gau, 2016). 


\section{CONCLUSIONES}

Finalmente, los resultados obtenidos en el presente trabajo respaldan considerablemente los cuatro objetivos planteados en el mismo.

1. Los resultados obtenidos en el presente estudio, a partir del análisis de la morfometría cerebral, indican que no existen diferencias globales en cuanto a volumen de sustancia gris, de sustancia blanca y de líquido cefalorraquídeo entre ambos grupos de participantes.

2. En relación con la sustancia gris en las regiones específicas (corticales, límbicas, estriatales y cerebelares) utilizadas en nuestro estudio, también concluimos que no existen diferencias entre ambos grupos.

3. Las diferencias que sí hemos encontrado se encuentran a nivel neuropsicológico. El TEA es un trastorno que presenta una alta heterogeneidad en cuanto a manifestaciones neuropsicológicas, según se ha documentado también en estudios previos en este campo. Las personas que presentan dicho trastorno muestran una diversidad de funciones más o menos alteradas con distinto grado de afectación. Así, por ejemplo, en relación con el lenguaje y la comunicación, podemos encontrar desde sujetos con TEA que no han podido desarrollar un habla funcional y presentan dificultades significativas a la hora de comunicarse hasta otros que tienen únicamente problemas en los aspectos pragmáticos del mismo. Si nos centramos en aspectos relacionados con el desarrollo de la cognición social, encontramos individuos con autismo con una falta considerable de empatía hasta otros que han aprendido a mostrar conductas empáticas adecuadas. La heterogeneidad observada en los TEA a nivel cognitivo hace que sea uno de los trastornos del neurodesarrollo más complejo de abordar.

4. En el estudio correlacional llevado a cabo entre una serie de variables morfométricas y las variables neuropsicológicas, los resultados obtenidos se relacionan con dicha heterogeneidad cognitiva observada en el TEA. De manera que esta variabilidad correlaciona positivamente de forma global con un mayor volumen de sustancia gris en zonas específicas en el grupo con autismo, sin 
embargo, en el grupo control la correlación es negativa. Los resultados indican que en el grupo con TEA:

(a) -Las variables de inteligencia mostraron una relación con la sustancia gris en el núcleo caudado izquierdo, en el cerebelo bilateral y en el tálamo bilateral.

(b) -Las variables de ToM mostraron una relación con la sustancia gris en la amígdala derecha y en el putamen bilateral.

(c) -Las variables del Cuestionario Sensory Profile mostraron una relación con la sustancia gris en el hipocampo y en la amígdala bilaterales, en el núcleo cingulado anterior derecho y en el cerebelo.

(d) -La variable del Cuestionario de Empatía mostró una relación con la sustancia gris en la amígdala bilateral.

(e) -Por último, el Factor 1 (CE, CSP y ToM) obtenido a partir del análisis factorial mostró una relación con la sustancia gris en hipocampo izquierdo y en el putamen izquierdo.

5. Nuestro estudio plantea un modelo general de retraso en el desarrollo cerebral de niños que presentan este trastorno. En relación con dicho modelo, uno de los resultados más consolidados en el autismo ha sido el crecimiento acelerado del cerebro en los primeros años de vida (especialmente en regiones frontales y temporales), seguido de una ralentización del crecimiento en la infancia tardía hasta el inicio de la adolescencia para igualarse y ser similar al de los sujetos con desarrollo típico en la adolescencia y en la vida adulta. En nuestro trabajo, las diferencias globales y locales entre ambos grupos no parecen relevantes. Sin embargo, como hemos indicado anteriormente, las diferencias entre los dos grupos aparecen cuando se correlacionan los resultados de las pruebas cognitivas con las regiones cerebrales específicas en las que se basa esta tesis, indicando una correlación diferente. Así, nuestro grupo con TEA muestra mejor rendimiento cognitivo y emocional cuando el volumen de sustancia gris en dichas estructuras es mayor mientras que el grupo control muestra una tendencia opuesta, es decir, mejor funcionamiento con menor volumen de sustancia gris. De modo que el grupo con autismo mostraría un retraso madurativo en estructuras clave para el desarrollo (límbicas, estriatales y cerebelares) al 
presentar mayor volumen de sustancia gris en estructuras clave implicadas en el desarrollo socioemocional y conductual, mientras que el grupo control presenta un mayor nivel de maduración cerebral al mostrar menor volumen de sustancia gris en dichas áreas. 


\section{VII- BIBLIOGRAFÍA}

Aboulafia-Brakha, T., Christe, B., Martory, M.D., \& Annoni, J.M. (2011). Theory of mind tasks and executive functions: A systematic review of group studies in neurology. Journal of Neuropsychology, 5(1), pp. 39-55. http:// dx.doi.org/10.1348/174866410X533660

Adams, Jr.R.B., Franklin, Jr. R.G., Kveraga, K., Ambady, N., Kleck, R.E., Whalen, P.J.,... \& Nelson, A.J. (2011). Amygdala responses to averted vs direct gaze fear vary as a function of presentation speed. Social Cognitive and Affective Neuroscience, 7, pp. 568577. doi:10.1093/scan/nsr038

Adelman, C.R. (2010). Factors that influence age of identification of children with autism and pervasive developmental disorders NOS. University of Houston. Disponible en ProQuest Dissertations \& Theses A\&I. (756862835). Recuperado de http://search.proquest.com/docview/756862835? accountid=14777

Adolphs, R. (2002). Neural systems for recognizing emotion. Current Opinion in Neurobiology, 12, pp. 169-177.

Adolphs, R. (2003). Cognitive neuroscience of human social behaviour. Nature Reviews, 4, pp. $165-178$.

Adolphs, R., Baron-Cohen, S., \& Tranel, D. (2002). Impaired recognition of social emotions following amygdala damage. Journal of Cognitive Neuroscience, 14, pp. 1264-1274.

Adolphs R., Tranel D. \& Damasio A.R. (2003). Dissociable neural systems for recognizing emotions. Brain and Cognition, 52, pp. 61-69.

Aguirre, R. (2013). Desarrollo de la cognición social en personas con Trastorno de Espectro Autista. Revista Chilena de Terapia Ocupacional, 13(2), pp. 11-19.

Alexander, G.E., DeLong, M.R., \& Strick, P.L. (2003). Parallel organization of functionally segregated circuits linking basal ganglia and cortex. Annual Review of Neuroscience, 9, pp. 357-381. 
Allen, G., McColl, R., Barnard, H., Ringe, W., Fleckenstein, J. \& Cullum, C. (2005). Magnetic resonance imaging of cerebellar-prefrontal and cerebellar parietal functional connectivity. Neuroimage, 28, pp. 39-48. Doi: 10.1016/j.neuroimage.2005.06.013

Amaral, D.G., Schumann, C.M. \& Nordahl, C.W. (2008). Neuroanatomy of autism. Trends Neurosci, 31, pp. 137-145.

Amaral, D.G. (2011). The promise and the pitfalls of autism research: an introductory note for new autism researchers. Brain Research, 1380, pp. 3-9.

American Psychiatric Association (1952). Diagnóstic and Statistical Manual of Mental Disorders (DSM-I). Washington, DC: American Psychiatric Association, APA.

American Psychiatric Association (1968). Diagnóstic and Statistical Manual of Mental Disorders (DSM-II, 2nd Edition). Washington, DC: American Psychiatric Association, APA.

American Psychiatric Association, (1980), Diagnostic and Statistic Manual of Mental Disorders (DSM-III, 3 rd Edition). Washington D.C.: America Psychiatric Association, APA.

American Psychiatric Association (1987). Diagnóstic and Statistical Manual of Mental Disorders (DSM-III-R, 3rd Edition, Revised). Washington, DC: American Psychiatric Association, APA.

American Psychiatric Association, (1994), Diagnostic and Statistic Manual of Mental Disorders (DSM-IV, 4th edition). Washington D.C.: America Psychiatric Association, APA.

American Psychiatric Association, (2000), Diagnostic and Statistic Manual of Mental Disorders (DSM-IV-R, 4th edition, Revised). Washington D.C.: America Psychiatric Association, APA. 
American Psychiatric Association, (2013), Diagnostic and Statistic Manual of Mental Disorders (DSM-5, 5th edition). Washington D.C.: America Psychiatric Association, APA.

Anagnostou, E., \& Taylor, M.J. (2011). Review of neuroimaging in autism spectrum disorders: what have we learned and where we go from here. Molecular Autism, 2(1), pp. 4.

Artigas-Pallarés, J. (2000). Aspectos neurocognitivos del Síndrome de Asperger. Revista de Neurología Clínica, 1, pp. 34-44.

Artigas-Pallarés, J. (2001). Las fronteras del autismo. Revista de Neurología Clínica, 2, pp. 211-224.

Artigas-Pallarés, J., y Narbona, J. (2011). Trastornos del Neurodesarrollo. Barcelona. Viguera Editores, pp. 310-333.

Artigas-Pallarés, J., y Paula, I. (2012). El autismo 70 años después de Leo Kanner y Hans Asperger. Revista de la Asociación Española de Neuropsiquiatría, 32(115), pp. 567-587. doi: 10.4321/S0211-57352012000300008

Artigas-Pallarés, J., y Paula, I. (2017). Deconstruyendo a Kanner. Revista de Neurología, 64(1), pp. 9-15.

Ashburner, J. (2007). A fast diffeomorphic image registration algorithm. Neuroimage 38(1), pp. 95-113.

Ashburner, J., Ziviani, J., \& Rogers, S. (2008). Sensory processing and classroom emotional, behavioral and educational outcomes in children with autism spectrum disorder. American Journal of Occupational Therapy, 62(5), pp. 564-573.

Asperger, H. (1938). Das Psychisch Abnorme Kind. Wiener Klinische Wochenschrift, 49, pp. 1-12.

Asperger, H. (1944). Die 'Autistischen Psychopathen' im Kindesalter. Archiv für Psychiatrie und Nervenkrankheiten, 117, pp. 76-136. 
Astington, J., \& Baird, J. (2005). Why language matters for theory of mind. Oxford, UK: Oxford University Press.

Astington, J.W., \& Edward, M.J. (2010). The Development of Theory of Mind in Early Childhood Janet Wilde. Encyclopedia on early childhoon development.

Ausderau, K., Sideris, J. Furlong, M. Little, L.M., Bulluck, J., \& Baranek, G.T. (2013). National Survey of Sensory Features in children with ASD: Factor Structure of the Sensory Experience Questionnaire (3.0). Journal of Autism and Developmental Disorders, 44(4), pp. 915-925. Advance on-line publication. doi: 10.1007/s.10803-0131945-1

Austin, G., Groppe, K., \& Elsner, B. (2014). The reciprocal relationship between executive function and theory of mind in middle childhood: A 1-year longitudinal perspective. Frontiers in Psychology, 5, pp. 1-11.

Auyeung, B., Wheelwright, S., Allison, C., Atkinson, M., Samarawickrema, N., \& BaronCohen, S. (2009). The Children's Empathy Quotient and Systemizing Quotient: Sex Differences in Typical Development and in Autism Spectrum Conditions. Journal of autism and developmental disorders, 39(11), pp. 1509-1521.

Aylward, E.H., Minshew, N.J., et al. (1999). MRI volumes of amygdala and hippocampus in non-mentally retarded autistic adolescents and adults. Neurology, 53(9), pp. 2145-2150.

Aylward, E.H., Minshew, N.J., Field, K., Sparks, B.F., \& Singh, N. (2002). Effects of age on brain volume and head circumference in autism. Neurology, 59(2), pp. 175-183.

Ayers, A.J. (1989). Sensory Integration and Praxis Tests manual. Los Angeles: Western Psychological Services.

Ayres, A.J., Robbins, J., \& McAtee, S. (1979). Sensory integration and the child. Los Angeles: Western Psychological Services.

Aziz-Zadeh, L., Wilson, S., Rizzolatti, G., \& Iacoboni, M. (2006). Congruent embodied representations for visually presented actions and linguistic phrases describing actions. Current Biology, 16, pp. 1818-1823. 
Bachevalier, J. (1994). Medial temporal lobe structures and autism : a review of clinical and experimental findings. Neuropsychologia, 32, pp. 627-648.

Bailey, A., Luthert, P., Dean, A., Harding, B., Janota, I., Montgomery, M., et al. (1998). A clinicopathological study of autism. Brain, 121(5), pp. 889-905. doi: 10.1093/brain/121.5.889

Baker, A.E.Z., Lane, A., Angley, M.T., \& Young, R.L. (2008). The relationship between sensory processing patterns and behavioural responsiveness in autistic disorder: A pilot study. Journal of Autism and Developmental Disorders, 38(5), pp. 867-875.

Baker, C.A., Peterson, E., Pulos, S., \& Kirkland, R.A. (2014). Eyes and IQ: A meta-analysis of the relationship between intelligence and "Reading the Mind in the Eyes.". Intelligence, 44, pp. 78-92. http://dx.doi.org/10.1016/j. intell.2014.03.001

Ballmaier, M., Schlagenhauf, F., Toga, A.W., Gallinat, J., Koslowski, M., Zoli, M.,... \& Heinz, A. (2008). Regional patterns and clinical correlates of basal ganglia morphology in non-medicated schizophrenia. Schizophrenia Research, 106(2-3), pp. 140-147.

Banerjee, R. (2002). Audience effects on self-presentation in childhood. Social Development, 1, pp. 487-507. doi : 10.1111/1467-9507.00212.

Banerjee, R., \& Watling, D. (2005). Children's understanding of faux pas: Associations with peer relations. Helenic Journal of Psychology, 2, pp. 27-45.

Banerjee, R., Watling, D. \& Caputi, M. (2011). Peer relations and the understanding of Faux Pas: Longitudinal Evidence for Bidirectional Associations. Child Development, 82, pp. 1887-1905. doi : 10.1111/ j.1467-8624.2011.01669.x

Baranek, G.T., Foster, L.G., \& Berkson, G. (1997). Tactile defensiveness and stereotyped behaviors. American Journal of Occupational Therapy, 51, pp. 91-95.

Baranek, G.T. (1999). Autism during infancy: A retrospective video analysis of sensorymotor and social behaviors at 9-12 months of age. Journal of Autism and Developmental Disorders, 29, pp. 213-224. 
Baranek, G.T., David, F.J, Poe, M.D., Stone, W.L., \& Watson, L.R. (2005). Sensory Experiences Questionnaire: Discriminating features in young children with autism, developmental delays, and typical development. Journal of Child Psychology and Psychiatry, 47(6), pp. 591-601.

Baranek, G.T., Boyd, B.A., Poe, M.D., David, F.J., \& Watson, L.R. (2007). Hyperresponsive sensory patterns in young children with autism, developmental delay and typical development. American Journal on Mental Retardation, 112, pp. 233-245.

Barnea-Goraly, N., Frazier, T.W., Piacenza, L., Minshew, N.J., Keshavan, M.S., Reiss, A. \& Hardan, A.Y. (2014). A preliminary longitudinal volumetric MRI study of amygdala and hippocampal volumes in autism. Progress in Neuro-Psychopharmacology and Biological Psychiatry, 48, pp. 124-128. http://dx.doi.org/10.1016/j.pnpbp.2013.09.010

Baron-Cohen, S. (1989a). Are autistic children 'behaviorists'? An examination of their mental-physical and appearance-reality distinctions. Journal of Autism and Developmental Disorders, 19, pp. 579-600.

Baron-Cohen, S. (1989b). The autistic child's theory of mind: a case of specific developmental delay. Journal of Child Psychology and Psychiatry, 30, pp. 285-298.

Baron-Cohen, S. (2000b). Theory of mind and autism. A fifteen year review. In BaronCohen, S., Taler-Flusberg, H., \& Cohen, D.J., eds. Understanding other minds. Perspectives from developmental cognitive neuroscience (2 ed). New York: Oxford University Press.

Baron-Cohen, S. (2001a). Theory of mind in normal development and autism. Prisme, 34, pp. 174-183.

Baron-Cohen, S. (2002). The extreme male brain theory of autism. Trends in Cognitive Sciences., 6, pp. 248-254.

Baron-Cohen, S. (2006). The hyper-systemizing, assortative mating theory of autism. Progress in Neuro-psychopharmacol and Biological Psychiatry, 30, pp. 865-872. (doi:10.1016/j.pnpbp. 2006.01.010) 
Baron-Cohen, S. (2007a). Transported into a world of emotion. The Psychologist, 20, pp. 76-77.

Baron-Cohen, S. (2009). The Empathizing-Systemizing (E-S) Theory. The Year in Cognitive Neuroscience. 1156, pp. 68-80. doi: 10.1111/j.1749-6632.2009.04467.x

Baron-Cohen, S. (2010). Autismo y Síndrome de Asperger. Madrid: Alianza Editorial S.A.

Baron-Cohen, S., Leslie, A.M., \& Frith, U. (1985). Does the autistic child have a "theory of mind?'. Cognition, 21, pp. 37-46.

Baron-Cohen, S., Leslie, A. M., \& Frith, U. (1986). Mechanical, behavioural and Intentional understanding of picture stories in autistic children. British Journal of Developmental Psychology, 4, pp. 113-125.

Baron-Cohen, S., Cox, A., Baird, G., Swettenham, J., Drew, A., Nightingale, N., Morgan, K., \& Charman, T. (1996). Psychological markers of autism at 18 months of age in a large population. British Journal of Psychiatry, 168, pp. 158-163.

Baron-Cohen, S., Riviere, A., Fukushima, M., French, D., Hadwin, J., Cross, P.,... \& Sotillo, M. (1996). Reading the mind in the face: A cross-cultural and developmental study. Visual Cognition, 3(1), pp. 39-59. doi : 10.1080/713756728.

Baron-Cohen, S., \& Hammer, J. (1997a). Parents of children with Asperger syndrome: what is the cognitive phenotype? Journal of Cognitive Neuroscience, 9, pp. 548-554.

Baron-Cohen, S., Baldwin, D.A., \& Crowson, M. (1997b). Do children with autism use the speaker's direction of gaze strategy to crack the code of language? Child Development, 68(1), pp. 48-57. doi : 10.1111/j.1467-8624.1997.tb01924.x

Baron-Cohen, S., Jolliffe, T., Mortimore, C., \& Robertson, M. (1997c). Another advanced test of theory of mind: Evidence from very high functioning adults with autism or Asperger Syndrome. Journal of Child Psychology and Psychiatry, 38, pp. 813-822.

Baron-Cohen, S., Wheelwright, S., \& Jolliffe, T. (1997d). Is there a "language of the eyes"? Evidence from normal adults and adults with autism or Asperger syndrome. Visual Cognition, 4, pp. 311-331. 
Baron-Cohen, S., Ring, H.A., Wheelwright, S., Bullmore, E.T., Brammer. M.J., Simmons, A. \& Williams, S.E. (1999a). Social intelligence in the normal and autistic brain: an fMRI. European Journal of Neuroscience, 11, pp. 1891-1898.

Baron-Cohen, S., O’Riordan, M., Stone, V., Jones, R., \& Plaisted, K. (1999b). Recognition of faux pas by normally developing children and children with Asperger syndrome or high-functioning autism. Journal of Autism and Developmental Disorders, 29, pp. 407418.

Baron-Cohen, S., Wheelwright, S., Stone, V., \& Rutherford, M. (1999c). A mathematician, a physicist and a computer scientist with Asperger syndrome: Performance on folk psychology and folk physics tests. Neurocase, 5, pp. 475-483.

Baron-Cohen, S., Ring, H.A., Bullmore, E.T., Wheelwright, S., Ashwin, C., \& Williams, S.C. (2000a). The amygdala theory of autism. Neuroscience and Biobehavioral Reviews, 24, pp. 355-364.

Baron-Cohen, S., Wheelwright, S., Spong, A. et al. (2001b) Are intuitive physics and intuitive psychology independent? A test with children with Asperger syndrome. Journal of Developmental and Learning Disorders, 5, pp. 47-78.

Baron-Cohen, S., Wheelwright, S., Hill, J., Raste, Y., \& Plumb, I. (2001c). The Reading the Mind in the Eyes test revised version: A study with normal adults, and adults with Asperger syndrome or high-functioning autism. Journal of Child Psychology and Psychiatry and Allied Disciplines, 42(2), 241-251.

Baron-Cohen, S., Richler, J., Bisarya, D., Gurunathan, N., \& Wheelwright, S. (2003). The systemizing quotient: An investigation of adults with Asperger syndrome or highfunctioning autism, and normal sex differences. Philosophical Transactions of the Royal Society B: Biological Sciences, 358, pp. 361-374.

Baron-Cohen, S., \& Wheelwright, S. (2004). The empathy quotient: An investigation of adults with Asperger syndrome or high functioning autism, and normal sex differences. Journal of Autism and Developmental Disorders, 34, pp. 163-175.

Baron-Cohen, S., Knickmeyer, R., \& Belmonte, M.K. (2005). Sex differences in the brain: Implications for explaining autism. Science, 310, pp. 819-823. doi:10.1126/science.1115455. 
Baron-Cohen, S., Wheelwright, S., Burtenshaw, A., \& Hobson, E. (2007b). Mathematical talent is linked to Autism. Human Nature, 18, pp. 125-131.

Baron-Cohen, S., Bowen D.C., Holt, R.J., Allison, C., Auyeung, B., Lombardo M.V., et al. (2015). The "Reading the Mind in the Eyes" Test: Complete Absence of Typical Sex Difference in 400 Men and Women with Autism. PLOS ONE, 10(8): e0136521.

Bartholomeusz, H.H., Courchesne, E., Karns, C.M. et al. (2002). Relationship between head circumference and brain volume in healthy normal toddlers, children, and adults. Neuropediatrics, 33, pp. 239-241.

Bassoon, M.A. \& Wingate, R.J. (2013). Congenital hypoplasia of the cerebellum: developmental causes and behavioral consequences. Frontiers in Neuroanatomy, 7, 29.

Bastian, A., \& Thach, W.T. (2002). Structure and function of the cerebellum. In: Manto, M.; Pandolfo, M., editors. The cerebellum and its disorders (pp. 49-66). Cambridge, UK: Cambridge UP.

Bauman, M.L. \& Kemper, T.L. (1985). Histoanatomic observations of the brain in early infantile autism. Neurology, 35, pp. 866-874.

Baumann, O. \& Mattingley, J.B. (2012). Functional topography of primary emotion processing in the human cerebellum. NeuroImage, 61 (4), pp. 805-811.doi: 10.1016/j.neuroimage.2012.03.044

Baurain, C., \& Nader-Grosbois, N. (2013). Theory of mind, socio-emotional problemsolving, socio-emotional regulation in children with intellectual disability and in typically developing children. Journal of Autism and Developmental Disorders, 43(5), pp. 10801097. http://dx.doi.org/10.1007/s10803-012-1651-4

Becker, E.B. \& Stoodley, C.J. (2013). Autism spectrum disorder and the cerebellum. International Review of Neurobiology, 113, pp. 1-34.

Behrmann, M., Thomas. C., \& Humphreys, K. (2006). Seeing it differently: visual processing in autism. Trends in Cognitive Sciences; 10, pp. 258-264. 
Belmonte, M.K., Cook, E.H. Jr, Anderson, G.M., Rubenstein, J.L., Greenough, W.T., Beckel-Mitchener, A., et al. (2004b). Autism as a disorder of neural information processing: directions for research and targets for therapy. Molecular Psychiatry, 9, pp. 646-663.

Belmonte, M.K., Gomot, M., \& Baron-Cohen, S. (2010). Visual attention in autism families: 'unaffected' sibs share atypical frontal activation. Journal of Child Psychology and Psychiatry, 51, pp. 259-276.

Benes, F.M. (1989). Myelination of cortical-hippocampal relays during late adolescence. Schizophrenia Bulletin, 15, pp. 585-593.

Benes, F.M., Turtle, M., Khan, Y., \& Farol, P. (1994). Myelination of a key relay zone in the hippocampal formation occurs in the human brain during childhood, adolescence, and adulthood. Archives of General Psychiatry, 51, pp. 477-484.

Bennetto, L., Pennington, B.F., \& Rogers, S.J. (1996). Intact and impaired memory functions in autism. Child Development, 67, pp. 1816-1835.

Ben-Sasson, A., Cermak S.A., Orsmond G.I., Tager-Flusberg H., Carter A.S., Kadlec M.B., et al. (2007). Extreme sensory modulations in toddlers with Autism Spectrum Disorders. American Journal of Occupational Therapy, 61, pp. 584-592.

Ben-Sasson, A., Hen, L., Fluss, R., Cermak, S.A., Engel-Yeger, B., \& Gal, E. (2009). A meta-analysis of sensory modulation symptoms in individuals with autism spectrum disorders. Journal of Autism and Developmental Disorders, 39, pp. 1-11.

Bettison, S. (1994). Abnormal responses to sound and the long-term effects of a new treatment program. Sydney, Australia: Autism Research Institute.

Bigler, E.D., Tate, D.F., et al. (2003). Temporal lobe, autism, and macrocephaly. AJNR: American Joural of Neuroradiology, 24(10), pp. 2066-2076.

Blakemore, S.J., \& Decety J. (2001). From the perception of action to the understanding of intention. Nature Reviews Neuroscience, 2, pp. 561-567. 
Blakemore, S.J. (2012). Imaging brain development: the adolescent brain. Neuroimage, 61, pp. 397-406. doi: 10.1016/j.neuroimage.2011.11.080

Blatt, G.J., Oblak, A.L. \& Schmahmann, J.D. (2013). Cerebellar Connections with Limbic Circuits: Anatomy and Functional Implications. Handbook of the Cerebellum and Cerebelar Disorders, pp.479-496.DOI: 10.1007/978-94-007-1333-8_22

Bleuler, E. (1911). Dementia praecox oder Gruppe der Schizophrenien. Leipzig: Deuticke.

Bleuler, E. (1950). Dementia praecox or the group of schizophrenias. Monograph series on schizophrenia (1). New York: International University Press.

Bogdashina, O. (2003). Sensory perceptual issues in autism and Asperger syndrome: different sensory experiences, different perceptual worlds. London: Jessica Kingsley.

Bolton, P.F., Roobol, M., Allsopp, L. et al. (2001). Association between idiopathic infantile macrocephaly and autism spectrum disorders. Lancet, 358, pp. 726-727.

Boll, S., Gamer, M., et al. (2011). Processing of facial expressions and their significance for the observer in subregions of the human amygdala. Neuroimage, 56(1), pp. 299-306.

Bowler, D.M., Stromm, E., \& Urquhart, L. (2001). Elicitation of first-order "theory of mind" in children with autism. In Riviere, A. \& Martos, J. (Comp.), El tratamiento del autismo. Nuevas perspectivas. Madrid: Ministerio de Trabajo y Asuntos Sociales.

Boyd, B.A., Baranek, G.T., Sideris, J., Poe, M.D., Watson, L.R., et al. (2010). Sensory features and repetitive behaviors in children with autism and developmental delays. Autism Research, 3, pp. 78-87.

Brambilla P., Hardan A., Ucelli di Nemi S., Pérez J., Soares J.C., \& Barale F. (2003). Brain anatomy and development in autism: review of structural MRI studies. Brain Research Bulletin, 61, pp. 557-569. Doi: 10.1016/j.brainresbull.2033.06.001

Brent, E., Rios, P., Happé, F., \& Charman, T. (2004). Performance of children with autism spectrum disorder on advanced theory of mind task. Autism, 8(3), pp. 283-299. 
Brown, C.D., (2002). Adolescent/Adult Sensory Profile manual. San Antonio, TX: Psychological.

Brown, T.T., \& Jernigan, T.L. (2012). Brain development during the preschool years. Neuropsychology Review. 22, pp. 313-333.

Buckner, R.L., Krienen, F.M., Castellanos, A., Díaz, J.C. \& Yeo, B.T.T. (2011). The organization of the human cerebellum estimated by intrinsic functional connectivity. $J$. Neurophysiology; 106 (5): 2322-2345.doi: 10.1152/jn.00339.2011

Bunge, S.A., \& Crone, E.A. (2009). Neural correlates of the development of cognitive control. Neuroimaging in developmental clinical neuroscience, pp. 22-37.

Burgess, N., Maguire, E.A., \& O'Keefe, J. (2002). The human hippocampus and spatial and episodic memory. Neuron, 35, pp. 625-641.

Bush, G., Luu, P., \& Posner, M.I. (2000). Cognitive and emotional influences in anterior cingulate cortex. Trends in Cognitive Sciences, 4, pp. 215-222.

Butman, J., \& Allegri, R.F. (2001). A cogniçao social e o córtex cerebral. Psicología: Reflexao e Crítica, 14(2), pp. 275-279.

Calder, A.J., Lawrence, A.D., \& Young, A.W. (2001). Neuropsychology of fear and loathing. Nature Reviews Neuroscience, 2, pp. 352-63.

Caminha, R.C., \& Lampreia, C., (2012). Findings on sensory deficits in autism: implications for understanding the disorder. Psychology and Neuroscience, 5(2), pp. 231-237. DOI: 10.3922/j.psns.2012.2.14

Canal-Bedia, R., García-Primo, P., Hernández-Fabián, A., Magán-Maganto, M., Sánchez, A.B., \& Posada-De la Paz, M. (2015). De la detección precoz a la atención temprana: estrategias de intervención a partir del cribado prospectivo. Revista de Neurología, 60(1), pp. 25-29.

Carlson, S. M., Moses, L. J., \& Breton, C. (2002). How specific is the relation between executive function and theory of mind? Contributions of inhibitory control and working 
memory. Infant and Child Development, 11(2), pp. 73-92. http://dx.doi.org/10.1002/icd.298.

Carmona, S., Proal, E., Hoekzema, E.A., Gispert, J.-D., Picado, M., Moreno, I.,.. \& Vilarroya, O. (2009). Ventro-striatal reductions underpin symptoms of hyperactivity and impulsivity in attention-deficit/hyperactivity disorder. Biological Psychiatry, 66, pp. 972977

Carpendale, J., \& Lewis, C. (2006). How children Develop Social Understanding. Oxford: Blackwell.

Carper, R.A., Moses, P., Tigue, Z.D., \& Courchesne, E. (2002). Cerebral lobes in autism: early hyperplasia and abnormal age effects. Neuroimage, 16, pp. 1038-1051.

Carper, R.A., \& Courchesne, E. (2005). Localized enlargement of the frontal cortex in early autism. Biological Psychiatry, 57(2), pp. 126-133.

Carr, L., Iacoboni, M., Dubeau, M.C., Mazziotta, J.C., \& Lenzi, G.L. (2003). Neural mechanisms of empathy in humans: a relay from neural systems for imitation to limbic areas. Proceedings of the National Academy of Sciences of the United States of America, 29, pp. 5497-5502.

Casanova, M.F., Buxhoeveden, D.P., Switala, A.E., \& Roy, E. (2002). Minicolumnar pathology in autism. Neurology, 58(3), pp. 428-432.

Cascio, C., McGlone, F., Folger, S., Tannan, V., Baranek, G., Pelphrey, K.A., et al. (2008). Tactile perception in adults with autism: a multidimensional psychophysical study. Journal of Autism and Developmental Disorders, 38, pp. 127-137.

Catani, M., Jones, D., Daly, E., Embiricos, N., Deeley, Q., Pugliese, L., et al. (2008). Altered cerebellar feedback projections in Asperger syndrome. Neuroimage, 41, pp. 1184-1191. doi: 10.1016/j.neuroimage.2008.03.041

Cauda, F., Geda, E., Sacco, K., D’Agata, F., Duca, S., Geminiani, G., et al. (2011). Grey matter abnormality in autism spectrum disorder: an activation likelihood estimation metaanalysis study. Journal of Neurology, Neurosurgery and Psychiatry, 82, pp. 1304-1313. doi: 10.1136/jnnp.2010.239111 
Cavanna, A.E. \& Trimble, M.R. (2006). The precuneus: a review of its functional anatomy and behavioural correlates. Brain, 129, pp. 564-583.

Caviness, V.S., Kennedy, D.N., Bates, J.F., \& Makris, N. (1996a). The developing brain: A morphometric profile. In: Thatcher RW, Lyon GR, Rumsey J, Krasnegor N, editors. Developmental neuroimaging: Mapping the development of brain and behavior (pp. 314). New York: Academic Press.

Caviness, V.S., Meyer, J., Makris, N., \& Kennedy, D.N. (1996b). MRI-based topographic parcellation of human neocortex: An anatomically specified method with estimate of reliability. Journal of Cognitive Neuroscience, 8, pp. 556-587.

Caviness, V.S., Kennedy, D.N., Richelme, C., Rademacher, J. \& Filipek, P.A. (1996). The human brain age 7-11 years: A volumetric analysis based on magnetic resonance images. Cerebral Cortex, 6(5), pp. 726-736.

Ceponiene, R., Lepistö, T., Shestakova, A., Vanhala, R., Alku, P., Näätänen, R., et al. (2003). Speech-sound-selective auditory impairment in children with autism: they can perceive but do not attend. Proceedings of the National Academy of Sciences of the United States of America, 100, pp. 5567-5572.

Cererols, R. (2010). Descubrir el Asperger. Barcelona: Editorial Amat.

Cerliani, L., Mennes, M., Thomas, R.M., Di Martino, A., Thioux, M., \& Keysers, C. (2015). Increased functional connectivity between subcortical and cortical resting-state networks in autism spectrum disorder. JAMA Psychiatry, 72, pp. 767-777. http:// dx.doi.org/10.1001/jamapsychiatry.2015.0101.

Cesaroni, L., \& Garber, M. (1991). Exploring the experience of autism through firsthand accounts. Journal of Autism and Developmental Disorders, 21, pp. 303-313.

Charman, T., Baron-Cohen, S., Swettenham, J., Baird, G., Cox, A. \& Drew, A. (2000). Testing joint attention, imitation and play as infancy precursors to language and theory of mind. Cognitive Development, 15, pp. 481-498. doi: 10.1016/S0885-2014(01)00037-5. 
Chen, Y.H., Rodgers, J. \& McConachie, H. (2009). Restricted and repetitive behaviours, sensory processing and cognitive style in children with autism spectrum disorders. Journal of Autism and Developmental Disorders, 39, pp. 635-642.

Chess, S. (1977), Follow-up report on autism in congenital rubella. Journal of Autism and Childhood Schizophrenia, 7(1), pp. 69-81.

Choe, M., Ortiz-Mantilla, S., Makris, N., Gregas, M., Bacic, J., Haehn, D.,... \& Grant, P.E. (2013). Cerebral Cortex, 23, pp. 2100-2117. doi: 10.1093/cercor/bhs 197

Clasificación Estadística Internacional de Enfermedades y Problemas relacionados con la Salud (CIE-10), (1993). Organización Mundial de la Salud.

Clifford, S.M., Hudry, K., Elsabbagh, M., Charman, T., Johnson, M.H., \& The BASIS Team (2013). Temperament in the first twoyears of life in infants at high-risk for autism spectrum disorders. Journal of Autism and Developmental Disorders, 43, pp. 673-686.

Conty, L., \& Grezes, J. (2012). Look at me, I'll remember you: the perception of selfrelevant social cues enhances memory and right hippocampal activity. Human Brain Mapping, 33(10), pp. 2428-2440.

Corbett, B.A., \& Constantine, L.J. (2006). Autism and attention deficit hyperactivity disorder: assessing attention and response control with the integrated visual and auditory continuous performance test. Child Neuropsychology, 12(4-5), pp. 335-348. [PubMed: 16911977

Corbett, B.A., Carmean, V., Ravizza, S., Wendelken, C., Henry, M.L. et al. (2009). A functional and structural study of emotion and face processing in children with autism. Psychiatry Research, 173, pp. 196-205.

Courchesne, E., Yeung-Courchesne, R., Press, G., Hesselink, J., \& Jernigan, T. (1988). Hypoplasia of cerebellar vermal lobules VI and VII in autism. The New England Journal of Medicine, 318, pp. 1349-1354. doi: 10.1056/NEJM198805263182102

Courchesne, E., Karns, C.M., Davis, H.R., Ziccardi, R., Carper, R.A., Tigue, Z.D.,... \& Courchesne, R.Y. (2001). Unusual brain growth patterns in early life in patients with autistic disorder: an MRI study. Neurology, 57, pp. 245-254. 
Courchesne, E. (2002). Abnormal early brain development in autism. Molecular Psychiatry, $7(2)$, pp. 21-23.

Courchesne, E., Carper, R., \& Akshoomoff, N. (2003). Evidence of brain overgrowth in the first year of life in autism. JAMA, 290, pp. 337-344.

Courchesne, E., Redcay, E., Kennedy, D.P., et al. (2004). The autistic brain: birth through adulthood. Current Opinion in Neurology, 17, pp. 489-496.

Courchesne, E., \& Pierce, K. (2005). Brain overgrowth in autism during a critical time in development: implications for frontal pyramidal neuron and interneuron development and connectivity. International Journal of Developmental Neuroscience, 23, pp. 153-170.

Courchesne, E., Pierce, K., Schumann, C.M., Redcay, E., Buckwalter, J.A., Kennedy, D.P., \& Morgan, J. (2007). Mapping early brain development in autism. Neuron, 56, pp. 399413. [PubMed: 17964254]

Courchesne, E., Webb, S.J., \& Schumann, C.M. (2010). From toddlers to adults: The changing landscape of the brain in autism. In Amaral, D.G., Dawson, G., \& Geschwind, D.H., editors. Autism Spectrum Disorders. Oxford University Press.

Courchesne, E., Campbell, K., \& Solso, S. (2011a). Brain growth across the life span in autism: age-specific changes in anatomical pathology. Brain Research, 1380, pp. 138145.

Courchesne, E., Mouton, P.R., Calhoun, M.E., et al. (2011b). Neuron number and size in prefrontal cortex of children with autism. JAMA, 306(18), pp. 2001-2010.

Crane, L., Goddard, L., \& Pring, L. (2009). Sensory processing in adults with autism spectrumdisorders. Autism, 13(3), pp. 215-228. Retrieved from http://www.ncbi.nlm.nih.gov/entrez/query.fcgi?cmd=Retrieve \&db=PubMed\&dopt=Citati on\&list_uids $=19369385$.

Cunningham, A.B., \& Schreibman, L. (2008). Stereotypy in autism: the importance of function. Research in Autism Spectrum Disorders, 2, 469-479. 
Dahlgren, S.O., \& Gillberg, C. (1989). Symptoms in the first two years of life: A preliminary population study of infantile autism. European Archives of Psychology and Neurological Sciences, 238, pp. 169-174.

Dapretto M., Davies M.S., Pfeifer J.H., Scott A.A., Sigman M., Bookheimer S.Y., \& Iacoboni M. (2005). Understanding emotions in others: mirror neuron dysfunction in children with autism spectrum disorders. Nature Neuroscience. doi: 10.1038/nn1611.

Davis, M., \& Whalen, P.J. (2001). The amygdala: vigilance and emotion. Molecular Psychiatry, 6, pp. 13-34.

Dawson, G., \& Fernald, M. (1987). Perspective-taking ability and its relationship to the social behavior of autistic children. Journal of Autism and Developmental Disorders, 17, pp. $487-498$.

Dawson, G., Webb, S., \& McPartland, J. (2005). Understanding the nature of face processing impairment in autism: insights from behavioral and electrophysiological studies. Developmental Neuropsychology; 27, pp. 403-424.

Dawson, G., et al. (2007). Rate of head growth decelerates and symptoms worsen in the second year of life in autism. Biological Psychiatry, 61, pp. 458-464.

DeGangi, G. \& Burk, R.A. (1983). DeGangi-Burk Test of Sensory Integration (TSI). Los Angeles: Western Psychological Services.

Delmonte, S., Gallagher, L., O'Hanlon, E., McGrath, J., \& Blasters, J. (2013). Functional and structural connectivity of frontostriatal circuitry in autism spectrum disorder. Frontiers in Human Neuroscience, 7, 430. http://dx.doi.org/10.3389/fnhum.2013.00430.

Dementieva, Y.A., et al. (2005). Accelerated head growth in early development of individuals with autism. Pediatric Neurology, 32, pp. 102-108.

Demetriou, A., Christou, C., Spanoudis, G., \& Platsidou, M. (2002). The development of mental processing: Efficiency, working memory, and thinking. Monographs of the Society for Research in Child Development, 67(1), pp. 1-156. 
Dennison, M., Whittle, S., Yücel, M., Vijayakumar, N., Kline, A., Simmons, J. et al. (2013). Mapping subcortical brain maturation during adolescence: evidence of hemisphere- and sex-specific longitudinal changes. Developmental Science, 16, pp. 772-791.

Deykin, E., \& MacMahon, B., (1979). The incidences of seizures among children with autistic symptoms. American Journal of Psychiatry, 136(10), pp. 1310-1312.

Diamond, A. (2000). Close interrelation of motor development and cognitive development and of the cerebellum and prefrontal cortex. Child Development, 71, pp. 44-56.

Diamond A. (2002). Normal development of prefrontal cortex from birth to young adulthood: cognitive function, anatomy, and biochemistry. In Stuss DT, Knight RT, eds. Principles of frontal lobe function (pp. 466-503). London: Oxford University Press.

Díez-Cuervo, A., Muñoz-Yunta, J.A., Fuentes-Biggi, J., Canal-Bedia, R., Idiazábal-Aletxa, M.A.,... y Posada-De la Paz, M. (2005). Guía de buena práctica para el diagnóstico de los trastornos del espectro autista. Revista de Neurología, 41(5), pp. 299-310.

Di Martino, A., Fair, D.A., Kelly, C., Satterthwaite, T.D., Castellanos, F.X., Thomason, M.E.,... \& Milham, M.P. (2014a). Unraveling the miswired connectome: a developmental perspective. Neuron, 83, pp. 1335-1353. http://dx.doi.org/10.1016/j.neuron.2014.08.050.

D’Mello, A.M., Crocetti, D., Mostofsky, S.H., et al. (2015). Cerebellar gray matter and lobular volumes correlate with core autism symptoms. Neuroimage: Clinical Journal, 7, pp. 631-639.

Doyle-Thomas, K.A., Duerden, E.G., Taylor, M.J., Lerch, J.P., Soorya, L.V., Wang, A.T.,... \& Anagnostou, E. (2013). Effects of age and symptomatology on cortical thickness in autism spectrum disorders. Research of Autism Spectrum Disorders, 7, pp. 141-150.

Donovan, A.P.A. \& Basson, M.A. (2016). The neuroanatomy of autism-a developmental perspective. Journal of Anatomy, pp. 1-12. doi: 10.1111/joa.12542

Ducharme, S., Albaugh, M.D., Nguyen, T.V., Hudziak, J.J., Mateos-Pérez, J., Labbe A,... \& Karama, S. (2016). Trajectories of cortical thickness maturation in normal brain 
development - the importance of quality control procedures. NeuroImage, 125, pp. 267279.

Duerden, E.G., Mak-Fan, K.M., Taylor, M.J., \& Roberts, S.W. (2012). Regional differences in grey and white matter in children and adults with autism spectrum disorders: an activation likelihood estimate (ALE) meta-analysis. Autism Research, 5, pp. 49-66. doi: 10.1002/aur.235

Dunn, W., \& Westman, K. (1995). The sensory profile. Kansas City: University of Kansas Medical Center.

Dunn, W. (1997). The impact of sensory processing abilities on the daily lives of young children and their families: A conceptual model. Infants and Young Children, 9, pp. 2335 .

Dunn, W. (1999). Development and validation of the short sensory profile. In W. Dunn (Ed.). The sensory profile examiner's manual. San Antonio, TX: Psychological Corporation.

Dunn, W. (1999). The Sensory Profile manual. San Antonia, TX: Psychological.

Dunn, W. (2002a). The Infant/Toddler Sensory Profile manual. San Antonio, TX: Psychological.

Dunn, W., Myles, B.S., \& Orr, S. (2002b). Sensory processing issues associated with Asperger syndrome: A preliminary investigation. American Journal of Occupational Therapy, 56(1), pp. 97-102.

Dunn, M.A., Gomes, H., \& Gravel, J. (2008). Mismatch negativity in children with autism and typical development. Journal of Autism and Developmental Disorders, 38, pp. 52-71.

Durston, S., Hulshoff Pol, H.E., Casey, B.J., Giedd, J.N., Buitelaar, J.K., \& Van Engeland, H. (2001). Anatomical MRI of the developing human brain: what have we learned? Journal of the American Academy of Child and Adolescent Psychiatry, 40(9), pp. 10121020. 
Dziuk, M.A., Gidley Larson, J.C., Apostu, A., Mahone, E.M., Denclkla, M.B., \& Mostofsky, S.H. (2007). Dyspraxia in autism: Association with motor, social, and communicative deficits. Developmental Medicine and Child Neurology, 49, pp. 734-739.

Ecker, C., Ginestet, C., Feng, Y., Johnston, P., Lombardo, M.V., Lai, M.C., et al. (2013). Brain surface anatomy in adults with autism: the relationship between surface area, cortical thickness, and autistic symptoms. JAMA Psychiatry, 70, pp. 59-70.

Ecker, C., Shahidiani, A., Feng, Y., Daly, E., Murphy, C., D’Almeida, V., et al. (2014). The effect of age, diagnosis, and their interaction on vertex-based measures of cortical thickness and surface area in autism spectrum disorder. Journal of Neural Transmission, 121, pp. 1157-1170.

Ermer, J., \& Dunn, W. (1998). The Sensory Profile: A discriminant analysis of children with and without disabilities. American Journal of Occupational Therapy, 52, pp. 283-290.

Etchepareborda, M.C., Díaz-Lucero, A., Pascuale, M.J., Abad-Mas, L., y Ruiz-Andrés, R. (2007). Síndrome de Asperger, los pequeños profesores: habilidades especiales. Revista de Neurología, 44(2), pp. 43-47.

Fanselow, M.S., \& Dong, H.W. (2010). Are the dorsal and ventral hippocampus functionally distinct structures? Neuron, 65(1), pp. 7-19.

Farrar, M.J., \& Maag, L. (2002). Early language development and the emergence of phonemic awareness. First Language, 22, pp. 197-213.

Fatemi, S.H., Aldinger, K.A., Ashwood, P., et al. (2012). Consensus Paper: Pathological role of the cerebellum in autism. Cerebellum 11, pp. 777-807.

Fernández-Andrés, M.I., Pastor-Cerezuela, G., Sanz-Cervera, P., \& Tárraga-Minguez, R. (2015). A comparative study of sensory processing in children with and without Autism Spectrum Disorder in the home and classroom environments. Research in Developmental Disabilities, 38, pp. 202-212. http://dx.doi.org/10.1016/j.ridd.2014.12.034

Flavell, J.H. (2004). Theory-of-mind development: Retrospect and prospect. Merril-Palmer Quarterly, 50, pp. 274-290. 
Fernell, E., Eriksson, M.A., \& Gillberg C. (2013). Early diagnosis of autism and impact on prognosis: a narrative review. Clinical Epidemiology, 5, pp. 33-43. doi.org/10.2147/CLEP.S41714

Fields, R.D., \& Stevens-Graham, B. (2002). New insights into neuron-glia communication. Science, 298, pp. 556-562. [PubMed: 12386325]

Filipek, P.A., Accardo, P.J., Ashwal, S., Baranek, G.T., Cook, E.H., Dawson, G.,... \& Volkmar, F.R. (2000). Practice parameter: Screening and diagnosis of autism: Report of the Quality Standards Subcommittee of the American Academy of Neurology and the Child Neurology Society. Neurology, 55(4), pp. 468-479. DOI 10.1212/WNL.55.4.468

Forman, S., Cohen, J., Fitzgerald, M., Eddy, W., Mintun, M., \& Noll, D. (1995). Improved assessment of significant activation in functional magnetic resonance imaging (fMRI): use of a cluster-size threshold. Magnetic Resonance in Medicine, 33, pp. 636-647.

Fountain, C., King, M.D., \& Bearman, P.S. (2011). Age of diagnosis for autism: individual and community factors across 10 birth cohorts. Journal of Epidemiology and Community Health, 65, pp. 503-510. DOI:10.1136/jech.2009.104588.

Franco, F., Itakura, S., Pomorska, K., Abramowski, A., Nikaido, K., \& Dimitriou, D. (2014). Can children with autism read emotions from the eyes? The eyes test revisited. Research in Developmental Disabilities, 3(5), pp. 1015-1026.

Frith, U. (1989). Autism: explaining the enigma. Oxford: Basil Blackwell.

Frith, U. (1991). Autism and Asperger Syndrome. Cambridge: Cambridge University Press.

Frith, U., \& Frith, C. (2003). Development and neurophysiology of mentalizing. Philosophical Transactions of the Royal Society of London - Series B: Biological Sciences, 258, pp. 459-473.

Fuster, J.M. (2002). Frontal lobe and cognitive development. Journal of Neurocytology, 31, pp. 373-385. 
Gabriels, R.L., Agnew, J.A., Miller, L.J., et al. (2008). Is there a relationship between restricted, repetitive, stereotyped behaviors and interests and abnormal sensory response in children with autism spectrum disorders? Research of Autism Spectrum Disorder, 2, pp. 660-670.

Gadad, B.S., Hewitson, L., Young, K.A., et al. (2013). Neuropathology and animal models of autism: genetic and environmental factors. Autism Research and Treatment, Article ID: 731935 .

Gadow, K.D., DeVincent, C.J., \& Pomeroy, J. (2006). ADHD symptom subtypes in children with pervasive developmental disorder. Journal of Autism and Developmental Disorders, 36, pp. 271-283. doi:10.1007/s10803-005-0060-3

Gargaro, B.A., Rinehart, N.J., Bradshaw, J.L., Tonge, B.J., \& Sheppard, D.M. (2011). Autism and ADHD: how far have we come in the comorbidity debate? Neuroscience and Biobehavioral Reviews, 35, pp. 1081-1098. doi:10.1016/j.neubiorev.2010.11.002

Geurts H.M., Verte S., Oosterlaan J., Roeyers H., \& Sergeant J.A. (2004). How specific are executive functioning deficits in attention deficit hyperactivity disorder and autism? Journal of Child Psychology and Psychiatry, 45(4), pp. 836-854. (PubMed: 15056314).

Giedd, J.N., Vaituzis, A.C., Hamburger, S.D., Lange, N., Rajapakse, J.C., Kaysen, D.,.. \& Rapoport, JL. (1996a). Quantitative MRI of the temporal lobe, amygdala, and hippocampus in normal human development: Ages 4-18 years. Journal of Comparative Neurology, 366(2), pp. 223-230.

Giedd, J.N., Snell, J.W., Lange, N., Rajapakse, J.C., Casey, B.J., Kozuch, P.L., et al. (1996b). Quantitative magnetic resonance imaging of human brain development: Ages 418. Cerebral Cortex, 6(4), pp. 551-560.

Giedd, J.N., Castellanos, F.X., Rajapakse, J.C., Vaituzis, A.C., \& Rapoport, J.L. (1997). Sexual dimorphism of the developing human brain. Progress in Neuropsychopharmacology and Biological Psychiatry, 21, pp. 1185-1201.

Giedd, J.N., Blumenthal, J., Jeffries, N.O., Castellanos, F.X., Liu, H., Zijdenbos, A., et al. (1999). Brain development during childhood and adolescence: a longitudinal MRI study. Nature Neuroscience, 2, pp. 861-863. doi:10.1038/13158. 
Giedd, J.N., \& Rapoport, J. (2010). Structural MRI of Pediatric Brain Development: What Have We Learned and Where Are We Going? Neuron, 67(5), pp. 728-734. doi: 10.1016/j.neuron.2010.08.040.

Gillberg, C.A. (2002). Guide to Asperger Syndrome. Cambridge: Cambridge University Press.

Gillberg, C., \& Coleman, M. (1996). Autism and medical disorders: A review of literature. Developmental Medicine and Child Neurology, 38, pp. 191-202.

Gillberg, C., \& Coleman, M. (2000). The biology of autistic syndromes. London: Cambridge Press.

Gilliam, J.E. (1995). Gilliam Autism Rating Scale. Austin, TX: PRO-ED.

Gilmore, J.H., Lin, W., Prastawa, M.W., Looney, C.B., Vetsa, Y.S., Knickmeyer, R.C.,... \& Gerig, G. (2007b). Regional gray matter growth, sexual dimorphism, and cerebral asymmetry in the neonatal brain. Journal of Neuroscience, 27, pp. 1255-1260 (PubMed: 17287499).

Glantz, L.A., Gilmore, J.H., Hamer, R.M., Lieberman, J.A., \& Jarskog, L.F. (2007). Synaptophysin and postsynaptic density protein 95 in the human prefrontal cortex from mid-gestation into early adulthood. Neuroscience, 149, pp. 582-591 (PubMed: 17916412).

Glickstein, M., Gerrits, N., Kralj-hans, I., Mercier, B., Stein, J. \& Voogd, J. (1994). Visual pontocerebelar projection in the macaque. J. Comp. Neurol., 349: pp. 51-72.

Golan, O., Baron-Cohen, S., Hill, J.J., et al (2006). The 'Reading the Mind in Films' Task: complex emotion recognition in adults with and without autism spectrum conditions. Society for Neuroscience, 1, pp. 111-123.

Goldberg, M. (2004). A car goes in the garage like a can of peas goes in the refrigerator: Do deficits in real-world knowledge affect the assessment of intelligence in individuals with autism? Focus on Autism and other Developmental Disabilities, 20(1), pp. 2-9. 
Goldberg, M.C., Mostofsky, S.H., Cutting, L.E., Mahone, E.M., Astor, B.C., Denckla, M.B., et al. (2005). Subtle executive impairment in children with autism and children with ADHD. Journal of Autism and Developmental Disorders, 35(3), pp. 279-293 (PubMed: 16119469).

Goldenfeld, N., Baron-Cohen, S., \& Wheelwright, S. (2005). Empathizing and systemizing in males, females and autism. Clinical Neuropsychiatry, 2(6), pp. 338-345.

Goldman-Rakic, P.S., Chafee, M., \& Friedman, H. (1993). Allocation of function in distributed circuits. In Ono, T., Squire, L.R., Raichle, M.E., Perrett, D.I., \& Fukuda, M., (Eds.), Brain mechanisms of perception and memory: From neuron to behaviour (pp. 445-456). New York: Oxford University Press.

Gordon, A.C., \& Olson, D.R. (1998). The relation between acquisition of a theory of mind and the capacity to hold in mind. Journal of Experimental Child Psychology, 68(1), pp. 70-83. http://dx.doi.org/10.1006/ jecp.1997.2423.

Gogtay, N., Giedd, J.N., Lusk, L., Hayashi, K.M., Greenstein, D., Vaituzis, A.C., et al. (2004). Dynamic mapping of human cortical development during childhood through early adulthood. Proceedings of the National Academy of Sciences of the United States of America, 101, pp. 8174-8179.

Grandin, T. (2000). My experiences with visual thinking sensory problems and communication difficulties. http://www.autism.org (accessed October 5, 2012).

Green, S.A., Hernández, L., Bookheimer, S.Y. \& Dapretto, M. (2016). Reduced Modulation of Thalamocortical Connectivity during Exposure to Sensory Stimuli in ASD. Autism Research, 10 (5), pp. 801-809.

Greenspan, S.I., \& Weider, S. (1997). Developmental patterns and outcomes in infants and children with disorders relating and communicating: A chart review of 200 cases of children with autistic spectrum diagnoses. Journal of Developmental and Learning Disorders, 1(1), pp. 87-142.

Greicius, M.D., Krasnow, B., et al. (2003). Regional analysis of hippocampal activation during memory encoding and retrieval: fMRI study. Hippocampus, 13(1), pp. 164-174. 
Greimel, E., Nehrkorn, B., Schulte-Ruther, M., Fink, G.R., Nickl-Jockschat, T., HerpertzDahlmann, B. et al. (2013). Changes in grey matter development in autism spectrum disorder. Brain Structure and Function, 218, pp. 929-942

Grelotti, D.J., Gauthier, I., \& Schultz, R.T. (2002). Social interest and the development of cortical face specialization: what autism teaches us about face processing? Developmental Psychobiology, 40, pp. 213-225.

Grove, R., Baillie, A., Allison, C., Baron-Cohen, S., \& Hoekstra, R. (2013). Empathizing, systemizing, and autistic traits: Latent structure in individuals with autism, their parents, and general population controls. Journal of Abnormal Psychology, 122(2), pp. 600-609.

Güçlü, B., Tanidir, C., Mukaddes, N.M., \& Unal, F. (2007). Tactile sensitivity of normal and autistic children. Somatosensory and Motor Research, 24, pp. 21-33.

GuiaSalud [Internet]. Guía de Práctica Clínica para el Manejo de Pacientes con Trastornos del Espectro Autista en Atención Primaria. [Actualizada el 07 de mayo de 2010. Citada el 4 de junio de 2010]. Recuperado de: http://www.guiasalud.es/egpc/autismo/completa/ index.html

Hadwin, J., Baron-Cohen, S., Howlin, P., \& Hill, K. (1996). Can we teach children with autism to understand emotions, belief, or pretence? Development and Psychopathology, 8, pp. 345-365.

Hadjikhani, N., Joseph, R.M., Snyder, J., \& Tager-Flusberg, H. (2006). Anatomical differences in the mirror neuron system and social cognition network in autism. Cerebral Cortex, 16, pp. 1276-1282.

Hamilton, K., Hoogenhout, M. \& Malcolm-Smith, S. (2016). Neurocognitive considerations when assessing Theory of Mind in Autism Spectrum Disorder. Journal and Adolescent Mental Health, 28(3), pp. 233-241. http://dx.doi.org/10.2989/17280583.2016.1268141

Happé, F. (1994). An advanced test of theory of mind: understanding of story characters thoughts and feelings by able autistic, mentally handicapped, and normal children and adults. Journal of Autism and Developmental Disorders; 24, pp. 129-154. 
Happé, F. (1995). The role of age and verbal ability in the theory of mind task performance of subjects with autism. Child Development, 66, pp. 843-855. http://dx.doi.org/10.2307/1131954.

Happé, F. (1996). Autism. London, UK: UCL Press.

Happé, F., \& Frith, U. (1996). The neuropsychology of autism. Brain, 119(4), pp. 13771400. http://dx.doi. org/10.1093/brain/119.4.1377.

Happé F., Winner, E., \& Brownell, H. (1998). Acquiered "Theory of mind" impairments following stroke. Cognition, 70(3), pp. 211-240.

Happé, F., \& Vital, P. (2009). What aspects of autism predispose to talent? Philosophical Transactions of the Royal Society B, 364, 1369-1375. (doi:10. 1098/rstb.2008.0332).

Happè, F., \& Frith, U. (2014). Annual Research Review: Towards a developmental neuroscience of atypical social cognition. Journal of Child Psychology and Psychiatry, 3(6), pp. 553-577.

Hardan, A.Y., Girgis, R.R., Adams, J., Gilbert, A.R., Keshavan, M.S., \& Minshew, N.J. (2006). Abnormal brain size effect on the thalamus in autism. Psychiatry Research, 147, pp. 145-151. [PubMed: 16945509].

Hardan, A.Y., Girgis, R.R., Adams, J., Gilbert, A.R., Melhem, N.M., Keshavan, M.S., et al. (2008a). Brief report: abnormal association between the thalamus and brain size in Asperger's disorder. Journal of Autism and Developmental Disorders, 38, pp. 390-394. DOI: $10.1007 / \mathrm{s} 10803-007-0385-1$.

Hardan, A.Y., Minshew, N.J., Melhem, N.M., Srihari, S., Jo, B., Bansal, R., et al. (2008b). An MRI and proton spectroscopy study of the thalamus in children with autism. Psychiatry Research, 163, pp. 97-105.

Hardan, A.Y., Libove, R.A., Keshavan, M.S., Melhem, N.M. \& Minshew, N.J. (2009). A preliminary longitudinal magnetic resonance imaging study of brain volume and cortical thickness in autism. Biological Psychiatry, 66(4), pp. 320-326. 
Hare, B. (2007). From nonhuman to human mind. What changed and why? Current Directions in Psychological Science, 16(2), pp. 60-64.

Harrison, J., \& Hare, D.J. (2004). Brief report: Assessment of sensory abnormalities in people with autistic spectrum disorders. Journal of Autism and Developmental Disorders, 34(6), pp. 727-730.

Hauser, S.L., De Long, G.R., \& Rosman, N.P. (1975). Pneumographic findings in the infantile autism syndrome. A correlation with temporal lobe disease. Brain, 98, pp. 667688.

Haxby, J.V., Hoffman, E.A., \& Gobbini, M.I. (2002). Human neural systems for face recognition and social communication. Biological Psychiatry, 51, pp. 59-67.

Hazen, E.P., Stornelli, J.L., O’Rourke, J.A., Koesterer, K., \& McDougle, C.J. (2014). Sensory Symptoms in Autism Spectrum Disorders. Harvard Review of Psychiatry, 22(2), pp. 112-124.

Hazlett, H.C., Poe, M., Gering, G., Smith, R.G., Provenzale, J., Ross, A. et al. (2005). Magnetic resonance imaging and head circumference study of brain size in autism: birth through age 2 years. Archives of General Psychiatry, 62(12), pp. 1366-1376.

Hazlett, H.C., Poe, M.D., Gerig, G., Smith, R.G., \& Piven, J. (2006). Cortical gray and white brain tissue volume in adolescents and adults with autism. Biological Psychiatry, 59(1), pp. 1-6. [PubMed: 16139816]

Hazlett, H.C., et al. (2011). Early brain overgrowth in autism associated with an increase in cortical surface area before age 2 years. Archives of General Psychiatry, 68, pp. 467-476.

Haznedar, M.M., Buchsbaum, M.S., et al. (2000). Limbic circuitry in patients with autism spectrum disorders studied with positron emission tomography and magnetic resonance imaging. American Journal of Psychiatry, 157(12), pp. 1994-2001.

Haznedar, M.M., Buchsbaum, M.S., Hazlett, E.A., LiCalzi, E.M., Cartwright, C. \& Hollander, E. (2006). Volumetric analysis and three-dimensional glucose metabolic mapping of the striatum and thalamus in patients with autism spectrum disorders. American Journal of Psychiatry, 163, pp. 1252-1263. (PubMed: 16816232). 
Henderson, H., Schwartz, C., Mundy, P., Burnette, C., Sutton, S., Zahka, N. \& Pradella, A. (2006). Response monitoring, the error-related negativity, and differences in social behaviour in autism. Brain and Cognition, 61(1), pp. 96-109. doi: 10.1016/j.bandc.2005.12.009.

Herbert, M.R., Ziegler, D.A., Deutsch, C.K. et al. (2003). Dissociations of cerebral cortex, subcortical and cerebral white matter volumes in autistic boys. Brain, 126, pp. 11821192.

Herbert, M.R., et al. (2004). Localization of white matter volume increase in autism and developmental language disorder. Annals of Neurology, 55, pp. 530-540.

Hilton, C., Graver, K., \& LaVesser, P. (2007a). Relationship between social competence and sensory processing in children with high functioning autism spectrum disorders. Research in Autism Spectrum Disorders, 1, pp. 164-173.

Hilton, C., Wente, L., LaVesser, P., Ito, M., Reed, C., \& Herzberg, G. (2007b). Relationship between motor skill impairment and severity in children with asperger syndrome. Research in Autism Spectrum Disorders, 1, pp. 339-349.

Hoddenbach, E., Koot, H.M., Clifford, P., Gevers, C., Clauser, C., Boer, F., \& Begeer, S. (2012). Individual differences in the efficacy of a short theory of mind intervention for children with autism spectrum disorder: A randomized controlled trial. Trials, 13(206), pp. 1-7. http://dx.doi.org/10.1186/1745-6215-13-206.

Hood, B., \& Willen, J. (1998). Adult's eyes trigger shifts of visual attention in human infants. Psychological Science, 9, pp. 131-134. doi: 10.1111/1467-9280.00024

Hoogenhout, M., \& Malcolm-Smith, S. (2014). Theory of mind in Autism Spectrum Disorder: Does DSM classification predict development? Research in Autism Spectrum Disorders, 8(6), pp. 597-607. http://dx.doi. org/10.1016/j.rasd.2014.02.005.

Hollander, E., Anagnostou, E., Chaplin, W., Esposito, K., Haznedar, M.M., Licalzi, E.,... \& Buchsbaum, M. (2005). Striatal Volume on Magnetic Resonance Imaging and Repetitive Behaviors in Autism. Biological Psychiatry, 58(3), pp. 226-232. doi:10.1016/j.biopsych.2005.03.040 
Hou, G., Yang, X., \& Yuan, T.F. (2013). Hippocampal Asymmetry: Differences in Structures and Functions. Neurochemistry, 38, pp. 453-460. DOI: 10.1007/s11064-0120954-3

Howard, M.A., Cowell, P.E., Bowcher, J., Broks, P., Mayes, A., Farrant, A., et al. (2000). Convergent neuroanatomical and behavioural evidence of an amygdala hypothesis of autism. Neuroreport, 11, pp. 2931-2935.

Howlin, P. (2003). Outcome in high-functioning adults with autism with and without early language delays: implications for the differentiation between autism and Asperger syndrome. Journal of Autism and Developmental Disorders, 33(1), pp. 3-13.

Huettel S.A., Song A.W., \& McCarthy G., (2004). Functional magnetic resonance imaging. Sunderland, M.A.: Sinauer Associates, Publishers.

Hüppi, P.S., Warfield, S., Kikinis, R., Barnes, P.D., Zientara, G.P., Jolesz, F.A.,.. \& \& Volpe, J.J. (1998). Quantitative magnetic resonance imaging of brain development in premature and mature newborns. Annals of Neurology, 43, pp. 224-235.

Huttenlocher, P.R. (1990). Morphometric study of human cerebral cortex development. Neuropsychology, 28, pp. 517-527.

Huttenlocher, P.R. \& Dabholkar, A.S. (1997). Regional differences in synaptogenesis in human cerebral cortex. Journal of Comparative Neurology, 387(2), pp. 167-178. [PubMed: 9336221]

Hyde, K.L., Samson, F., Evans, A.C., \& Mottron, L. (2010). Neuroanatomical differences in brain areas implicated in perceptual and other core features of autism revealed by cortical thickness analysis and voxel-based morphometry. Human Brain Mapping, 31, pp. 556566.

Iacoboni, M., \& Dapretto, M. (2006). The mirror neuron system and the consequences of its dysfunction. Nature Reviews Neuroscience, 7, pp. 942-951.

Ito, M. (2008). Control of mental activities by internal models in the cerebellum. Nature Reviews Neuroscience, 9, pp. 304-313. 
Jack, C.R.Jr, Twomey, C.K., Zinsmeister, A.R., Sharbrough, F.W., Petersen, R.C., \& Cascino, G.D. (1989). Anterior temporal lobes and hippocampal formations: Normative volumetric measurements from MR images in young adults. Radiology, 172(2), pp. 549554.

Jasmin, E., Couture, M., McKinley, P., Reid, G., Fombonne, E., \& Gisel, E. (2009). Sensorimotor and daily living skills of preschool children with autism spectrum disorders. Journal of Autism and Developmental Disorders, 39, pp. 231-41.

Jernigan, T.L., Trauner, D.A., Hesselink, J.R., \& Tallal, P.A. (1991). Maturation of human cerebrum observed in vivo during adolescence. Brain, 114, pp. 2037-2049.

Jetha, M.K., \& Segalowitz, S.J. (2012). Structural brain development in late childhood, adolescence, and early adulthood. In Jetha, M.K. \& Segalowitz, S.J., eds. Adolescent brain development (pp. 1-18). San Diego: Academic Press. Retrieved from http://www.sciencedirect.com/science/ article/pii/B9780123979162000013.

Jiao, Y., Chen, R., Ke, X., Chu, K., Lu, Z., \& Herskovits, E.H. (2010). Predictive models of autism spectrum disorder based on brain regional cortical thickness. Neuroimage, 50, pp. 589-99.

Johnson-Ecker, C.L., \& Parham, L.D. (2000). The evaluation of sensory processing: A validity study using contrasting groups. American Journal of Occupational Therapy, 54, pp. 494-503.

Johnston, M.V. (2004). Clinical disorders of brain plasticity. Brain and Development, 26(2), pp. 73-80. [PubMed: 15036425]

Johnston, M.V., Ishida, A., Ishida, W.N., Matsushita, H.B., Nishimura, A., \& Tsuji, M. (2009). Plasticity and injury in the developing brain. Brain and Development, 31, pp. 110. doi:1.1016/j.braindev.2008.03.014. [PubMed: 18490122].

Jolliffe, T., \& Baron-Cohen, S. (1999b). A test of central coherence theory: Linguistic processing in high-functioning adults with autism or Asperger syndrome: Is local coherence impaired? Cognition, 71(2), pp. 149-185. 
Jolliffe, T. \& Baron-Cohen, S. (2001). A test of central coherence theory: can adults with high functioning autism or Asperger syndrome integrate fragments of an object. Cognitive Neuropsychiatry, 6, pp. 193-216. (doi:10.1080/1354680 0042000124)

Joseph, R.M., Ehrman, K., McNally, R., \& Keehn, B. (2008). Affective response to eye contact and face recognition ability in children with ASD. Journal of the International Neuropsychological Society, 14, pp. 947-955.

Joseph, R.M., \& Tager-Flusberg, H. (2004). The relationship between theory of mind and executive functions to symptom type and severity in children with autism. Development and Psychopathology, 16, pp. 137-155.

Kanner, L. (1943). Autistic disturbances of affective contact. Nervous Child. 10, pp. 217250 .

Kanner, L. (1951). The conception of wholes and parts in early infantile autism. American Journal of Psychiatry, 108, pp. 23-26.

Kanner, L. (1968). Autistic disturbances of affective contact. Acta Paedopsychiatrica, 35, pp. 100-136.

Katuwal, G.J., Baum, S.A., Cahill, N.D., Dougherty, C.C., Evans, E., Evans, D.W., ...Michael, A.M. (2016). Inter-Method Discrepances in Brain Volume Estimation May Drive Inconsistent Findings in Autism. Front.Neurosci. 10: 439.doi: 10.3389/fnins.2016.00439

Kaufmann, W.E., Cooper, K.L., Mostofsky, S.H., Capone, G.T., Kates, W. R., Newschaffer, C.J., et al. (2003). Specificity of cerebellar vermian abnormalities in autism: a quantitative magnetic resonance imaging study. Journal of Child Neurology, 18, pp. 463470. doi: 10.1177/08830738030180070501

Kawashima, R., Sugiura, M., et al. (1999). The human amygdala plays an important role in gaze monitoring. A PET study. Brain, 122(4), pp. 779-783.

Kelly, A.M.C., Di Martino, A., Uddin, L., Shehzad, Z., Gee, D.G., Reiss, P.T.,..Milham, M.P. (2008). Development of anterior cingulate functional connectivity from late childhood to early adulthood. Cerebral Cortex, 19, pp. 640-657. doi: 10.1093/cercor/bhn 117 
Kemper, T.L., \& Bauman, M. (1998). Neuropathology of infantile autism. Journal of Neuropathology and Experimental Neurology, 57, pp. 645-652.

Kern, J.K., Trivedi, M.H., Garver, C.R., Grannemann, B.D., Andrews, A.A., Savla, J.S.,... \& Schroeder, J. L. (2006). The pattern of sensory processing abnormalities in autism. Autism 10, pp. 480-494. (doi:10.1177/1362361306066564).

Kern, J.K., Trivedi, M.H., Grannemann, B.D., Garver, C.R., Johnson, D.G., Andrews, A.A., et al. (2007b). Sensory correlations in autism. Autism, 11(2), pp. 123-134. Retrieved from http://www.ncbi.nlm.nih.gov/entrez/query.fcgi?cmd=Retrieve $\& d b=P u b M e d \& d o p t=C i t a t i$ on\&list_uids=17353213.

Kientz M.A., \& Dunn W. (1997). A comparison of the performance of children with and without autismo $\mathrm{n}$ the sensory profile. American Journal of Occupational Therapy, 51(7), pp. 530-537.

Kim, J.E., Lyoo, I.K., et al. (2010a). Laterobasal amygdalar enlargement in 6- to 7-year-old children with autism spectrum disorder. Archives of General Psychiatry, 67(11), pp. 1187-1197.

Kim, S.Y., Mo, J.W., et al. (2010b). The expression of non-clustered protocadherins in adult rat hippocampal formation and the connecting brain regions. Neuroscience, 170(1), pp. 189-199.

Klin, A., Klaiman, C., y Jones, W. (2015). Rebajar la edad de diagnóstico del autismo: la neurociencia del desarrollo social afronta un importante problema de salud pública. Revista de Neurología, 60(1), pp. 3-11.

Knickmeyer, R.C., Gouttard, S., Kang, C., Evans, D., Wilber, K., Smith, J.K.,... \& Gilmore, J.H. (2008). A structural MRI study of human brain development from birth to 2 years. Journal of Neuroscience, 28(47), pp. 12176-12182.

Khundrakpam, B.S., Lewis, J.D., Kostopoulos, P., Carbonell, F. \& Evans, A.C. (2017). Cortical Thickness Abnormalities in Autism Spectrum Disorders Through Late Childhood, Adolescence and Adulthood: A Large-Scale MRI Study. Cerebral Cortex, 27, pp. 1721-1731. doi: 10.1093/cercor/bhx038 
Krain, A.L., \& Castellanos, F.X. (2006). Brain development and ADHD. Clinical psychology review, 26(4), pp. 433-444. http://dx.doi.org/10.1016/j.cpr.2006.01.005.

Kretschmann, H.J., Kammradt, G., Krauthausen, I., Sauer, B., \& Wingert, F. (1986). Growth of the hippocampal formation in man. Bibliotheca Anatomica, 28, pp. 27-52.

Krug, D.A., Arick, J., \& Almond, P. (1980). Behavior checklist for identifying severely handicapped individuals with high levels of autistic behavior. Journal of Child Psychology and Psychiatry, 21, pp. 221-229.

Lai, M.C., Lombardo, M.V., Pasco, G., Ruigrok, A.N.V., Wheelwright, S.J., Sadek, S.A.,... \& Baron-Cohen, S. (2011). A behavioral comparison of male and female adults with high functioning autism spectrum conditions. PLOS ONE, 6(6), e20835.

Lai, C.Y., Chung, J.C., Chuan, C.C., \& Li-Tsang, C.W. (2011). Sensory processing measure-HK Chinese version: Psychometric properties and pattern of response across environments. Research in Developmental Disabilities, 32(6), 2636-2643.

Lainhart, J.E., Piven, J., Wzorek, M., et al. (1997). Macrocephaly in children and adults with autism. Journal of American Academy of Child and Adolescent Psychiatry, 36(2), pp. 282-290.

Lainhart, J.E. (2006). Advances in autism neuroimaging research for the clinician and geneticist. American Journal of Medical Genetics Part C: Seminars in Medical Genetics, 142(1), pp. 33-39. [PubMed: 16419098]

Lampreia, C. (2004). Uma perspectiva desenvolvimentista sóciopragmática para o entendimento do autismo e suas implicações para a intervenção precoce. In Mendes, E.G., Almeida, M.A., \& Williams, L.C.A. (Eds.), Temas em educação especial: Avanços recentes (pp. 289-296). São Carlos, S.P.: EDUFSCar.

Lane, A.E., Young, R.L., Baker, A.E.Z., \& Angley, M.T. (2010). Sensory processing subtypes in autism: Association with adaptative behaviour. Journal of Autism and Developmental Disorders, 40, pp. 112-122.

Lane, A.E., Dennis, S.J., \& Geraghty, M.E. (2011). Brief report: Further evidence of sensory subtypes in autism. Journal of Autism and Developmental Disorders, 41, pp. 826-831. 
Lane, A.E., Molloy, C.A. \& Bishop S.L. (2014). Classification of Children with Autism Spectrum Disorder by Sensory subtype: A case for Sensory-Based Phenotypes. Autism Research, 7, pp. 322-333.

Langen, M., Schnack, H.G., Nederveen, H., Bos D., Lahuis, B.E., De Jonge, M., et al. (2009). Changes in the developmental trajectories of striatum in autism. Biological Psychiatry, 66, pp. 327-333.

Langen, M., Bos, D., Noordermeer, S.D.S., Nederveen, H., van Engeland, H. \& Durston, S., (2013). Changes in the Development of Striatum Are Involved in Repetitive Behavior in Autism. Biological Psychiatry. http://dx.doi.org/10.1016/j.biopsych.2013.08.013

Langen, M., Bos, D., Noordermeer, S.D., Nederveen, H., Engeland, H., \& Durston, S. (2014). Changes in the development of striatum are involved in repetitive behaviour in autism. Biological Psychiatry, 76(5), pp. 405-411.

Lau, C.G., \& Zukin, R.S. (2007). NMDA receptor trafficking in synaptic plasticity and neuropsychiatric disorders. Nature Reviews Neuroscience, 8(6), pp. 413-426. [PubMed: 17514195]

Lavenex, P., \& Banta-Lavenex, P. (2013). Building hippocampal circuits to learn and remember: insights into the development of human memory. Behavioural Brain Research, 254, pp. 8-21.

Lawson, J., Baron-Cohen, S., \& Wheelwright, S. (2004). Empathising and systemising in adults with and without Asperger syndrome. Journal of Autism and Developmental Disorders, 34, pp. 301-310.

LeCouteur, A., Rutter, M., Lord, C., Rios, P., Robertson, S., Holdgrafer, M., et al. (1989). Autism Diagnostic Interview: A standardized investigator-based instrument. Journal of Autism and Developmental Disorders, 19, pp. 363-387.

Lee, D.O., \& Ousley, O.Y. (2006). Attention-deficit hyperactivity disorder symptoms in a clinic sample of children and adolescents with pervasive developmental disorders. Journal of Child and Adolescent Psychopharmacology, 16, pp. 737-746. doi:10.1089/cap.2006. 16.737 
Leekman, S. (1990). Jokes and lies: Children's understanding of intentional false hood. En A. Whiten (Ed.), Natural theories of mind: Evolution, development and simulation of everyday mindreading (pp. 159-174). Oxford, England: Basil Blackwell.

Leekam, S., \& Perner, J. (1991). Does the autistic child have a metarepresentational deficit? Cognition, 40, pp. 203-218.

Leekman, S. (1992). Believing and deceiving: steps to becoming a good liar. In Ceci, S.J., DeSimone, M., Leichtman, M., \& Putnick, M. (Eds.), Cognitive and Social Factor in Early Deception (pp. 47-62). Hillsdale, NJ: Erlbaum.

Leekam, S.R., Nieto, C., Libby, S.J., Wing, L., \& Gould, J. (2007). Describing the sensory abnormalities of children and adults with autism. Journal of Autism and Developmental Disorders, 37(5), pp. 894-910.

Leekam, S.R., Prior, M.R., \& Uljarevic, M. (2011). Restricted and repetitive behaviors in autism spectrum disorders: a review of research in the last decade. Psychological Bulletin, 137, 562-593.

Lenroot, R.K., \& Giedd, J.N. (2006). Braindevelopment in children and adolescents: Insights from anatomical magnetic resonance imaging. Neuroscience and Biobehavioral Reviews, 30, pp. 718-729.

Lenroot, R.K., Gogtay, N., Greenstein, D.K., Wells, E.M., Wallace, G.L., Clasen, L.S., et al. (2007). Sexual dimorphism of brain developmental trajectories during childhood and adolescence. NeuroImage, 36, pp. 1065-1073.

Lerner, M.D., Hutchins, T.L., \& Prelock, P.A. (2011). Brief report: Preliminary evaluation of the theory of mind inventory and its relationship to measures of social skills. Journal of Autism and Developmental Disorders, 41, pp. 512-517.

Leslie, A.M. (1987). Presence and representation: the origins of 'theory of mind'. Psychological Review, 94, pp. 412-36.

Leslie, A.M. (1988). Some implications of pretence for mechanisms underlying the child's theory of mind. En Astington, W., Harris, P.L., \& Olson, D.R. (Eds.), Developing theories of mind (pp.19-46). Cambridge: Cambridge University Press. 
Leslie, A.M., \& Frith, U. (1988). Autistic children's understanding of seeing, knowing and believing. British Journal of Developmental Psychology, 6, pp. 315-324.

Lewis, J.D., \& Elman, J.L. (2008). Growth related neural reorganization and the autism phenotype: a test of the hypothesis that altered brain growth leads to altered connectivity. Developmental Science, 11, pp.135-155.

Li, Y.J., Ga, S.N., Huo, Y., Li, S.Y., \& Gao, X.G. (2007). Characteristics of hippocampal volumes in healthy Chinese from MRI. Neurological Research, 29(8), pp.803-806.

Lin, S., Keysar, B., \& Epley, N. (2010). Reflexively mindblind: Using theory of mind to interpret behavior requires effortful attention. Journal of Experimental Social Psychology, 46(3), pp. 551-556. http://dx.doi.org/10.1016/j. jesp.2009.12.019

Lin, H-Y., Ni, H-C., Lai, M-C., Tseng, W-Y.I., \& Gau, S.S-F. (2015). Regional brain volume differences between males with and without autism spectrum disorder are highly age-dependent. Molecular Autism, 6, 29. DOI: 10.1186/s13229-015-0022-3

Lind, S.E., \& Bowler, D.M. (2009). Language and theory of mind in autism spectrum disorder: The relationship between complement syntax and false belief task performance. Journal of Autism and Developmental Disorders, 39(6), pp. 929-937. http://dx.doi.org/10.1007/s10803-009-0702-y.

Liss, M., Saulnier, C., Fein, D., \& Kinsbourne, M. (2006). Sensory and attention abnormalities in autistic spectrum disorders. Autism, 10(2), pp. 155-172.

Little, L.M., Ausderau, K., Sideris, J., \& Baranek, G.T. (2015). Activity Participation and Sensory Features Among Children with Autism Spectrum Disorders. Journal of Autism and Developmental Disorders, 45(9), pp. 2981-2990. doi: 10.1007/s10803-015-2460-3

Lombardo, M.V., Barnes, J.L., Wheelwright, S.J., \& Baron-Cohen, S. (2007). Selfreferential cognition and empathy in autism. PLoS One, 2(9): e883. doi:10.1371/journal .pone.0000883.

Lombardo, M.V., \& Baron-Cohen, S. (2010). Unraveling the paradox of the autistic self. Wiley Interdisciplinary Reviews: Cognitive Science, 1(3), pp. 393-403. 
Lord, C., Rutter, M., DiLavore, P., \& Risi, S. (1999). Autism Diagnostic Observation Schedule-WPS. Los Angeles, CA: Western Psychological Services.

Lovaas, I., Newsom, C., \& Hickman, C. (1987). Self-stimulatory behavior and perceptual reinforcement. Journal of Applied Behavior Analysis, 20, pp. 45-68.

Low, J., \& Perner, J. (2012). Implicit and explicit theory of mind: State of the art. British Journal of Developmental Psychology, 30(1), pp. 1-13. http://dx.doi.org/10.1111/j.2044835X.2011.02074.X

Luciana, M., Conklin, H.M., Hooper, C.J., \& Yarger, R.S. (2005). The development of nonverbal working memory and executive control processes in adolescents. Child Development, 76, pp. 697-712.

Ludlow, A., Mohr, B., Whitmore, A., Garagnani, M., Pulvermüller, F., \& Gutierrez, R. (2014). Auditory processing and sensory behaviours in children with autism spectrum disorder as revealed by mismatch negativity. Brain and Cognition, 86, pp. 55-63. http://dx.doi.org/10.1016/j.bandc.2014.01.016

Luna, B., Garver, K.E., Urban, T.A., Lazar, N.A., \& Sweeney, J.A. (2004). Maturation of cognitive processes from late childhood to adulthood. Child Development, 75, pp. 13571372 .

Mak-Fan, K.M., Taylor, M.J., Roberts, W., \& Lerch, J.P. (2012). Measures of cortical grey matter structure and development in children with autism spectrum disorder. Journal of Autism and Developmental Disorders, 42(3), pp. 419-427. http://dx.doi.org/10.1007/s10803-011-1261-6

Mak-Fan, K.M., Morris, D., Vidal, J., Anagnostou, E., Roberts, W., \& Taylor, M.J. (2013). White matter and development in children with an autism spectrum disorder. Autism, 17(5), pp. 541-557.

Maldjiang, J.A., Laurienti, P.J., Burdette, J.B. et al. (2003). An Automated Method for Neuroanatomic and Cytoarchitectonic Atlas-based Interrogation of Fmri Data Sets. Neuroimage, 19, pp. 1233-1239. 
Mamah, D., Harms, M.P., Wang, L., Barch, D., Thompson, P., Kim, J.,.. \& Csernansky, J.G. (2008). Basal ganglia shape abnormalities in the unaffected siblings of schizophrenia patients. Biological Psychiatry, 64(2), pp. 111-120. doi:10.1016/j.biopsych.2008.01.004

Mantini, D., \& Vanduffel, W. (2013). Emerging roles of the brain's default network. Neuroscientist, 19, pp. 76-87. doi: 10.1177/1073858412446202.

Marco, E.J., Hinkley, L.B., Hill, S.S., \& Nagarajan, S.S. (2011). Sensory processing in autism: a review of neurophysiologic findings. Pediatric Research, 69, pp. 48R-54R.

Marsh, R., Gerber, A.J., \& Peterson, B.S. (2008). Neuroimaging studies of normal brain development and their relevance for understanding childhood neuropsychiatric disorders. Journal of the American Academy of Child and Adolescent Psychiatry, 47, pp. 12331251.

Martín-Borreguero, P. (2004), El Síndrome de Asperger: ¿Excentricidad o discapacidad social? Madrid: Alianza Editorial.

Martínez-Sanchis, S. (2015). Papel de la corteza prefrontal en los problemas sensoriales de los niños con trastornos del espectro autista y su implicación en los aspectos sociales. Revista de Neurología, 60(1), pp. S19-S24.

Matsui, M., Tanaka, C., Niu, L., Noguchi, K., Bilker, W.B., Wierzbicki, M,... \& Gur, R.C. (2016). Age-related Volumetric Changes of Prefrontal Gray and White Matter from Healthy Infancy to Adulhood. International Journal of Clinical and Experimental Neurology, 4(1), pp. 1-8. DOI: 10.12691/ijcen-4-1-1

Matsuzawa, J., Matsui, M., Konishi, T., Noguchi, K., Gur, R.C., Bilker, W., \& Miyawaki, T. (2001). Age-related volumetric changes of brain gray and white matter in healthy infants and children. Cerebral Cortex, 11, pp. 335-342. (PubMed: 11278196)

Mayes, S.D., \& Calhoun, S.L. (1999). Symptoms of autism in young children and correspondence with the DSM. Infants and Young Children, 12, pp. 90-97.

Mazza, M., Pino, M.C., Mariano, M., Tempesta, D., Ferrara, M., De Berardis, D., et al. (2014). Affective and cognitive empathy in adolescents with autism spectrum disorder. Frontiers in Human Neuroscience, 8, article 791. 
McAlonan, G.M., Daly, E., Kumari, V., Critchley, H.D., van Amelsvoort, T., Suckling, J. et al. (2002). Brain anatomy and sensorimotor gating in Asperger's syndrome. Brain, 125, pp. 1594-1606.

McAlonan, G.M., Cheung, V., Cheung, C., Suckling, J., Lam, G.Y., Tai, K.S., ...Chua, S.E. (2005). Mapping the brain in autism. A voxel-based MRI study of volumetric differences and intercorrelations in autism. Brain, 128, pp. 268-276.doi: 10.1093/brain/awh332

McIntosh, D.N., Miller, L.J., \& Shyu, V. (1999a). Development and validation of the short sensory profile. In W. Dunn (Ed.), Sensory Profile: User's manual, pp.59-73. San Antonio, TX: The Psychological Corporation.

Meltzoff, A.N. (2002). Elements of a developmental theory of imitation. In Meltzoff, A.N. \& Prinz, W. (Eds.), The Imitative Mind: Development, Evolution and Brain Bases (pp. 19-41). New York: Cambridge University Press.

Mercadillo, R.E., Díaz, J.L., y Barrios, F.A. (2007). Neurobiología de las emociones morales. Salud Mental, 30(3), pp. 1-11.

Mills, K.L., Goddings, A.L., Herting, M.M., Meuwese, R., Blakemore, S.J., Crone, E.A.,... \& Sowell, E.R. (2016). Structural brain development between childhood and adulthood: convergence across four longitudinal samples. NeuroImage. 141, pp. 273-281.

Miller, L.J., Schoen, S., Coll, J., Brett-Green, B., \& Reale, M. (2005). Final report: Quantitative psychophysiologic examination of sensory processing in children with autism spectrum disorders. Los Angeles, CA: Cure Autism Now.

Miller, L.J., Anzalone, M.E., Lane, S.J., Cermak, S.A., \& Osten, E.T. (2007). Concept evolution in sensory integration: A proposed nosology for diagnosis. The American Journal of Occupational Therapy, 61, pp. 135-140.

Miller, L.J., Anzalone, M.E., Lane, S.J., Cermak, S.A., \& Osten, E.T. (2013). Concept evolution in sensory integration: A proposed nosology for diagnosis. The American Journal of Occupational Therapy, 61, pp. 135-130. doi: 10.5014/ajot.61.2.135 
Milligan, K., Astington, J.W., \& Dack, L.A. (2007). Language and theory of mind: Metaanalysis of the relation between language ability and false belief understanding. Child Development, 78(2), pp. 622-646. http://dx.doi. org/10.1111/j.1467-8624.2007.01018.x

Minshew, N.J., \& Keller, T.A. (2010). The nature of brain dysfunction in autism: functional brain imaging studies. Current Opinion in Neurology, 23, pp. 124-130.

Mitchell, J.P., Macrae, C.N., \& Banaji, M.R. (2006). Dissociable medial prefrontal contributions to judgments of similar and dissimilar others. Neuron, 18, pp. 655-663.

Mosconi, M.W., Zwaigenbaum, L., \& Piven, J. (2006). Structural MRI in autism: Findings and future directions. Clinical Neuroscience Research, 6(3-4), pp. 135-144.

Mosconi, M.W., Cody-Hazlett, H., Poe, M.D., et al. (2009). Longitudinal study of amygdala volume and joint attention in 2- to 4-year old children with autism. Archives in General Psychiatry, 66, pp. 509-516.

Moya-Albiol, L., Herrero, N., y Bernal, M.C. (2010). Bases neuronales de la empatía. Revista de Neurología, 50, pp. 89-100.

Mulas, F., Hernández-Muela, S., Etchepareborda, M.C., y Abad-Mas, L. (2005), Bases clínicas neuropediátricas y patogénicas del trastorno del espectro autista. In Mulas, F., ed. Autismo infantile (pp. 57). Barcelona: Viguera.

Munson, J., Dawson, G., Abbott, R., et al. (2006). Amygdalar volume and behavioral development in autism. Archives in General Psychiatry, 63(6), pp. 686-693. [PubMed: 16754842]

Muftuler, L.T., Davis, E.P., Buss, C., Head, K., Hasso, A.N., \& Sandman, C.A. (2011). Cortical and subcortical changes in typically developing preadolescent children. Brain Research, 1399, pp. 15-24.

Mutlu, A.K., Schneider, M., Debanné, M., Badoud, D., Eliez, S., \& Schaer, M. (2013). Sex differences in thickness, and folding developments throughout the cortex. NeuroImage, 82, pp. 200-207. http://dx.doi.org/10.1016/j.neuroimage.2013.05.076 
Nacewicz, B.M., Dalton, K.M., et al. (2013). Amygdala volume and nonverbal social impairment in adolescent and adult males with autism. Archives in General Psychiatry, 63(12), pp. 1417-1428.

Nair, A., Carper, R.A., Abbott, A.E., Chen, C.P., Solders, S., Nakutin, S., ...Müller, R.A. (2016). Regional Specificity of Aberrant Thalamocortical Connectivity in Autism. Hum Brain Mapp., 36 (11): pp. 4497-4511.doi: 10.1002/hbm.22938

National Institute for Health and Care Excellence (NICE) (2013). The management and support of children and young people on the autism spectrum. NICE Clinical Guideline 170. London, UK: NICE.

Nedelcu, D.G., y Buceta, M.J. (2012). El Perfil Cognitivo de los Niños con Trastorno de Asperger y Autismo de Alto Funcionamiento. Revista Iberoamericana de Diagnóstico y Evaluación Psicológica, 34(1), pp. 103-116.

Newton, P., Reddy, V., \& Bull R. (2000). Children's everyday deception and performance on false belief tasks. British Journal of Developmental Psychology, 18, pp. 297-317. doi: $10.1348 / 026151000165706$

Nickl-Jockschat, T., Habel, U., Michel, T.M., Manning, J., Laird, A.R., Fox, P.T., et al. (2012). Brain structure anomalies in autism spectrum disorder-a metaanalysis of VBM studies using anatomic likelihood estimation. Human Brain Mapping, 33, pp. 1470-1489. doi: 10.1002/hbm.21299

Norbury, C.F., \& Bishop, D.V. (2002). Inferential processing and story recall in children with communication problems: A comparison of specific language impairment, pragmatic language impairment and highfunctioning autism. International Journal of Language and Communication Disorders, 37(3), pp. 227-251.

Nordahl, C.W., Scholz, R., Yang, X., Buonocore, M.H., Simon, T., Rogers, S., et al., (2012). Increased rate of amygdala growth in children aged 2 to 4 years with autism spectrum disorders: a longitudinal study. Archives in General Psychiatry, 69, pp. 53-61.

Noterdaeme, M., \& Hutzelmeyer-Nickels, A. (2010). Early symptoms and recognition of pervasive developmental disorders in Germany. Autism, 14(6), pp. 575-588. DOI: $10.1177 / 1362361310371951$. 
O’Donnell, S., Deitz, J., Kartin, D., Nalty, T., \& Dawson, G. (2012). Sensory processing, problem behavior, adaptive behavior, and cognition in preschool children with autism spectrum disorders. American Journal of Occupational Therapy, 66, pp. 586-594.

O’Hare, A.E., Bremmer, L., Nash, M., Happé, F., \& Pettigrew, L.M. (2009). A Clinical Assessment Tool for Advanced Theory of Mind Performance in 5 to 12 years olds. Journal of Autism and Developmental Disorders, 39, pp. 916-928. DOI: 10.1007/s10803009-0699-2.

O’Hearn, K., Asato, M., Ordaz, S., \& Luna B. (2008). Neurodevelopment and executive function in autism. Development and Psychopathology, 20, pp. 1103-1132. doi: 10.1017 /S0954579408000527

O'Neill, J.L. (1999). Through the eyes of aliens: A book about autistic people. London: Jessica Kingsley.

O’Neill, M., \& Jones, R.S. (1997). Sensory-perceptual abnormalities in autism: A case for more research? Journal of Autism and Developmental Disorders, 27(3), pp. 283-293.

Ornitz, E.M. (1989). Autism at the interface between sensory and information processing. In G. Dawson (Ed.), Autism: Nature, diagnosis and treatment (pp. 174-207). New York: Guilford.

Ornitz, E.M., Lane, S.J., Sugiyama, T., \& de Traversay, J. (1993). Startle modulation studies in autism. Journal of Autism and Developmental Disorders, 23, pp. 619-637.

O’Riordan, M., Plaisted, K., Driver, J., \& Baron-Cohen, S. (2001). Superior visual search in autism. Journal of Experimental Psychology: Human Perception and Performance, 27, pp. 719-730. (doi:10.1037/0096- 1523.27.3.719).

Ostby, Y., Tamnes, C.K., Fjell, A.M., Westlye, L.T., Due-Tonnessen, P., \& Walhovd, K.B., (2009). Heterogeneity in subcortical brain development: a structural magnetic resonance imaging study of brain maturation from 8 to 30 years. Journal of Neuroscience, 29, pp. $11772-11782$

Osterling, J., \& Dawson, G. (1994). Early recognition of children with autism: A study of first birthday home videotapes. Journal of Autism and Developmental Disorders, 24, pp. 247-257. 
Ozonoff, S., Pennington, B.F., \& Rogers, S.J. (1991). Executive function deficits in high functioning autistic individuals: Relationship to theory of mind. Journal of Child Psychology and Psychiatry, and Allied Disciplines, 32(7), pp. 1081-1105. http://dx.doi.org/10.1111/j.1469-7610.1991.tb00351.x

Ozonoff, S., \& McEvoy, R.E. (1994). A longitudinal study of executive function and theory of mind development in autism. Development and Psychopathology, 6(3), pp. 415-431. http://dx.doi.org/10.1017/ S0954579400006027.

Ozonoff, S., \& Miller, J. (1995). Teaching theory of mind: A new approach to social skills training for individuals with autism. Journal of Autism and Developmental Disorders, 25, pp. 415-434.

Ozonoff, S., South, M., \& Miller, J.N. (2000). DSM-IV- defined Asperger syndrome: cognitive, behavioral and early history differentiation from high-functioning autism. Autism, 4(1), pp. 29-46.

Ozonoff, S., Cook, I., Coon, H., Dawson, G., Joseph, R. et al. (2004). Performance on Cambridge neuropsychological test automated battery subtests sensitive to frontal lobe function in people with autistic disorder: evidence from the collaborative programs of excellence in autism network. Journal of Autism and Developmental Disorders, 34, pp. $139-150$.

Ozonoff, S., Cook, I., Coon, H., Dawson, G., Joseph, R.M., Klin, A., et al. (2004). Performance on CANTAB subtests sensitive to frontal lobe function in people with autistic disorder: Evidence from the CPEA Network. Journal of Autism and Developmental Disorders, 34, pp. 139-150.

Packard, M.G., \& Knowlton, B.J. (2002). Learning and memory functions of the basal ganglia. Annual Review of Neuroscience, 25(1), pp. 563-593.

Padmanabhan, A., Lynn, A., Foran, W., Luna, B., \& O'Hearn, K. (2013). Age related changes in striatal resting state functional connectivity in autism. Frontiers in Human Neuroscience, 7, article 814. http://dx.doi.org/10.3389/fnhum.2013.00814. 
Palmen, S.J., et al. (2005). Increased gray-matter volume in medicationnaive highfunctioning children with autism spectrum disorder. Psychological Medicine, 35, pp. $561-570$.

Palmen, S.J., Durston, S., et al. (2006). No evidence for preferential involvement of medial temporal lobe structures in high-functioning autism. Psychological Medicine, 36(6), pp. $827-834$.

Paus, T. (2010). Sexual dimorphism in the adolescent brain: role of testosterone and androgen receptor in global and local volumes of grey and white matter. Hormones and Behavior, 57, pp. 63-75.

Paus, T., Zijdenbos, A., Worsley, K., Collins, D.L., Blumenthal, J., Giedd, J.N.,... \& Evans, A.C. (1999). Structural maturation of neural pathways in children and adolescents: in vivo study. Science, 283, pp. 1908-1911. [PubMed: 10082463]

Paus, T., Keshavan, M. \& Giedd, J.N. (2008). Why do many psychiatric disorders emerge during adolescence? Nature Reviews. Neuroscience, 9, pp. 947-957.

Plaisted, K., O'Riordan, M., \& Baron-Cohen, S. (1998). Enhanced visual search for a conjunctive target in autism: A research note. Journal of Child Psychology and Psychiatry, 39, pp. 777-783.

Parham, C.J. (2007). Sensory Processing Measure manual. Los Angeles: Western Psychological Services.

Pedazra, O., Bowers, D., \& Gilmore, R. (2004). Asymmetry of the hippocampus and amygdala in MRI volumetric measurements of normal adults. Journal of the International Neuropsychological Society, 10(5), pp. 664-678.

Perich-Alsina, J., Aduna de Paz, M., Valls, A., \& Munoz-Yunta, J.A. (2002). Thalamic spectroscopy using magnetic resonance in autism. Revista de Neurología, 1, pp. S68-71. [PubMed: 12447793]

Perner J., \& Howes D. (1992). "He thinks he knows" and more developmental evidence against the simulation (role-taking) theory. Mind and Language, 7, pp. 72-86. doi: 10.1111/j.1468-0017.1992.tb00197.x 
Perner, J., \& Lang, B. (1999). Development of theory of mind and executive control. Trends in Cognitive Sciences, 3(9), pp. 337-344. http://dx.doi.org/10.1016/S13646613(99)01362-5

Perner, J., Lang, B., \& Kloo, D. (2002). Theory of Mind and Self-Control: More than a Common Problem of Inhibition. Child Development, 73(3), pp. 752-767. http://dx.doi.org/10.1111/1467-8624.00436

Peterson, C.C., Wellman, H.M., \& Liu, D. (2005). Steps in Theory of Mind Development for Children with Deafness or Autism. Child Development, 76(2), pp. 502-517. http://dx.doi.org/10.1111/j.1467-8624.2005.00859.x

Pfefferbaum, A., Mathalon, D.H., Sullivan, E.V., Rawles, J.M., Zipursky, R.B., \& Lim, K.O. (1994). A quantitative magnetic resonance imaging study of changes in brain morphology from infancy to late adulthood. Archives of Neurology, 51, pp. 874-887.

Pfluger, T., Weil, S., Weis, S., Vollmar, C., Heiss, D., Egger, J.,... \& Hahn, K. (1999). Normative volumetric data of the developing hippocampus in children based on magnetic resonance imaging. Epilepsia. 40(4), pp. 414-423.

Philip, R.C.M., Dauvermann, M.R., Whalley, H.C., Baynham, K., Lawrie, S.M., \& Stanfield, A.C. (2012). A systematic review and meta-analysis of the fMRI investigation of autism spectrum disorders. Neuroscience and Biobehavioral Reviews, 36, pp. 901-942. doi: 10.1016/j.neurobiorev.2011.10.008

Piek, J.P., \& Dyck, M.J. (2004). Sensory-motor deficits in children with developmental coordination disorder, attention deficit hyperactivity disorder and autistic disorder. Human Movement Science, 23, pp. 475-488.

Pierce, K., \& Courchesne, E. (2001). Evidence for a cerebellar role in reduced exploration and stereotyped behavior in autism. Biological Psychiatry, 49(8), 655-664.

Pino, M.C., Tempesta, D., Catalucci, A., Anselmi, M., Nigri, A., Iaria, G., et al. (2016). Altered Cortico-Limbic Functional Connectivity During an Empathy Task in subjects with Post-Traumatic Stress Disorder. Journal Psychopathological Behaviour Assessment, pp. 1-8. doi:10.1007/s10862-016-9538-x. 
Piven, J., Arndt, S., Bailey, J., Havercamp, S., Andreasen, N.C., \& Palmer, P. (1995). An MRI study of brain size in autism. American Journal of Psychiatry, 152, pp. 1145-1149.

Piven, J., Bailey, J., Ranson, B.J., \& Arndt, S. (1997). An MRI study of the corpus callosum in autism. American Journal of Psychiatry, 154(8), pp. 1051-1056.

Polak, A., \& Harris, P.L. (1999). Deception by young children following noncompliance. Developmental Psychology, 35, pp. 561-568. doi: 10.1037/00121649.35.2.561

Portela, V., Vírseda, A., y Gayubo, L. (2003). Revisión sobre el estudio de la teoría de la mente y trastornos generalizados del desarrollo y esquizofrenia. Actas de Psiquiatría, 31(6), pp. 339-346.

Pratt, C., \& Bryant, P. (1990). Young children understand that looking leads to knowing (so long as they are looking into a single barrel). Child Development, 61, pp. 973-983.

Premack, D., \& Woodruff, G. (1978). Does chimpanzee have a theory of mind? Behavioral and Brain Sciences, 4, pp. 9-30.

Rao, P.A., \& Landa, R.J. (2013). Association between severity of behavioral phenotype and comorbid attention deficithyperactivity disorder symptoms in children with autism spectrum disorders. Autism, 18, pp. 272-280. doi:10.1177/ 1362361312470494

Rauschecker, J.P., \& Marler, P. (1987). What signals are responsible for synaptic changes in visual cortical plasticity? In Rauschecker, J.P. \& Marler, P. (Eds.), Imprinting and cortical plasticity (pp. 193-200). New York: Wiley.

Raznahan, A., Toro, R., Daly, E., Robertson, D., Murphy, C., Deeley, Q., et al. (2010). Cortical anatomy in autism spectrum disorder: an in vivo MRI study on the effect of age. Cerebral Cortex, 20, pp. 1332-1340.

Raznahan, A., Lerch, J.P., Lee, N., Greenstein, D., Wallace, G.L., Stockman, M., et al. (2011). Patterns of coordinated anatomical change in human cortical development: a longitudinal neuroimaging study of maturational coupling. Neuron, 72, pp. 873-884. [PubMed: 22153381] 
Raznahan, A., Lenroot, R., Thurm, A., Gozzi, M., Hanley, A., Spence, S.J., et al. (2012). Mapping cortical anatomy in preschool aged children with autism using surface-based morphometry. NeuroImage Clinical, 2, pp. 111-119. doi:10.1016/j.nicl.2012.10.005.

Reed, T., \& Peterson, C. (1990). A comparative study of autistic subjects' performance at two levels of visual and cognitive perspective taking. Journal of Autism and Developmental Disorders, 20, pp. 555-568.

Reiss, A.L., Abrams, M.T., Singer, H.S., Ross, J.L., \& Denckla, M.B. (1996). Brain development, gender and IQ in children: A volumetric imaging study. Brain, 119, pp. $1763-1774$.

Reynolds, S., Bendixen, R., Lawrence, T., \& Lane, S. (2011). A pilot study examining activity participation, sensory responsiveness and competence in children with high functioning Autism Spectrum Disorder. Journal of Autism and Developmental Disorders, 41, pp. 1496-1506. doi: 10.1007/s10803-010-1173-x

Riedel, A., Maier, S., Ulbrich, M., Biscaldi, M., Ebert, D., Fangmeier, T., et al. (2014). No significant brain volume decreases or increases in adults with high-functioning autism spectrum disorder and above average intelligence: a voxel-based morphometric study. Psychiatry Res. 223, 67-74. doi: 10.1016/j.pscychresns.2014.05.013

Rimland, B., \& Edelson, S.M. (1995). Brief Report: A pilot study of auditory integration training in autism. Journal of Autism and Developmental Disorders, 25, pp. 61-70.

Ritvo, E.R., Freeman, B.J., Scheibel, A.B., Duong, T., Robinson, H., Guthrie, D., et al. (1986). Lower Purkinje cell counts in the cerebella of four autistic subjects: initial findings of the UCLA-NSAC Autopsy Research Report. American Journal of Psychiatry, 143 , pp. 862-866.

Rizzolatti, G., Fadiga, L., Gallese, V., \& Fogassi, L. (1996). Premotor cortex and the recognition of motor action. Brain Research and Cognitive Brain Research, 3, pp.131-41.

Rizzolatti, G, \& Fabbri-Destro, M. (2010). Mirror neurons: from discovery to autism. Experimental Brain Research, 200(3-4), pp. 223-237. 
Rogers, S.J., Hepburn, S., \& Wehner, E. (2003). Parent reports of sensory symptoms in toddlers with autism and those with other developmental disorders. Journal of Autism and Developmental Disorders, 33, pp. 631-642.

Rogers, S.J., \& Ozonof, S. (2005). Annotation: What do we know about sensory dysfunction in autism? A critical review of the empirical evidence. Journal of Child Psychology and Psychiatry, 46, pp. 1255-1268.

Rojas, D.C., Smith, J.A., et al. (2004). Hippocampus and amygdala volumes in parents of children with autistic disorder. American Journal of Psychiatry, 161(11), pp. 2038-2044.

Rojas, D.C., Peterson, E., Winterrowd, E., Reite, M.L., Rogers, S.J., \& Tregellas, J.R. (2006). Regional gray matter volumetric changes in autism associated with social and repetitive behavior symptoms. BMC Psychiatry, 6, 56. doi: 10.1186/1471-244X-6-56

Ruggieri, V.L. (2013). Empatía, cognición social y trastornos del espectro autista. Revista de Neurología, 56(1), pp. S13-S21.

Rommelse, N.N., Geurts, H.M., Franke, B., Buitelaar, J.K., \& Hartman, C.A. (2011). A review on cognitive and brain endophenotypes that may be common in autism spectrum disorder and attention-deficit/hyperactivity disorder and facilitate the search for pleiotropicgenes. Neuroscience and Biobehavioral Reviews, 35, pp. 1363-1396. doi:10.1016/j.neubiorev.2011.02.015

Rump, K.M., Giovannelli, J.L., Minshew, N.J., \& Strauss, M.S. (2009). The development of emotion recognition in individuals with autism. Child Development, 80, pp. 1434-1447.

Rutter, M., Le-Couteur, A., \& Lord, C. (2003). Autism Diagnostic Interview Revised. Los Angeles, CA (USA): Western Psychological Services.

Shallice, T. (2001). "Theory of mind" and the prefrontal cortex. Brain, 124, pp. 247-248.

Samson, D., Apperly, I.A., Chiavarino, C., \& Humphreys, G.W. (2004). Left temporoparietal junction is necessary for representing someone else's belief. Nature Neuroscience, 7, pp. 499-500. 
Saxe, R. \& Wexler, A. (2005). Making sense of another mind: the role of the right temporoparietal junction. Neuropsychologia, 43, pp. 1391-1399.

Say, G.N., Sahin, B., Aslan, K., Akbas, S., Incesu, L., \& Ceyhan, M. (2014). Increased Laterality of the Thalamus in Children and Adolescents with Asperger's Disorder: A MRI and Proton Spectroscopy Study. Psychiatry investing, 11(3), pp. 237-242. http://dx.doi.org/10.4306/pi.2014.11.3.237

Scaife, M., \& Bruner, J. (1975). The capacity for joint visual attention in the infant. Nature, 253, pp. 265-266.

Scottish Intercollegiate Guidelines Network (SIGN) (2007). Assessment, diagnosis and clinical interventions for children and young people with autism spectrum disorders. Edinburgh, Scotland. Recuperado de: http://www.sign.ac.uk/guidelines/fulltext/98/

Schain, R.J., \& Yanner, H. (1960). Infantile autism: An analysis of 50 cases and a consideration of certain relevant neurophysiologic concepts. Journal of Pediatrics, 57, pp. 560-67.

Schmahmann, J.D. (2000).The role of the cerebellum in affect and psychosis. Journal of Neurolinguistics, 13: 189-214

Schell, A.M., Dawson, M.E., Rissling, A., et al. (2005). Electrodermal predictors of functional outcome and negative symptoms in schizophrenia. Psychophysiology, 42, pp. 483-492.

Scheel, C., Rotarska-Jagiela, A., Schilbach, L., Lehnhardt, F.G., Krug, B., Vogeley, K., et al. (2011). Imaging derived cortical thickness reduction in high-functioning autism: key regions and temporal slope. Neuroimage, 58, pp. 391-400.

Scherf, K.S., Smyth, J.M., \& Delgado, M.R. (2013). The amygdala: an agent of change in adolescent neural networks. Hormones and Behavior, 64, pp. 298-313.

Schick, B., de Villiers, P., de Villiers, J., \& Hoffmeister, R. (2007). Language and theory of mind: A study of deaf children. Child Development, 78(2), pp. 376-396. http://dx.doi.org/10.1111/j.1467-8624.2007.01004.x 
Schienle, A. \& Scharmüller, W. (2013). Cerebellar activity and connectivity during the experience of disgust and happiness. Neuroscience, 246, pp. 375381.doi:10.1016/j.neuroscience.2013.04.048

Schoen, S.A., Miller, L.J., Brett-Green, B.A., \& Nielsen, D.M. (2009). Physiological and behavioral differences in sensory processing: a comparison of children with autism spectrum disorder and sensory modulation disorder. Frontiers in Integrative Neuroscience, 3, 29.

Schopler, E., Reichler, R.J., DeVellis, R.F. \& Daly, K. (1980). Toward objective classification of childhood autism: Childhood Autism Rating Scale (CARS). Journal of Autism and Developmental Disorders, 10, pp. 91-103.

Schopler, E., Reichler, R.J., \& Renner, B.R. (1994). The Childhood Autism Rating Scale. Los Angeles, CA: Western Psychological Services.

Schuetze, M., Park, M.T.M., Cho, I.Y.K., McMaster F.P., Chakravarty M.M., \& Bray S.L. (2016). Morphological alterations in the thalamus, striatum and pallidum in Autism Spectrum Disorder. Neuropsychopharmacology, 41, pp. 2627-2637. doi:10.1038/npp.2016.64

Schumann, C.M., Hamstra, J., Goodlin-Jones, B.L., Lotspeich, L.J., Kwon, H., Buonocore, M.H.,... \& Amaral, D.G. (2004). The amygdala is enlarged in children but not adolescents with autism; the hippocampus is enlarged at all ages. Journal of Neuroscience, 24, pp. 6392-6401.

Schumann, C., Barnes, C.C., Lord, C., \& Courchesne, E. (2009). Amygdala enlargement in toddlers with autism related to severity of social and communication impairments. Biological Psychiatry, 66, pp. 942-949.

Schumann, C.M., Bloss, C.S., Barnes, C.C., Wideman, G.M., Carper, R.A., Akshoomoff N.,... Courchesne, E. (2010). Longitudinal magnetic resonance image study of cortical development through early childhood in autism. Journal of Neuroscience, 30, pp. 44194427. [PubMed: 20335478].

Sears, Ll., Vest, C., Mohamed, S., Bailey, J., Ranson, B.J., \& Piven, J. (1999). An MRI study of the basal ganglia in autism. Progress in Neuro-psychopharmacology and Biological Psychiatry, 23(4), pp. 613-624. 
Serrano-Ortiz, J. (2012). Desarrollo de la Teoría de la Mente, Lenguaje y Funciones Ejecutivas en niños de 4 a 12 años. (Tesis Doctoral). Universidad de Girona, Facultat de Ciències Socials, de l' Educació i de la Salut, España.

Shah, A., \& Frith, U. (1983). An islet of ability in autism: a research note. Journal of Child Psychology and Psychiatry, 24, pp. 613-620. (doi:10.1111/j.1469-7610.1983.tb00137.x)

Shah, A., \& Frith, U. (1993). Why do autistic individuals show superior performance on the block design test? Journal of Child Psychology and Psychiatry, 34, pp. 1351-1364. (doi:10.1111/j.1469- 7610.1993.tb02095.x).

Shamay-Tsoory, S.G., Tomer, R., \& Aharon-Peretz, J. (2005). The Neuroanatomical basis of understanding sarcasm and its relationship to social cognition. Neuropsychology, 3(3), pp. 288-300.

Shamay-Tsoory, S.G., Aharon-Peretz, J., \& Perry, D. (2009). Two systems for empathy: a double dissociation between emotional and cognitive empathy in inferior frontal gyrus versus ventromedial prefrontal lesions. Brain, 132, pp. 617-627.

Shamay-Tsoory, S.G. (2011). The neural bases for empathy. Neuroscientist, 17, pp. 18-24.

Shaw, P., Kabani, N.J., Lerch, J.P., Eckstrand, K., Lenroot, R. et al. (2008). Neurodevelopmental trajectories of the human cerebral cortex. Journal of Neuroscience, 28 , pp. 3586-3594.

Shen, M.D., Kim, S.H., McKinstry, R.C., Gu, H., Hazlett, H.C., Nordahl, C.W., ...Piven, J. (2017). Increased Extra-axial Cerebrospinal Fluid in High-Risk Infants Who Later DevelopAutism.Biological Psychiatry. http://dx.doi.org/10.1016/j.biopsych.2017.02.1095

Simmons, D.R., Robertson, A.E., McKay, L.S., Toal, E., McAleer, P., \& Pollick, F.E. (2009). Vision in autism spectrum disorders. Vision Research, 49, pp. 2705-2739.

Sivaswamy, L., Kumar, A., Rajan, D., Behen, M., Muzik, O., Chugani, D., et al. (2010). A diffusion tensor imaging study of the cerebellar pathways in children with autism spectrum disorder. Journal of Child Neurology, 25, pp. 1223-1231. doi: $10.1177 / 0883073809358765$ 
Slade, L., \& Ruffman, T. (2005). How language does (and does not) relate to theory of mind: A longitudinal study of syntax, semantics, working memory and false belief. British Journal of Developmental Psychology, 23(1), pp. 117-141. http://dx.doi.org/10.1348/026151004X21332.

Sodian, B., \& Frith, U. (1992). Deception and sabotage in autistic, retarded, and normal children. Journal of Child Psychology and Psychiatry, 33, pp. 591-606.

Sodian, B. (2005). Theory of Mind-The Case for Conceptual Development. En W. Schneider, W., Schumann-Hengsteler, R. \& Sodian, B. (Eds.), Young children's cognitive development: Interrelationships among executive functioning, working memory, verbal ability and theory of mind (pp. 95-130). Mahwah, NI: Lawrence Erlbaum Associates.

Sowell, E.R., Thompson, P.M., Holmes, C.J., Jernigan, T.L., \& Toga, A.W. (1999). In vivo evidence for post-adolescent brain maturation in frontal and striatal regions. Nature Neuroscience, 2, pp. 859-861.

Sowell, E.R., Thompson, P.M., Tessner, K.D., \& Toga, A.W. (2001). Mapping continued brain growth and gray matter density reduction in dorsal frontal cortex: inverse relationships during postadolescent brain maturation. Journal of Neuroscience, 21, pp. 8819-8829.

Sowell, E.R., Trauner, D.A., Gamst, A., \& Jernigan, T.L. (2002). Development of cortical and subcortical brain structures in childhood and adolescence: a structural MRI study. Developmental Medicine and Child Neurology, 44(1), pp. 4-16.

Sowell, E.R., Thompson, P.M., Leonard, C.M., Welcome, S.E., Kan, E., \& Toga, A.W. (2004). Longitudinal mapping of cortical thickness and brain growth in normal children. Journal of Neuroscience, 24, pp. 8223-8231.

Sparks, B.F., Friedman, S.D., Shaw, D.W., Aylward, E.H., Echelard, D., et al. (2002). Brain structural abnormalities in young children with autism spectrum disorder. Neurology, 59, pp. 184-192.

Sparrow, S.S., Balla, D.A., \& Cicchetti, D.V. (1984). Vineland Adaptive Behavior Scales: interview edition survey form manual. Circle Pines, MN: American Guidance Service. 
Spitz, R.A. (1945), Hospitalism: Inquiry into genesis of psychiatric conditions in early childhood. Psychoanalytic Study of the Child, 1, pp. 53-74.

Ssucharewa, G.E. (1926). Die schizoiden Psychopathien im Kindesalter. Monatsschrift Fur Psychiatrie Und Neurologie, 60, pp. 235-261.

Steele, S., Joseph, R.M., \& Tager-Flusberg, H. (2003). Brief report: Developmental change in theory of mind abilities in children with autism. Journal of Autism and Developmental Disorders, 33(4), pp. 461-467.

Stern, E. (1952). A propos d'un cas d'autisme chez un jeune enfant. Archives Francaises De Pediatrie, 9, pp. 157-164.

Stigler, K.A., McDonald, B.C., Anand, A., Saykin, A.J., \& McDougle, C.J. (2011). Structural and functional magnetic resonance imaging of autism spectrum disorders. Brain Research, 1380, pp. 146-161.

Stone, V., Baron-Cohen, S., \& Knight, K. (1999). Frontal lobe contributions to theory of mind. Journal of Cognitive Neuroscience, 10, pp. 640-656.

Stoodley, C.J. (2012). The cerebellum and cognition: evidence from functional imaging studies. Cerebellum, 11, pp. 352-365.

Stoodley, C.J. (2014). Distinct regions of the cerebellum show gray matter decreases in autism, ADHD, and developmental dyslexia. Frontiers in Systems Neuroscience, 8, article 92. doi: 10.3389/fnsys.2014.00092

Stoodley, C.J., \& Schmahmann, J.D. (2010). Evidence for topographic organization in the cerebellum of motor control versus cognitive and affective processing. Cortex, 46, pp. 831-844. doi: 10.1016/j.cortex.2009.11.008

Stuss, D.T., Gallup, Jr.G.G., \& Alexander., M.P. (2001). The frontal lobes are necessary for 'theory of mind'. Brain, 124(2), pp. 279-286.

Sullivan, K., Zaitchik, D., \& Tager-Flusberg, H. (1994). Preschoolers can attribute secondorder beliefs. Developmental Psychology, 30(3), pp. 395-402. 
Sullivan, K., Winner, E. \& Hopfield, N. (1995). How children tell a lie from a joke: the role of second-order mental states attributions. British Journal of Developmental Psychology, 13, pp. 191-204. doi: 10.1111/j.2044-835X.1995.tb00673.x

Sussman, K., Leung, R.C., Vogan, V.M., Lee, W., Trelle, S.Lin, S.,.. \& Taylor, M.J. (2015). The autism puzzle: Diffuse but no pervasive neuroanatomical abnormalities in children with autism. NeuroImage: Clinical, $8, \quad$ pp. 170-179. http://dx.doi.org/10.1016/j.nicl.2015.04.008

Sussman, D., Leung, R.C., Chakravarty, M.M., Lerch, J.P., \& Taylor, M.J. (2016). The developing human brain: age-related changes in cortical, subcortical and cerebellar anatomy. Brain and Behavior; 6(4), e00457. doi: 10.1002/brb3.457

Swettenham, J. (1996). Can children with autism be taught to understand false belief using computers? Journal of Child Psychology and Psychiatry, 37, pp. 157-165.

Swettenham, J., Baron-Cohen, S., Gomez, J.-C., \& Walsh, S. (1996). What's inside a person's head? Conceiving of the mind as a camera helps children with autism develop an alternative theory of mind. Cognitive Neuropsychiatry, 1, pp. 73-88.

Tager-Flusberg, H. (1999). A psychological approach to understanding the social and language impairments in autism. International Review of Psychiatry, 11, pp. 325-334.

Tager-Flusberg, H., \& Joseph, R.M. (2005). How language facilitates the acquisition of false belief understanding in children with autism. In Astington, J. \& Baird, J. (Eds.), Why language matters for theory of mind? (pp. 298-318). Oxford, UK: Oxford University Press.

Tager-Flusberg, H. (2007). Evaluating the Theory of Mind hypothesis of autism. Current Directions in Psychological science, 16, pp. 311-315.

Talay-Ongan, A., \& Wood, K. (2000). Unusual sensory sensitivities in autism: A possible crossroads. International Journal of Disability, Development and Education, 47(2), pp. 201-212. 
Talwar, V., \& Lee, K. (2002a). Developmental of lying to conceal a transgression: Children's control of expressive behaviour during verbal deception. International Journal of Behavioral Development, 26, pp. 436-444. doi: 10.1080/01650250143000373.

Tanaka, C., Matsui, M., Uematsu, A., Noguchi, K., \& Miyawaki, T. (2012). Developmental Trajectories of the Fronto-Temporal Lobes from Infancy to Early Adulthood in Healthy Individuals. Developmental Neuroscience, 34, pp. 477-487. DOI: 10.1159/000345152

Tang, G., Gudsnuk, K., Kuo, S.H., Cotrina, M.L., Rosoklija, G., Sosunov, A. et al. (2014). Loss of mTOR-dependent macroautophagy causes autistic-like synaptic pruning deficits. Neuron, 83, pp. 1131-1143.

Tazumi, T., Hori, E., et al. (2010). Neural correlates to seen gaze-direction and head orientation in the macaque monkey amygdala. Neuroscience, 169(1), pp. 287-301.

Tecchio, F., Benassi, R., Zappasodi, F., Gialloreti, L. E., Palermo, M., Seri, S., et al. (2003). Auditory sensory processing in autism: A magnetoencephalographic study. Biological Psychiatry, 54, pp. 647-654.

Teffer, K., \& Semendeferi, K. (2012). Human prefrontal cortex: evolution, development, and pathology. Progress in Brain Research, 195, pp. 191-218.

Thakkar, K.N., Polli, F.E., Joseph, R.M., Tuch, D.S., Hadjikhani, N., Barton, J.J.S., \& Manoach, D.S. (2008). Response monitoring, repetitive behaviour and anterior cingulate abnormalities in autism spectrum disorders (ADS). Brain, 131, pp. 2464-2478. doi: 10.1093/brain/awn099

Thirion-Marissiaux, A.F., \& Nader-Grosbois, N. (2008). Theory of mind "beliefs", developmental characteristics and social understanding in children and adolescents with intellectual disabilities. Research in Developmental Disabilities, 29(6), pp. 547-566. http://dx.doi.org/10.1016/j.ridd.2007.09.004

Tirapu-Ustárroz, J., Pérez-Sayes, G., Erekatxo-Bilbao, M., y Pelegrín-Valero, C. (2007). ¿Qué es la teoría de la mente? Revista de Neurología, 44(8), pp. 479-489.

Toga, A.W., Thompson, P.M., \& Sowell ER. (2006). Mapping brain maturation. Trends in Neurosciences, 29, pp. 148-159. 
Tomasello, M. (1995). Joint attention as social cognition. In Moore, C. \& Dunham, P. (Eds.), Joint attention: its origins and role in development (pp. 103-130). Nueva Jersey: Erlbaum.

Tomasello, M. (1999). The Human Adaptation for Culture. Annual Reviews, 28, pp. 509529.

Tomasello, M. \& Carpenter, M. (2007). Shared intentionality. Developmental Science, 10(1), pp. 121-125. doi: 10.1111/j.1467-7687.2007.00573.x

Tomchek, S.D., \& Dunn, W. (2007). Sensory processing in children with and without autism: a comparative study using the short sensory profile. American Journal of Occupational Therapy, 61, pp. 190-200.

Thompson, D.K., Wood, S.J., Doyle, L.W., Warfield, S.K., Egan, G.F., \& Inder, T.E. (2009). MR-determined hippocampal asymmetry in full-term and preterm neonates. Hippocampus, 19(2), pp. 118-123.

Thompson, J., \& Parasuraman, R. (2012). Attention, biological motion, and action recognition. NeuroImage, 59, pp. 4-13.

Tsatsanis, K.D., Rourke, B.P., Klin, A., Volkmar, F.R., Cicchetti, D., \& Schultz, R.T. (2003). Reduced thalamic volume in high-functioning individuals with autism. Biological Psychiatry, 53, pp. 121-129. [PubMed: 12547467]

Uddin, L.Q., Supekar, K., Lynch, C.J., Khouzam, A., Phillips, J., Feinstein, C., et al. (2013). Salience network-based classification and prediction of symptom severity in children $\begin{array}{lllll}\text { with autism. JAMA Psychiatry, } & \text { 70(8), } & \text { pp. } & \text { 869-879. }\end{array}$ doi:10.1001/jamapsychiatry.2013.104.

Uematsu, A., Matsui, M., Tanaka, C., Takahashi, T., Noguchi, K., Suzuki, M., \& Nishijo, H. (2012). Developmental Trajectories of Amygdala and Hippocampus from Infancy to Early Adulthood in Healthy Individuals. PloS One, 7(10): e46970. doi: 10.1371/jornal.pone.0046970 
Ulay, H.T., \& Ertugrul, A., (2009). Neuroimaging Findings in Autism: A Brief Review. Turkish Journal of Psychiatry, 20(2), pp. 164-174.

Urošević, S., Collins, P., Muetzel, R., Lim, K., \& Luciana, M. (2012). Longitudinal changes in behavioral approach system sensitivity and brain structures involved in reward processing during adolescence. Developmental Psychology, 45(5), pp. 1488-1500.

Utsunomiya, H., Takano, K., Okazaki, M., \& Mitsudome, A. (1999). Development of the temporal lobe in infants and children: Analysis by MR-based volumetry. American Journal of Neuroradiology, 20(4), pp. 717-723.

Van der Geest, J.N., Chantal, K., Gert, C., Marinus Nicolaas, V., \& Herman van, E. (2001). Eye movements, visual attention, and autism: a saccadic reaction time study using the gap and overlap paradigm. Biological Psychiatry, 50, pp. 614-619.

Van Krevelen, D.A. (1952). Early infantile autism. Acta Paedopsychiatrica, 91, pp. 81-97.

Ventura-Campos, N. (2013). Contributions to statistical Learning for Magnetic Resonance Images. (Tesis doctoral). Universitat Jaume I, Facultad de Matemática Computacional, España.

Via, E., Radua, J., Cardoner, N., Happé, F., \& Mataix-Cols, D. (2011). Meta-analysis of Gray Matter Abnormalities in Autism Spectrum Disorder. Should Asperger Disorder Be Subsumed Under a Broader Umbrella of Autistic Spectrum Disorder? Archives in General Psychiatry, 68(4), pp. 409-418.

Vicker, B. A. (1993). Tracking facilitated communication and auditory integration training in Indiana. In Proceedings 1993. International Conference on Autism. Bethesda, MD: Autism Society of America.

Volkmar, F.R., \& Pauls, D. (2003). Autism. The Lancet, 362(9390), pp. 1133-1141.

Volkmar, F., Chawarska, K., \& Klin, A. (2005). Autism in infancy and early childhood. Annual Review of Psychology, 56, pp. 315-336. 
Waiter, G.D., Williams, J.H., Murray, A.D., Gilchrist, A., Perrett, D.I., \& Whiten, A. (2004). A voxel-based investigation of brain structure in male adolescents with autistic spectrum disorder. NeuroImage, 22(2), pp. 619-625.

Waiter, G.D., Williams, J.H., Murray, A.D., Gilchrist, A., Perrett, D.I., \& Whiten, A. (2005). Structural white matter deficits in high-functioning individuals with autistic spectrum disorder: a voxel-based investigation. Neuroimage, 24, pp. 455-461.

Walhovd, K.B., Fjell, A.M., Giedd, J., Dale A.M., \& Brown, T.T. (2016). Through thick and thin: a need to reconcile contradictory results on trajectories in human cortical development. Cerebral Cortex, 27(2), pp. 1472-1481. doi: 10.1093/cercor/bhv301.

Wallace, G.L., Dankner, N., Kenworthy, L., Giedd, J.N., \& Martin, A. (2010). Age-related temporal and parietal cortical thinning in autism spectrum disorders. Brain, 133, pp. 3745-3754. [PubMed: 20926367]

Wallace, G.L., Eisenberg, I.W., Robustelli, B., Dankner, N., Kenworthy, L., Giedd, J.N. \& Martin, A. (2015). Longitudinal cortical development during adolescence and young adulthood in autism spectrum disorder: increased cortical thinning but comparable surface area changes. Journal of the American Academy of Child and Adolescent Psychiatry, 54, pp. 464-469.

Wang, S.S., Kloth, A.D., \& Badura, A. (2014). The cerebellum, sensitive periods and autism. Neuron, 83, pp. 518-532.

Watling, R.L., Deitz, J., \& White, O. (2001). Comparison of sensory profile scores of young children with and without autism spectrum disorders. American Journal of Occupational Therapy, 55, pp. 416-423.

Wegiel, J., Flory, M., Kuchna, I. et al. (2014b). Stereological study of the neuronal number and volume of 38 brain subdivisions of subjects diagnosed with autism reveals significant alterations restricted to the striatum, amygdala and cerebellum. Acta Neuropathologica Communications, 2, 141.

Wellman, H.M., Cross, D., \& Watson, J. (2001). Meta-analysis of theory-of-mind development: The truth about false belief. Child Development, 72(3), pp. 655-684. http://dx.doi.org/10.1111/1467-8624.00304 
Wellman, H.M., \& Liu, D. (2004). Scaling of Theory-of-Mind tasks. Child Development, 75(2), pp. 523-541. http:// dx.doi.org/10.1111/j.1467-8624.2004.00691.x

Wheelwright, S., Baron-Cohen, S., Goldenfeld, N., Delaney, J., Fine, D., Smith, R.,.. \& Wakabayashi, A. (2006). Predicting Autism Spectrum Quotient (AQ) from the Systemizing Quotient-Revised (SQ-R) and Empathy Quotient (EQ). Brain Research, 1079(1), pp. 47-56.

White, S., Happé, F., Hill, E., \& Frith, U. (2009). Revisiting the Strange Stories: Revealing Mentalizing Impairments in Autism. Child Development, 80(4), pp. 1097-1117.

Wierenga, L., Langen, M., Ambrosino, S., van Dijk, S., Oranje, B., \& Durston, S. (2014). Typical developmental of basal ganglia, hippocampus, amygdala and cerebellum from age 7 to 24. NeuroImage, 96, pp. 67-72. doi: 10.1016/j.neuroimage.2014.03.072

Wiggins, L.D., Robins, D.L., Bakeman, R., \& Adamson, L.B. (2009). Sensory abnormalities as distinguishing symptoms of Autism Spectrum Disorders in young children. Journal of autism Developmental Disorder, 39, pp. 1087-1091. doi:10.1007/s10803-009-0711-x.

Wilde, J., Astington H., \& Barriault, T. (2001). Children's theory of mind: How young children come to understand that people have thoughts and feelings. Infants and Young Children, 13(3), pp. 1-12.

Wilke, M., Krageloh-Mann, I., \& Holland, S.K. (2007). Global and local development of gray and white matter volume in normal children and adolescents. Experimental Brain Research, 178, pp. 296-307.

Wilson, A.E., Smith M.D., \& Ross H.D. (2003). The nature and effects of young children's lies. Social Development, 12, pp. 21-45. doi: 10.1111/1467-9507.00220

Williams, D. (1992). Nobody nowhere: The extraordinary autobiography of an autistic. London: Jessica Kingsley.

Wimmer, H., \& Perner, J. (1983). Beliefs about beliefs: Representation and constraining function of wrong beliefs in young children's understanding of deception. Cognition, 13, pp. 103-128. 
Wing, L. (1981), Asperger's Syndrome: A clinical account. Psychological Medicine, 11, pp. 115-30.

Wing, L. (1988). Aspects of Autism: Biological Research. Gaskell, Royal College of Psychiatrists and The National Austistic Society: London.

Wing, L. (1997). The Autistic Spectrum. Oxford, UK: Pergamon.

Wing, L., \& Wing, J.K. (1971). Multiple impairments in early childhood autism. Journal of Autism and Childhood Schizophrenia, 1, pp. 256-266.

Wing, L., \& Gould, J. (1979). Severe Impairments of Social Interaction and Associated Abnormalities in Children: Epidemiology and Classification, Journal of Autism and Developmental Disorders, 9, pp. 11-29.

Wing, J.K. (1966). Diagnosis, epidemiology, aetiology. In Wing, J.K. (Ed.), Early childhood autism: Clinical, educational and social aspects (pp. 3-49). London: Pergamon.

Woo, C.W., Krishnan, A., \& Wager, T.D. (2014). Cluster-extent based thresholding in fMRI analyses: pitfalls and recommendations. Neuroimage, 91, pp. 412-419.

Yakovlev, P.I., \& Lecours, A.R. (1967). The myelogenetic cycles of regional maturation of the brain. In Minkowski, A. (Ed.), Regional development of the brain in early life (pp. 370). Oxford: Blackwell Scientific.

Yang, D.Y-J., Beam, D., Pelphrey, K.A., Abdullahi, S., \& Jou, R.J. (2016). Cortical morphological markers in children with autism: a structural magnetic resonance imaging study of thickness, area, volume and gyrification. Molecular Autism, 7, 11. DOI: 10.1186/s13229-016-0076-X

Yeung-Courchesne, R., \& Courchesne, E. (1997). From impasse to insight in autism: From behavioral symptoms to biological explanations. Development and Psychopathology, 9, pp. 389-419.

Yorbık, Ö., Özdağ, M.F., Söhmen, T., et al. (2001). Otistik bozuklukta EEG, BBT ve MRI inceleme sonuçları. Çocuk ve Gençlik Ruh Sağlığı Dergisi, 2, pp. 94-98. 
Ystad, M.A., Lundervold, A.J., Wehling, E., Espeseth, T., Rootwelt, H., Westlye, L.T. et al. (2009). Hippocampal volumes are important predictors for memory function in elderly women. BMC Medical Imaging, 9, 17.

Zielinski, B.A., Prigge, M.B., Nielsen, J.A., et al. (2014). Longitudinal changes in cortical thickness in autism and typical development. Brain, 137, pp. 1799-1812.

Zilbovicius, M., Garreau, B., Samson, Y., Remy, P., Barthelemy, C., Syrota, A. \& Lelord, G. (1995). Delayed maturation of the frontal cortex in childhood autism. American Journal of Psychiatry, 152, pp. 248-252.

Ziv, Y., Hadad, B.S., Khateeb, Y., \& Terkel-Dawer, R. (2014). Social information processing in preschool children diagnosed with autism spectrum disorder. Journal Autism Developmental Disorders 44(4), pp. 846-859. 